\title{
Causes, Mechanisms, and Remedies of Top-Down Cracking of Asphalt Pavements: State-of-the-Art
}

\author{
A thesis submitted to \\ the Faculty of Graduate Studies and Research \\ in partial fulfillment of the requirements for the degree of
}

Master of Applied Science

by

\begin{abstract}
Adnan M. Hammoud
B.Sc.

Department of Civil and Environmental engineering Carleton University
\end{abstract}

Ottawa-Carleton Institute of Civil and Environmental Engineering March, 2010

(C) 2010 Adnan M. Hammoud 
Library and Archives

Canada

Published Heritage

Branch

395 Wellington Street

Ottawa ON K1A ON4

Canada
Bibliothèque et

Archives Canada

Direction du

Patrimoine de l'édition

395 , rue Wellington

Ottawa ON K1A ON4

Canada
Your file Votre référence
ISBN: $978-0-494-68650-8$
Our file Notre référence
ISBN: $978-0-494-68650-8$
NOTICE:

The author has granted a nonexclusive license allowing Library and Archives Canada to reproduce, publish, archive, preserve, conserve, communicate to the public by telecommunication or on the Internet, loan, distribute and sell theses worldwide, for commercial or noncommercial purposes, in microform, paper, electronic and/or any other formats.

The author retains copyright ownership and moral rights in this thesis. Neither the thesis nor substantial extracts from it may be printed or otherwise reproduced without the author's permission.

\section{AVIS:}

L'auteur a accordé une licence non exclusive permettant à la Bibliothèque et Archives Canada de reproduire, publier, archiver, sauvegarder, conserver, transmettre au public par télécommunication ou par l'Internet, prêter, distribuer et vendre des thèses partout dans le monde, à des fins commerciales ou autres, sur support microforme, papier, électronique et/ou autres formats.

L'auteur conserve la propriété du droit d'auteur et des droits moraux qui protège cette thèse. $\mathrm{Ni}$ la thèse ni des extraits substantiels de celle-ci ne doivent être imprimés ou autrement reproduits sans son autorisation.
In compliance with the Canadian Privacy Act some supporting forms may have been removed from this thesis.

While these forms may be included in the document page count, their removal does not represent any loss of content from the thesis.
Conformément à la loi canadienne sur la protection de la vie privée, quelques formulaires secondaires ont été enlevés de cette thèse.

Bien que ces formulaires aient inclus dans la pagination, il n'y aura aucun contenu manquant.

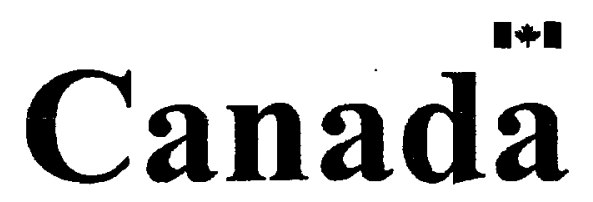




\begin{abstract}
One of the major distresses affecting the service life of asphalt pavements is the phenomenon known as Top-Down Cracking (TDC). A literature review was conducted of the current and previous efforts invested in the field. The study addresses the initiation, progression mechanisms, causes, and the applied remedies to the problem of TDC. It is demonstrated that thermal analytical models which have been used in the literature over the past decades failed to explain the main cause of thermal transverse cracking. Moreover, the study showed that load-induced tensile stresses and strains are not the sole cause of TDCs. It has been shown that the current compaction methods and techniques continue to be the most predominant cause of TDC. Additionally, analysis performed in this thesis attempted to identify the promising techniques to mitigate TDC. While these techniques were developed, the most effective current approach appears to be a new compaction technology termed "AMIR". The research also included laboratory investigation to assess the influence of TDC on the environmental performance and on the integrity of the asphalt concrete layer. Results of laboratory tests suggested that topdown-cracks can lead to serious environmental problems related to pollution agents interacting with the cracked pavement leading to significant loss of its mechanical properties and adverse effects on the environment.
\end{abstract}




\section{Acknowledgments}

My most and sincere thanks are to God for giving me the strength and patience to complete this thesis. I would like to express my deep appreciation and grateful thanks to my thesis supervisor Professor A. O. Abd El Halim for his continual assistance, and encouragement. His support and guidance throughout the completion of this research has been invaluable. Also, I would like to express my thanks and gratitude for the financial support provided by NSERC and Carleton University.

I would like to thank the staff members at the Civil and Environmental Engineering Laboratory whom have helped me in completing my laboratory tests of this research. Thanks are due to all my graduate colleagues, with whom I studied at Carleton University, shared ideas, views and spent time during my study period.

My gratitude is to my family members whose continuous encouragement and support motivated me to carry out my studies. I am especially indebted to my father for his valuable guidance and support, and to my mother "may Allah bless her" who made me capable to get this degree. Finally, my heartfelt thanks are to my wife for her patience and sacrifice, my sons and my daughter, whom I have not been able to give enough time during my study. 


\section{Table of Contents}

Abstract $\quad$ ii

Acknowledgements $\quad$ iii

Table of Contents $\quad$ iv

List of Tables vii

List of Figures viii

Glossary $\quad$ xi

Chapter 1: Introduction 1

1.1 Overview 1

1.2 Types of Pavement Surface Distress 4

1.3 Types of Cracks 6

1.3.1 Bottom up Cracks 6

1.3.2 Top-Down Cracks 12

1.4 Research Scope and Objective 14

$\begin{array}{ll}1.5 \text { Thesis Organization } & 15\end{array}$

Chapter 2: Location, Characteristic, and Classification of Top-DownCrack

2.1 Location, Characteristic of Top-Down Crack 17

2.2 Top-Down Crack Classification 20

2.2.1 Transverse Top-Down Cracks (TTDC) 20

2.2.2 Longitudinal Top-Down Cracks (LTDC) 23

2.2.3 Network of Longitudinal and Transverse Cracks (NLTC) 25

Chapter 3: Causes and Mechanisms of Top-Down Cracks 27

3.1 Introduction 27

3.2 Compaction Method 29

3.2.1 Asphalt Concrete Pavement Density 29

3.2.2 Air Voids Percent in Asphalt Concrete Layers 31

3.2.3 Asphalt Compaction Objectives and Theoretical Considerations $\quad 32$

3.3 Deficiency with Current Compaction Equipment 33

3.3.1 Causes of Compaction Induced Cracks $\quad 35$

3.3.2 Explanation for the Initiation of Top-Down Cracks 37

3.3.3 Direction of Rolling 39 
3.4 Factors Affecting the Construction Method $\quad 40$

$\begin{array}{ll}3.4 .1 \mathrm{Du} \text { to Paving Operation } & 40\end{array}$

3.5 Factors Affecting the Tensile Stresses in the Pavement Surface 42

3.5.1 Load Induced Stresses and Strains 42

3.5.2 Thermal Induced Stresses 49

3.5.2.1 Mechanism of Thermal Cracking $\quad 54$

3.5.2.2 Types of Thermal Transverse Top-Down Cracks 56

3.5.3 Thickness of Asphalt Concrete Pavement Layer 57

3.6 Factors Affecting the Tensile Strength of the Asphalt Concrete Mixture 59

3.6.1 Asphalt Age Hardening 59

$\begin{array}{ll}3.6 .2 \text { Segregation } & 60 \\ 3.6 .2 .17 y p e s & 61\end{array}$

3.6.2.1 Types of Segregation $\quad 61$

3.6.2.2 Density in Segregated Area $\quad 63$

3.6.2.3 Causes of Segregation $\quad 63$

3.6.2.4 Degrees of Segregation $\quad 65$

3.6.2.5 Segregation Effects on Top-Down Cracks 66

Chapter 4: Remedies and Treatments for Prevention of Top-Down Cracks 70

4.1 Introduction $\quad 70$

4.2 Treatment of Bottom up Cracks (BUC) 71

4.2.1 Breaking the Existing Cracked Pavement Layer 72

4.2.2 Sawing the Asphalt Overlay above the Concrete Joint 74

4.2.3 Increasing the Tensile Strength of the Asphalt Pavement Overlay 74

4.2.4 Reducing the Magnitude of the Tensile Stresses at the Crack-Overlay 76

Interface

4.3 Treatment of Top-Down Crack (TDC) 76

4.3.1 Increasing the Applied Pressure by the Conventional Roller 77

$\begin{array}{ll}\text { 4.3.2 Using the Pneumatic Tire Roller } & 78\end{array}$

$\begin{array}{ll}\text { 4.3.3 Asphalt Multi-Integrated Roller (AMIR) } & 79\end{array}$

4.3.4 Overlaying, Patch up, and Removing the Full Depth $\quad 84$

4.3.5 Development of the Superpave Mix Design Method 84

4.4 Treatment due to Load Induced Tensile Stresses 85

4.5 Treatment due to Thermal Stresses $\quad 85$

4.5.1 Bond Characteristics $\quad 86$

$\begin{array}{ll}\text { 4.5.2 Aggregate Quality } & 87\end{array}$

4.5.3 Pavement Dimensions $\quad 88$

4.5.4 Traffic Loadings $\quad 88$

4.6 Treatment due to the Effects of Age Hardening 89

4.7 Treatment due to the Effect of Segregation 90 
5.1 Introduction 93

5.2 Influence of Properties of Asphalt Pavement on Thermal Cracking 94

$\begin{array}{ll}\text { 5.2.1 Coefficient of Thermal Contraction } & 97\end{array}$

$\begin{array}{ll}\text { 5.2.2 Pavement Temperature } & 99\end{array}$

5.2.3 Penetration Index 100

5.2.4 Mixture Stiffness $\quad 101$

5.2.5 Thermal Stress Induced Cracks 103

5.2.6 Tensile Strength of the Asphalt Pavement Layer 106

$\begin{array}{ll}\text { 5.2.7 Top-Down Cracks Potential } & 107\end{array}$

5.3 Load Induced Tensile Stress $\quad 117$

5.4 Compaction Process 121

Chapter 6: Influence of TDC on the Integrity of Asphalt Concrete 125 Pavement

6.1 Introduction 125

6.2 Laboratory and Field Investigations 127

$\begin{array}{ll}\text { 6.2.1 Specific Gravity Tests } & 129\end{array}$

6.2.2 Permeability Test 131

6.2.2.1 Laboratory Permeability Test 132

6.2.2.2 Field Permeability Test 141

6.2.3 Chemical Analyses of Water $\quad 146$

6.2.4 Effect of Spilled Oil on the Asphalt Pavement Integrity 151

6.2.5 Indirect Tensile Strength Test 158

$\begin{array}{ll}\text { Chapter 7: Conclusions } & 166\end{array}$

$\begin{array}{ll}\text { References } & 173\end{array}$ 


\section{List of Tables}

Descriptions

Page

Table 5.1 : Main input parameters

108

Table 6.1 : Results of the specific gravity tests

130

Table 6.2 : Measured data and the calculated permeability coefficient for

144 the car/un-cracked lane

Table 6.3 : Measured data and the calculated permeability coefficient for

145 the bus/cracked lane.

Table 6.4 : Results of chemical analysis tests

Table $6.5:$ Influence of TDC on the absorption percent by the specimens

Table 6.6 : Influence of TDC on the fragmented material percent from the specimens

Table 6.7 : Indirect tensile strength test results 


\section{List of Figures}

Descriptions

Figure 1.1 : Reflection cracking at joints 8

Figure $1.2 \quad$ : High severity reflection cracking at joints $\quad 8$

Figure $1.3:$ Three level of severity in fatigue cracking 10

Figure $1.4 \quad$ : Low severity fatigue cracking 10

Figure $1.5:$ Moderate severity fatigue cracking 11

$\begin{array}{llll}\text { Figure } & 1.6 & \text { : High severity fatigue cracking } & 11\end{array}$

$\begin{array}{lll}\text { Figure } 2.1 & \text { : Longitudinal Cracking } & 19\end{array}$

$\begin{array}{lll}\text { Figure } 2.2: \text { TTDC across the lane } & 23\end{array}$

Figure $2.3 \quad$ : Longitudinal cracking in the wheel path 24

Figure $3.1 \quad$ : Schematic of pre-compaction asphalt mix aggregate/binder 34 structure

Figure 3.2 : Schematic of compaction asphalt mix structure 34

Figure $3.3:$ Schematic of conventional steel roller compaction asphalt 38 mix structure

Figure 3.4: Curved transverse crack 39

$\begin{array}{lll}\text { Figure } 3.5: \text { Paver-caused TDC } & 42\end{array}$

Figure $3.6 \quad$ : Longitudinal cracking on the wheelpath of an asphalt 44

Figure $3.7 \quad$ : Different stresses states at the top and bottom of the asphalt 45 concrete layer

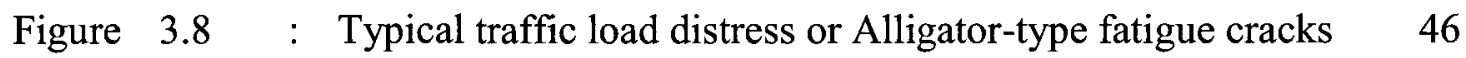

$\begin{array}{llll}\text { Figure } 3.9: \text { Wheel coordinates system } & 46\end{array}$

$\begin{array}{llll}\text { Figure } & 3.10 \quad \text { Single short longitudinal crack } & 48\end{array}$

$\begin{array}{llll}\text { Figure } 3.11 \quad \text { Longitudinal cracks grow longer while sister cracks form } & 48\end{array}$

Figure 3.12 : Longitudinal cracks and sister cracks connected by short 49 transverse cracks

Figure $3.13:$ Low-temperature cracking (transverse cracks) 50

Figure 3.14 : Schematics of (a) tangential stress $\sigma$ t and radial stress or, and 55 (b) a hairline crack in an aggregate-matrix system associated with TDC

Figure 3.15 : Types of thermal stress-induced transverse crack 56

$\begin{array}{llll}\text { Figure } 3.16: \text { Segregation of coarse aggregate around crack } & 67\end{array}$

$\begin{array}{llll}\text { Figure } 3.17: \text { TDC occurring in segregated area } & 68\end{array}$

Figure 3.18 : TDC occurring approximately 18-in from the center of the 68 wheelpath 
Figure $4.1 \quad$ : Vibratory - compacted section flowed by pneumatic roller of 79 Ottawa field trial

Figure $4.2 \quad:$ Asphalt Multi-Integrated Roller (AMIR) Prototype 81

Figure 4.3 : Static steel compacted asphalt section 81

Figure 4.4: AMIR Compacted asphalt section 82

Figure 4.5 : HIPAC device 83

Figure $4.6 \quad$ : Asphalt density versus number of passes of HIPAC device $\quad 83$

$\begin{array}{lll}\text { Figure } 5.1 \text { : Slippage cracking } & 96\end{array}$

Figure 5.2 : Proposed research approach for investigating thermal cracks 98

$\begin{array}{lll}\text { Figure } 5.3: \text { Daily asphalt layer surface temperature } & 104\end{array}$

Figure $5.4:$ Relationship between the tensile stresses and the mix 106

Figure 5.5 : Cracking temperature: when tensile stresses is equal to the 109

Figure 5.6 : Development in the thermal stresses 111

$\begin{array}{lll}\text { Figure } 5.7 \text { : Bond resistance and cracking stresses } & 112\end{array}$

Figure 5.8 : Spacing between transverse cracks is less than the width of 115 the pavement section

Figure 5.9 : Cracks have been initiated at an earlier stage as a compaction 115 induced cracks

Figure $5.10:$ Thermal stresses will act to propagate the already initiated 116

Figure $5.11:$ An indication for tensile stresses at the top of the AC surface 118

$\begin{array}{llll}\text { Figure } 6.1: \text { Cracked specimens (SC1\&SC3) } & 127\end{array}$

$\begin{array}{lll}\text { Figure } 6.2: \text { Reference un-cracked specimen } & 128\end{array}$

Figure $6.3 \mathrm{a}:$ Measuring the weight of the specimen for the dry and the 129 saturated surface dry cases

$\begin{array}{llll}\text { Figure } & 6.3 \mathrm{~b} & \text { Measuring the weight of the specimen immersed in water } & 129\end{array}$

$\begin{array}{lll}\text { Figure } 6.4: \text { Laboratory assembled permeameter } & 134\end{array}$

Figure $6.5:$ Rubber tab was secured around the middle part of the 134

Figure 6.6 : Silicon sealant was secured around the pipe at the top and 135 bottom edges of the test specimen

Figure $\quad 6.7 \quad$ : The small pipe with the joint and the collector were placed \& 135 the pipes with the joint were tightly secured

$\begin{array}{lll}\text { Figure } 6.8: & \text { The long pipe with the joint and the specimen were placed } 135\end{array}$

$\begin{array}{llll}\text { Figure } 6.9: \text { Calculated water head (SC) } & 136\end{array}$

Figure $6.10:$ Calculated permeability for each head (SC) 136

$\begin{array}{lll}\text { Figure } 6.11: \text { Calculated water head (ANC) } & 137\end{array}$

Figure 6.12 : Calculated permeability for each head (ANC) 137

$\begin{array}{lll}\text { Figure } 6.13: \text { Calculated average water head } & 140\end{array}$ 
Figure $6.14:$ Calculated average permeability 140

Figure $6.15:$ Permeability test equipment 142

Figure $6.16:$ More permeable pavement 143

Figure 6.17 : Low permeable pavement 143

Figure 6.18 : Oil is applied over and collected under the asphalt specimen 152

Figure 6.19 : Percent of penetrated oil through the specimens 154

Figure $6.20:$ Percent of absorbed oil by the specimens 154

$\begin{array}{llll}\text { Figure } & 6.21 & \text { Stripping occurred to cracked specimens (SC2, SC3) after } & 155\end{array}$

Figure 6.22 Collected oil under (a) cracked specimen (b) un-cracked 155

$\begin{array}{lll}\text { Figure } & 6.23 \quad \text { No oil passed through the specimen (ANC25) } & 156\end{array}$

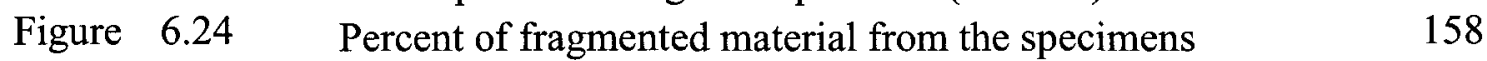

Figure 6.25 Indirect tensile strength test a) loading mode, b) failure mode 159

$\begin{array}{llll}\text { Figure } & 6.26 & \text { Measured indirect tensile strength test for control specimens } & 162\end{array}$

$\begin{array}{lll}\text { Figure } & 6.27 & \text { Effect of oil spill on the measured indirect tensile strength } \\ 162\end{array}$

Figure 6.28 Indirect tensile strength test results for un-cracked specimens,

Figure 6.29 Indirect tensile strength test results for cracked specimens, those went under the oil test and the control specimen as weil 


\section{Glossary}

\begin{tabular}{|c|c|}
\hline AASHTO & $\begin{array}{l}\text { American Association of State Highway and Transportation } \\
\text { Officials }\end{array}$ \\
\hline $\mathrm{AC}$ & : Asphalt Concrete \\
\hline AMIR & : Asphalt Multi Integrated Roller \\
\hline ANC & : AMIR Un-cracked specimen \\
\hline ASTM & : American Society for Testing and Materials \\
\hline BUC & : Bottom up Cracks \\
\hline c & : Specific heat in $\left(\mathrm{J} / \mathrm{kg} .{ }^{\circ} \mathrm{C}\right)$ \\
\hline $\mathrm{CO} 2$ & Carbon dioxide \\
\hline ESAL & Equivalent Single Axial Load \\
\hline HIPAC & : Hot Iron Process Asphalt Compaction \\
\hline HMA & : Hot Mix Asphalt \\
\hline $\mathbf{H}_{\max }$ & : maximum tensile strength \\
\hline $\mathrm{k}$ & : Coefficient of thermal conductivity \\
\hline LTDC & : Longitudinal Top-Down Crack \\
\hline MDOT & : Michigan Department of Transportation \\
\hline NLTC & : Network of Longitudinal and Transverse Crack \\
\hline PEN & : penetration \\
\hline $\mathrm{PC}$ & Plane Concrete \\
\hline PI & : penetration index \\
\hline PTS & : slope of the penetration temperature curve \\
\hline $\mathrm{R}_{\mathrm{H}}$ & : relative stiffness \\
\hline $\mathrm{S}$ & : binder stiffness \\
\hline $\mathrm{SC}$ & : Cracked specimens \\
\hline $\mathrm{S}_{\text {mix }}$ & : mixture stiffness \\
\hline SSD & : saturated surface dry \\
\hline $\mathrm{T}_{0}$ & daily maximum temperature in ${ }^{\circ} \mathrm{C}$, \\
\hline $\mathrm{T}_{1}$ & : the amplitude of the temperature cycle in ${ }^{\circ} \mathrm{C}$, \\
\hline $\mathrm{T}_{\mathrm{air}}$ & : air temperature \\
\hline Ter & : cracking temperature \\
\hline TDC & : Top-Down Crack \\
\hline TFOT & : Percent penetration after then film test. \\
\hline $\mathrm{T} i$ & : midpoint temperature of interval $i$ \\
\hline TOC & Total Organic Carbon \\
\hline TPT & : Temperature of the penetration test. \\
\hline $\begin{array}{l}T_{\text {R\&B }} \\
\text { TTDC }\end{array}$ & $\begin{array}{l}: \text { softening point } \\
: \text { Transverse Top-Down Crack }\end{array}$ \\
\hline
\end{tabular}




$\begin{array}{ll}\mathrm{T}_{\mathrm{z}} & : \text { Asphalt pavement temperature at the depth } \mathrm{z} \text { below the surface } \\ \mathrm{V}_{\mathrm{A}} & : \text { percent air void in the mixture } \\ \mathrm{WSDOT} & : \text { Washington State Department of Transportation } \\ \mathbb{Z} & : \text { Depth below asphalit pavement surface } \\ \alpha & : \text { Coefficient of thermal contraction of the asphalt concrete } \\ \Delta \mathrm{T} & : \text { temperature interval } \\ \rho & : \text { Material density in } \mathrm{kg} /\left(\mathrm{m}^{3} .{ }^{\circ} \mathrm{C}\right) \\ \sigma \mathrm{r} & : \text { Radial stress } \\ \sigma \mathrm{t} & : \text { Tangential tensile stresses } \\ \sigma_{\mathrm{xx}} & : \text { Transverse stress } \\ \tau & : \text { time variable } \\ \tau_{\mathrm{xy}} & : \text { Shear stress }\end{array}$




\section{CHAPTER ONE}

\section{Introduction}

\subsection{Overview}

Top-Down crack (TDC) is one of the major distresses affecting the long term performance of asphalt concrete pavement (AC). Top-down crack initiates at the surface of asphalt pavements and propagate downward in relatively short period of time (Myers et al., 1998). In some cases, this type of crack, TDC, has been the predominant type of deterioration mode of pavement. It could appear as longitudinal crack just outside the wheelpaths, over time, it forms an extensive network of longitudinal cracks connected by short transverse cracks, which ultimately reduce the service life of the road pavements (Uhlmeyer et al., 2000). TDC has also been experienced as transverse cracks just after the compaction process which was attributed to the conventional compaction process using the steel drum roller followed by the pneumatic roller (Abd El Halim et al., 1993).

The mechanism causing surface cracks due the compaction process was not fully understood and it was believed that any compaction problem is usually explained by problems related to mix properties. Therefore existing asphalt pavement design methods address conventional fatigue cracks of the asphalt pavement as a result of repeated tensile strains initiate from the bottom of the intermediate binder course and propagate up to the surface-wearing course. However, research work over the past 25 years identified TDC as the major contributor of surface deterioration and several research studies completed in 
order to investigate and determine the causes and mechanisms of TDC (Abd El Halim et al., 1993).

Since the surface course is the exposed layer to traffic load and carries the direct loads per area as compared to other layers, researchers assumed that surface failure was caused by excessive load-induced tensile stresses. These tensile stresses are considered to affect on the surface course when TDC is first observed (Uhlmeyer et al., 2000). The uniformity of the cracking patterns has always suggested that uniform loading conditions, such as those induced by low temperature, are the main contributor to the observed surface cracking. Therefore it was stated that low temperature cracking are induced by thermal-induced tensile stresses and reduction of pavement surface's tensile strength due to compaction, AC partial segregation and age hardening (Haas and Joseph, 1987; Shields et al., 1964).

Cracks which appear at the pavement surface very early after compaction termed the compaction induced cracks, have been attributed to the cylindrical shape of the conventional rigid steel drum roller (Abd El Halim 1985, 1986, 1987). It was stated that the traditional compaction equipments cause a small curved contact area between the steel drum and the asphalt mat. Consequently and under the pressure produced by the roller; horizontal forces between the steel drum roller and the flat asphalt layer is induced. In addition to these horizontal forces, it was explained that the difference between the stiffness of a conventional steel drum roller and that of hot soft asphalt layer would contribute to the cracking phenomena during compaction. Due to the induced horizontal forces, the compaction cracks are initiated on the surface of the pavement and thus reduce the pavement strength. Other factors affect the propagation of the initiated 
cracks will reduce the fatigue resistance of the pavement dramatically and over time the performance drops (Rickards et al., 1999; Abd El Halim 1994). Therefore, the main causes of TDCs can be divided into four categories: compaction method, construction method, higher tensile stresses, and lower tensile strength at the pavement surface. It could also occur by a combination of these categories. In Chapter three each category will be described thoroughly.

Density and air voids are among the most significant factors affecting the durability and the performance of the pavement structure. Abd El Halim et al., (1993) pointed to the relationship between the surface cracks and the quality of the compacted layer including the density and air voids. One of the main shortcomings of TDC was that they were not considered when asphalt structures are analyzed and therefore, their influence on pavement service life after the compaction process was neglected. However, results of several field and laboratory studies showed that applying the proper compaction process in the field will reduce the percentage of air voids and increase the density of the layer and its uniformity resulting in increasing the service life of the road pavement (Abd El Halim and Haas, 1994).

Once the crack is initiated at the surface, it will propagate vertically downward reaching some depth into the pavement and laterally along the surface at different rates. Top down crack, TDC, of asphalt pavement does not constitute a serious problem on its own, but it does cause several problems to the pavement structure and specially could accelerate the deterioration process of underlayers and effectively reduce the pavement service-ability rating and its structural ability. As a result, different preventive actions were proposed and implemented to prevent initiation and propagation of the crack. The 
appropriate choice depends on understanding the main cause of the problem and the related factors affecting the growth of the problem.

A compaction loading exercise of long duration on the asphalt surface at high temperatures is considered one of the major remedies in the asphalt concrete construction industry. That was achieved by the invention of the Asphalt Multi Integrated Roller (AMIR). It was demonstrated that the match between the geometry and the stiffness between the AMIR roller and the asphalt mat could provide a smooth surface free of surface cracks. Moreover the large flat contact between the roller rubber belt and the flat asphalt minimize the horizontal forces those produced on the asphalt pavement under the roller (Abd El Halim et al., 1993).

\subsection{Types of Pavement Surface Distress}

Surface distress of asphalt pavement was defined by the Highway Research Board, as "any indication of poor or unfavourable pavement performance or signs of impending failure" (Highway Research Board, 1970). They can dramatically reduce the performance of the pavement. It is important to distinguish between the different types and modes of surface distresses, so that it would be possible to apply the proper technique of treatment. That would be possible by understanding the causes and behaviour of the various pavement distresses. Asphalt pavement distresses that can badly affect the surface of asphalt pavement have four main categories of surface distress modes depending on its appearance and location within the pavement surface (U.S Department of Transportation 2003). These types are listed as: 
- Patches and potholes, due to removal and replacement or applying additional material to the pavement surface after original construction.

- Surface deformation - a form of rutting and shaving associated to transverse and vertical displacement due to excessive loading, parking, accelerating vehicles.

- Surface defects - a form of bleeding, polished aggregate, and raveling square associated with excess bituminous binder, surface binder worn away, movement of aggregate particles, and loss of asphalt binder.

- Cracking, such as, fatigue cracking, block cracking, wheel and non-wheelpath longitudinal cracking, slippage; joint reflective, and thermal cracking; and top-down transverse and longitudinal cracking, due to the excessive repeating traffic loading, fatigue, thermal gradation, low temperature contraction, old cracks/joints in the underlying layer, and defected compaction method.

Other types of pavement surface distresses such as, Lane-to- shoulder drop-off, and water bleeding and pumping, due to shoulder settlements caused by pavement layer material differences, seeping or ejection of water from the bottom of the pavement layer through existing cracks.

Based on a questionnaire completed by 22 European countries in 1999 it was illustrated that rutting, loss of skid resistance, and surface initiated cracking, in that order were the top three common types of flexible pavement distresses. Clearly, when problems occurred to the surface of $\mathrm{AC}$ pavements, engineers should be aware of the mechanisms that lead to the observed asphalt distresses in order to fix these problems (Uhlmeyer et al., 2000). A study was completed by Svasdisant, (2003) which included a number of projects to investigate the type of distress occurred to the asphalt pavement. Results were 
examined and it was concluded that the most predominant distress type was cracking, however, few projects showed signs of raveling and rutting. Surface cracks could initiate as a standalone distress mode, as will be discussed later in this thesis. Themal and low temperature surface cracking of asphalt pavements are also known to be one of the leading distress mode observed on most paved roads in cold regions.

Although most of these pavement distresses can badly reduce the service life of the asphalt pavement, the aim of this thesis is to focus on the cracking form. The next section briefly discusses the different types of cracks

\subsection{Types of Cracks}

Based on how the cracks are propagated in the pavement layers, asphalt pavement cracks could be divided in two types, each type is influenced by many factors; environmental and structural conditions. These types are as follows:

\subsubsection{Bottom up Cracks}

Bottom up cracks are defined as cracks initiated at the bottom of the asphalt layer and propagate through the entire thickness of the layer to become visible on its surface. These cracks are divided into two major categories according to the main causes associated with the initiation and the propagation of each one as explained below.

\section{- Transverse Joint or Transverse Reflective Cracks}

One major type of distress influencing the life of an overlay has been known and recognized since 1934 and termed "reflective cracking". It is a type of transverse cracks 
that is thought to be caused by the existence of cracks in either an old flexible or rigid concrete pavement underlying the new asphalt overlay (Lauter, 1998). These cracks have been known for a long time and are thought to be caused due to discomtinuity or a crack that already exists at the top of the underlying layer. It is often observed that the new surface cracks in the newly constructed overlay occurred over the same position of the original joint/crack at the bottom of the AC or Plane Concrete (PC) layer, thus the term "reflective cracks" was used.

Horizontal movement due to seasonal expansion and contraction at the concrete joints and cracks was the major cause of this reflective cracking by generating higher stress value on the asphalt over joints and transverse cracks. The basic principle of the occurrence of these reflective cracks is that the generated tensile stresses at the interface of the existed joint/crack and the overlaid $\mathrm{AC}$ layer are significantly increased due to the discontinuity at the tip of the crack. The developed tensile stresses rapidly exceed the tensile strength of the $\mathrm{AC}$ overlay and the crack forms at the interface and quickly propagates upward to the surface of the AC layer. The propagation of these surface cracks is accelerated by low temperature stresses induced at the pavement surface (Lauter, 1998). Figure 1.1 shows the reflection crack at joints and differentiate it from transverse cracks. When the mean width of the cracks exceeds $19 \mathrm{~mm}$, the severity level of the crack is considered to be high as show in Figure 1.2 (Pagani et al., 1999; Dempsey, 2002; U.S Department of Transportation, 2003). It is worth noting that the term "reflective cracking" was dropped from the definition of crack types in 2000 as one of the main conclusions and recommendations of the International Conference of Rilem (Taylor et al., 2000). 

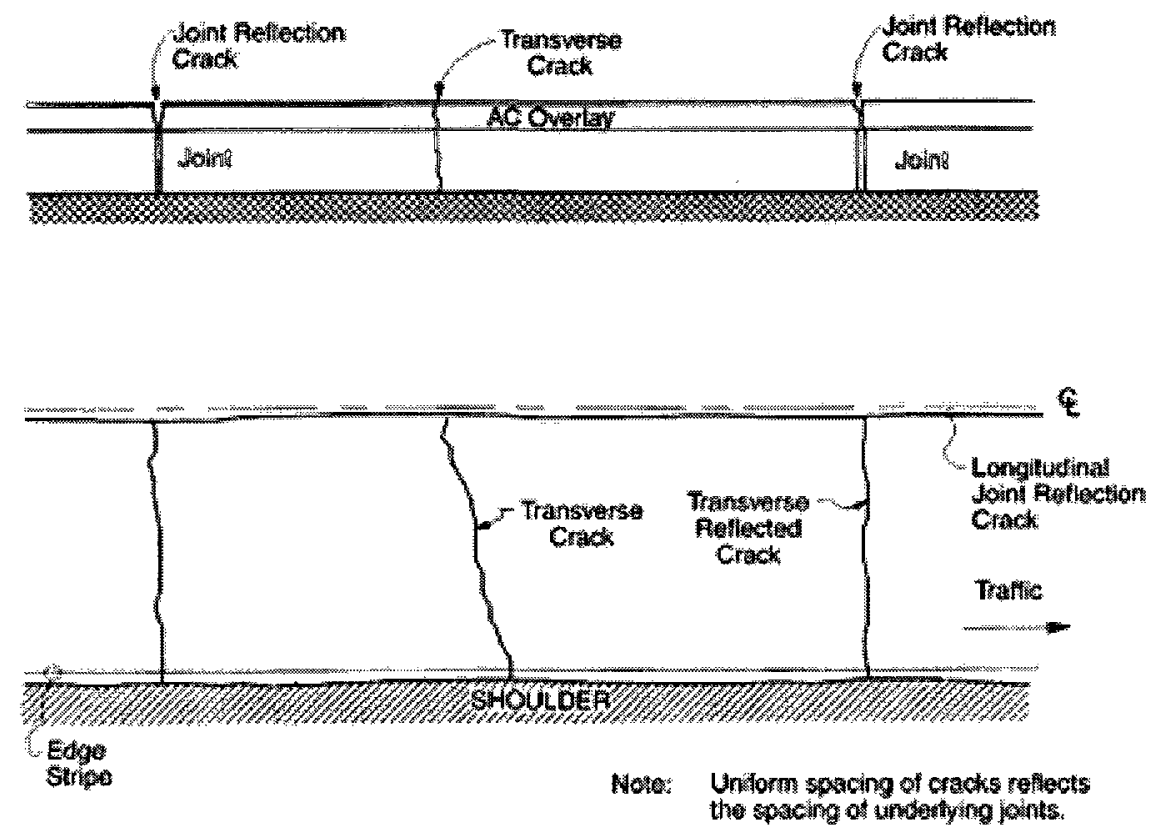

Figure 1.1 Reflection cracking at joints

(U.S Department of Transportation, 2003)
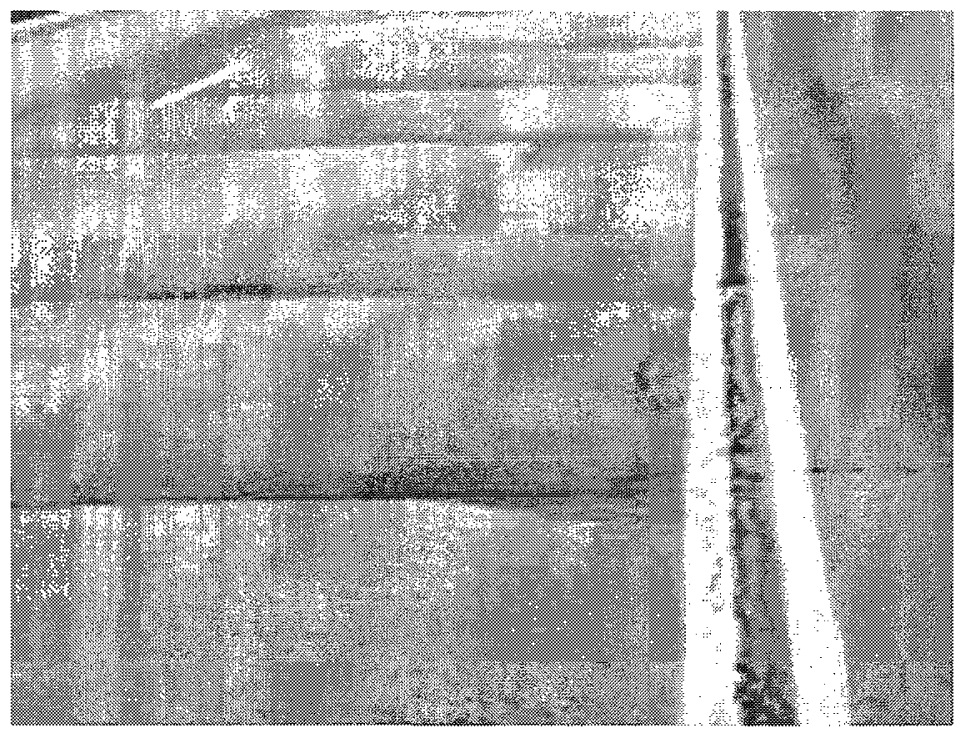

Figure 1.2 High severity reflection cracking at joints

(U.S Department of Transportation, 2003) 


\section{- Fatigue Cracking}

Thinner AC pavement is more susceptible to the bottom-up fatigue cracking mode. Studies done by Washington State Department of Transportation (WSDOT) stated that this type of cracks occurs within one to four years when the pavement thickness is not adequate, as an average thickness of $107 \mathrm{~mm}$. Some authors stated that fatigue cracking in the under wearing surface layer was not verified if the pavement thickness exceed $180 \mathrm{~mm}$ (Uhlmeyer et al., 2000).

The main cause of the fatigue cracking is due to the maximum tensile bending stresses that arise at the bottom of the asphalt layers when the pavement is subjected to high load-induced tensile strains. Another cause of fatigue cracking that develops at the bottom of the asphalt layers is typically the weakness in the underlying layers; like the base or the subgrade. Fatigue cracking can appear at the top surface of the pavement layer in three levels of severity; low, moderate, and high as shown in Figure 1.3. In the low severity level the number of cracks is small, few of them are connected, cracks are not sealed in this level, and no pumping is observed as shown in Figure 1.4. Although pumping does not appear in the moderate level of severity, however, the cracks are weakly interconnected forming a complete pattern; treatment is required in this level by applying crack sealant as shown in Figure 1.5. If pavement partially interconnected pieces start to move from the complete pattern of interconnected cracks when the pavement is subjected to traffic repeated loads, the level of severity is categorized as high, pumping may be evident, and crack sealant is necessary for treatment as shown in Figure 1.6 (Uhlmeyer et al., 2000; Isaac and Robert, 2008). 


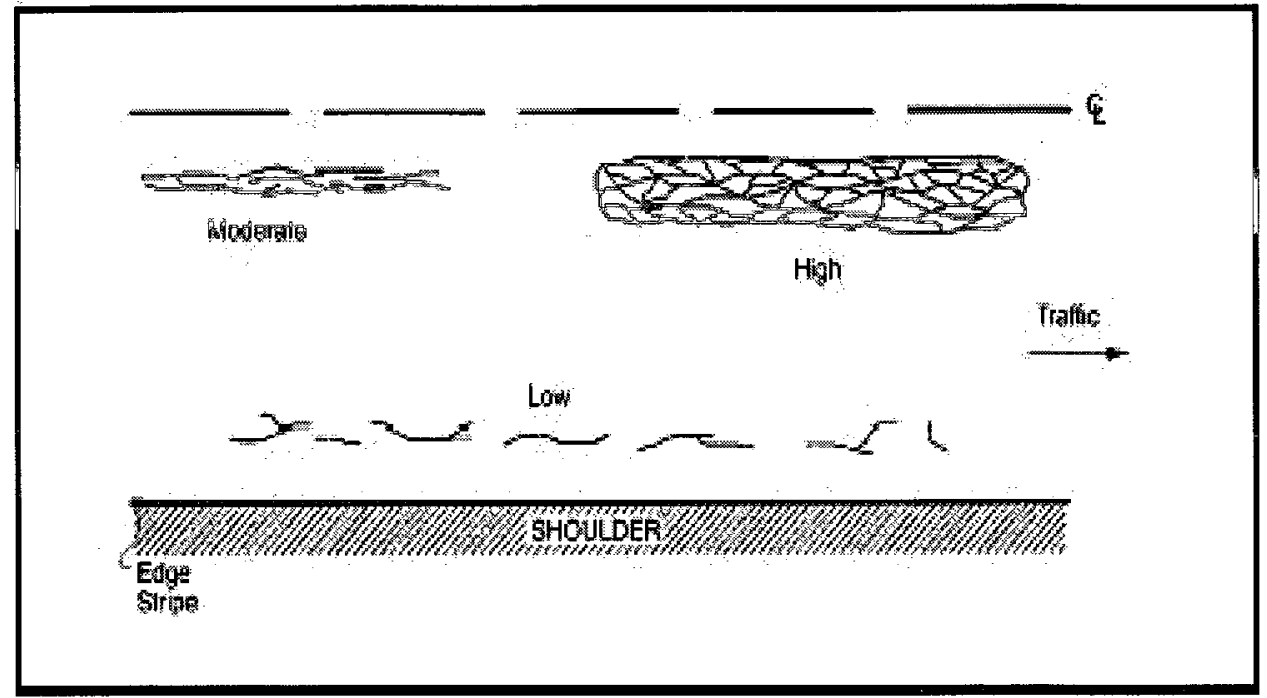

Figure 1.3 Three levels of severity in fatigue cracking (U.S Department of Transportation, 2003)

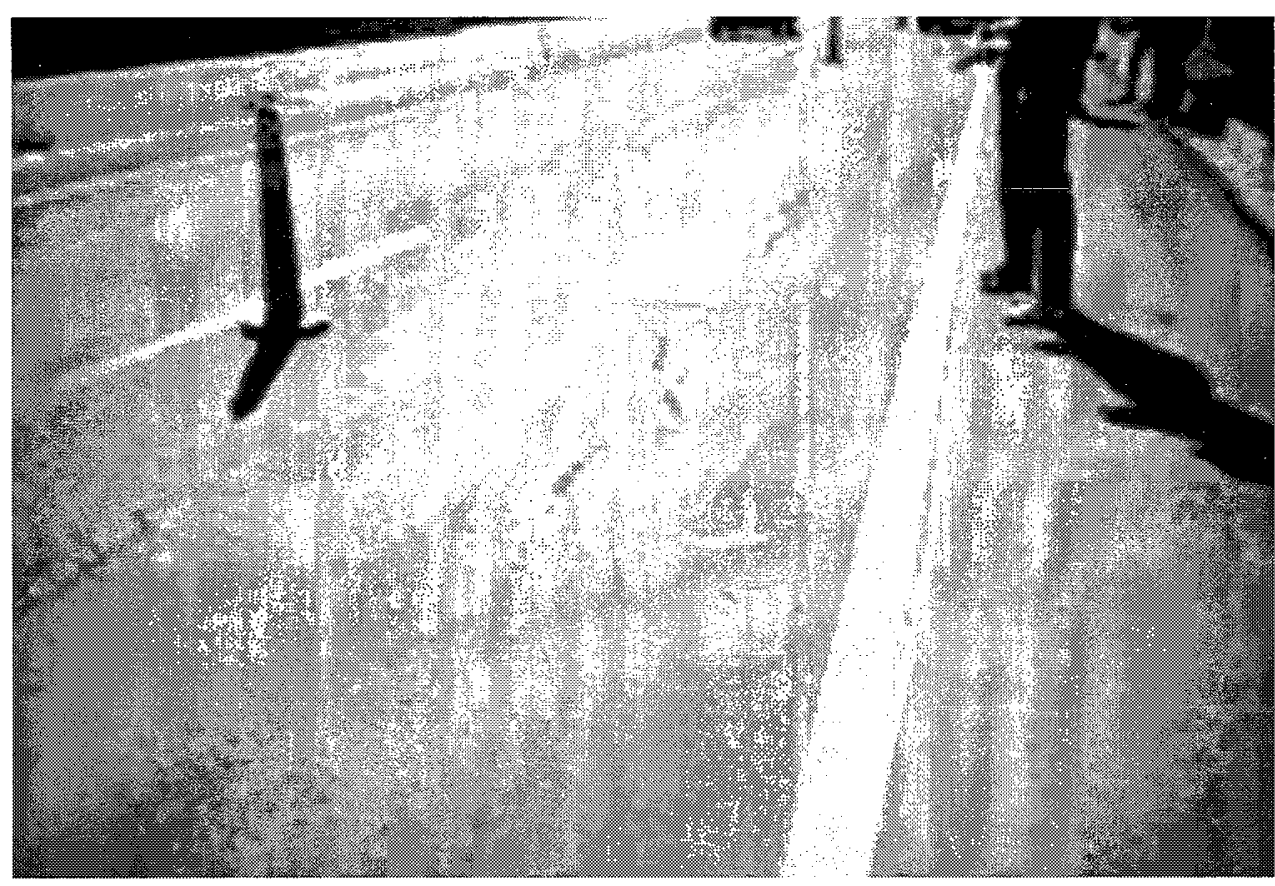

Figure 1.4 Low severity fatigue cracking

(U.S Department of Transportation, 2003) 


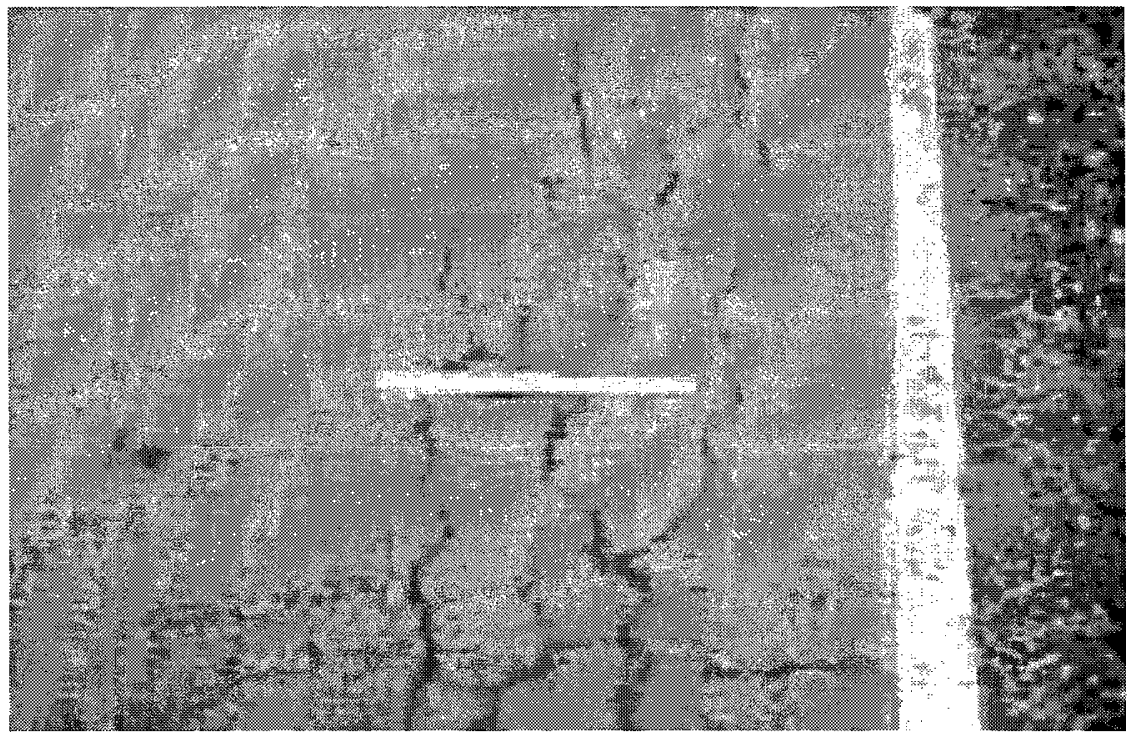

Figure 1.5 Moderate severity fatigue cracking

(U.S Department of Transportation, 2003)

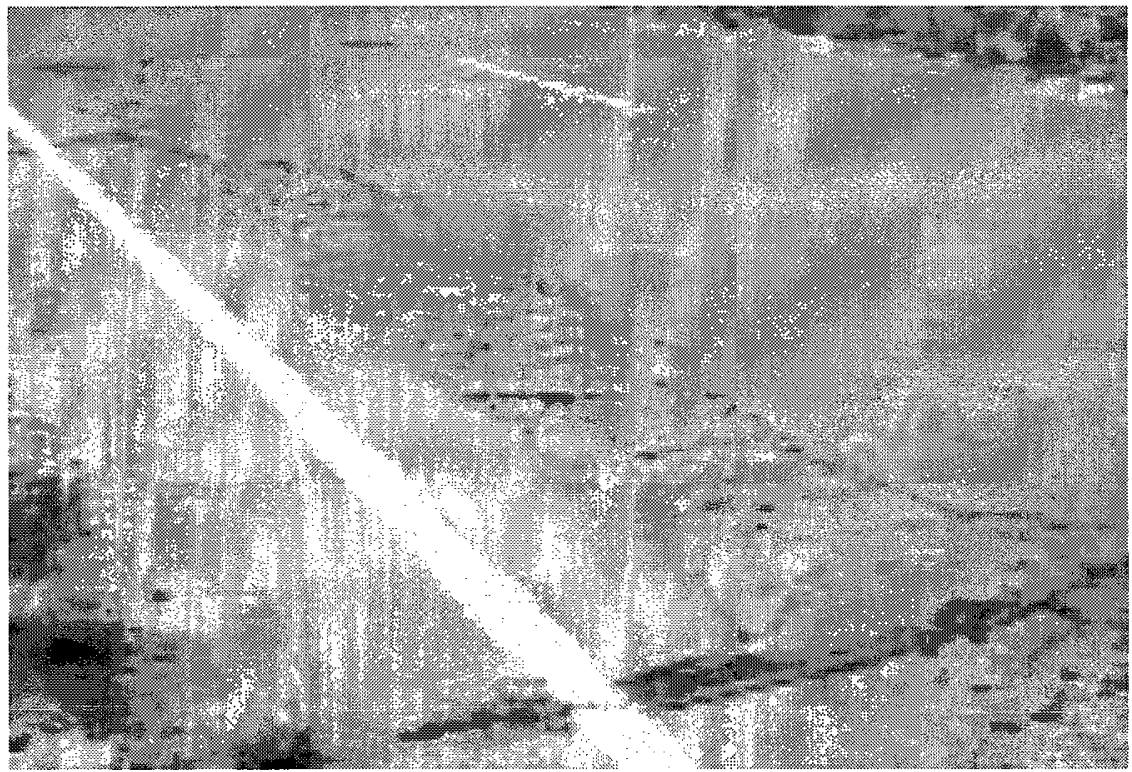

Figure 1.6 High severity fatigue cracking (U.S Department of Transportation, 2003)

When the AC layer experiences surface cracks it will be susceptible to the infiltration of water within the pavement structure. The moisture penetrating the $\mathrm{AC}$ layer weakens the 
asphalt binder material and stripping it from the aggregate. Moreover, when the pavement structure is subjected to freeze-thaw cycles, water can cause structural damage to the pavement layer. It can also cause damage to the base and subgrade material, which malkes the flexible pavement structure subject to other forms of pavement deterioration (Loria, 2008). To prevent the occurrence of the reflective cracking it was suggested to remove and replace the underlying distressed pavement surfacing based on the severity of distress as will be discussed in Chapter four in this thesis (Uhlmeyer et al., 2000).

Isaac and Robert, (2008) reported some guidance for design of asphalt pavement for bottom up fatigue cracking. The guidance shows that the thickness required for the design of bottom up fatigue cracking does not account for any other pavement distresses. That means if the asphalt concrete design results in a thickness less than that presented from this guidance, consideration should be taken since the designed pavement section will indicate risk of under design and will be very prone to fatigue cracking.

\subsubsection{Top-Down Cracks}

Traditionally, pavement distresses were attributed to bottom up cracks caused by tensile stresses underneath the AC layer or reflective cracks. Conversely, top-down cracking is another mode of failure which occurs as longitudinal or transverse cracks that initiate at AC pavement surface and propagate over time downward and outward; partially or the full depth throughout the layer thickness of the asphalt concrete (Uhlmeyer, 2000). Low temperature and construction quality were attributed to the occurrence of TDC (Freitas et al., 2003; Myers et al., 2001). Cracks were considered to occur when thermal stresses exceed the tensile strength of the asphalt layer, or due to the fatigue caused by daily 
temperature cycles (Easa et al., 1996). However there is another type of transverse cracks 25 to $76 \mathrm{~mm}$ apart, this type of cracks is called the roller-checking phenomenon and is occurred during the compaction process (Scherocman and Martenson, 1982).

It was reported by Abd El Halim, $(1984,1987,1994)$ that a number of serious deficiencies had appeared on the top surface of the new compacted asphalt mat at the time of construction, just after the roller finishes the compaction of the asphalt layer. These deficiencies were classified as TDC. Its cause was explained because of the mismatch between the cylindrical shape of the conventional steel drum roller when it interfaces with the soft flat asphalt mat. Moreover, Abd El Halim emphasized the initiation of TDC as a result of the difference in the relative rigidity between the hard cylindrical drum roller and the soft flat asphalt layer during compaction.

In some cases, TDC has even been the predominant type of deterioration mode of the pavements. Filed investigation on 13,612 km in Colorado asphalt pavement reported that 42 percent of the pavement was in poor condition, cracking was assigned the responsible factor, and Top-down cracking was considered a significant portion of this distress (Harmelink et al., 2008). Also 90 percent of asphalt pavements that are scheduled for rehabilitation in Florida are due to TDC (Myers et al., 1998). A study conducted by the WSDOT where cores were recovered along 513 lane $\mathrm{km}$, it was concluded that 51 percent of the total length exhibited identifiable top-down cracks; however, no stripping appeared within the cored layers. There were considerable agreements among a number of researchers and their associated studies, they concluded that the problem of top down cracks initiated at the surface is extensive in many countries, and it was observed that the 
ages of the start of the surface crack varies from one country to another. Some reported 1 to 5 years and others reported 10 years (Uhlmeyer et al., 2000).

Top down cracks is an observable fact for the last two decades, which have attracted the concerns of many pavement engineers and highway departments; this type of cracks is prevalent in asphalt pavements and mostly occurs within the wearing course of the AC (Lippert, 2001; Harmelink et al., 2008; Molenaar's, 1984). It was documented by Myers et al., (2001) that top-down cracks could also exhibited in two forms, the block cracking which is distributed irregularly on the surface and is attributed to the age of the mixture. Surface-initiated longitudinal wheelpath cracking is considered the other form of TDCs. These surface initiated cracks appear just outside the wheelpaths and extend along the roadway in straight and parallel forms, over time; they form an extensive network of longitudinal cracks connected by short transverse cracks, which ultimately reduce the life of the pavement (Schorsch, 2003).

There are different factors causing TDC, therefore determining the factors that result in the initiation of TDC are extensively discussed in Chapter Three of this thesis.

\subsection{Research Scope and Objective}

The scope of this research is to focus on the causes and mechanisms leading to the phenomenon of top down cracking in asphalt layers. Also, the research work presented in this thesis attempts to quantify the effect of the surface cracks through performing well planned laboratory tests demonstrating the negative effects these cracks may have on the strength of the cracked asphalt pavements as well as possible environmental damage. 
With this scope in mind, the main objective of this research is to carry out an in depth state-of-the-art study to identify the main factors that govern the initiation and propagation of top down asphalt cracks and determine best ways to prevent the occurrence of pavement cracking. More specifically, this thesis is carried out to achieve the following objectives:

- Study the factors influencing the initiation of TDCs, and review the mechanisms that lead to the crack propagation stages.

- Identify the "real" causes of TDC and study the predominate factors affecting these causes.

- Assess the treatment used to minimize and control the occurrence of asphalt cracking and determine the most predominant methods or techniques of remedies.

- Perform an analysis on the factors affecting the occurrence of TDCs.

- A laboratory investigation to assess the effects of TDC on the integrity of $\mathrm{AC}$ pavement and the possible damage to the environment.

To accomplish the above stated objectives, a research plan was designed and is presented in section 1.5.

\subsection{Thesis Organization}

This research thesis is organized as follows:

Chapter 1 - Provides a general introduction describing different types of pavement distresses and the main objectives of the research.

Chapter 2 - Presents a review of the location, characteristic and classification of TDCs 
Chapter 3 - Discuss the stat-of-the art of the factors affecting the initiation and propagation of TDCs

Chapter 4- Presents the implemented remedies to overcome the problem of TDCs

Chapter 5 - Analyzes the factors affecting TDCs.

Chapter 6 - Influence of TDC on the integrity of AC pavement through a well planned laboratory testing program.

Chapter 7 - Summarizes the principle findings of the thesis. 


\section{CHAPTER TWO}

\section{Location, Characteristic, and Classification of Top-Down-Crack}

\subsection{Location, Characteristic of Top-Down Crack}

Location of TDC is the spot on the pavement surface where the crack is first initiated. Location is a key element to distinguish TDC from all other types of cracks. Top-DownCrack may be classified according to its location, appearance, and the mechanics of its propagation. This chapter deals specifically with the subject of top-down cracks.

It was reported by Abd El Halim, et al., (1994) that defects appeared on the surface of asphalt concrete pavements at the time of construction in the form of hairline cracks distributed on the entire pavement surface. These cracks have been traditionally termed "checking". The cracks are often observed to be initiated underneath the steel drum roller within the contact area with the asphalt mat as transverse very small and thin cracks which are very difficult to be seen by the naked eye. Furthermore, after short period of time the observed surface cracks would connect forming a curved crack across the width of the paved lane rather than a straight line. The use of conventional steel rollers results in this crack shape during the compaction process due to the relative deference in the stresses distribution across and under the width of the steel drum roller. The stress distribution under the steel drum is higher at the edges compared with the stress values under the centre. This stress variation results in constraining the forward movement of the asphalt material at the edges of the drum roller relative to the less constrained material under the centre of the drum. As a result, the compaction induced cracks under the steel drums takes the shape of a curve rather than a straight line. Once 
these cracks are initiated they will continue to propagate through the layer thickness, thus causing the unexpected earlier deterioration reported almost globally (Abd El Halim et $\bigotimes_{\circ}$ 1994).

Moreover, the compaction initiated cracks may generate number of separated shorter slabs in the longitudinal direction of the pavement. The reported separated slabs are explained as a result of shrinking of the asphalt mat due to severe cold temperatures. The shrinking of the asphalt slab may produce thermal stresses causing the occurrence of thermal transverse cracks (Lauter, 1998). Furthermore, areas experiencing temperatures above freezing such as desert climates in summer seasons can also be subject to the appearance of TDC due to large temperature changes between day and night.

Top-Down-Cracks could also appear as longitudinal ones which may be found either within the area of the wheelpath or outside as adjacent cracks to the wheelpath (Matsunno and Nishizawa, 1992; Freitas et al., 2002). Also they could appear both inside and outside the wheelpath areas in a short time after construction as shown in Figure 2.1 (Uhlmeyer et al., 2000). However Svasdisant et al., (2001) reported that the majority of the longitudinal TDCs were observed outside the wheelpaths, with a few in the wheelpaths. Several studies suggested that the location of crack initiation occurred under the critical applied loads. Svasdisant et al., (2001) in their study concluded that TDCs are located approximately at the same position of the maximum surface tensile stress. In contrast, results from a study carried out by Myers et al., (2002) while confirmed that the initiation of TDCs was indeed under the wheel path, it concluded that the location was not the same position of the maximum surface tensile stress. Furthermore, it has been suggested that the magnitude and direction of crack tip tensile stresses depends on the 
gradients in the stiffness between the surface and the base layer which play a major role for the development of the cracks in the asphalt pavements (Myers and Roque, 2002).

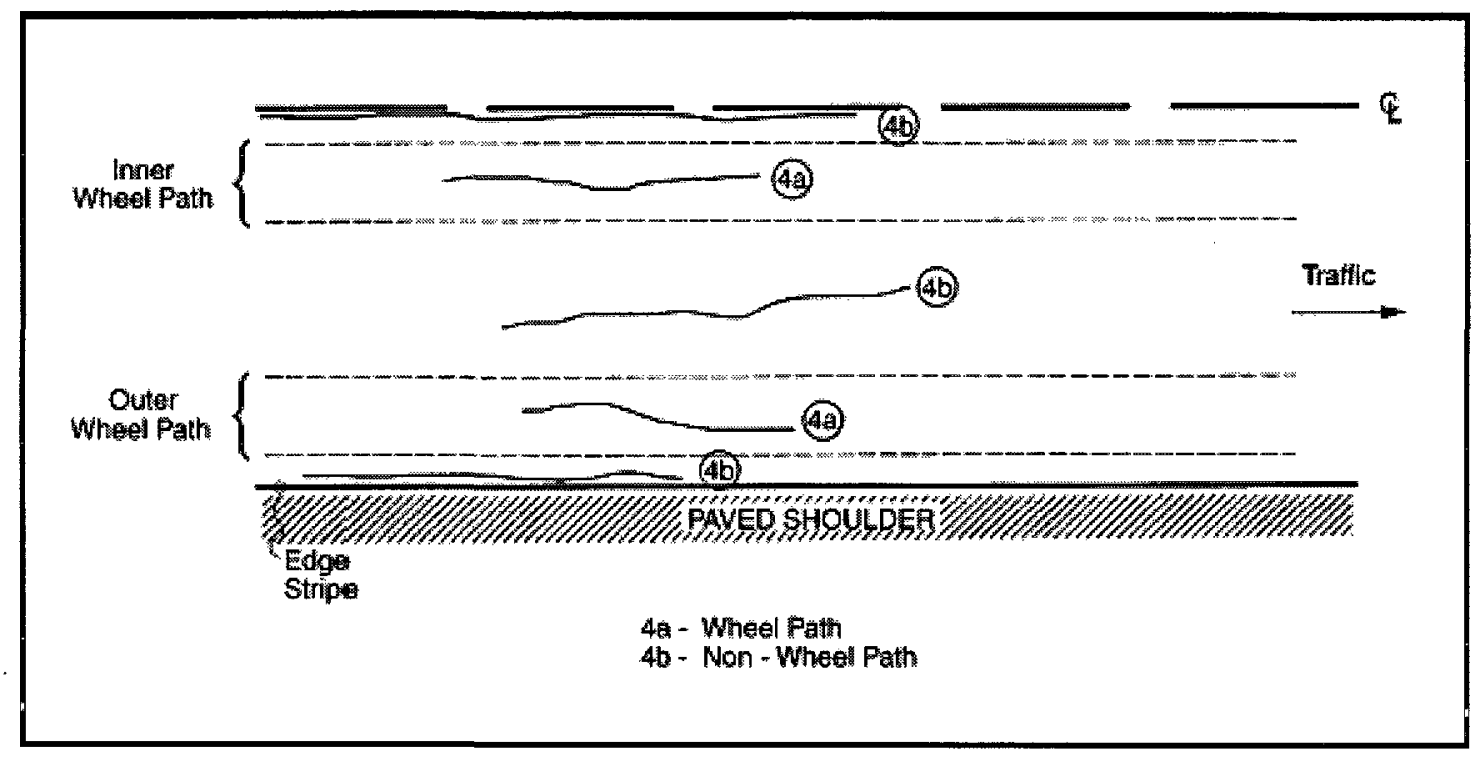

Figure 2.1 Longitudinal Cracking (U.S Department of Transportation, 2003)

Taking the age of the asphalt pavement as a criterion for the initiation of top down cracks, it was exhibited that for a well structurally designed pavement that is adequate to carry the required single axle loads, the cracks were reported to start appearing within 3 to 8 years in Washington State, also it was registered at 1 to 5 years in Japan, 3 to 5 years in France, 5 to 10 years in Florida and 10 years in the United Kingdom (Matsuno and Nishizawa, 1992; Myers, 2000; Uhlmeyer et al., 2000). However as indicated earlier, Abd El Halim et al., (1994) reported that TDCs can be seen as micro cracks in the pavement surface just after the compaction process is finished during the construction phase of the asphalt pavement and they concluded that these micro cracks were 
developed to macro cracks year after year depending on the temperature differentials between summer and winter seasons among other factors.

\subsection{Top-Down Crack Classification}

Top-Down-Crack classification procedure was developed based on crack appearance, location and the mechanics of crack propagation. Such procedure was developed to separate TDC from other types of cracks, and is presented in this section.

In general, any cracks that initiate at the surface of the pavement and propagate downward could be considered as TDC. Field observations were conducted by Schorsch, (2003) and depending on the type and causes of the first observed crack; TDCs were classified into three categories namely:

1. Transverse Top-Down Cracks (TTDC)

2. Individual Longitudinal Top-Down Cracks or groups of parallel (LTDC).

3. Network of Longitudinal and Transverse Cracks (NLTC)

\subsubsection{Transverse Top-Down Cracks (TTDC)}

Transverse Top-Down Cracks are recognized by the paving industry as the predominant type of TDC in the world, it has been attributed to the compaction process under the mechanism of the conventional steel roller during the construction process. It has two categories; the first one which extends in the shoulders of the road and it has a considerable width and some inches in depth. While the second category, those appear on the surface just after the compaction method as hairline cracks at right angle to the pavement centre line. Once these cracks initiated they will extend and widen with time 
through the layer width and depth. This second type attracted the attention of many researchers and an intensive effort has been spent on studying it since 1965 especially in Canada and the Northern part of U.S.A, because of severe cold winters (Fromm 1972). The surface cracks when in their micro stage can be seen as sets of small cracks connected together to form a large crack across the paved lane.

Thermal stresses due to cold temperatures and low tensile strength of the $\mathrm{AC}$ mixes is another cause that explains the occurrence of TTDC when located at the centre of the lane and perpendicular to the direction of vehicle traveling. Over time, the crack propagates across the lane and other transverse crack develops. Depending on the condition of the tensile stresses at the pavement surface TTDC may or may not be connected with longitudinal TDC. Tire kneading action delayed the initiation of TTDC in the wheel path, and that could be a reason why they first appear in the middle of the lane (Schorsch, 2003).

In addition to these fundamental characteristics of the observed cracks it was observed that, the width of the paved lane is often much wider than the measured spacing between successive transverse cracks. This later observation raised serious doubt about the assumption that transverse cracks are the result of thermal stresses due to their apparent uniformity. Moreover, surface cracks or TDC will first initiate during process of compaction in the first stage of construction. The temperature of the laid hot mix asphalt mat before compaction will normally be close to $150^{\circ} \mathrm{C}$ and will continue to drop during compaction until it reaches the air temperature after completion of construction. Clearly this temperature will never reach as high as the original temperatures during construction even during the peak hot summer days which may not exceed 40 to $46^{\circ} \mathrm{C}$. Hence, one 
could consider the warmer summer temperatures as cooler ones compared to the one under which the surface cracks were induced. The difference in temperature (about 100 ${ }^{\circ}$ ) ) explains the often observed open cracks during the summer high temperature periods. Finally, many of the surface cracks remain open and visible during the warmest summer temperatures which again contradict the assumption that they were generated at temperatures less than -10 to $-30^{\circ} \mathrm{C}$. This observation confirms the analysis that these cracks were initiated at temperatures as high as 140 to 150 (Abd El Halim, 1984).

According to Schorsch, (2003) TTDC is likely to have one or more of the criteria listed below

- Hair line cracks fully distributed on the pavement surface during the compaction process, the conventional steel roller is the main cause that induces this form of TDC

- Short transverse cracks that appear at the center of the lane. These TTDCs are attributed to low temperatures and thermal tensile strength.

- Transverse cracks that across or almost across the lane Figure 2.2 and appear at a constant interval throughout the pavement section. These cracks cause roughness to the pavement surface due to low profile at the crack edge. High thermal stresses at the pavement surface give the tendency to these cracks to occur at the surface and propagate downward.

- All short transverse cracks connecting LTDCs. These short cracks could be located anywhere along the pavement.

- Transverse cracks in segregated areas. 


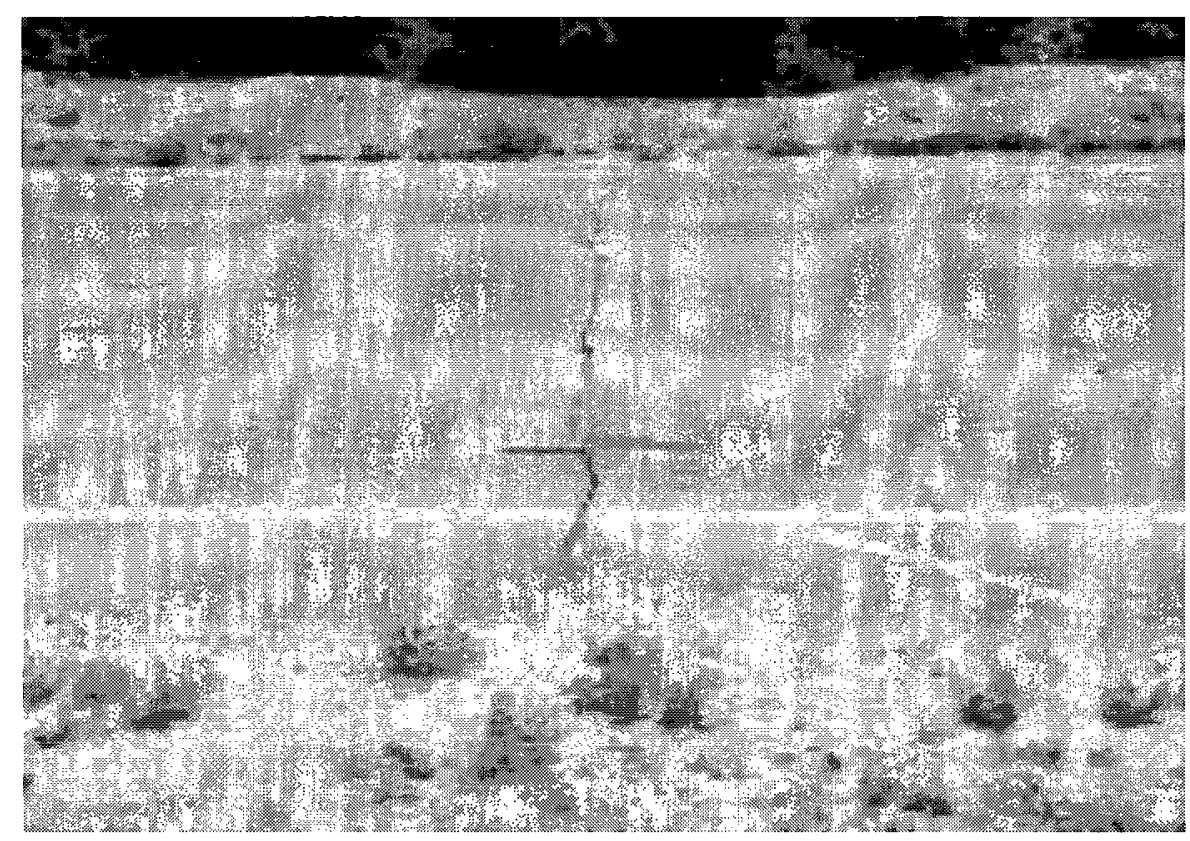

Figure 2.2 TTDC across the lane

(U.S Department of Transportation, 2003)

\section{Influence of the subgrade type on the pattern of transverse cracks}

It is difficult for the designer to choose the subgrade type under the asphalt pavement. The influence of subgrade layer under the AC layer on the pattern of transverse cracks was discussed by Guylain and Claude, (1999), they reported that cracks appeared at longer spacing followed by subdivision of the long slab into shorter segments was due to clay subgrade in most pavements. In sand subgrade the pattern of crack development is erratic and on several situations the distance between the transverse cracks varies between 1 to 3 m (3 to 10) feet (Guylain and Claude, 1999).

\subsubsection{Longitudinal Top-Down Cracks (LTDC)}

Longitudinal Top-Down Cracks appear in the pavement surface in a parallel position to traffic direction. Low tensile strength of the asphalt concrete mix, induced tensile stresses 
due to tire pavement interaction are the main cause of this type of LTDC. Differential of the stiffness between the underneath course layer and the pavement asphalt layer causes the increase in the tensile stresses and hence accelerate the occurrence of LTDC.

The characteristics of LTDC that has been observed in the field and is highly considered LTDC if it satisfies one or more of the following criteria:

- Longitudinal crack located at the edges of the wheelpath.

- Parallel low to medium severity longitudinal crack which is separated by 0.3 to $1 \mathrm{~m}$ and can be found at the centre of the wheelpaths or within the edge as shown in Figure 2.3.

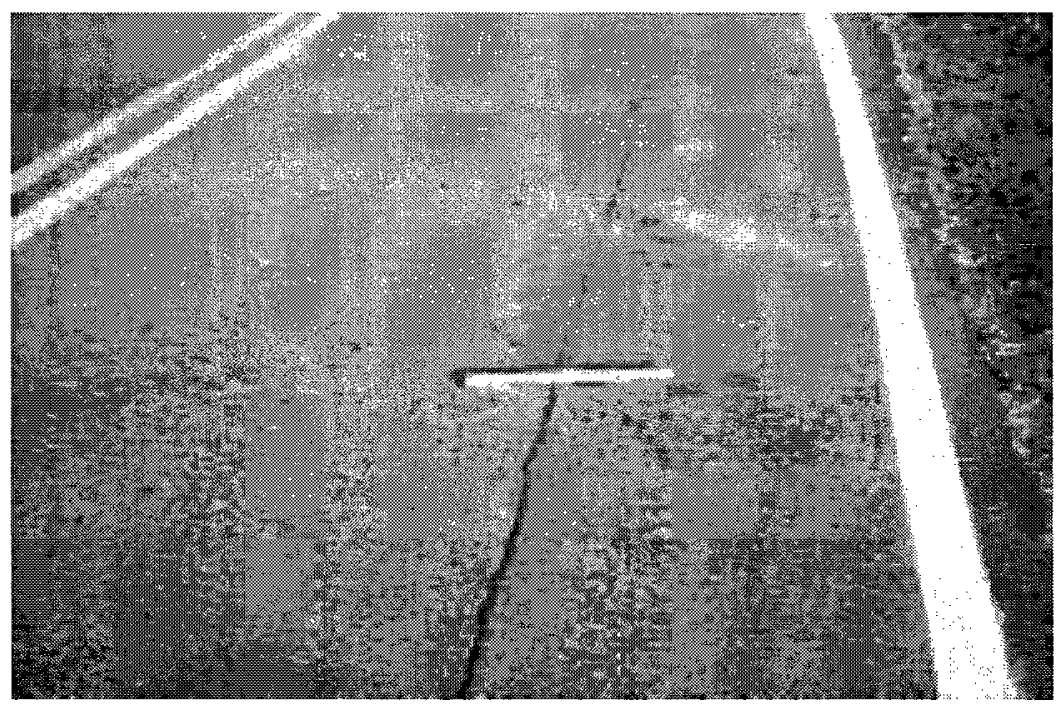

Figure 2.3 Longitudinal cracking in the wheel path (U.S Department of Transportation, 2003)

- Crack caused due to opening of the paving joint, and can be found between two lanes, between the traffic lane and the pavement shoulder or between an old pavement lane and a pavement widening strip 
- Longitudinal crack that is located in segregated areas or in areas where the AC mix has low asphalt content, and hence low tensile strength.

- If the longitudinal TDC appeared in random or meanders distribution it would be classified as fatigue cracking

\subsubsection{Network of Longitudinal and Transverse Crack (NLTC)}

Network of longitudinal and transverse crack is also termed as block cracking caused due to hardening of the $\mathrm{AC}$ binder. Particle segregation is another cause of the propagation of NLTC, the shape of the segregated area control the appearance of this type of crack. It propagates within the segregated area at a relatively fast rate, which decreases as the crack begins to penetrate non-segregated areas.

Network of longitudinal and transverse crack is observed as a network if they satisfy one or more of the following criteria (Schorsch, 2003):

1- Crack placed around the wheel path and separated by a distance of $1 \mathrm{~m}(3 \mathrm{ft})$ apart.

2- Crack extends throughout the pavement in a twisty shape

3- Finally, a localized network of crack is not TDC if it is located around the center of the wheel paths. These cracks are fatigue cracks

\section{Summary}

Top down crack is classified into three categories namely:

- Transverse top-down crack which appears as micro cracks in the pavement surface just after the compaction process of the asphalt pavement. It was also attributed to 
thermal stresses due to cold temperatures and low tensile strength of the AC mixes. It was recognized by the paving industry as the predominant type of TDC in the world

- Longitudinal top-down crack which appears in the pavement surface in a parallel position to traffic direction. Low tensile strength of the asphalt concrete mix, induced tensile stresses due to tire pavement interaction are the main causes of this type of LTDC.

- Network of longitudinal and transverse crack is also termed as block cracking caused due to hardening of the AC binder. Particle segregation is another factor of the NLTC propagation, the shape of the segregated area control the appearance of this crack.

With the classifications for TDC described above, it would be important to know the main factors affecting the causes of TDC while that would give us a full understanding how and why these cracks appear in the surface of the asphalt layer. The next chapter will discuss the factors affecting the initiation and the causes of TDC. 


\section{CHAPTER THREE}

\section{Causes and Mechanisms of Top-Down Cracks}

\subsection{Introduction}

For long time, most existing asphalt pavement design methods determine the pavement cross-section and predict pavement roughness based on the traditional assumption that pavement cracking initiate at the bottom of the asphalt layer and propagate upward to reach its surface. Subsequently, several of these methods address certain types of pavement distresses such as conventional fatigue cracking, which initiates as a result of repeated tensile strains at the bottom of the asphalt layer. However, and as discussed earlier, most recently it has been pointed out that the dominant type of distress in pavement surface was Top-Down-Crack which initiates at the pavement surface and over time it propagates downwards throughout the asphalt concrete layer. Although TDC has been widely observed and studied around the world, no design method has been developed to determine the potential of the occurrence of TDC. However, some top-down cracking models have been incorporated into the recent AASHTO design guide in 2002 (Schorsch et al., 2004).

There is little consensus as to the causes of TDC, however, determining the factors that govern its potential is essential to specify these causes and to find out up to what extant each cause could be valid, and hence conduct a study on the availability and validity of different types of remedies.

In this chapter the factors that govern the potential of TDC will be discussed in the following order: 
1. Factors related to the compaction induced crack.

2. Factors affecting the construction induced crack.

\section{Factors contributing to the tensille stresses induced in the $\mathbb{A C}$ layer.}

4. Factors influencing the tensile strength of the $\mathrm{AC}$ mixture.

Based on several publications in the literature, it was indicated that TDC could be caused by one of the above factors or by a combination of several factors. Results of various analytical and field studies carried out by Abd El Halim et al., between (1984 to 2007) on the conditions during compaction of newly laid asphalt layers showed that observed surface crack is caused by currently used steel drum rollers. Among the significant results of these studies was the fact that compaction induced crack can reduce the fatigue life of the finished pavement by more than $50 \%$. According to Abd El Halim (1994), for more than 85 years the pavement industry has been confronting the same types of problems without any solution insight. He observed that these types of problems continue to occur as a result of wrong assumptions and subsequent failure to identify the main causes and mechanisms associated with the compaction problems.

Gerritsen et al., (1987) conducted a study to investigate the causes of TDC on pavements in the Netherlands. They concluded that TDC is most likely caused due to poor compaction, binder stiffening, or low binder content. It was also concluded that high surface tensile stresses induced at the tire edge could lead to the occurrence of TDC (Molenaar, 1984). Matsuno and Nishizawa, (1992) reported that TDC composes a major distress in Japan that occurs near the wheelpaths in pavements ranging from 1 to 5 years old. They conducted a finite element analysis of flexible pavement in hot temperature and concluded that, traffic loads produce high tensile stresses at the tire edge causing TDC 
initiation. Dauzats and Rampal, (1987) studied TDC in southern France and concluded that thermal stresses in the asphalt surface course are responsible for the initiation of TDC. On the basis of field investigation of flexible pavements, Svasdisant et al., (2001) studied the variation in the pavement deflection along and across the pavement by applying 249 sets of the non destructive deflection test and determining the degree of propagation of TDC for 67 cores. They concluded that TDC was associated with the high radial tensile stresses at the $\mathrm{AC}$ surface induced by a combination of load, temperature, and hardening of the asphalt binder.

The next sections discuss in more details the factors governing the potential of TDC.

\subsection{Compaction Method}

The compaction method of $\mathrm{AC}$ mixture in the field is affected by several factors including, AC density, air voids percent, and the compaction equipment and procedure itself. Deficiencies of the compaction process could affect the value and distribution of the density of the AC mix; lead to insufficient or extremely high air voids percent in addition to the phenomenon of compaction induced cracking. The effects of each of these factors are presented in the subsections below (Abd El Halim et al., 1993).

\subsubsection{Asphalt Concrete Pavement Density}

Compaction of the $\mathrm{AC} \mathrm{mix} \mathrm{is} \mathrm{that} \mathrm{part} \mathrm{of} \mathrm{the} \mathrm{construction} \mathrm{process} \mathrm{that} \mathrm{is} \mathrm{largely}$ responsible for the qualities of the mechanical properties of the finished pavement. The mechanical properties in turn will depend on the degree and quality of compaction. The 
degree of compaction of the mixture is measured by the obtained density and its uniformity along and across the compacted mat. Density is defined as the ratio of the total mass to the total volume. Imoreasing density to reach predetermined optimum value and reducing air voids are most significant variables that affect the durability and the performance of the pavement structure (Linden et al., 1989; Brown, 1990; Abd El Halim et al., 1993). Apart from the fact that the density of asphalt pavement does increase with traffic loading, it is desirable to obtain the required density during the compaction process. That would be achieved by placing more material in a given volume to obtain the maximum theoretical density; any compaction effort beyond this point will make no difference and may in fact cause reduction in the value of maximum density (Scherocman, 1984; Pagani et al., 1999).

Many pavement experts studied the effect of compaction on the performance of the asphalt concrete mix on the assumption that performance of pavement is dependent only on achievement of higher density and lower air voids. It could be stated that everyone in the pavement industry would agree that higher asphalt concrete densities will play an essential role in enhancing the overall strength, durability, impermeability, skid resistance, resistance to deformation and resistance to moisture damage. However, the mechanism that govern the interaction between the presently used steel drum rollers and the compacted asphalt mat during the compaction process has not been fully understood, resulting in the failure to properly develop effective and efficient solutions for several old problems related to long term performance of asphalt paved roads (Abd El Halim and Haas 1994; Rickards et al., 1999). 


\subsubsection{Air Voids Percent in Asphalt Concrete Layers}

Although the asphalt mix design procedures specify a range in the air voids content from $3 \%$ to $5 \%$ as recommended by the asphalt institute, however, good compaction practice that leads to this desirable air voids percentage on the Hot Mix Asphalt (HMA) is very hard to attain. Because the air voids content in the constructed asphalt pavement tend to be greater than the specified range due to compaction variability. Practically, under the conventional compaction method and at the end of the final rolling process the density level of most AC pavement is less than desired. As a result, the air void content is expected to be higher than predetermined and ranges in the range of $6 \%$ to $9 \%$ could be obtained in the field. The lower densities associated with higher air voids usually do not satisfy the required specifications specifically that of air voids which is considered as too high in the AC mix. The involuntary produced air voids in the compacted asphalt mat lead to cause deficiency in the pavement structure during construction of the $\mathrm{AC}$ mix, and cause a significant reduction in the pavement service life (Svasdisant et al., 2001).

A mixture that is properly designed and well compacted will contain enough air voids to prevent bleeding of the asphalt concrete mixture by providing some room to the asphalt cement to expand under high temperature which is called the plastic flow phenomenon. On the other hand, if the air voids exceeds the specified limit, the asphalt concrete mixture will be permeable and will allow air and water to go through it, also under traffic load throughout its life; large amount of the asphalt binder will fill in the voids leading to rutting and stability problems. Thus, desired air voids in the mix are typically an air void content of at least $2 \%$ and preferably $3 \%$ (Scherocman, 1984). 
However based on results from a study conducted on the effect of air voids on the long term performance of the asphalt pavement, Linden et al., (1989), concluded that for every $1 \%$ increase in air voids over $7 \%$ would result in about $10 \%$ loss in pavement life. They have also pointed out that there is a difference in the air voids content in the constructed pavement across the lane width of the asphalt mat which they attributed its cause to the effect of the traffic load within the wheelpath. That leads to the observation that asphalt mats experience further densification under the effect of traffic loads, similar to the effect of the compaction process, after construction is finished.

\subsubsection{Asphalt Compaction Objectives and Theoretical Considerations}

Attaining optimum compaction to improve the physical and mechanical properties of the mixture and getting the ultimate performance of the finished pavement has always been the principal objective in the pavement industry. It is well known that applying the optimum compaction process will reduce the percentage of air voids and increase the density of the layer and consequently extending the service life of the asphalt pavements (Scherocman 1984, Abd El Halim and Haas, 1994).

Understanding the mechanism of how the bond material perform when it is mixed with the granular particles, and how these particles are distributed within the mix under the compaction process, is the right track to achieve the objectives of the optimum compaction process. The bond material in the asphalt concrete mix flows under the external compaction force causing reorientation in the aggregate particles until the equilibrium state occurs. During this process the bitumen will experience shear flow at the binder aggregate interface as illustrated in Figure 3.1. While the asphalt layer is 
conventionally compacted under high temperature, the bitumen material will be in lubricant stat and will creep. Therefore maximizing particle contact is the first goal that should be achieved in the asphalt compaction process to increase the shear resistance and build a structure that resist the deformation at high temperature as shown in Figure 3.2 (Rickards et al., 1999).

However at high temperature the asphalt concrete binder responds in a viscoelastic-plastic manner that depends on temperature, load duration and load magnitude. This response resists and governs its flow away from the voids during compaction. Under high temperature, the asphalt concrete stiffness and viscosity is decreased, whish facilitate the movement of the material under the compaction load. However, if the load is applied rapidly, there will be a time delay for the binder to flow from the small pores and thereby allow a reduction in volume due to the elastic behavior of the binder. Appling a sufficient load for a longer time will result in viscous flow and compaction of the asphalt mixture. The amount of flow will increase as the temperature remains high, and thus the optimum compaction will be achieved. Thus, an asphalt mat can be more effectively compacted when subjected to a load of sufficient duration at higher temperatures (Pagani et al., 1999).

\subsection{Deficiency with Current Compaction Equipment}

The compaction process is defined as the densification of each asphalt left by the utilization of compaction equipment such as the conventional steel roller, followed immediately by pneumatic tire roller (Pagani et al., 1999). Deficient compaction 


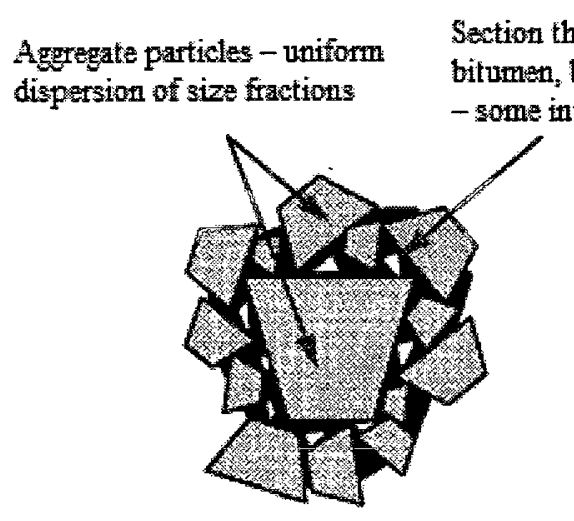

Two dimensional representation of aggregate skaleton in loose mix

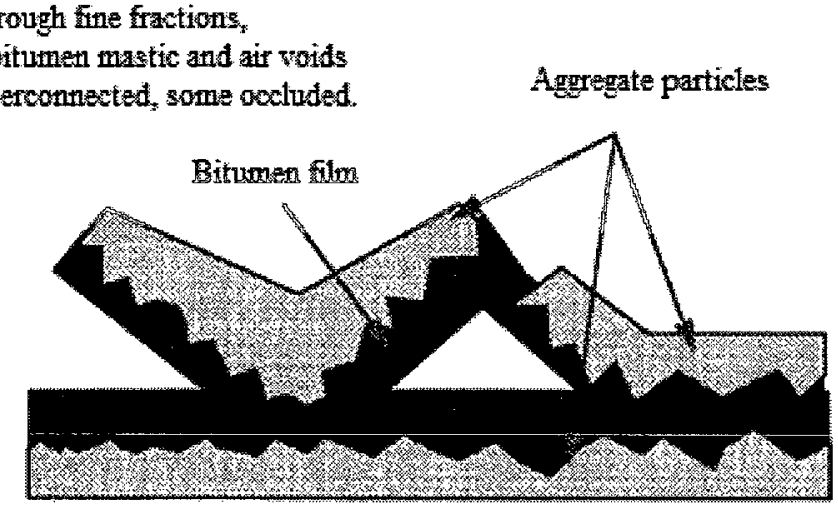

Detail rapresentation of aggregate contact points pre compaction

Figure 3.1 Schematic of pre-compaction asphalt mix aggregate/binder structure

(Rickards et al., 1999)

Aggregate particles - uniform dispersion of size fractions
On compaction, aggregate particles maks contact in thres dimensions, thus may tol appest its contact on atwo dimensional plane. Entrained air is expelled and woids diminished or filled.

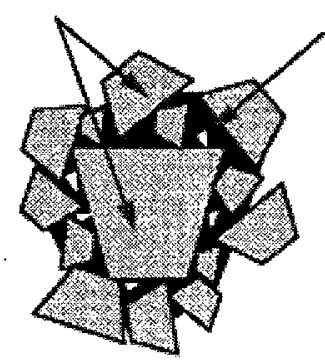

Two dimensional representation of aggregate skefeton in compacted mix
Agregate particle reorientation may require rotation and or shear displaxement

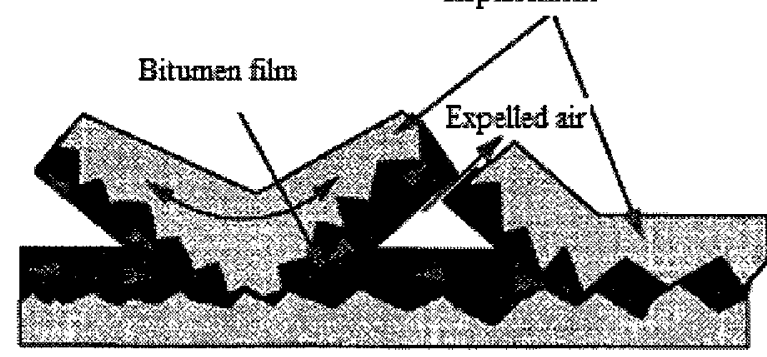

Reorizntation of aggregate particles in the compaction propess is essentially related to shear in the binder silm

\section{Figure 3.2 Schematic of compaction asphalt mix structure}

(Rickards et al., 1999)

equipment will lead to compaction problems appearing on the pavement surface. Current compaction equipments used in asphalt compaction are characterized by their cylindrical shape and stiff material relative to the more flat and softer asphalt mat. As now known, 
several research works identified these traditional rollers with several problems observed on the surface of the finished pavement as will be discussed below (Abd El Halim et al., 1993; Mun, 2003).

\subsubsection{Causes of Compaction Induced Cracks}

Scherocman and Martenson, (1982) described compaction cracks (roller checking cracks), as those cracks extending through the asphalt depth between 6 to $10 \mathrm{~mm}$ deep and are distributed as short transverse cracks 25 to $76 \mathrm{~mm}$ apart. They explained that the load produced by the conventional steel roller on the asphalt mat during compaction is causing tension stresses, due to these stresses, cracks are formed in the surface of the asphalt mat. However, the authors did not explain how at such higher temperatures and the semi-fluid state of the compacted asphalt such tensile stresses would generate. Furthermore, most of the studies attempted to identify the compaction problems with poor mix design or temperature variations. In 1984, Abd El Halim explained the causes of the reported surface cracks as the result of incompatibility between the geometries and materials of the roller and the asphalt mat.

Several field studies were carried out by Abd El Halim et al., (1993) to investigate the effects of the interface between the compactors and the asphalt on the end results of the compaction process. These studies showed that traditional compaction equipment were the major cause of the compaction induced cracks. Also, laboratory tests performed on cores recovered from the field suggested that present compactor will produce asphalt layer full of surface cracks which affect its mechanical properties and shorten the service life of the paved road significantly. For many decades, asphalt surface cracks known as 
"hairline cracks" have been recognized and observed during the construction phase. However, they were not considered to be structurally a cause for damaging the pavement buit rather as unsightly without adverse effect to the pavement. Consequently, many pavement engineers did not pay much attention to analyze and investigate these cracks. However pavement distresses which occurs very early after construction is considered one of the main problems that is facing the pavement industry (Abd El Halim and Haas, 1994).

For many years, the compaction induced cracks reported on the surface of the asphalt pavement have been explained as a result of the reflected cracks which start at the bottom where a cracked rigid asphalt concrete layer and extend upward. In summary, the failure to understand the mechanisms and causes of the reported compaction cracks are due to several reasons among them are: (1) Lack of research work dealing with construction issues, (2) Absence of serious challenge to the belief that deficiencies in the bottom layers are the main cause of the surface cracks, (3) Belief that the problem is related to poor design or manufacturing to the asphalt mix, and (4) Compaction equipment have been around for a century without question their performance. Because of the fallacy of this approach, many attempts to eliminate or minimize compaction induced cracks have been considered and implemented in the field (Abd El Halim 1984, 1986 and 1987; Abd El Halim and Haas, 1994). Clearly, none of the proposed and attempted field solutions and remedies provided a long term full-proof solution to any of the existing problem, 


\subsubsection{Explanation for the Initiation of Top-Down Cracks}

Abd El Halim, (1983) developed and presented the concept of relative rigidity and applied it on the problem of asphalt compaction. He showed that the mismatch between the rigidity of the soft flat asphalt mat and the rigid steel drum roller at the time of construction is the leading cause of the phenomena of compaction induced cracks. In addition to the mismatch in the relative rigidities the small area of contact of $100 \mathrm{~mm}$ by the width of the roller as shown in Figure 3.3 imposed very high loads on the compacted area. Due to the applied pressure and because of the small contact area, an intense pressure impulse, which is typically $1.38 \mathrm{MPa}$, is produced over the contact area. Under the normal compaction speed of $10 \mathrm{~km} / \mathrm{h}$, the time duration for the induced pressure over the contact area is 0.036 second. Because of the short duration and the high pressure the asphalt material reacts with high elastic stiffness leaving no chance to the bitumen to flow between the aggregate particles. That is why these two factors "short duration and the high pressure" are considered two significant factors which contribute to poor quality of compaction including the initiation of the compaction cracks on the pavement surface (Rickards et al., 1999).

The cylindrical shape of the steel drums produce radial and tangential forces generating the horizontal forces that push and pull the asphalt in front of and behind the drum respectively as the roller travels, as illustrated in Figure 3.3. When the induced horizontal forces initiate the compaction cracks on the surface of the pavement, the result 


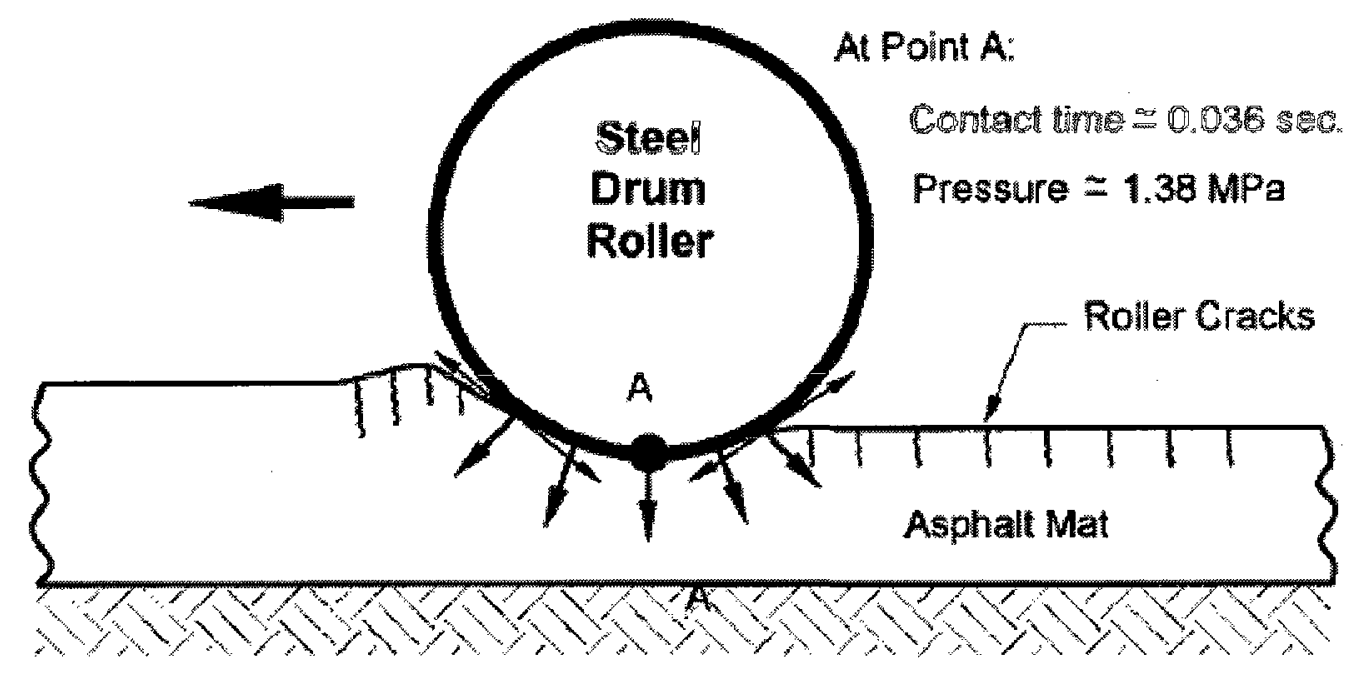

Figure 3.3 Schematic of conventional steel roller compaction asphalt mix structure (Rickards et al., 1999)

is a loss of strength and the opening of the surface to allow water to attack the inside of the asphalt mix. Once the cracks are initiated, other factors affecting the propagation of the initiated cracks such as freezing water trapped within the surface cracks would reduce the fatigue resistance. The stresses generated from the increase of volume of frozen water $(9 \%)$ are also increased, causing the cracks in the transverse directions to expand and propagate to form larger cracks as seen on the surface of the pavement in one of the three forms described before (Rickards et al., 1999).

Propagation of cracks, any cracks, starts when they are first initiated in the form of micro cracks as was discussed earlier. Under other factors such as time, traffic loads, and thermal induced stresses the cracks would connect with each other and continue to propagate in all directions. When completed, cracks can be seen as curved shape as 
shown in Figure 3.4, with a varied spacing in the longitudinal directions ranging from $250 \mathrm{~mm}$ to $10000 \mathrm{~mm}$ (Abd El Halim et al., 1994).

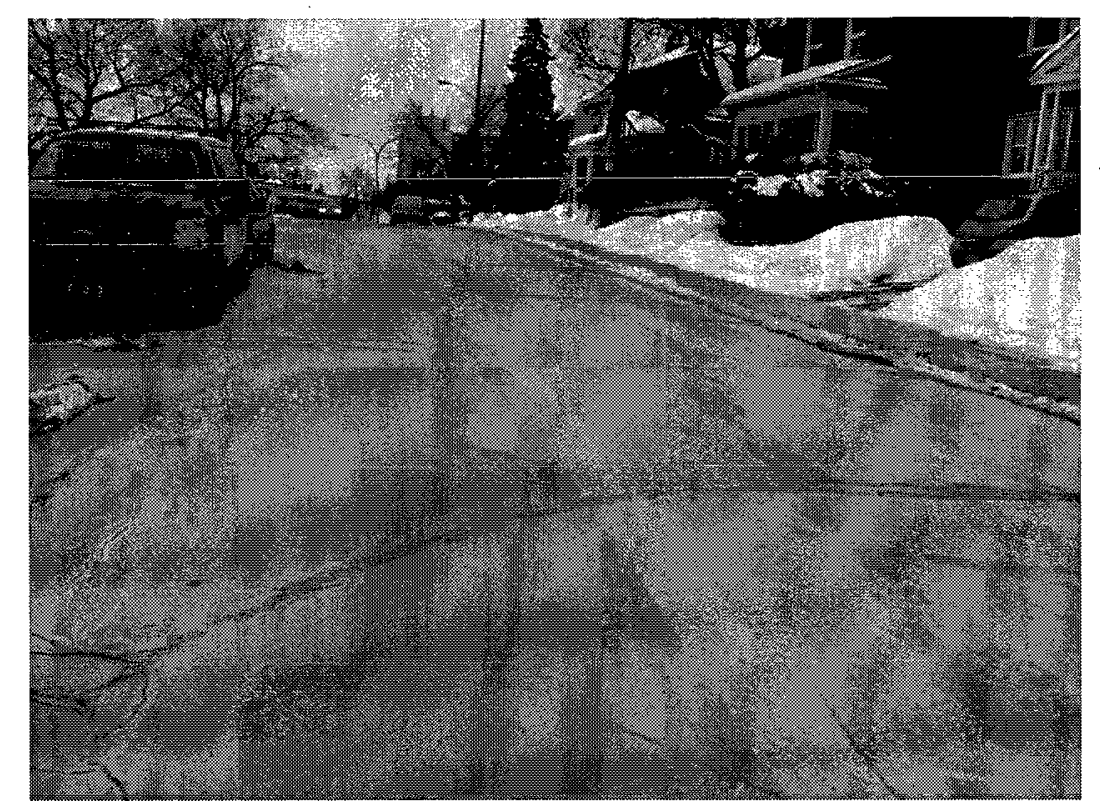

Figure 3.4 Curved transverse cracks taken on Bronson Pi, Ottawa. 2009

\subsubsection{Direction of Rolling}

The spacing between consecutive transverse cracks has often been reported to be much less than the width of the paved lane with the absence of longitudinal cracks within the lane itself. This phenomenon was addressed by studying the effect of the direction of rolling on the characteristic and properties of asphalt layers compacted using the conventional steel roller. The interlock between the aggregate and the asphalt binder of the compacted asphalt mix depend on the direction of rolling and are considered to be higher in the same direction of compaction and less in the perpendicular direction. Subsequently, the resistance to transverse cracks should be higher than the resistance to longitudinal cracks for a crack free finished asphalt mat after the compaction process. 
Compaction using the current cylindrical steel drum roller will induce high pressure due to the small contact area between the roller and the asphalt mat, this small area with the high pressure ensures that the tensile resistance to transverse cracking is higher than the tensile resistance in the longitudinal direction. This lead to the expectation of the occurrence of longitudinal cracks before any transverse cracks developed. However, many researchers have explained the appearance of the transverse cracks by thermal stresses. Therefore, it is important to note that since the temperature has no preference to either direction, one should expect that cracks should appears equally in both the transverse and the longitudinal directions of the asphalt mat and consequently the cracks should be equally spaced in the two directions (Abd El Halim et al., 1994).

Results of the tests conducted on cores extracted from sections compacted by the conventional steel roller followed by the pneumatic rubber roller illustrated that the transverse tensile strength is less than the longitudinal tensile strength. Furthermore, the test results showed that the resistance to longitudinal cracking was four times the resistance to the transverse cracking confirming the findings that steel rollers are not capable to deliver the expected compaction quality (Abd E1 Halim and Haas, 1994).

\subsection{Factors Affecting the Construction Method}

\subsubsection{Due to Paving Operation}

An investigation reported by Myers et al., (2001) and conducted by the Illinois Department of Transportation, (1993) on top down longitudinal cracking of $37.47 \mathrm{~cm}$. (14.75 in) pavement thickness, for several sections of bituminous pavement after five years from the construction time. It was concluded that the paving operation creates a 
weak plane surface causing longitudinal cracking. Because these cracks are formed near the wheelpaths, traffic loading can accelerate the propagation of the cracking further leading to its deterioration.

It was explained by Uhlmeyer et al., (2000) in WSDOT that deficiencies left behind the paver screed during construction were the cause for the initiation of top down cracking 2 to 3 years after construction and those cracks effect unconstructively the long term performance for the pavement network in Washington. Lay down and compaction equipment take the high portion of the data gathered by Myers et al., (2001) for modeling and analysis. The results showed that mix longitudinal segregation, which is the physical separation of the mix particles due to their difference in size, shape, and density, occurred near the conveyors edges. Longitudinal cracking were observed in this longitudinal segregation several years later as shown in Figure 3.5. Also according to the visual characterization done by Freitas et al., (2003), segregation which increases the roughness of the cracked area was attributed to the deficiency in the paving process.

Based on the literature, it is believed that TDC includes both longitudinal and/or transverse cracks and its potential is also affected by all the factors influencing the magnitude of the induced tensile stresses and tensile strength of the AC mix (Schorsch and Svasdisant, 2003). Therefore, in the next sections, the factors that result in high tensile stresses at the pavement surface will be discussed; as well factors that result in low tensile strength of the mix will be presented. 


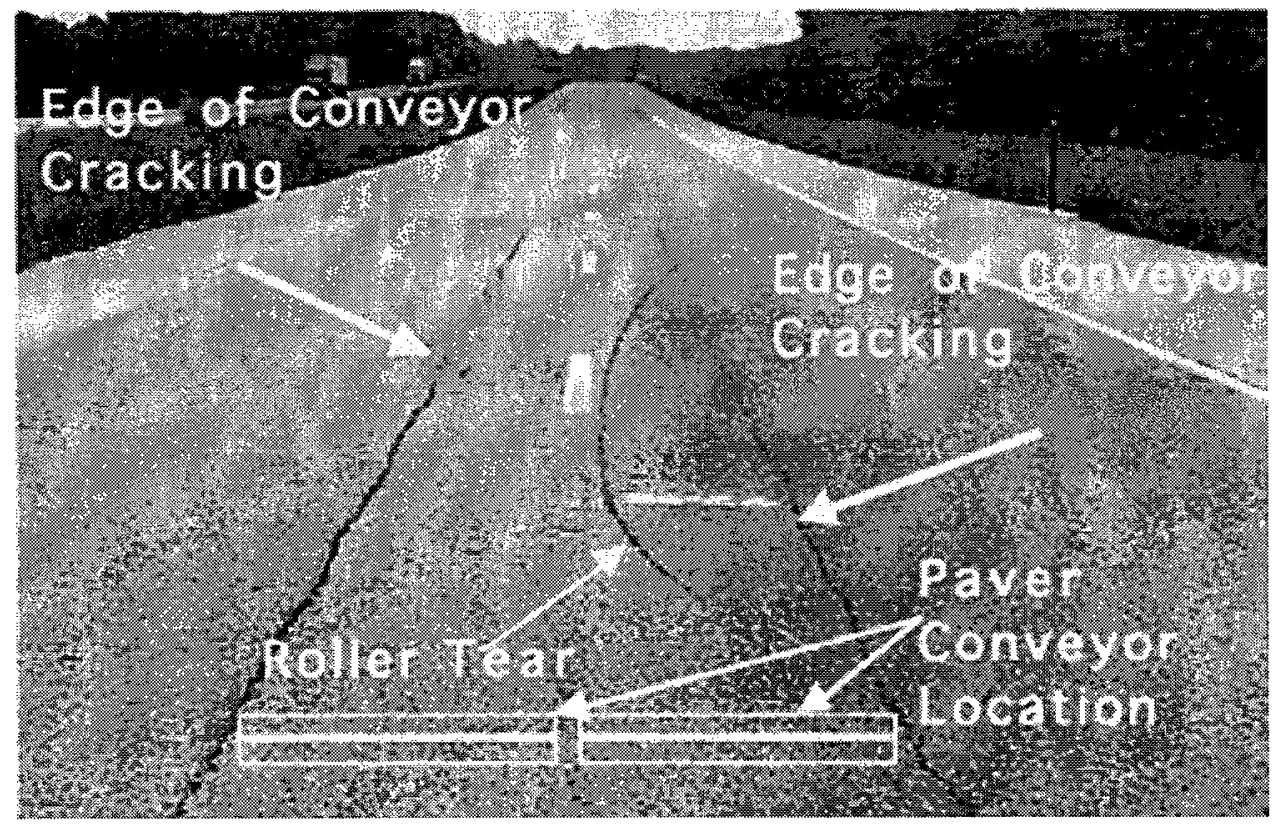

Figure 3.5 Paver-caused TDC

(Myers et al., 2001)

\subsection{Factors Affecting the Tensile Stresses in the Pavement Surface}

In this section, the following factors affecting the induced tensile stress in the AC layer are reviewed:

- Load induced stresses and strains

- Thermal induced stresses

- Thickness and modulus of each pavement layer

Results from field studies carried out by Svasdisant et al., (2001) suggested that TDCs could also be initiated due to the effect of a combination of the above factors.

\subsubsection{Load Induced Stresses and Strains}

Tensile stresses which may cause surface cracking could occur in the vicinity of the wheelpaths area where TDC are observed and explained due to radial forces near the tire 
edges of the truck tires. Figure 3.6 illustrates the concentration of longitudinal cracks in the wheelpaths as evidence of the influence of radial truck tires stresses on surface cracking (Myers et al., 2001). The inside and outside edges of the tire were noticed to be the critical tensile stresses location as shown in Figure 3.7. Moreover, analysis using finite-element method performed by California Department of Transportation showed that the interface between the edge of the truck tires and the asphalt concrete wearing course experienced high stresses. Figure 3.8 illustrated the alligator cracks which are formed due to repeated traffic loads, when these loads induce stresses bigger than the tensile strength of the asphalt pavement, cracks appear (Uhlmeyer et al., 2000). Svasdisant et al., (2001) in his analysis proved that TDC appear in a location very well corresponding to the location of the maximum tensile stresses.

The pressure induced from the tire inflation was considered to create high tirepavement contact stress (Yoder and Witczak, 1975). The induced stresses on the surface of the pavement are categorized into three basic distributions as shown in Figure 3.9 and they are classified as follows (Myers et al., 1999):

- Vertical contact stress, which is in the normal to the pavement surface.

- Lateral contact stress (also known as the transverse stress or the shear stress), which is perpendicular to the direction of the moving traffic or wheels, and

- Longitudinal stress, which is in the direction of the moving contact area.

Myers et al., (2001) reported that, these stresses are the cause of the initiation of top down cracks. They modeled a cracked pavement under specific load using finite element technique and analyzed the pavement response throughout the depth of the asphalt layers. 


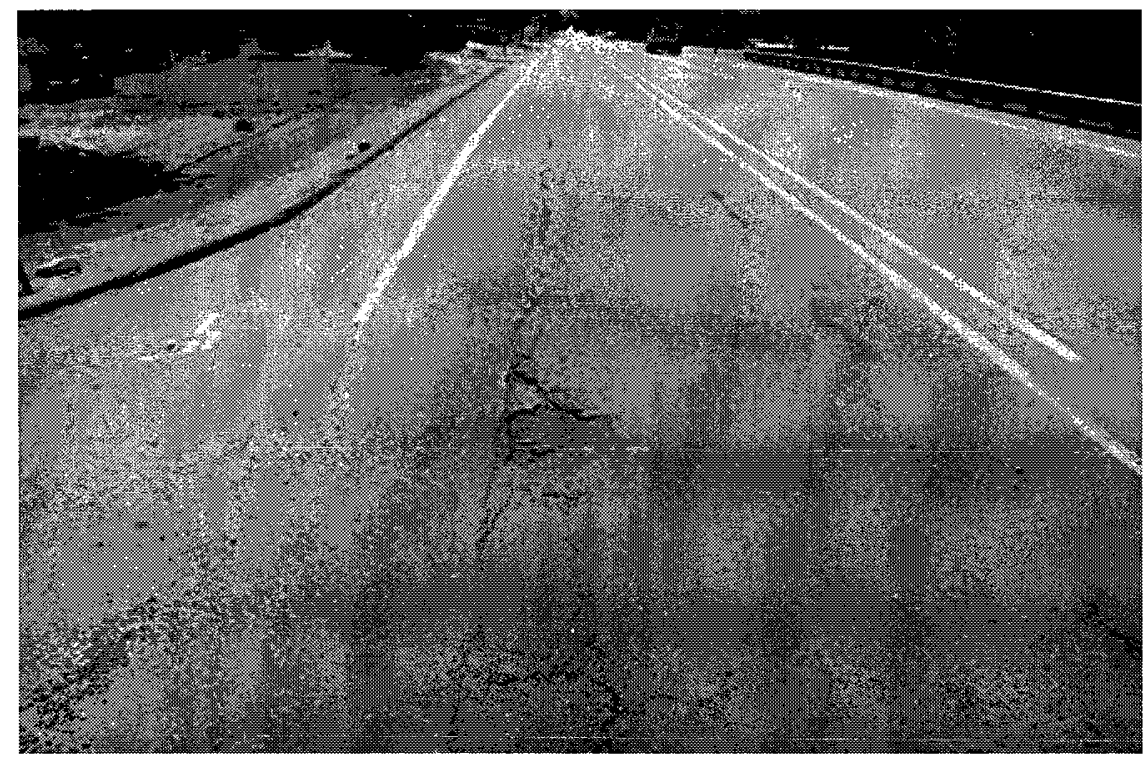

Figure 3.6 Longitudinal cracking on the wheelpath of an asphalt pavement (Myers et al., 2001)

They concluded that crack initiation was not affected by shear stresses, no matter where the load was acting. On the other hand, high tensile stresses induced by lateral contact stresses was the identifiable factor for the crack propagation along with load positioning which reveal a considerable effect on the stress intensity. As a comparison, the vertical contact stresses was not as destructive to the pavement surface as the lateral stresses, while the longitudinal contact stresses have the least effect to the surface distress. These findings could give an explanation to the occurrence of longitudinal top-down cracks, however their analysis revealed that these stresses was not a cause of any transverse cracking. Therefore, with the wide spread of the transverse cracking over asphalt pavement, this model will not be applicable. 


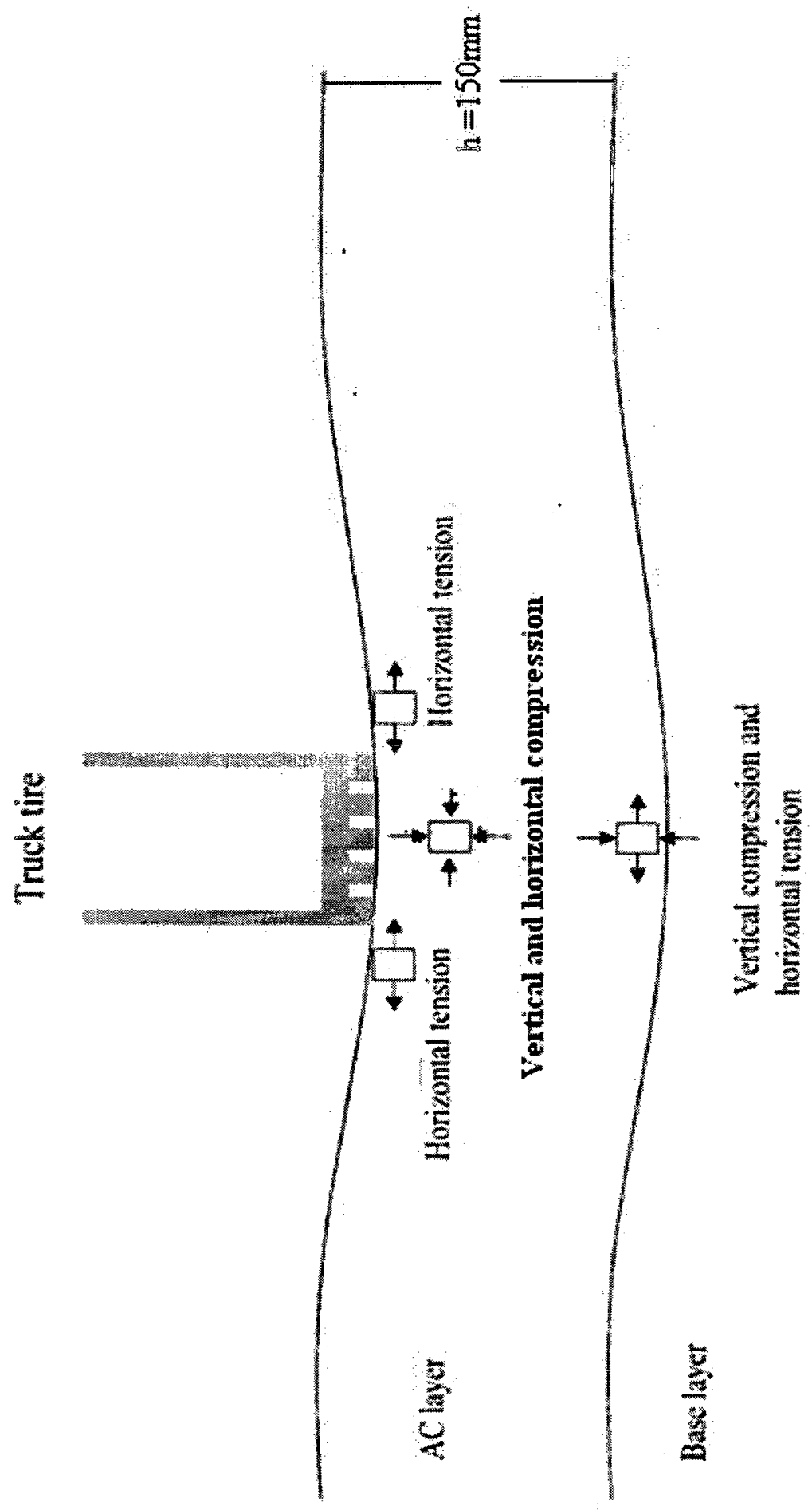

Figure 3.7 Different stress states at the top and bottom of the asphalt concrete layer (Svasdisant, 2003) 


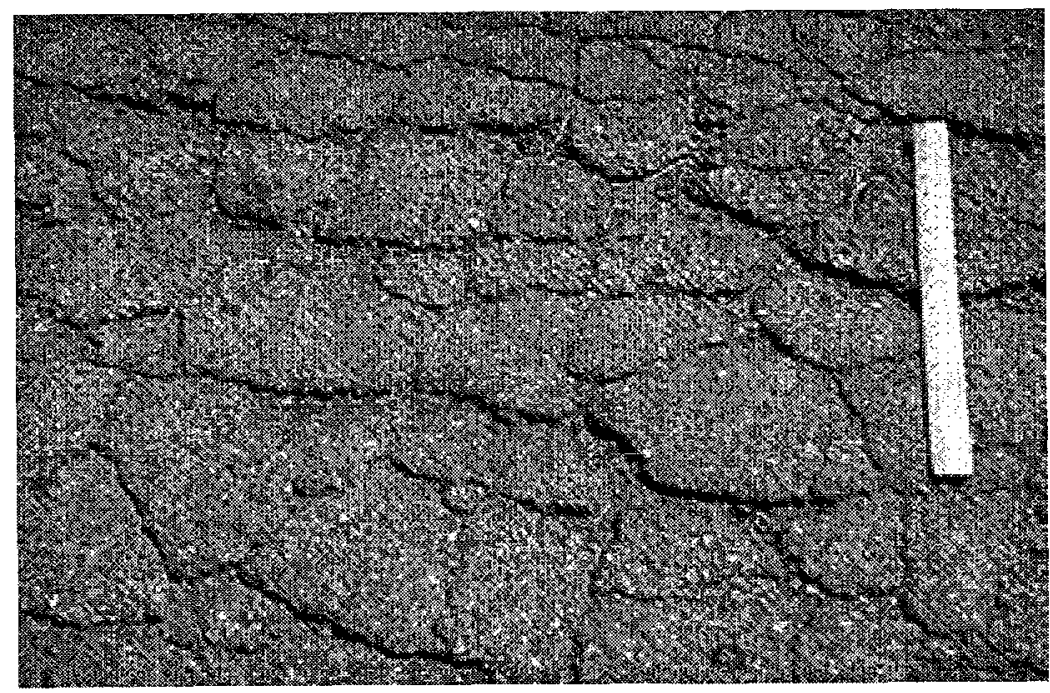

Figure 3.8 Typical traffic load distress or Alligator-type fatigue cracks (Svasdisant, 2003)

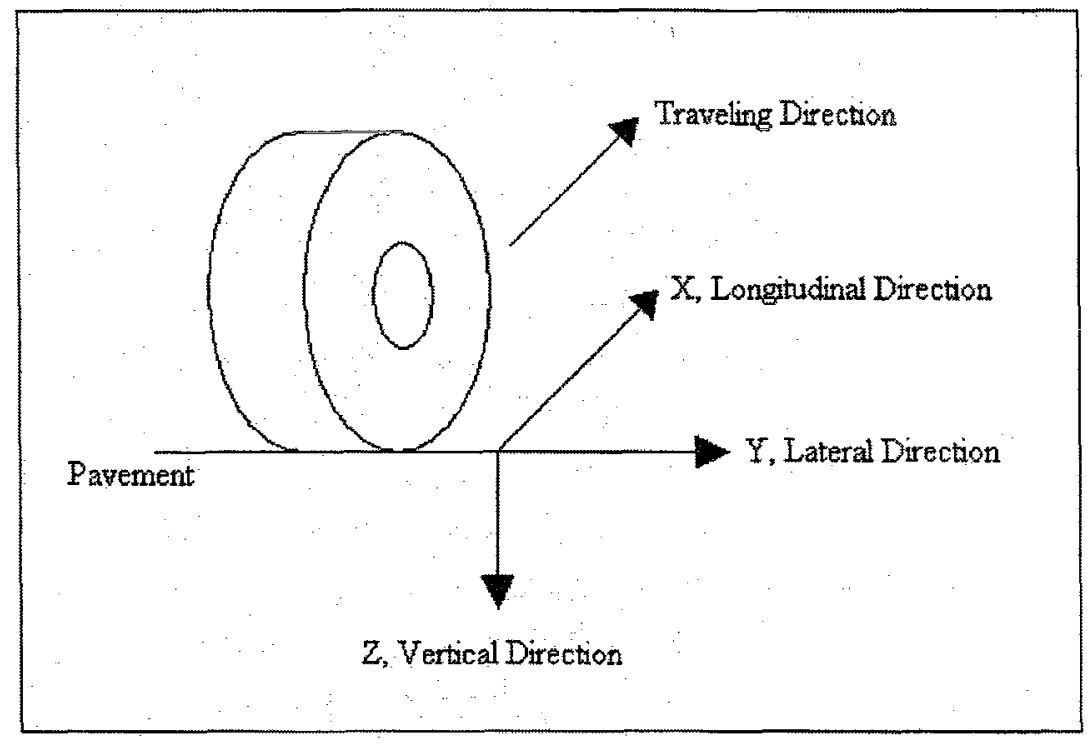

Figure 3.9 Wheel coordinates system

(Myers et al., 1999)

It was reported by Svasdisant et al., (2001); Matsuno and Nishizawa, (1992); and Schorsch, (2003) that most TDC tend to begin as longitudinal cracks due the tensile stresses and over time they develop according to the following three stages: 
In the first stage, a single short longitudinal crack develops just outside of the wheel path as shown in Figure 3.10. The mechanism for crack propagation might change if the crack length exceeds such value $(12.5 \mathrm{~mm})$ due to different load positions. This mechanism was explained as if the crack grows beyond the short crack length stage $(12.5 \mathrm{~mm})$, load closer to the crack is expected not to induce tension. This will lead to a slowdown in the crack propagation. In this case the crack will propagate in another location according to the applied load (Myers and Roque, 2002). In the second stage, the original longitudinal cracks grow longer while sister cracks form over time and propagate parallel to the wheel path as shown in Figure 3.11. It was observed by Uhlmeyer et al., (2000) that truck tires induced tensile stresses were a primary cause of longitudinal crack and the growing mechanism of these cracks is due to combination of truck tires load and thermal stresses. In the third stage, both the original longitudinal cracks and sister cracks evolve into extensive longitudinal cracks connected by short transverse cracks as shown in Figure 3.12. Although the longitudinal cracks were attributed to the load induced by truck tire, there was no explanation how these transverse cracks are initiated. Each pavement can be categorized into one of the above three stages of crack development in the longitudinal direction (Svasdisant et al., 2001; Schorsch, 2003).

While it was defended that high tensile stresses were the main cause of TDC, due to traffic loading, it was also considered that temperature gradients, binder ageing and construction quality (materials, compaction and paving) contributed as additional factors causing TDC (Freitas et al., 2003; Svasdisant et al., 2001). The stresses induced due to temperature differentials are discussed in the next section. 


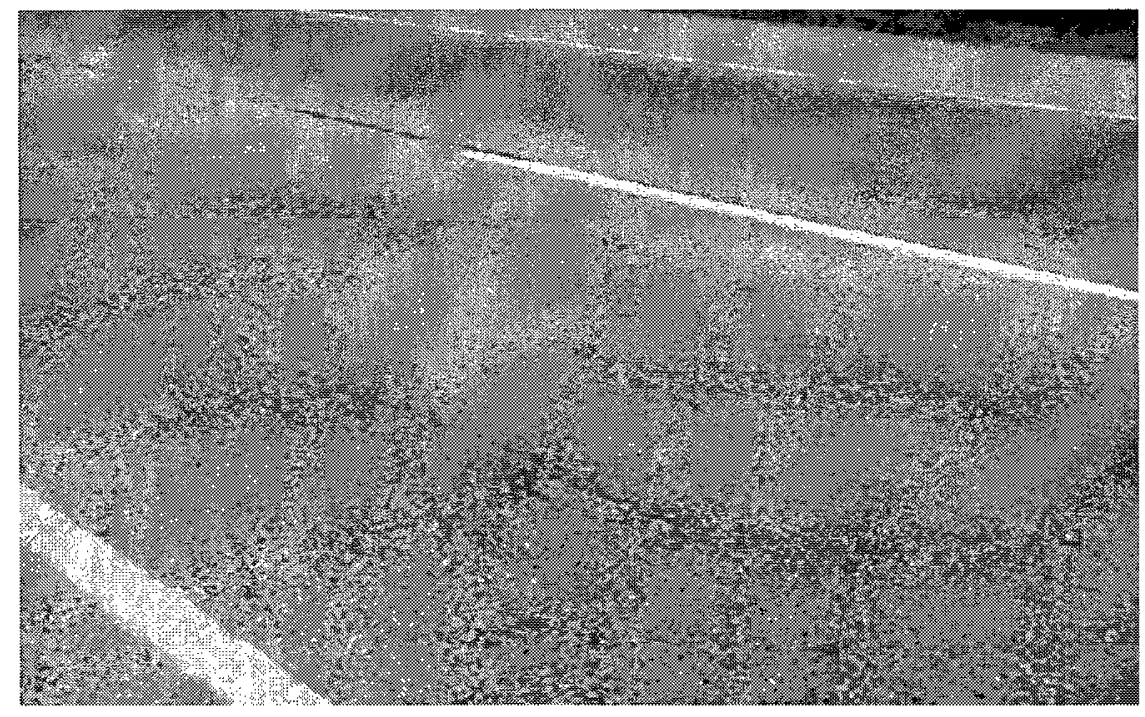

Figure 3.10 Single short longitudinal crack

(Svasdisant et al., 2001)

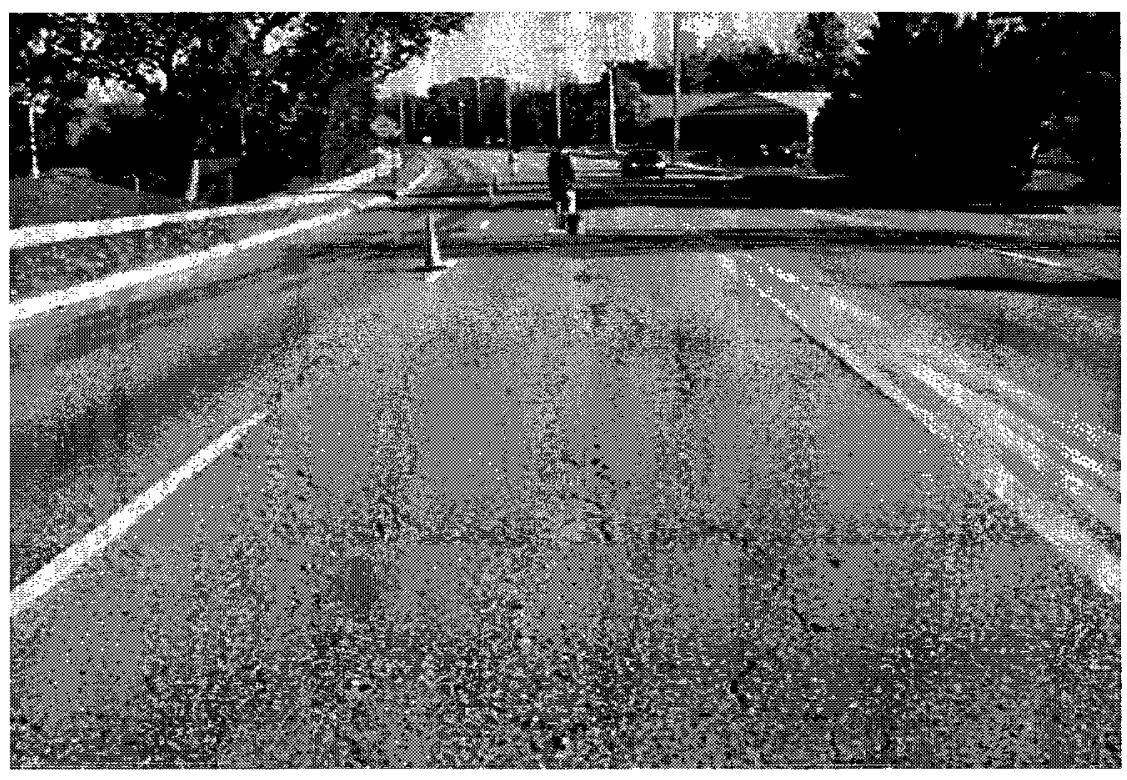

Figure 3.11 Longitudinal cracks grow longer while sister cracks form (Svasdisant et al., 2001) 


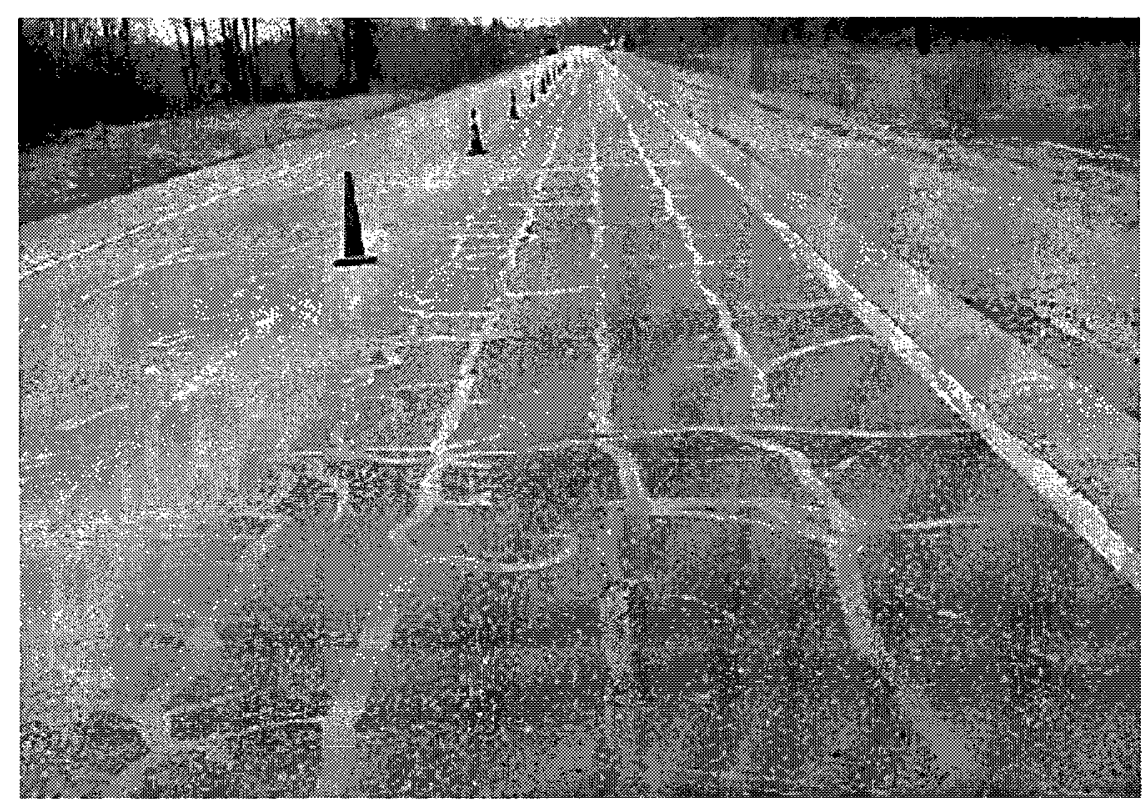

Figure 3.12 Longitudinal cracks and sister cracks connected by short transverse cracks (Svasdisant et al., 2001)

\subsubsection{Thermal Induced Stresses}

Thermal stresses were considered as one of the main contributors to the initiation of low temperature transverse cracking, which is also known as thermal-or cold temperaturecracking. Thermal cracking of asphalt layers is one of the primary distress mechanisms caused by decreasing temperature. It has been recognized as common problem induced by the effects of temperature and the quality of the asphalt pavement. Micro cracks occur at the top of a pavement layer when thermal stresses in the pavement layer are in excess of the tensile strength of the asphalt material. Once the crack is initiated, regular temperature cycles cause it to grow greater in width resulting in a poor riding quality of the pavement and leading to a further propagation through the full depth of the asphalt layer and structural damage (Haas and Joseph, 1987). Uhlmeyer et al., (2000) also 
reported that surface cracks were caused by thermal stresses, and the loads from the truck tires accelerate their propagation.

Thermal cracking is one of the major distresses which occur in the pavement as transverse cracks as shown in Figure 3.13. This uniform cracking pattern suggests uniform loading conditions which are seen on asphalt pavements especially in North America and northern parts of Europe and Japan when the temperatures drop steeply at regular intervals during cold winter months. However, areas which experience temperatures above freezing such as desert climates are subject to this type of distress due to large changes in the daily temperature (Shields et al., 1964).

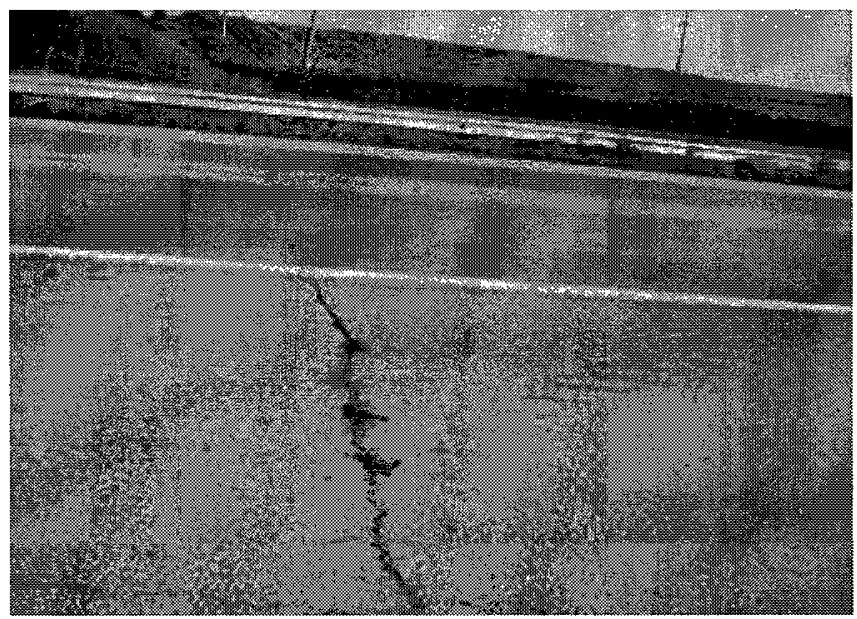

Figure 3.13 Low-temperature cracking (transverse cracks) (Stock and Arand, 1993)

Abd El Halim, (1984) provided different explanation to the regularly spaced transverse cracks where crack are observed to occur when asphalt temperatures are as high as 150 ${ }^{\circ} \mathrm{C}$ during compaction. Clearly, this temperature will never be exceeded once the asphalt mat is opened to traffic. The maximum temperature during any summer days will never exceed $50{ }^{\circ} \mathrm{C}$, thus, the summer temperature is relatively much cooler than the one under 
which cracks are initiated. In these warm seasons cracks which could not fully propagate during cold weather will continue propagation slowly under cycles of tensile stresses at their tips. As the temperature drops, the same stress state will be repeated and another propagation cycle will starts leading new cracks to appear at the end of cold seasons. This mechanism explains the often reported wide cracks in the summer months.

Abd El Halim et al., (1994) reported that as the temperature of the newly compacted asphalt mat decreases with time, the asphalt mat will shrink in its longitudinal direction resulting in increasing its stiffness. The presence of the micro cracks in the surface would increase its surface area resulting in accelerating the cooling process of the mat compared with the temperature of the asphalt at the lower un-cracked portion of the mat. The difference in the temperature between the tip of the crack and its bottom would create the $\mathrm{V}$ shape of the micro cracks which would generate stress concentrations at the bottom of the cracks along and across the asphalt mat. As the temperature is decreased the stresses at the tip of the crack will be increased and will increase the process of crack propagation (Abd El Halim et al., 1994). If the induced stresses were higher than the asphalt tensile strength, and less than the bond resistance between the asphalt layer and the underneath layer, failure will occur and uniformly spaced transverse cracks will appear, and significantly shorten the length of the asphalt mat into smaller slabs, as will be discussed in Chapter five.

The induced temperature gradients which is caused due to the exposure of the AC surface to direct sunlight and the 24-h fluctuation of ambient temperature, is considered another factor that causing non uniformity in the stiffness of the asphalt concrete layer Myers and Roque, (2002). It was reported that the variability in temperature creates high 
concentration in the tensile stresses in the asphalt pavement with increasing the crack length. Svasdisant et al., (2001) tested in their study the daytime and nighttime temperature difference in asphalt pavements between the $\mathbb{A C}$ surface course and the $A C$ base. They concluded that these temperature differences were the main cause of differential stiffness in the AC courses.

There are two types of thermal stresses-induced cracking: low temperature cracking and thermal fatigue cracking. Low temperature cracking occurs due to a quick contraction in the asphalt pavement under a drop in temperature, because of rapid contraction, the generated stresses build up in the asphalt mix rapidly, when it reaches a certain point cracks occur. This point of temperature is called cracking temperature or the critical temperature. While a low temperature plays a role in inducing thermal stress of the pavement, thermal cycle above the critical temperature which is a kind of repeated thermal contraction and expansion above critical temperature can also build up and induce larger enough thermal stresses in the AC layer which eventually form TDC. This is the second type of cracking which is called thermal fatigue cracking, and it may occur independent of the pavement interaction with the tires (Lim, 1998). Thermal fatigue cracking is attributed mainly to daily thermal stresses, and to the thermally sensitive binder in asphalt concrete, it occurs when the fatigue caused by daily temperature cycles exceeds the fatigue resistance of the asphalt layer.

As was mentioned in chapter one, the reflective cracks caused due to pre-existing cracks at the top of the asphalt layer underneath the asphalt overlay. Although the drop in temperature was stated not to be the main cause of the reflective cracking, but the mechanism of the thermal cracks, especially the extreme temperature variation in freeze- 
thaw cycle cause stresses within the pavement layers, these stresses are the cause of pavement susceptible to the existing cracks in the underneath layer (Lauter, 1998).

Cold temperaiures cause high stresses and stiffen the material, making it prone to thermal cracking. Abd El Halim and Haas, (1994) conducted a study by extracting a number of cores from a site that was traffic free for two years to determine the effect of the cold temperature. The first group of the core specimens was extracted 3 weeks after compaction and additional asphalt core specimens were taken one winter after construction from the test section. The specimens were insulated and were protected from the surrounding environment affects. The results showed that low temperatures decrease the fatigue resistance in the transverse direction and promote the already initiated cracks caused by compaction deficiencies to evolve into wider transverse cracks.

The surrounding environment can influence badly in the pavement system. One of these environmental factors is the presence of moisture, when pavement layers are exposed to freeze and thaw cycles the cracks in the top surface will propagate rapidly due to the presence of moisture and will accelerate the pavement damage (Shalaby, 1997; Lauter, 1998). Another environmental factor affecting thermal cracks; is the pavement age. With time the asphalt concrete mix becomes stiffer and that could increase the frequency of the crack occurrence (Haas et al., 1972; Lauter, 1998). Moreover, the existing cracks may generate number of separated shorter slabs in the longitudinal direction of the pavement. That was explained as a result of the asphalt mat shrink due to cold temperature, this shrink produced thermal stresses. As a result thermal transverse cracks are produced (Lauter, 1998). 


\subsubsection{Mechanisms of Thermal Cracking}

The main mechanism developed to explain the occurrence of thermal cracks was presented by Kim et al., (2003). The mechanism assumes that the asphalt mixture consists of binding material, and the aggregates with the binding material, forming a thin layer of asphalt film or matrix composed of asphalt cement and fine materials. The aggregate particles are covered by the asphalt matrix as shown in Figure 3.14 (a). The developed cohesion of the asphalt concrete mixture is due to binding forces that the asphalt matrix provides to the mix.

It has been noted that asphalt concrete mixtures would exhibit low performance due to thermal induced cracks appeared in the surface of the asphalt layer when it is exposed to low temperatures. These cracks are initiated because of the tangential tensile stresses $\left(\sigma_{t}\right)$ originated in the asphalt matrix surrounding the aggregate particles. The difference in the coefficients of thermal expansion between the flexible asphalt matrix and the stiffer aggregate particles was considered as a reason to the occurrence of the tangential tensile stresses. That was explained because the difference in the coefficients gives the asphalt matrix the tendency to contract more than the aggregate when the mix is exposed to low temperature (Kim et al., 2003).

Under the produced tangential tensile stresses around the aggregate the thin asphalt binder mat may flow between the aggregate particles and relax the stresses and preventing the occurrence of the cracks that would only happened under high temperature. However, when the temperature drops below the point where asphalt binder becomes brittle, the stiff characteristic of the asphalt binder cause accumulation to the tensile stresses and when these stresses exceed the strength of the matrix, surface thermal 
cracks are expected to initiate in the asphalt pavement and propagated down in the asphalt matrix as shown in Figure 3.14 (b) (Kim et al., 2003).

Low temperature cracking test of $\mathrm{AC}$ mix was conducted by ZZubeck and Vinsom, (1996). The test results indicated that when the temperature dropped, the tensile strength of the AC increased till the temperature reached to such a point, which called the cracking temperature. When the temperature decreases under the temperature of cracking point, the tensile strength of the AC decreases. Heukelom, (1996) obtained similar results indicating that there is a limit for increasing the stiffness of the asphalt cement and at the

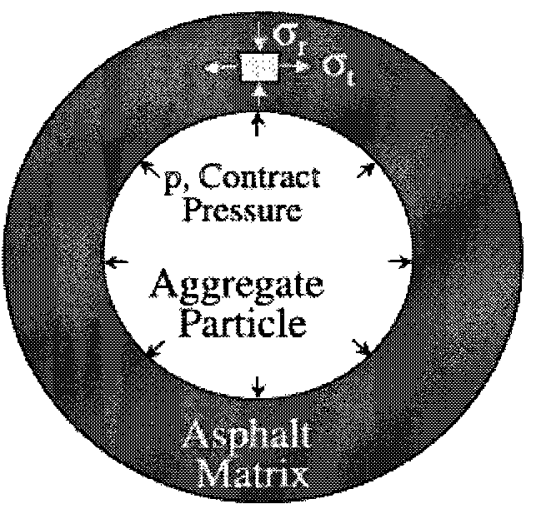

(a)

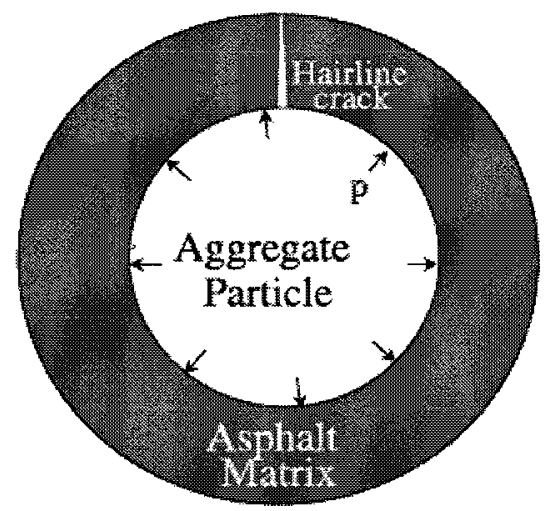

(b)

Figure 3.14 Schematics of (a) tangential stress $\sigma_{t}$ and radial stress $\sigma_{\mathrm{r}}$, and (b) a hairline crack in an aggregate-matrix system associated with TDC (Kim et al., 2003)

same time increasing the asphalt tensile strength, after which the tensile strength of the $\mathrm{AC}$ mixture decreases while the stiffness continues to increase

From the previous study it was concluded that thermal induced tensile stresses, resulting from either a combined action of low temperatures and thermal fatigue caused 
by daily temperature variation or from one of them, was expected to contribute to the TDC initiation. However a comprehensive discussion was presented in Chapter five, results show that thermal- induced stresses was not the cause of the initiation of TDCs.

\subsubsection{Types of Thermal Transverse Top-Down Cracks}

Thermal induced top down cracks are classified into three different types according to their position relative to the lane centerline as shown in Figure 3.15 (Lim, 1998). The three crack types are:

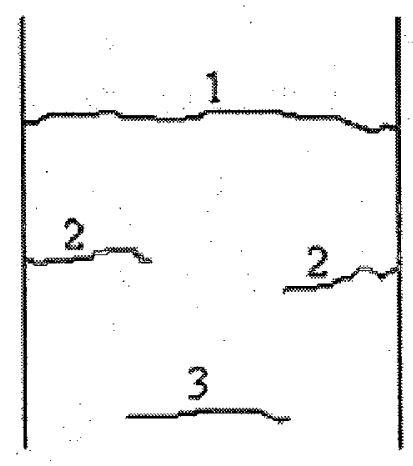

Figure 3.15 Types of thermal stress-induced transverse crack

- The first type of the transverse cracks is one that extends from one edge of the paved lane to the other edge as indicated by crack 1 in Figure 3.15 .

- The second type is a transverse crack that initiates from one edge of the paved lane and stops at a distance of the other edge and termed 2 in Figure 3.15. It has been reported that the width of crack type 2 is larger when closer to the edge of the lane and decreases as the cracks are creeping towards the centerline.

- The third type of transverse cracks is the one shown as type 3 in the Figure 3.15. These cracks often seen initiating at the centre of the paved lane and creep towards 
the edges as shown in Figure 3.15. In contrast to type 2 crack, the width of this crack is wider at the center of the pavement than at its two ends.

Since these three types of transverse cracks are initiated at the surface one expect to see the crack opining at the surface to be wider and it narrows as the crack goes deeper into the bottom of the asphalt layer forming a V shape. Clearly this observation confirmed that the crack must have initiated from the surface of the asphalt layer (Lim, 1998).

\subsubsection{Thickness of Asphalt Concrete Pavement Layer}

Field observations reported by Uhlmeyer et al., (2000) showed that TDCs tend to occur in pavements with AC thickness of $115 \mathrm{~mm}$, while other studies done by Nunn, (1998) proved that those cracks appear when the AC thickness exceeds $160 \mathrm{~mm}$ in depth. Conventionally, asphalt pavements were designed for a thickness less than $160 \mathrm{~mm}$, but due to the growth in truck traffic which has increased the Equivalent Single Axial Load (ESAL) levels, pavement engineers are trying to satisfy the requirements for the new load levels by increasing the pavement thickness more than $160 \mathrm{~mm}$. More over due to rapid deterioration of asphalt pavements major rehabilitation projects leading to adding new overlays thus increasing the asphalt concrete thickness and moving it toward the $160 \mathrm{~mm}$ and more (Svasdisant et al., 2001).

Higher asphalt concrete thickness reduces the tensile stress at the bottom of the $\mathrm{AC}$ layer and the compressive stress at the top of the subgrade resulting in improving the fatigue life of the asphalt concrete pavements and extending its service life. For higher traffic levels or longer performance period, thicker pavements are usually recommended. As illustrated in subsection (3.5.1), there are three types of tire pavement contact stresses; 
vertical contact stress, lateral contact stress, and longitudinal stress, the lateral and longitudinal contact stresses are not influenced by the layer thickness of the pavement layers including the $\mathbb{A C}$ layer (Molenaar, 1984). However the vertical contact stresses are dependent on the thickness of the pavement layers (Myers et al., 1999).

Site investigation done by Schorsch, (2003) using a number of cores with different thicknesses shows that the pavement thickness does not play a main role on LTDC propagation. However, according to the Washington State Department of Transportation and other stats in the United States, it was reported that thicker asphalt concrete was susceptible to longitudinal cracks and those cracks tend to crack from top of the wearing course and propagate down to the top of the underlying bituminous layers.

Uhlmeyer et al., (2000) examined a number of cores taken from the field; he reported that the tensile stresses induced in the AC pavement due to applied load disperse with depth, as a result the cracks ended at the bottom of the wearing course. Field observations done by Myers et al., (2001) showed that there is a variation in the propagation in the cracks along the depth of the asphalt layers where as the induced high tensile stresses penetrate to only about $10 \mathrm{~mm}$ down from the asphalt's surface. Myers and Roque, (2002) revealed that a crack depth of $25 \mathrm{~mm}$ was the ultimate depth for the occurrence of maximum stress intensity, while in thicker pavement the $188 \mathrm{~mm}$ depth was enough for the most significant stresses to arise.

Surface surveying conducted by Freitas et al., (2003) revealed that, pavements with $190 \mathrm{~mm}$ of bituminous layers, the depth of the progression do not exceed $150 \mathrm{~mm}$. However, in pavements with a higher total thickness of bituminous layers, deeper cracks 
of $190 \mathrm{~mm}$ have been found. This observation demonstrates that pavement thickness could be an indication to the depth the crack will propagate to.

\subsection{Factors Affecting the Tensile Strength of the Asphalt Concrete Mixture}

In addition to stresses generated by traffic and/or temperature changes, changes in the tensile strength of the $\mathrm{AC}$ mixture can be additional factor leading to initiation and propagation of surface cracks. Therefore, it is important to briefly discuss the main factors affecting the tensile strength of asphalt mixes. There are several factors influencing the strength including the environment, mix design, aggregate segregation and compaction techniques. The effect of the compaction process on the tensile strength of the AC mixture was discussed in details earlier in this chapter, while the other two factors will be discussed in the following sections

\subsubsection{Asphalt Age Hardening}

The increase potential of TDC in asphalt pavement has been associated with the high susceptibility of asphalt binders to age hardening and consequently the reduction in pavement's fatigue life. Asphalt ageing is indicated by the rate at which the asphalt hardens. The long term resistance to the effect of ageing is defined as the durability of the asphalt concrete. The rate of hardening is influenced by the air voids content in the asphalt concrete and the asphalt layer thickness. An in service void content of $3 \%$ will be adequate for the asphalt pavement to be durable in order to avoid bleeding due to low air void percent and to avoid hardening by providing acceptable low air voids content 
(Pagani et al., 1999). Aging affects the engineering properties of AC mix, specifically, the asphalt binder and typically occurs in two phases, short and long term. The short-term aging occurs during the mixing and placement of the $A C$, while the $A C$ mix is prone to oxidation. Long-term aging occurs after placement of the $\mathrm{AC}$ mix, while the surface course is exposed to sunlight and oxygen, the asphalt binder goes under progressive oxidation causing an increase in the stiffness and brittleness of the binder. It has been noted that long term aging affects the top asphalt concrete layer or the wearing course; while the lower layers may not be affected which explains why the rate of hardening is affected by the asphalt layer thickness (Svasdisant et al., 2001).

It was also studied by Svasdisant et al., (2001) who examined the tensile strength on a number of flexible asphalt specimens obtained from conventional compacted section which has TDC on its surface. The study was done by conducting a series of indirect tensile strength tests. It was concluded that the tensile strength of the surface course was lower than that of the lower course. This was explained as of two possible reasons, due to long term aging induced by expositing the surface course to sunlight. Or, due to the presence of TDC which was exhibited at the pavement surface before the test. The stiffness of an AC mix could be estimated based on the hardening level using the Shell design method based on the stiffness or modulus of the binder which is an indicator to the hardening level of the $\mathrm{AC}$ mix and to the percent volume of the binder in the mix.

\subsubsection{Segregation}

Segregation refers to the physical separation of coarse and fine aggregates and it is often observed during transportation and placement of the asphalt mixture before compaction. 
Clearly, the separation of the two aggregate gradations of the designed mix would have adverse effects on the overall properties of the placed mixture and its long term performance. Furthermore, segregation substantially reduces the tensile strength and the fatigue performance of $\mathrm{AC}$ mixtures and thus provides an environment for TDC to initiate. Researchers differ widely on the definition of segregation. One of these definitions describes the problem as: "the uneven distribution of coarse and fine particles from one point along the pavement to another that has typically been based on visual observation of the pavement surface and judgment" (Chang et al., 2002).

There are no clear guidelines or rapid test methods for the detection of segregation or determination and quantification of its seriousness. Michigan Department of Transportation stated that segregation is visually identifiable. The absence of any rational for assessing the effect of segregation creates significant uncertainty between paving contractors and state highway agencies in spite of the fact that present specifications require that asphalt mixes not be segregated. It was reported by Chang et al., (2002) that there is one major factor to separate between segregated areas and non segregated areas and it is that segregated areas have significant difference in gradation relative to non segregated areas.

\subsubsection{Types of Segregation}

Segregation is divided into two types; one is termed temperature segregation and the other one is called particle segregation. The mix properties and the asphalt construction method are the main two factors that control segregation. The two types are discussed in more details below. 


\section{Temperature Segregation}

The main cause of the temperature segregation is the asphalt construction process, and the viscoelastic-behavior of the asphalt material which lead the asphalt mixture to exhibit different engineering characteristics. This type of segregation is reported to be caused by temperature differentials during the paving process. This difference in the temperature leads to non-uniformity in the compacted density and the air voids content. As the temperature is dropped, the air voids could increase up to $4 \%$ than observed in normal areas (Schorsch et al., 2004).

\section{Particle Segregation}

For lack of experienced workers and/or non efficient practice during the mixing process of the asphalt materials, the coarse and fine aggregates could be distributed unevenly within the mix causing particle segregation. The lack of uniformity could lead to different two distinguished concentrations of coarse and fine particles. Accordingly, it is possible to divide particle segregation into two sub-types: coarse and fine segregation (Henault et al., 1999).

\section{Coarse and Fine Segregated Areas}

According to the asphalt content, the asphalt segregation could vary from very coarse to very fine. Coarse segregated areas can be identified by high air void content and have a coarser pattern which is 8 to 15 percent higher than non-segregated areas. Also, the air voids are 3 to 5 percent higher with 1 to 2 percent lower asphalt content. Raveling is the common associated distress with coarse segregation. Conversely pavement areas that 
have higher asphalt content with lower air voids and smooth surface texture is more subject to fine segregation which could increase the potential of rutting due to the lack of coarse aggregates in the mix and the concentration of the fine material. Therefore, asphalt content values can be used as an indicator of segregation in contrast to non-segregated areas which exhibited higher void content values than areas with medium or heavy segregation (Chang, 2000).

\subsubsection{Density in Segregated Area}

Several field tests carried out by Schorsch et al., (2004) to investigate the pavement density at different locations in the test sites using the field density method as well as measuring the laboratory density of asphalt cores recovered from the field. The test site was divided in two sections, segregated areas and non-segregated areas. From the test results, it is noticeable that the density of the cracked areas is less than the un-cracked areas. Therefore density was confirmed to be as an indicator for segregated and nonsegregated areas (Schorsch et al., 2004).

\subsubsection{Causes of Segregation}

Segregation may occur at any time during the mixing or the different paving stages from one or a combination of the following five major causes. They include mixture design, stockpiling, hot-mix asphalt production, truck loading and unloading, and paving operations. It was reported that segregation does not appear immediately after the construction process is completed. However as the pavement is opened to traffic, the interaction between the tires and the pavement results in contraction which removes the 
thin mastic layer off the top surface and exposing the surface cracks (Henault et al., 1999).

\section{- Design of Asphalt Mixture:}

Asphalt mix design is a key element for determining the gradation of coarse and fine aggregates to be combined to achieve the required percentage of air void volume, density, and asphalt content which are the main factors controlling the level of segregation. The gap-graded aggregate and low asphalt binder content mixes are prone to segregation (Henault et al., 1999).

\section{- Improper Stockpiling}

Improper stockpiling can also result in segregation, during the stockpiling process the larger aggregate sizes are more likely to roll to the outside of the pile and settle at the bottom, therefore aggregate should be stockpiled in truckload sized piles and be placed in a manner that prevents material from rolling down along slopes. That could be achieved if the slope angle is less than the angle of repose as recommended by Brock et al., (1996).

\section{- Hot-Mix Asphalt Production,}

Segregation can also occur during production process while large particles will generally flow through a drum mixer more quickly than smaller ones during the first and last mixes. Also inadequate operation of the loader that scoops up the side of the stockpile instead of pushing the bucket into the pile could cause non-uniformly fed to the bins. 
Moreover some uncoated material in the patch plant could be collected and discharge in one time as concentrated slug (Brock et al., 1996).

\section{- Truck Loading and Unloading}

When truck is loaded with no attention for the procedure that reduces segregation, large aggregate particles will segregate and roll to outside and the bottom of the truck. That could occur during truck loading, transportation, and unloading (Henault et al., 1999).

\section{- Paving Operation}

Paver movement, conveyer slots, hopper operations, and auger speed could cause the occurrence of segregation.

\subsubsection{Degrees of Segregation}

In order to study the segregation characteristics, researchers have defined three categories of the degrees of segregation. These categories were defined by Michigan Department of Transportation (MDOT), as light, medium, and heavy, (Chang et al., 2002).

Light - The fine matrix in place, more stone than the surrounding matrix.

Medium - Lack of surrounding fine matrix, significantly more stone on the surrounding mat.

Heavy - Stone against stone, little or no matrix. 


\subsubsection{Segregation Effects on Top-Down Cracks}

Investigations and observations from several researchers such as Schorsch et al., (2004) verified that the cracks that occur at the segregated area were initiated from the pavement surface. Therefore, segregation was also understood to be one of the factors that cause TDC. It was also observed by Schorsch, (2003) that TDC were associated with segregation in $63 \%$ of a number of investigated pavement projects. Each degree of segregation is considered to be as an indication for the expected level of TDC propagation. Moreover the results indicated that lack in the efficiency of the construction process causes segregation in the asphalt pavement and hence significant cracking will occur shortly after construction.

In 1997 a project of rehabilitating a highway in Denver state was granted a bonus for quality and smoothness, within one year the pavement surface experienced longitudinal cracking ranged in its severity from low to medium. The cracks had rapidly led to deterioration of the entire project after 3 years along the wheelpaths. Field investigations took place over 25 sites in Colorado to determine the pavement mixture characteristics for the cracked sections. Number of cores was extracted from different projects in the cracked sites. The results indicated that cracks of $72 \%$ of the sites were judged to be top down crack; moreover $67 \%$ of the reported top down cracks had visual evidence of segregation as shown in Figure 3.16. Pockets segregation at the bottom of the tested asphalt concrete layer was one of the concluded factors which caused the longitudinal cracks. These pocket segregation was not visible from the surface during construction because of the aggregate concentration in the top layers (Harmelink et al., 2008). 


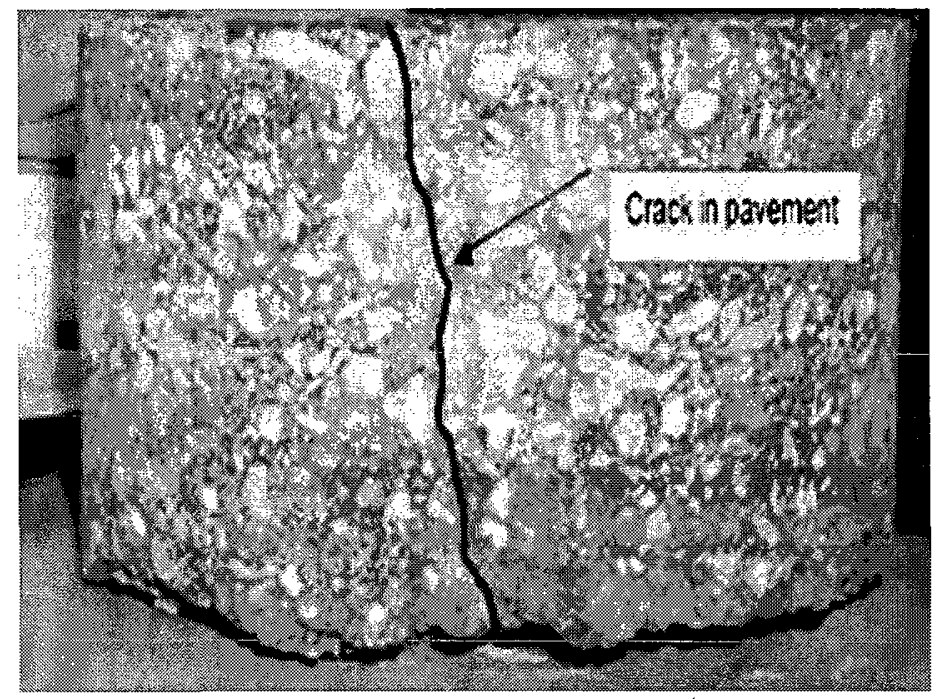

Figure 3.16 Segregation of coarse aggregate around crack (Harmelink et al., 2008)

Schorsch et al., (2004) in their observations through different distressed sites using asphalt coring reported that TDCs were the predominant cracks in the segregated areas. Figure 3.17 shows a photograph of a site exhibiting TDC with the cracks occurring in the segregated areas and is associated with the position of the wheelpath as shown in Figure 3.18. The correlation of segregation with the pavement performance has also been studied by Chang, (2000); Khedaywi and White, (1996) and Brown et al., (1989). They have verified that segregation is one of the dominant factors in reducing the service life of the asphalt pavement.

From the previous discussion it does not appear that segregation explain the incidence of the TDC distress areas in the asphalt pavement surface, however it is certainly reasonable that segregation of the type described before may accelerate the incidence of surface-initiated cracking. The variability in construction in the form of asphalt pavement segregation does not explain how these TDCs is initiated and 


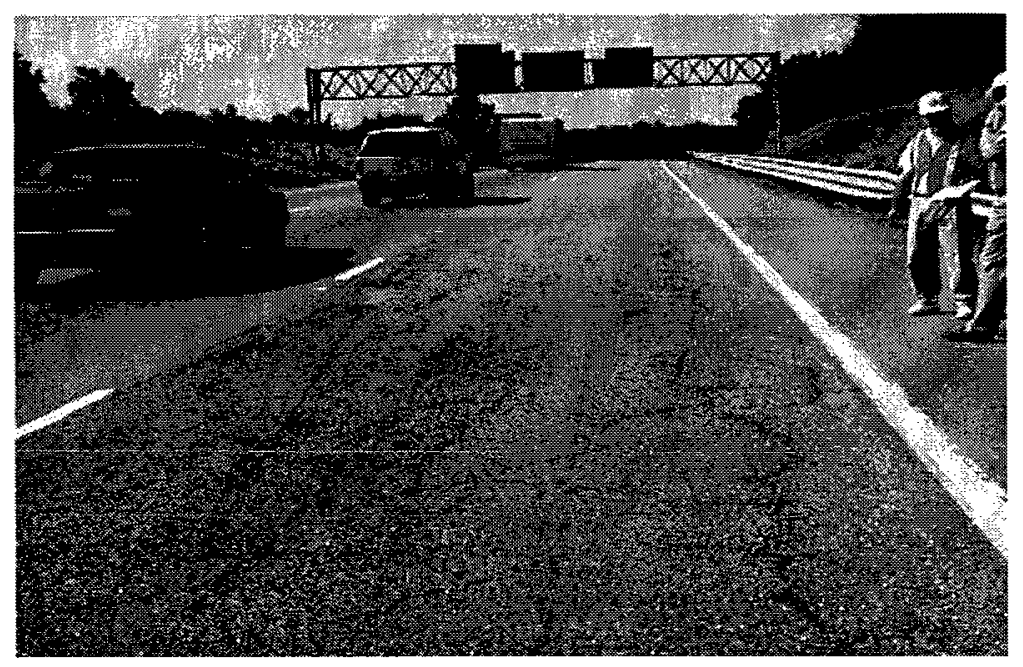

Figure 3.17 TDC occurring in segregated area

(Schorsch et al., 2004)

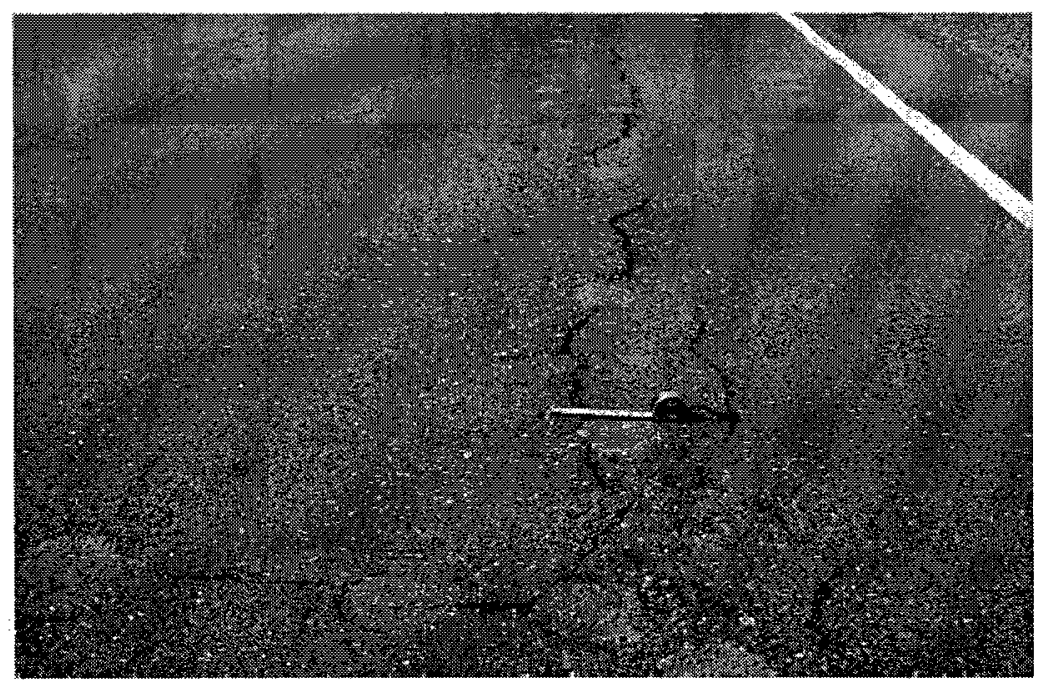

Figure 3.18 TDC occurring approximately 18-in from the center of the wheelpath (Schorsch et al., 2004)

propagated. However, it may in certain cases contribute to the propagation of the surface TDCs; either in the wheelpaths as LTDC or in the transverse direction. The contribution may be due to localized weakening or aging due to particle segregation in the $\mathrm{AC}$ mat. Particle segregation would cause reduction in the tensile strength of the AC mix in the 
segregated areas. Further, because of the high air voids in segregated areas, the AC mix is more susceptible to oxidation and moisture damage resulting in substantial decreases in the tensile strength of the mix. Depending on the existed initiated cracks, the crack could be longitudinal or transverse. The presence of thermal stresses may also help the propagation of TTDC.

\section{Summary}

This chapter presented an overview of the surface cracks, their main causes and mechanisms, in addition to discussion of the results of numerous field studies. In addition, this chapter explained how the cracks are initiated, and propagated. Full understanding of these mechanisms would provide us with a guide to identify the different stages TDC takes to form a severe distress to the asphalt structure. The next chapter discusses the remedies and treatments for TDC. 


\section{CHAPTER FOUR}

\section{Remedies and Treatments for Prevention Top-Down Cracks}

\subsection{Introduction}

The wide spread of top down cracks coupled with the findings of comprehensive research showed that, majority of TDCs are occurring during the early years after construction of new. asphalt layers. Recent research led to the development of several methods and techniques for minimization and prevention of the phenomenon of TDC. Despite the fact that pavement engineers are aware of different methods and remedies to deal with different asphalt cracking, the appropriate choice depends mainly on understanding the main cause of the problem and the related factors affecting the growth of the surface cracking. Therefore, it is important to understand the extant of each method of treatment and its true effect on the long-term performance of the asphalt surfaces. In the next sections, several approaches and methods are presented, with certain methods showed good results for only few months while other methods showed more effective results. However, some of the reported remedies were proved to be a major cause of top down cracks (Wang, 2003). Therefore, it is important to assess the different treatment techniques used to minimize and control the occurrence of asphalt surface cracking and determine the most efficient methods or techniques of treatment and remedies. It is important to review the current treatment for preventing cracks propagating from the bottom up in order to identify the ones that can be used for the TDC phenomenon. 


\subsection{Treatment of Bottom up Cracks (BUC)}

As was discussed earlier, one of the main problems associated with appearance of surface cracks was the problem known as "reflective cracks". It has been traditional practice to treat a cracked asphalt concrete layer through the use of a thin asphalt overlay. The addition of asphalt overlay has been the most commonly used treatment in North America for correcting the effects of the reflection cracking. However, it was reported that, although the application of $60 \mathrm{~mm}$ thick layer of asphalt concrete was expected to restore the serviceability of the cracked underlayer and improve the riding surface, cracking is still appearing on new overlaid layer within very short time. Numerous efforts have been made to reduce or prevent the so called reflective cracking of the asphalt pavement overlay. These attempts include increasing the tensile strength of the asphalt overlay and reducing the values of the tensile stresses produced between the cracked underlay and the overlaid layer among other methods. This practice was achieved through (Loria, 2008):

- Breaking the existing old rigid cracked Layer,

- Sawing the new asphalt overlay over the concrete joints,

- Increasing the tensile strength of the asphalt pavement overlay through the use of textile fabrics, and membranes, reinforcing metallic and nonmetallic grids and steel meshes, and

- Reducing the magnitude of the tensile stresses at the crack-overlay interface through the use of stress absorbing membranes inter-layers,

The application of one or more of the above methods to control the appearance of surface cracks was proven to be ineffective and on many occasions questionable. The main 
reasons for the failure of the proposed approaches have to do with the absence of a clear understanding of the main causes of the problem, poor definition of the reflection cracking problem and the occurrence of TDC much earlier than the initiation of BUC at the bottom of the asphalt overlay. In the following section the four main techniques are presented and discussed.

\subsubsection{Breaking the Existing Cracked Pavement Layer}

It is interesting to note that current causes of the appearance of the so called "reflective cracks" on the surface of the top layer is the presence of cracks in the underlying layer. Yet, one of the most popular techniques to reduce the effect of reflective cracks is to increase the number of cracks in the old layer. It is explained that horizontal movement due to seasonal expansion and contraction at the concrete joints and cracks generate tremendous stresses on the asphalt overlay on top of the existing joints and transverse cracks. Breaking the existing concrete pavement into smaller fragment before overlaying would reduce the stresses. Thus, it is hypothesized that the small fragments will minimize the temperature-related expansion and contraction stresses in the asphalt concrete overlay. Therefore the acting mechanism of this method depends on dissipating the tensile stresses produced by the broken layer by reducing the total movement of the broken underneath asphalt pavement layer. From field tests conducted by Noonan, (1980) on two slab segments, the first one as the control segment while the other one was broken into fragments, it was observed that the broken section could retard the overlay cracking over the control section. The broken section was still in good condition after 14 years of service with the smaller fragment sections performing better. Moreover applying a thick 
overly over the broken underlay apparently has prevented the cracked areas from being deteriorated further. Although this method was the most effective one in reducing the reflection cracking, however it did not totally elmimate the cracks. Moreover it was considered an expensive method due to rocking and tipping for unseated fragment (Noonan, 1980; Freeman, 2002).

The used methods to fracture slabs are based on reducing the concrete slab to very short rigid slabs, having textural and gradation characteristics similar to a crushed aggregate material, therefore the closely small spaced pieces will have limited movement in the horizontal and the vertical direction. The applied load is still transferring across the crack with maintaining the structure capacity. This method is accomplished by using a pavement breaker or spring arm hammer depending in the used technique (Freeman, 2002).

Abd El Halim, (1984) gave an explanation to this method of remedy which is the most effective for eliminating reflection cracking, by breaking the under layer into small fragment. He stated that as the underlying pavement is transformed to small slabs the rigidity of this layer will become less than the previous unbroken under layer, hence the new underlay will provide less rigid support under the overlaid pavement layer. Under the light of the method of relative rigidity described earlier, which was produced by Abd El Halim, (1986), this condition of the new pavement structure will be less prone to the occurrence of TDC. 


\subsubsection{Sawing the Asphalt Overlay above the Concrete Joint}

Based on the belief that reflection cracking will occur, sawing joints in the new overlay directly over the old one in the concrete pavement has been expected to provide a plane of stress relief in the overlay, hence producing a controlled reflective crack, that can be sealed effectively and prevent intrusion of water or objectionable materials. The sealant process should be applied at the same day before it gets affected by the difference in the day temperature. The efficiency of the sawed joints depend on the accuracy of aligning the saw cut in the asphalt overlay pavement in relation to the underneath crack or joint in the underlay asphalt pavement. Two disadvantages are attributed with this method, loose contact between the applied sealant and the pavement leading it to come out but it could be replaced, and the occurrence of raveling distress at the edge of the sawed joints. Moreover, very small percent of the sawed joints has experienced cracks at very early age after applying the sealant, either as corner cracking or as compression cracking (Noonan, 1980). Compared to breaking the existing concrete pavement the expenses of the sawing method is relatively more expensive.

\subsubsection{Increasing the Tensile Strength of the Asphalt Pavement Overlay}

Nonmetallic material like fabric and geotextile was used to reduce and control reflective cracks. The main mechanism behind this method is to absorb the high tensile stresses over the joint by increasing the area of asphalt exposed to these stresses. That could be achieved by using fabric mesh; the fabric mesh has high ability to absorb higher tensile strains through stretching, and is placed over the joints and cracks before the overlaying application (Loria, 2008; Noonan, 1980). This process starts with preparing a surface 
over the crack and joint; free of any dust to be capable to receive an emulsion material. The emulsion material acts as a bond to the geotextile when it is placed over the crack; finally the new asphalt layer is paved over the fabric and geotextille. Several problems were reported due to the use of the geotextiles including, stripping of the new asphalt layer due to trapping the water within its body, separation between the fabric and the overlay, and failure to prevent the appearance of surface cracks despite of its expensive application (Abd El Halim, 1983).

Noonan, (1980) conducted a large number of field tests, half of it was controlling spots and the other halt was treated by applying the fabric mish in the overlays, to determine its effectiveness. The tests were conducted after seven months; the results revealed that fabric reinforcement appears to be not effective on prevention of reflective cracking on the investigated pavement (Noonan, 1980).

The reinforcing metallic grids were used as candidates for reinforced flexible pavement like steel, aluminum and copper. Although steel is one of the most common reinforcement meshes, but it can be subject to corrosion, the existence of de-icing salt may increase the corrosion. Also the high coast of steel would likely limit its economic viability. Steel reinforcement in the asphalt pavement affects the future recyclability of the asphalt pavement. The use of aluminum as a reinforcement has less economic viability, but its lower tensile strength and high sensitivity to some acids prevent it from being a practical use in the pavement area. Under the relatively high cost of the copper, it has never been used as a reinforcing material (Abd El Halim, 1983). 


\subsubsection{Reducing the Magnitude of the Tensile Stresses at the Crack-}

\section{Overlay Interface}

The concept behind this method is to reduce the magnitude of the tensile stresses before they affect the new asphalt mix overlay. That was achieved by either placing a stress absorbing membrane inter-layer or by increasing the thickness of the asphalt pavement overlay. Applying a chip seal membrane, which is considered a highly flexible layer will reduce the magnitude of the tensile stresses, the effectiveness of this membrane depend on increasing its binder content by increasing its thickness. To control the thickness a double layer could be applied, however a good design is the one that does not have negative impact on the long-term performance of the asphalt pavement overlay by involving an optimum thickness with adequate membrane inter-layer to prevent rutting and shoving problems due to traffic over load (Loria, 2008).

\subsection{Treatment of Top-Down Crack (TDC)}

In spite of the numerous mechanisms dealing with the BUC problems and treatments developed to prevent them, the literature suggests failure of proposed solutions and lack of effective mechanism to explain its occurrence. The work carried out to determine the causes and mechanisms of top down cracks revealed three significant observations: "1" The time of the occurrence of surface cracks is right at time of construction, "2" The cracks are caused mainly due to improper compaction process, and " 3 " the cracks are initiated regardless of type of mix and/or the existing pavement structure.

As was discussed in Chapter three, conventional steel rollers will induce micro cracks on the pavement surface during the construction process. Once these cracks 
initiated they will propagate through the layer thickness (Abd El Halim et al., 1994). It has been explained that these cracks are caused by the mismatch between the rigidities and geometries of the rollers and new asphalt layer. It was concluded that the occurrence of these cracks is inevitable as long as the compacting device is cylindrical in shape of stiff material.

Some adaptations to conventional compaction equipment and methods which is expected to eliminate the occurrence of TDC are presented in the next sub-sections. However, it was shown that some of these adaptations may increase the cracking problem.

\subsubsection{Increasing the Applied Pressure by the Conventional Roller}

To achieve high density during the construction of the asphalt concrete pavement, the conventional cylindrical rigid wheel rollers are used in the compaction process. When the load is applied rapidly from the steel drum roller for a short duration, the asphalt mat responds with a high elastic stiffness and relatively small deformations. This increase in asphalt mat's stiffness can lead to a poor compaction practice where the desirable air voids and density cannot be reached (Abd El Halim and Haas, 1994). One of the remedies which was expected to overcome this deficiency which occurred in the surface of the asphalt concrete layer is to increase the applied load by the conventional roller or to use vibration. The extra pressure was created by replacing the static steel roller with a vibratory roller or by ballasting the roller with either sand or water. However this solution does not eliminate the problem of cracking; furthermore, it may cause breakage of the aggregate particles and cause the compaction cracks on the surface (Rickards et al., 
1999). Moreover, it was explained that TDCs occurred because of the excessive bending in the pavement layers due to the excessive vibrating load. Replacing the static steel roller with a vibratory roller which has extra impact load would increase the bending stresses in the asphalt pavement layers. The creation of the bending stresses is due to the applied load in the pavement surface which could also produce stresses in the bottom layers of the asphalt structure (Rickards et al., 1999).

\subsubsection{Using the Pneumatic Tire Roller}

Also using the pneumatic tire roller after the conventional steel roller was assumed to eliminate the surface cracks through the kneading effect. It was believed in the industry that the compaction induced cracks which occurred on the surface after using the steel drum roller will be sealed or healed and cured after few passes of the pneumatic tire roller. However, reported field observations of healing effects were never verified with any serious research work. There was not any experimental work that supports the assumption which state that compaction cracks can be eliminated by pneumatic rollers and only field inspection was the main base for this assumption (Abd El Halim and Haas, 1994; Abd El Halim et al., 1993). Laboratory testing performed on asphalt cores and slabs recovered from field sections which were subject to the application of pneumatic rollers as shown in Figure 4.1, illustrated that the cracks were never healed and their presence affected the mechanical properties adversely. Besides the ineffectiveness of the rubber rolling it was reported by Rickards et al., (1999) that the applied water on the rubber tires which is used to create an insulator between the tires and the premature 
asphalt could be forced to go down through the surface induced cracks due to the hydraulic pressure induced in the water film at the asphalt tire interface.

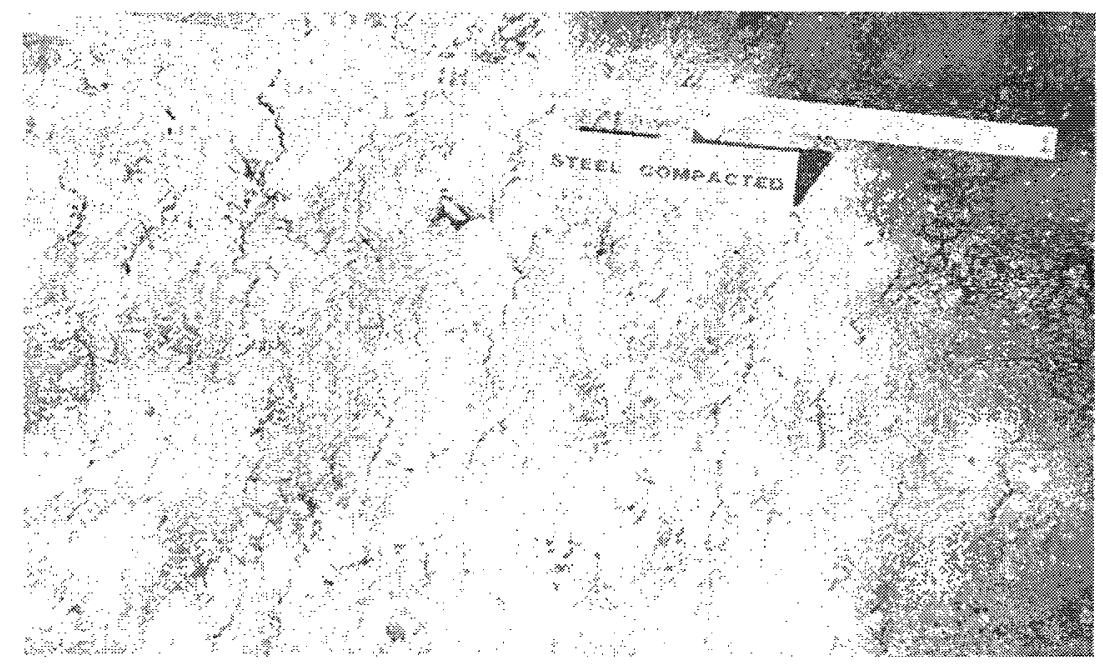

Figure 4.1 Vibratory - compacted section flowed by pneumatic roller of Ottawa field trial (Abd El Halim et al., 1993)

To achieve optimum compaction it is important to understand the factors that govern the quality of compaction such as load of compaction and rate of its application, speed of compaction, and contact time during compaction. The following section deals with the factors that contribute to quality of compaction (Rickards et al., 1999).

\subsubsection{Asphalt Multi-Integrated Roller (AMIR)}

In spite of many attempts to improve the quality control of the properties of the asphalt concrete components by controlling the temperature during compaction, good rollers' operators and improved asphalt mix design, the construction-induced cracks are still observed on numerous new finished projects. One of the most recent and important 
innovations in the asphalt concrete field to eliminate these induced surface cracks was the newly developed asphalt multi-integrated roller (AMIR) by Abd El Halim, (1987). It was demonstrated that this new type roller which its main feature is a flat rubber plate, overcomes the problem of construction induced cracks by resolving the problem of mismatch between the geometry and the rigidity of the soft asphalt concrete mat and the stiff cylindrical steel drums, Figure 4.2.

The concentrated compacting pressure produced by the present two large conventional drums was converted to a uniform pressure by providing the design of the AMIR compactor. The most important improvements the AMIR compactor achieved were the significant reduction of the applied pressure, redistribution of the concentrated pressure to a more uniform pressure, and much longer contact duration between the applied pressure and the asphalt mat. Svec and Abd E1 Halim, (1991) concluded that the use of the new AMIR compactor provided a satisfactory crack-free surface and tight surface texture.

Result of permeability tests performed in Canada and Australia showed that the elimination of the construction cracks resulted in significant reduction in the permeability of the newly compacted asphalt mat by more than $400 \%$ (Abd El Halim et al., 1993; Rickards et al., 1999; Mostafa and Abd El Halim 2006). Figures 4.3 and 4.4 show the effects of the compaction techniques on the surface cracks of the same asphalt mix. A commercial version of AMIR compactor was designed and built by Pioneer Road Service, an Australian firm dealing with asphalt construction. Figure 4.5 demonstrates a version of the Australian Hot Iron Process Asphalt Compaction (HIPAC), (Rickards et al., 1999). 


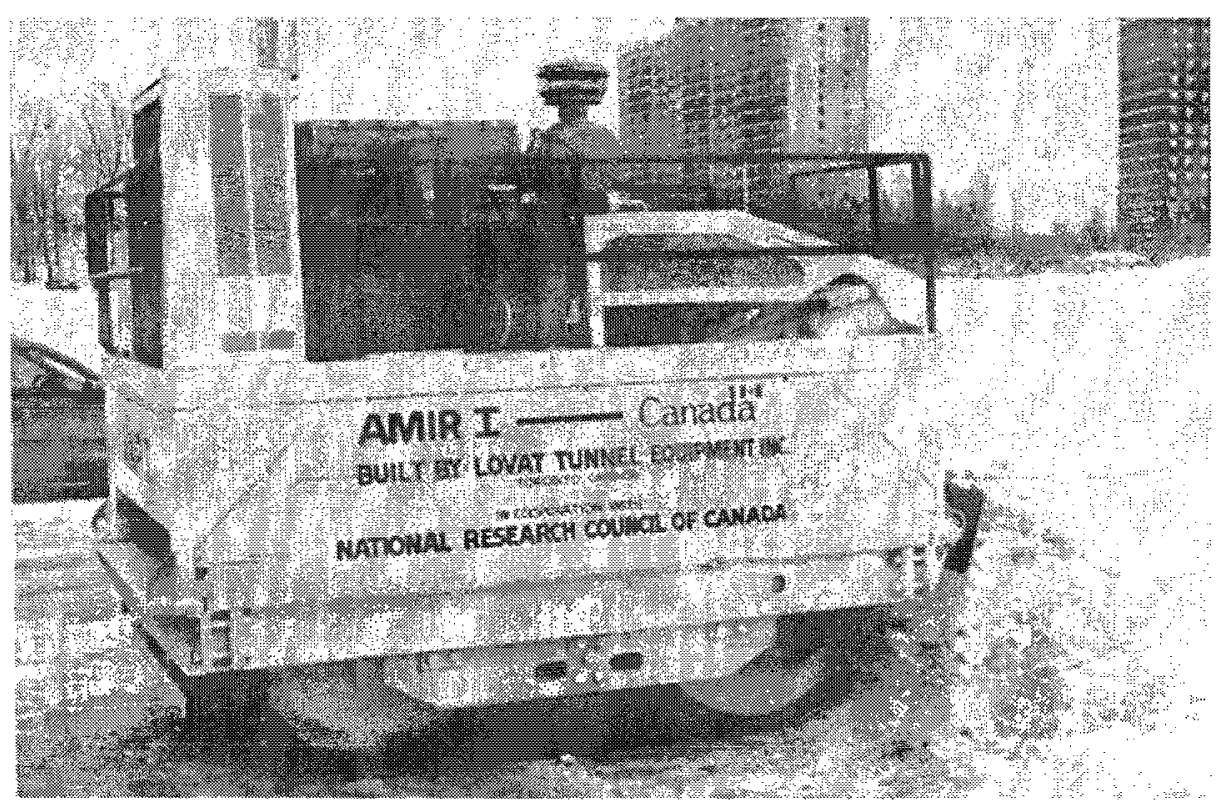

Figure 4.2 Asphalt Multi-Integrated Roller (AMIR) Prototype

(Abd El Halim et al., 1993)

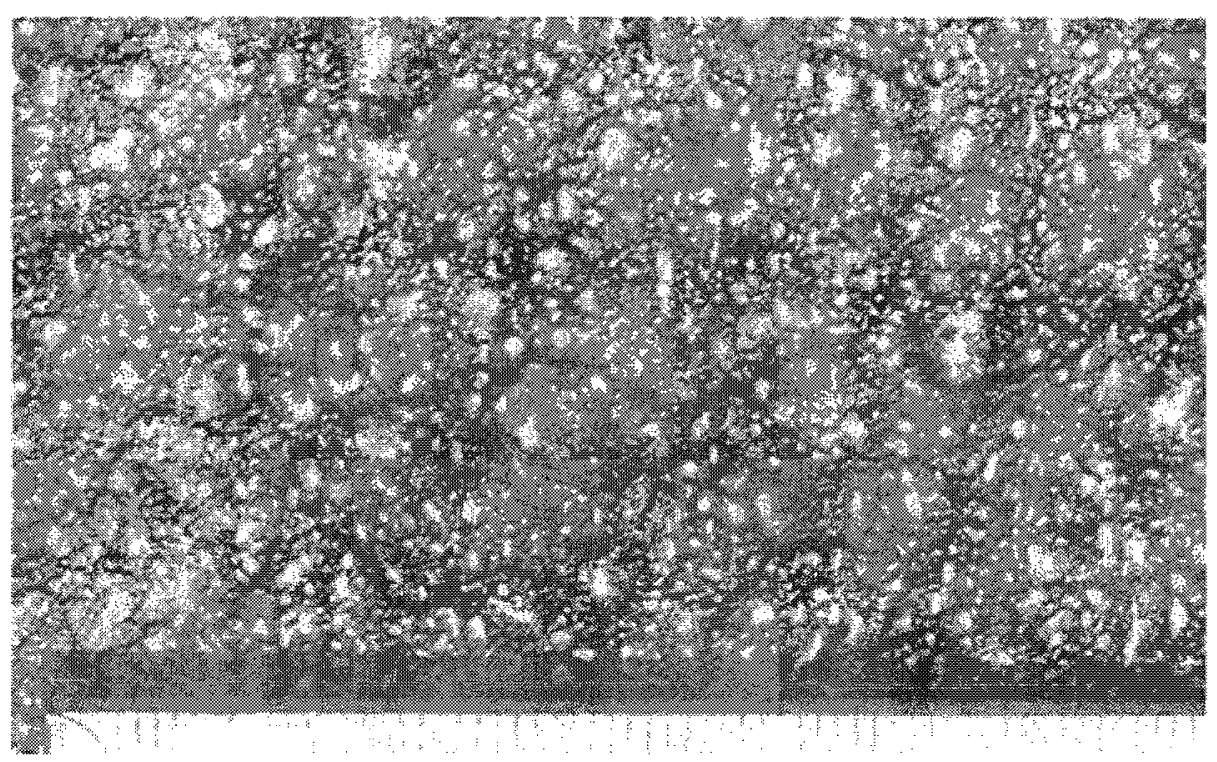

Figure 4.3 Static steel compacted asphalt section (Abd El Halim et al., 1993)

The significant development occurred to HIPAC is that it consisted of two separate rubber belts as shown in Figure 4.5. Field investigation of HIPAC prototype took place in 
Victoria Australia in 1998 to evaluate the asphalt density with the roller speed and number of roller passes, results showed that an acceptable finished pavement surface of 96 percent compaction was reached after only one pass with maximum load duration of

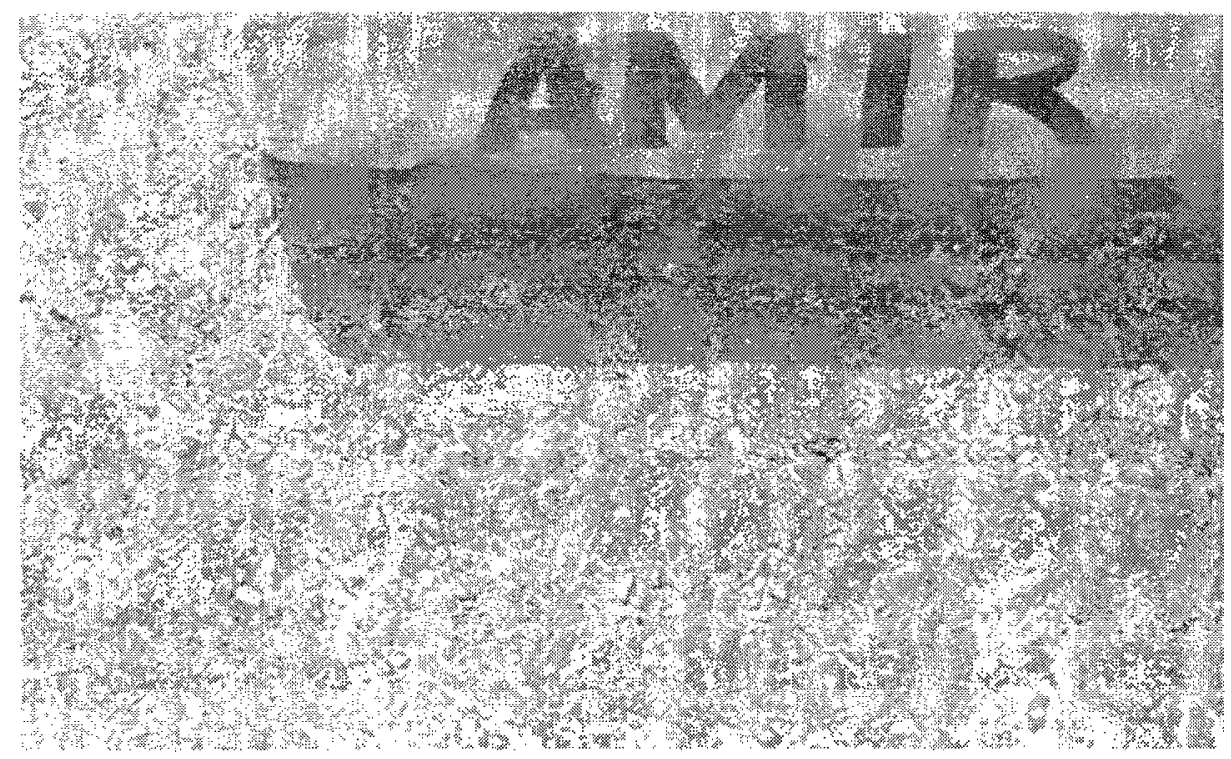

Figure 4.4 AMIR Compacted asphalt section (Abd El Halim et al., 1993)

52.65 seconds. The same compaction percent or even less was achieved by many passes using the conventional steel roller followed by a rubber wheel roller. Because the load duration was long in the case of the HIPAC equipment, it was assumed that equilibrium was achieved in the asphalt layer for the applied load stress and additional consolidation could be facilitated by adding more compaction energy. However, the maximum density was achieved during the initial pass, field results shows that 3 percent of the compaction was added to the initial density by increasing the number of passes to five passes as shown in Figure 4.6 (Rickards et al., 1999). 


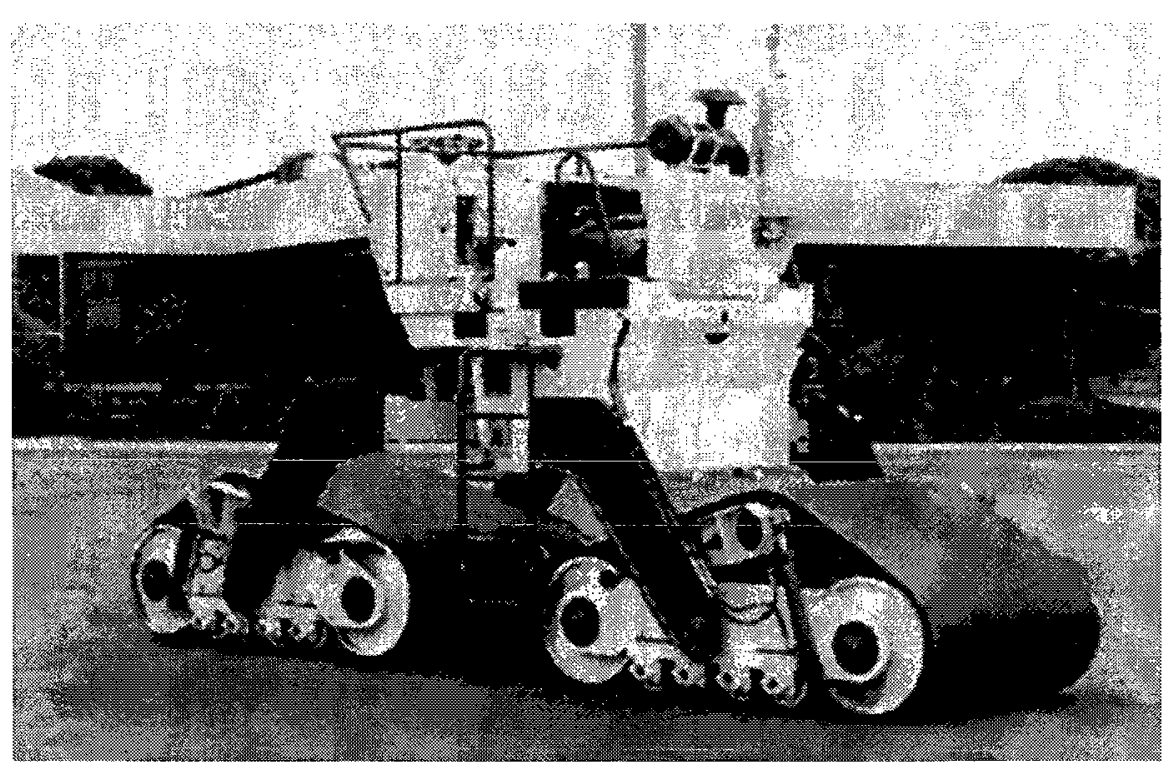

Figure 4.5 HIPAC device

(Rickards et al., 1999)

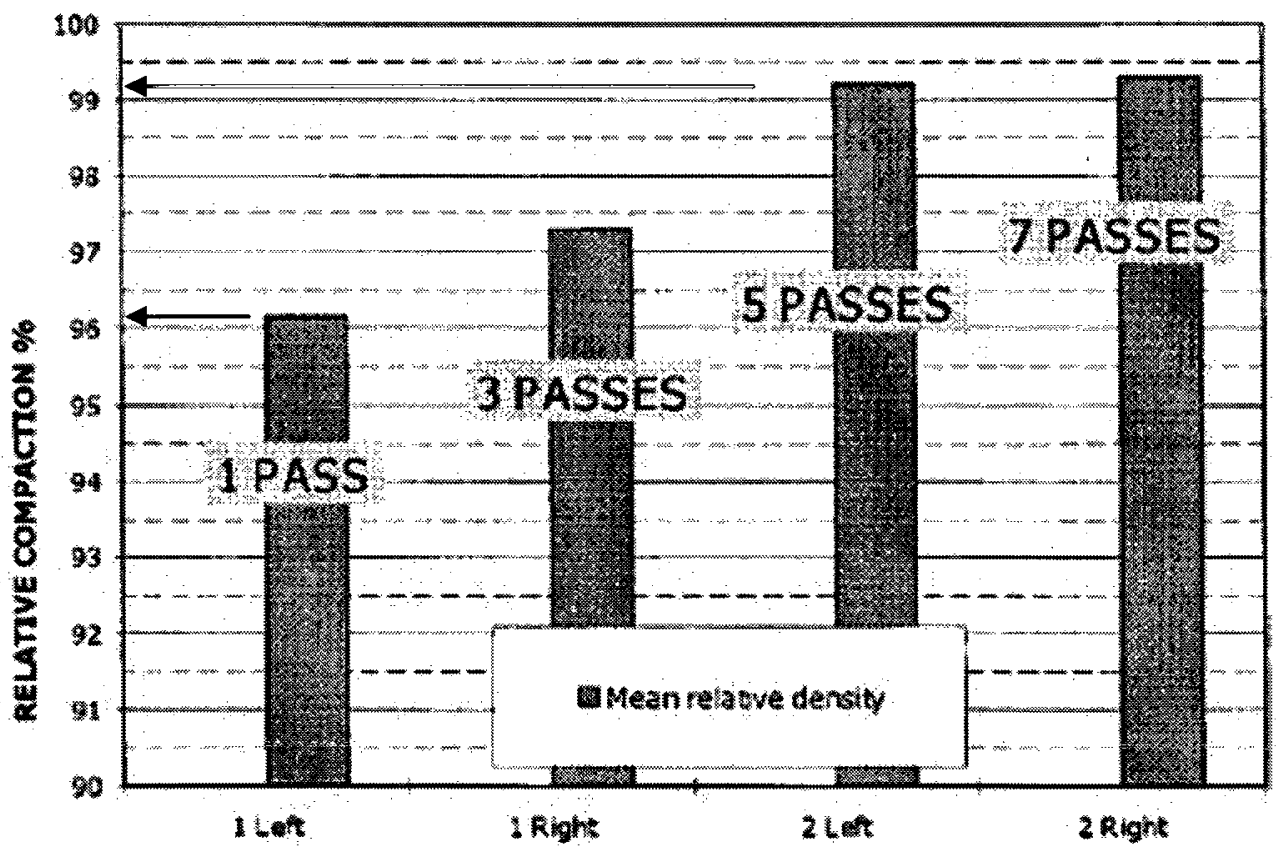

Site number

Figure 4.6 Asphalt density versus number of passes of HIPAC device (Rickards et al., 1999) 


\subsubsection{Overlaying, Patch up, and Removing the Full Depth}

The problem with TDC is that once they occur nothing can stop their propagation in all directions. Therefore, at the present time the absence of the new IIIPAC on a commercial scale forced highway agencies to apply different kinds of remedies and field methods. Methods such as overlaying, patch up, and removing the full depth have been recommended and followed in the field. Their effectiveness depends on the severity of the cracks and the costs of application. Overlaying the existing cracked surface is widely known as a method of treatment when severe cracking is observed while patch up is applied for limited deteriorated areas before the overlaying process. Furthermore, other cases when the cracks propagate the entire depth of the asphalt layers, removing the full depth and replacing it could be an option (Uhimeyer et al., 2000). However, these techniques do not address the main cause of the TDC but rather treat their effect which could be very costly and repetitive.

\subsubsection{Development of the Superpave Mix Design Method}

Over the past decades, extensive research work have been devoted to develop an asphalt mix with superior mechanical properties with the premise that an improved mix quality would enhance the mix's abilities to prevent or minimize the occurrence of cracking. The development of the superpave mix method certainly enhanced the long term performance of newly constructed pavements (Zhang and Huber, 1996). However, it has been reported that using the superpave mix design method did not totally eliminate the problem of cracking and in some cases it was reported that it increased the defects in the asphalt pavement during its construction (Rickards et al., 1999). 


\subsection{Treatment due to Load Induced Tensile Stresses}

One of the traditional techniques to repair pavements exhibiting surface-initiated longitudinal wheel path cracks involves overlaying the cracked asphali concrete layer. Myer et al., (2001) has reported that TDC initiation is pertinent to thicker asphalt concrete pavements. This indicates that the method of rehabilitation which increases the thickness of the asphalt layer by overlaying will not be effective. Subsequently, methods which could be more effective include milling and replacing the defective layer which will result in maintaining the same thickness of the repaired layer. This method was reported as the preferred rehabilitation option (Uhlmeyer et al., 2000). However, while the longitudinal cracked section is milled and replaced with hot mix asphalt in this process, Harmelink et al., 2008 demonstrated the deficiencies of this type of remedies as two longitudinal cracks were created adjacent to the treated crack. Clearly, the reported observation indicated that the proposed treatment is not effective. While the problem of TDC is still been attributed to load induced stresses, the pavement industry is still seeking to treat this problem. The lack of understanding the real causes of the problem of crack initiation led to the implement of numerous research and studies including development of invalid and ineffective solutions, thus wasting the huge investments and efforts on attempting to solve the wrong problem.

\subsection{Treatment due to Thermal Stresses}

There is no asphalt mix method that guarantees the elimination or prevention of thermal cracks. Thermal cracks are expected to appear on the pavement surface as long as low temperature conditions exist. It was discussed in Chapter 3 that the difference in the 
coefficient of thermal expansion between the flexible asphalt matrix and the aggregate particles is considered as one of the main reasons to the occurrence of local thermal tensile stresses in addition to the global stresses. The difference in the coefficients of expansion and contraction of the two main components of the asphalt mix leads to significant generation of local stresses acting on the microscopic scale of the mix. Furthermore, the difference in the coefficients causes the asphalt matrix to contract more than aggregate when the mix is exposed to low temperature which may result in local separation at the interface between the asphalt matrix and aggregates. Several studies determined the major factors contributing to the thermal cracking phenomenon such as thermal properties of asphalt cement, structural design, environmental conditions, age of pavement, construction processes, and physical properties of the aggregates and asphalt cement binder (Seddik, 1995; Vinson et al., 1989; McGennis, 1995). It has been suggested that controlling these factors and attempting to minimize their adverse effects will present the most effective method of dealing with the problem of thermal cracking. These factors are discussed below.

\subsubsection{Bond Characteristics}

Asphalt concrete mixtures consist of aggregates and asphalt binders. The performance of the asphalt concrete mix against thermal cracking is dependent on the properties of the individual materials and the properties of the mixture of both materials.

In order to prevent or reduce thermal cracking, the binder must not crack under cold temperature. Generally, a stiffer asphalt binder is more prone to low temperature cracking than a soft asphalt binder. More over it was suggested that the bond between 
the asphalt layers, which could be between the base course and the surface course or between the existed asphalt and the new overlays during the rehabilitation process, should be strong enough to reduce thermal cracking (Fabb, 1974). This hypothesis was approved to be incorrect as will be described in more details in Chapter 5. It was documented that the bond between the asphalt layer and the underlayer will work as a constrains to the surface layer and makes it more susceptible to the thermal induced stresses, when these stresses exceeds the tensile strength of the asphalt mix, thermal cracks could be initiated Guylain and Claude, (1999).

\subsubsection{Aggregate Quality}

Aggregate characteristics used in asphalt concrete mixtures are important in reducing the effect of applied stresses and resisting thermal cracking. It is well established fact that thermal cracks occur under cold temperatures split the aggregates rather than the asphalt binder and that is how thermal cracking are recognized. Therefore, the physical and thermal properties of the used aggregates are very important to reduce the occurrence of thermal cracking. The main properties and characteristics that influence the thermal behaviour of the aggregates in the asphalt mix are:

- Angular shape, rough surface texture and gradation,

- High abrasion resistance, low absorption,

- Low freeze-thaw loss, where the freeze-thaw cycles effect the stability of the aggregate specially when the aggregate is under constrained condition, and

- High tensile strength. 
These properties will provide better thermal performance of asphalt pavement and will have greater resistance to thermal cracking (Shalaby, 1997).

\subsubsection{Pavement Dimensions}

The design and construction of the roads also affect the thermal cracking. Haas and Hajek, (1972) indicated in their investigation that insulating properties of the pavement is improved as the thickness of the pavement is increased which help to lower the temperature gradients and hence minimize the thermal cracking. Another factor which should be considered in the design is the road width, Shalaby, (1997) indicated that transverse cracking appears at an interval of $30 \mathrm{~m}$ for a typical road that is $8 \mathrm{~m}$ wide, while an interval of $45 \mathrm{~m}$ will be exhibired in case of airport runway that is $16-32 \mathrm{~m}$ wide. It was concluded that the width of the road is influencing the occurrence of transverse cracking.

\subsubsection{Traffic Loadings}

Traffic loadings do not cause thermal cracks, but do accelerate the growth of existing cracks. Traffic loading has been reported as a major factor that may increase the rate of propagation of thermal cracks over time (Deme, 1987). When paving and compaction are completed, certain preventative process can be taken to avoid future pavement distress. Primarily load restrictions are placed on roads that are subjected to extreme freeze thaw cycles during critical months where the difference in temperature is high (Lauter, 1998). 


\subsection{Treatment due to the Effects of Age Hardening}

The first thing most researchers think about to solve factors affecting TDC problems in pavement is to apply some changes in the $A C$ mix. Clearly, there are practical limits on how much one can do to exert changes to the mix composition, therefore changes in the mix design was proven not to overcome the problems of age hardening of bitumen. The top few millimeters of the pavement surface were shown to be much more susceptible to age hardening than the lower part of the layer; therefore an effective remedy will be the one that reduces the aging of that layer. One of the used techniques to overcome this problem is the application of surface dressing (Rolt et al., 1986; Rolt, 2000).

Surface Dressing, also known as chip seal or spray seal, was reported as an effective technique to reduce the hardening of bitumen in the upper $3 \mathrm{~mm}$ of the $\mathrm{AC}$ pavement surface and therefore in reducing the risk of top-down cracking. The process starts by spraying a fast setting emulsion onto the road surface, and then the chippings are spread on top and normally rolled to ensure proper embedment. This method provides a much-improved surface texture. Usually emulsions containing 60 to $70 \%$ bitumen are used for surface dressing. The asphalt mix design specifies the capacity of extra bitumen in the wearing course of the AC. If this capacity is exceeded instability and poor surface texture become serious problems, therefore, the used emulsion should be enough to provide the required film thickness on the road and at the same time it should not be prone to surface run-off. The choice and concentration of emulsifier also dictates the rate of "breaking" and "setting" of the emulsion with different aggregates and under various climactic conditions. The emulsifier contributes to the ultimate adhesion of the binder aggregate system (Rolt et al., 1986; Rolt, 2000). 
A study done by Rolt, (2000) revealed that, after 24 months from applying the surface dressing over the pavement surface, the rate of bitumen hardening at the surface was significantly reduced and the bitumen viscosity could be decreased 70 times less than the unsealed pavement, which gives a good indication of the advantages in placing surface dressing on an asphalt surfacing, however there was not any reporting on the effect of surface dressing on surface cracking.

\subsection{Treatment due to the Effect of Segregation}

Longitudinal cracks which could propagate due to segregation were associated with traditional conveyer system and material transfer devices, therefore, it was suggested by Mum, (2003) to modify the material transfer systems and the pavers in a way that alleviate segregation. That could be achieved by assuring a good mix process in the paver before laying HMA down. The investigation carried out by Read, (1996) revealed that remixing of the HMA before it is being loaded to the paver will reduce the amount of segregation in the HMA pavement. Moreover, it was reported by Kennedy et al., (1991) that a proper design mix will alleviate the occurrence of segregation in the asphalt mix. Kennedy et al., concluded that a good determination to the asphalt binder content and the best selection of the aggregate size and gradation have a significant effect in controlling the amount of segregation that could occur to the asphalt pavement structure. Superpave mix was also recommended by Harmelink et al., (2008) where they explained that increasing the asphalt cement content in the mix could reduce the occurrence of segregation and consequently the possibility of the propagation of TDCs. One of the suggested remedies to the cracks which appear in segregated areas is to apply sealing 
along the crack in its early stage, and before the cracks propagate into wider cracks, Harmelink et al., (2008).

\section{Summary}

- This chapter presented an overview of the promising techniques to mitigate asphalt surface cracking in asphalt pavement layer. Overall, the previous literature suggests a great deal of variability in methods regarding the process of BUCs and TDCs remediation, in order to achieve satisfactory overall pavement performance. While these methods were developed, the most effective current approach appears to be the new compaction technology. Therefore, if a reliable method and an economic technique could be demonstrated to minimize or delay the occurrence of the observed cracks it would certainly be a valuable approach to pavement designers and engineers.

- Understanding the extant of each method of treatment and its true effect on the longterm performance of asphalt surface will help pavement engineers to choose the most effective method of treatment.

- Methods applied to control the appearance of surface BUC was proven to be ineffective under the absence of clear understanding of the main cause of the problem.

- It was shown that some adaptations to conventional compaction equipment and methods which is expected to eliminate the occurrence of TDC may increase the cracking problem. 
- Treating the effect of TDC without understanding the real causes of the problem of crack initiation could be very costly by wasting the huge investments and efforts on attempting to solve the wrong problem and could lead to the implement of repetitive research and studies with invalid and ineffective solutions.

The next chapter discusses and analyzes the causes of TDC. 


\section{CHAPTER FIVE}

\section{Top-Down Cracks: Analysis and Discussion}

\subsection{Introduction}

The literature review presented in the previous Chapters showed that there are several thermal theories and approaches to explain the phenomena of surface cracking. Traditionally and for a very long time, cracks appear on the surface of the top asphalt layer have been assumed to initiate at the bottom of that layer. The results of the traditional school of thinking led to the fact that all current asphalt structural design methods have based their analysis on the assumption that the finished structure is free of defects and any construction cracks. Finally, the majority of experimental investigations were performed to simulate the problem in the laboratory, were carried out on specimens without cracks. As a result of these deficiencies one major conclusion of this review is that, unless research and analysis are performed on asphalt specimens reflecting the actual geometry and construction conditions in the field, the problem of surface cracking will not be resolved.

One can realize the major differences between two pavement structures having similar geometry, same asphalt mix and same field conditions but one has no construction defects, while the other has full surface cracks and other defects induced during the construction phase. As was explained by Abd El Halim (1984), the main cause that is most probably leading to the initiation of top down cracks, is that TDC has more to do with the compactors geometry and stiffness than the quality of the mix itself. The most

obvious outcome of the defected finished asphalt layer is that, while the expected service 
life according to the adopted design method may range between 15 to 20 years, the finished layer failed within very short period after its construction. The effect of the surface cracks or compaction induced cracks is that the newly constructed asphalt layer would lose the majority of its structural integrity. Also, the presence of the surface cracks during construction may alter the structural behaviour of the layer and influence the generated stresses and the expected tensile strength. In the next sections, the different factors affecting the initiation of TDC in the surface of the asphalt concrete layer are discussed and analyzed according to the following order:

1. Thermal Induced Tensile Stresses

2. Load Induced Tensile Stresses

3. Compaction Process

\subsection{Influence of Properties of Asphalt Pavement on Thermal Cracking}

Thermal induced tensile stresses have been widely reported to be one of the major factors that affect the occurrence of TDC. According to the basic fundamentals of physics, a free body of any restraints will contract when temperatures drop without generating any internal stresses or strains. Similarly, when an asphalt concrete layer experiences a temperature drop, it would contract freely without generating any internal stresses if it was not restrained. However, and due to several reasons the asphalt pavement layer which is a component of the overall pavement structure would always experience some level of restraint because of the bond with the underlying layer. Subsequently, tensile stresses will be generated and they will start to build up along the entire length of the road. The volumetric contraction in the pavement layer leads to the development of 
thermal tensile stresses which will continue to increase as long as there is a resistance provided by the bond mechanism. Depending on the resistance provided by the bond mechanism, tensile stresses can reach a value when it would exceed the tensile strength of the asphalt pavement layer, thus initiating cracks. However, if the bond resistance is lower than the induced thermal stresses, these stresses would break the bond and cracking will not result since the layer will act as a free body. Typically, these thermal stresses would be less than the tensile strength of the asphalt pavement layer and the stresses will be balanced by the tensile strength, and the asphalt pavement layer will not experience any cracks.

Poor bonding between the asphalt pavement layers leads to other modes of distress. One of the most common distresses is slippage cracking. Slippage cracking usually occurs during vehicles acceleration and deceleration process. The horizontal forces induced due to the rapid change in the vehicle acceleration act on the top asphalt layer and push it away from the layer beneath it generating tangential stresses. This occurs most often in areas like intersections, sharp curves. The generated tangential stresses in the pavement layers interface separate the top layer from the bottom one, cause the pavement surface to slippage as shown in Figure 5.1 (Hachiya and Sato, 1997).

It is important to note that laboratory simulation of thermal induced stresses is extremely difficult to duplicate the field conditions for two critical reasons. The first one is that the thermal stresses generated in the field are generated by the drop in temperature which causes the contraction of a constrained length of the asphalt pavement layer. The generated stresses are function of the temperature drop. The second reason deals with the method of inducing the stresses in the laboratory which are based on applying mechanical 
induced stresses on strained and small asphalt specimens until failure. Clearly, these two conditions do not satisfy the actual conditions to simulate actual thermal stresses generated in the field.

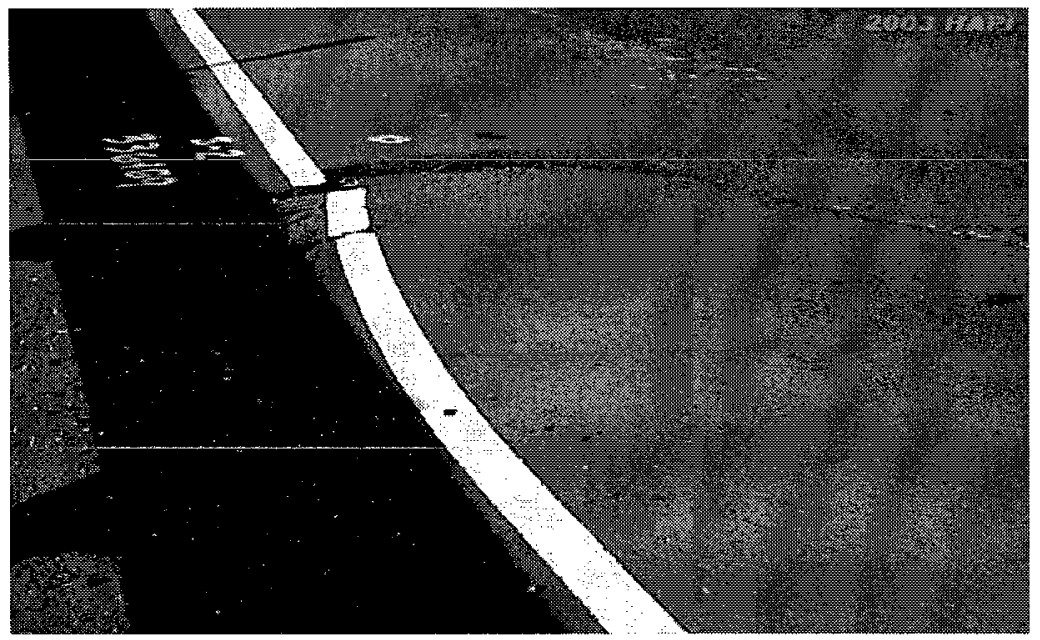

Figure 5.1 Slippage cracking

Hachiya and Sato, 1997

In order to understand the mechanisms that lead the asphalt pavement to fail due to thermal stresses, one has to be able to predict whether these stresses will exceed the tensile strength of the asphalt mix, and the effect of the bond resistance between the asphalt pavement layer and the underneath supporting layer. Clearly, the induced thermal stresses must exceed the tensile strength of the asphalt pavement layer and at the same time each of the stresses and the tensile strength should be equal to or less than the bond resistance between the top layer of the pavement and the one immediately underneath it. Furthermore, because of the complexity and uncertainties associated with the thermal cracking phenomena it is important to consider the reliability formulation of lowtemperature cracking. This approach involves several basic pavement properties including the coefficient of thermal contraction, pavement temperature, penetration 
index, penetration and softening points, binder stiffness, and mixture stiffness. Several analytical models utilizing the data and information relevant to pavement geometries and properties were developed by Hills and Brien (1966); Heukelom (1966); Collop et al., (2009) among many other researchers to predict the occurrence of transverse cracking. In this section the induced thermal stresses, the tensile strength and the bond resistance between the asphalt pavement layer and the underneath supporting layer are investigated and examined as well as their influence on the occurrence of TDC. Figure 5.2 shows the research approach followed in this chapter.

\subsubsection{Coefficient of Thermal Contraction}

The first factor to be addressed is the coefficient of thermal contraction of the asphalt concrete, $\alpha$, which depends on the asphalt mix design, the asphalt concrete mix, used aggregate type and gradation, maximum aggregate size, density, binder type, asphalt content, and the applied temperature. The coefficient of thermal contraction has been shown to vary according to the pavement temperature (Easa et al., 1996). It is important to note that asphalt mixtures are composite materials and therefore determination of a simple coefficient of contraction and expansion is a very complex issue. The problems associated with this coefficient can be summarized as (1) complexity of the composition of the asphalt mixture, (2) presence of several materials with great variations within and between the materials, (3) the locality of the thermal stresses versus a general behaviour, and (4) the dependency of the coefficients on several other factors hard to quantify or control. However, and in spite of the recognized complexities with the coefficient and for ease of computations analysis were performed with the assumption that while there was a 
variation in the temperature, a fixed value for $\alpha$ was used throughout the calculations.

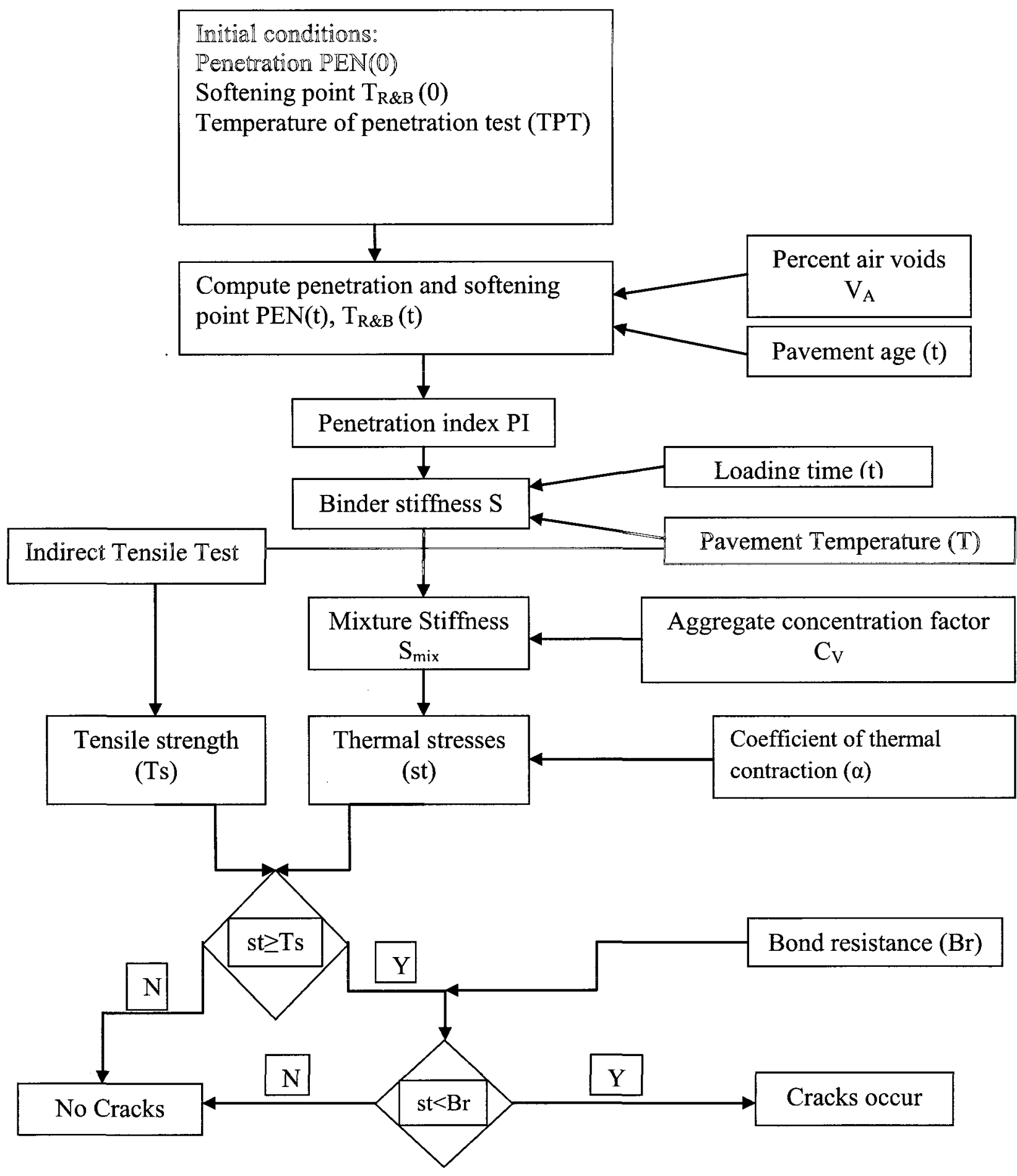

Figure 5.2 Proposed research approach for investigating thermal cracks 


\subsubsection{Pavement Temperature}

It was documented that the thermal induced surface tensile stresses are proportional to the drop of negative temperature and the daily differences during the evening and nighttime in winter months (Guylain and Claude, 1999; Schorsch, 2003). A regression analysis was conducted by Guylain and Claude, (1999) on data collected from eight Canadian sites. This data represented the minimum air temperature versus minimum asphalt layer temperature at different depths. Using this data a simplified model was developed by Guylain and Claude, (1999) to determine minimum asphalt pavement layer temperature based on air temperature at any depth below asphalt pavement layer surface based on minimum air temperature in Canada. This form is presented as:

$\mathbf{T}_{\mathbb{Z}}=\mathbf{a}_{0}+\mathbf{a}_{1} \mathbf{T}_{\mathbf{a i r}}+\mathbf{a}_{2} \mathbf{z}$

Where $\mathrm{a}_{0}=(-0.3794), \mathrm{a}_{1}=(0.7193), \mathrm{a}_{2}=(0.0411)$

$\mathrm{T}_{\mathrm{z}}=$ Asphalt pavement layer temperature at the depth $\mathrm{z}$ below the surface $\left({ }^{\circ} \mathrm{C}\right)$

$\mathrm{T}_{\text {air }}=$ Air temperature ${ }^{\circ} \mathrm{C}$.

$\mathrm{z}=$ Depth below asphalt pavement layer surface $(\mathrm{mm})$

The correlation $\left(\mathrm{R}^{2}\right)$ for this model was 0.93 .

In order to assess the effect of change of temperature on the initiation of thermal cracks it is assumed in this section that the maximum air temperature is $+5^{\circ} \mathrm{C}$ and the minimum is $-40{ }^{\circ} \mathrm{C}$ which is the coldest possible temperature observed in the majority of the Ottawa paved roads. Also, a common thickness of majority of the asphalt layer of a pavement structure is $150 \mathrm{~mm}$. Using the equation developed by Guylain and Claude, (1999) to determine the expected pavement temperature at different depths for the assumed data, it is shown that over a pavement depth of $150 \mathrm{~mm}$ the calculated 
temperature changed by approximately $6.2{ }^{\circ} \mathrm{C}$. Clearly, a change of $6{ }^{\circ} \mathrm{C}$ under the extreme temperature of $-40^{\circ} \mathrm{C}$ could not generate temperature gradient over a $150 \mathrm{~mm}$ deep layer that is sufficient to cause high thermals tresses to induce thermal cracks as will be discussed later.

\subsubsection{Penetration Index}

The penetration index is one of the required factors for determining the binder stiffness and hence the mixture stiffness, and the tensile stresses of the asphalt pavement layer. To calculate the penetration index (PI) of asphalt, it is required to find first, the penetration PEN $(t)$ of the asphalt and the softening point (Ring and Ball temperature, $T_{R \& B}$ ) at any age during the service life of the mixture, as was defined by Pfieffer and Van Doormaal, (1936). To determine the penetration PEN(t) and the softening points $T_{R \& B}(t)$ for the AC mix, aging models were utilized according to Shahin and McCullough, (1972), these models are presented as follows:

$$
\begin{aligned}
\operatorname{PEN}(t)= & -48.258-2.561 \sqrt{t}+0.1438 \operatorname{PEN}(0)-8.466 \frac{V_{A}}{1+\sqrt{t}} \\
& +1.363 \operatorname{TFOT}+0.9225 \frac{\operatorname{PEN}(0)}{1+\sqrt{t}} \\
T_{R \& B}(t)= & -4.632+3.162 \sqrt{t}+1.585 T_{R \& B}(0)-0.93 \text { TFOT }
\end{aligned}
$$

Where

PEN(0), TR\&B $(0)$ are the initial penetration and softening point TFOT is the percent penetration after thin film oven test (ASTM D2872) 
$\mathrm{V}_{\mathrm{A}}$ is the percent air void in the mixture

$t$ is the pavement age in months

The penetration index PI is then determined from equation 5.4 (Pfieffer and Van Doormaal, 1936).

$$
P I=\frac{20-500 P T S}{1+50 P T S}
$$

Where PTS is the slope of the penetration temperature curve. Assuming the penetration at the softening point is $800 \mathrm{dmm}$ as was founded by Pfieffer and Van Doormaal, (1936) for most bitumen, then

$$
P T S=\frac{\log 800-\log \operatorname{Pen}(t)}{T_{R \& B}(t)-T P T}
$$

where

TPT is the temperature of the penetration test.

\subsubsection{Mixture Stiffness}

To determine the thermal stresses, it is essential to find out the mixture stiffness property. The mixture stiffness, $\mathrm{S}_{\text {mix }}$, is dependent on the binder stiffness, $\mathrm{S}$, and the aggregate concentration factor, $\mathrm{C}_{\mathrm{v}}$ and can be obtained using the following Heukelom's relationship, (Heukelom, 1966). 
$S_{m i x}=S\left(1+\frac{2.5 C_{v}}{n\left(1-C_{v}\right)}\right)^{n}$

where

$n=0.83 \log \left(\frac{4.0 \times 10^{5} \mathrm{MPa}}{S}\right)$

where $\mathrm{S}$ and $\mathrm{S}_{\text {mix }}$, are the binder and mixture stiffness in MPa, and $\mathrm{C}_{\mathrm{v}}$ is the aggregate concentration factor and it ranges from 0.7 to 0.9 .

Based on Van der Poel monograph (Shahin and McCullough, 1972), the stiffness of the asphalt binder is determined. The stiffness is updated during the thermal cycle because it is dependent on the temperature, the penetration index, and the loading time (the time taken by the temperature to drop). The following regression model is used for binder stiffness ranging from $10^{-8}$ to $1.0 \mathrm{MPa}$ (Shahin and McCullough, 1972).

$$
\begin{aligned}
\log S= & -2.35927-0.06743 T-0.90251 \log t+3.8 \times 10^{-4} T^{2} \\
& -1.38 \times 10^{-3} T \log t+6.61 \times 10^{-3} P I T
\end{aligned}
$$

with $\mathrm{R}^{2}=0.99$. For binder stiffness ranging from 1.0 to $2,000 \mathrm{MPa}$ the regression model is:

$$
\begin{aligned}
\log S= & -2.90072-0.11485 T-0.38423 P I-0.94259 \log t \\
& -0.000879 T \log t-0.05643 P I \log t-0.02915 \log ^{2} t \\
& -0.00051837 T^{2}+0.00113 P I^{3} T-0.01403 \times 10^{-5} P I T^{3}
\end{aligned}
$$


with $\mathrm{R}^{2}=0.98$. Where, $\mathrm{T}=$ mean asphalt pavement layer temperature of day; $\mathrm{t}=$ loading time in $\mathrm{s}$; and $\mathrm{PI}=$ penetration index.

\subsubsection{Thermal Stress Induced Cracks}

As discussed earlier in the literature, thermal cracking of asphalt pavement has been explained as caused mainly by low temperatures. Cold conditions are assumed to induce shrinkage and the formation of tensile stresses in the pavement materials, which in turn produces fracture when the tensile strength of the asphalt is exceeded under special constrained condition. Several researchers have attempted to estimate cracking temperatures in asphalt material, using either laboratory determined values (Anderson 2001, Haas 1972) or with empirical approaches (Andrew et al., 2008). In the following section, thermal stresses are calculated using the approximate elastic method of Hills and Brien, (1966) which assumes that:

- Loading is uniaxial and the material exhibit elastic behavior,

- Coefficient of thermal contraction is constant and does not change with change of time and/or temperature; and

- Pavement layers are homogeneous and crack free, a case which contradicts the main findings of this research.

Based on these assumptions, the limiting stresses can be found by summing the stresses over the daily temperature drop, $\operatorname{Tr}$. The temperature drop $\operatorname{Tr}$ is calculated from the daily air temperature cycle at the asphalt pavement layer surface which is presented in cosine curve in the following model, Equation 5.10 (Easa et al., 1996). Figure 5.3 illustrate the 
daily temperature cycle which consists of two phases, each of 12 hour duration. Only the cooling phase is considered in the analysis.

$g(t)=T_{0}+T_{1}\left[\cos \left(\frac{2 \pi}{24} t\right)-1\right]$

Where $g(t)=$ surface temperature, $t=$ time in hours starting from noon time, and the maximum and minimum daily surface temperatures are $T_{0}$ and $\left(T_{0}-2 T_{1}\right), T_{1}=$ amplitude of the temperature cycle in ${ }^{\circ} \mathrm{C}$.

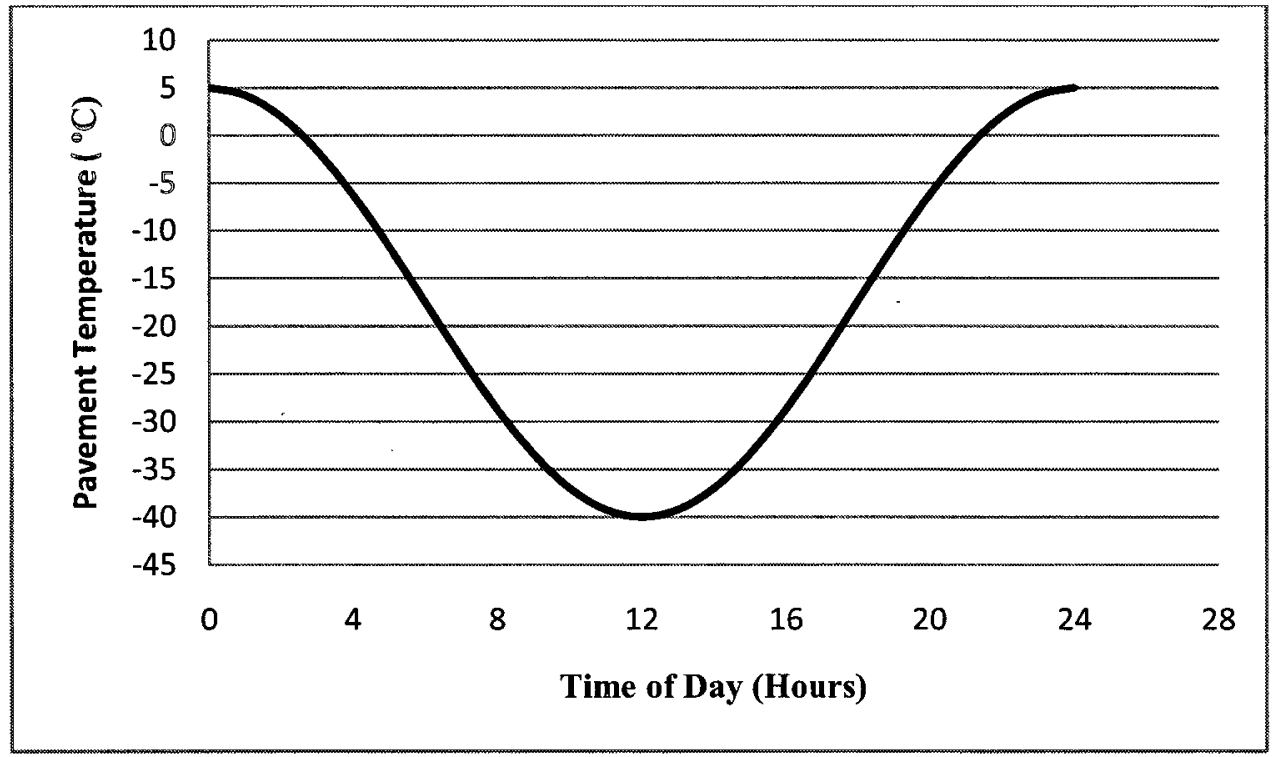

Figure 5.3 Daily asphalt layer surface temperatures

(Easa et al, 1996)

For the $-40{ }^{\circ} \mathrm{C}$ example the maximum change in temperature can be as high as $45^{\circ} \mathrm{C}$ between time 0 hour and $12: 00$ or $3.75{ }^{\circ} \mathrm{C}$ per hour. The temperature drop $T_{r}$ is then divided into (n) equal intervals each of length $\Delta \mathrm{T}$. The mixture stiffness at the midpoints of each interval $i$, is then computed and the accumulated stresses are found by summing 
on all intervals during a loading cycle, as the following (Hills and Brien, 1966):

accumulated stresses $=\sum_{i=1}^{K} \alpha S_{m i x}\left(T_{i}, t\right) \Delta T$.

Where

$\mathrm{T} i=$ midpoint temperature of interval $i ; \mathrm{S}_{\operatorname{mix}}\left(\mathrm{T}_{\mathrm{i}}, \mathrm{t}\right)=$ mixture stiffness at $\mathrm{T}$, and loading time $\mathrm{t}$; and $\Delta \mathrm{T}=$ temperature interval.

One of the important assumptions in treating the thermal stresses generated in the asphalt pavement is that the boundary conditions must follow a fully bonded case between the top asphalt layer and the one immediately underneath it. Only, when the bond is fully mobilized between the two layers thermal stresses will be generated. Equation 5.11 is presented in Figure 5.4, the figure illustrates that as the temperature of the $\mathrm{AC}$ mix decreases the accumulated stresses increases, given a fully bonded structure. Furthermore, from Equation 5.1 and according to Lunardini, (1985) the temperature increases along the depth of the asphalt pavement layer. Thus, the tensile stresses are supposed to be much higher at the top layer of the pavement than the lower layers. This should give thermal cracks the motivation to be initiated from the top surface of the pavement layer and propagated to the bottom. Moreover, during construction, bottom asphalt pavement layer temperature will be higher than the surface temperature due to the exposure of the surface layer to the weather temperature which is much less than the AC mix temperature, therefore the cracks should be initiated from the top layer of the asphalt pavement and extend to the bottom. However, it will be seen that, these cracks should be observed only if the tensile stresses causing pavement rupture are lower than the bond 
resistance between the asphalt pavement layer and the underneath layer, at the same time the induced stresses should be higher than the pavement tensile strength.

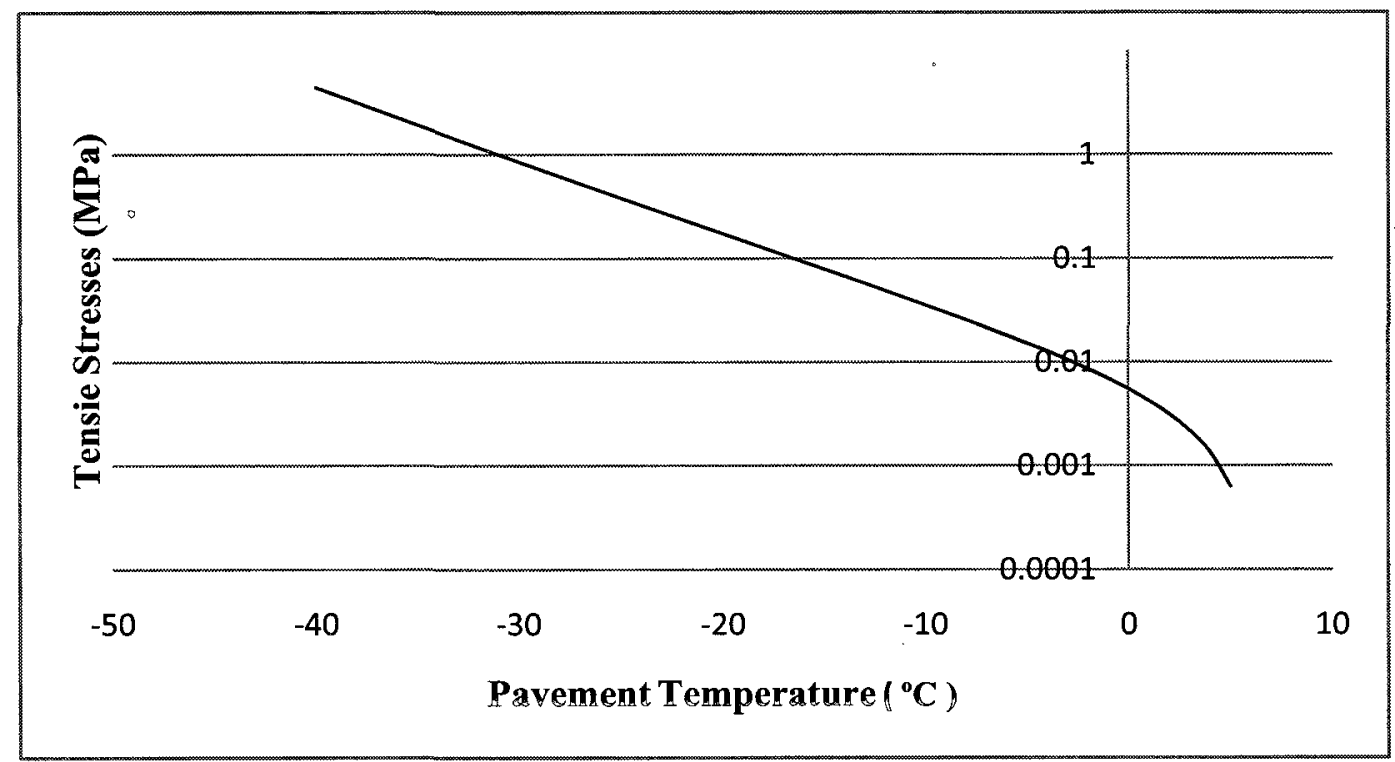

Figure 5.4 Relationship between the tensile stresses and the mix temperature

\subsubsection{Tensile Strength of the Asphalt Pavement Layer}

Literature indicates that the tensile strength is a function of temperature while it increases with decreasing temperature till it reaches a peak value. After that value any decrease in the temperature will cause a decrease in the tensile strength (Vinson et al., 1989). The values for the tensile strength were measured by the indirect tensile test method at different temperatures (Kim and El Hussein, 1995). Regression analysis was utilized to find the relation between the values of the tensile strength of the asphalt pavement and the temperature. In this relation the tensile strength of the asphalt pavement is equal to: $r_{0}+r_{1} T+r_{2} T^{2}+r_{3} T^{3}+r_{4} T^{4}+r_{5} T^{5}+r_{6} T^{6}$ 
with $\mathrm{R}^{2}=0.98$, and where $\mathrm{r}_{0}, \mathrm{r}_{1}, \ldots, \mathrm{r}_{6}=$ regression coefficients estimated by method of least squares to be as the following:

$r_{0}=0.743844, r_{1}=0.221589, r_{2}=0.034331, r_{3}=0.001386, r_{4}=2.57 \mathrm{E}-05, r_{5}=2.68 \mathrm{E}-07$,

$\mathrm{r}_{6}=1.41 \mathrm{E}-09$

The relation between the tensile strength and the temperature of the asphalt pavement is then applied to predict the cracking temperature as discussed in the following section.

\subsubsection{Top-Down Cracks Potential}

Asphalt pavement is composed of asphalt pavement layer which consists of two layers, surface wearing course, and the bonding course. The wearing course transfers traffic loads to the undemeath basecourse layer through the bonding course. The bonding course works as a binder between the wearing course and the underneath layer by penetrating the voids of the basecourse or the subbase. The material used, the bearing strength of the underneath layer, and the intended use, are the factors controlling the thickness of the wearing and bonding course.

Due to drop in temperature the contraction stresses will be generated along the asphalt pavement layer, however the only situation that will increase thermal contraction stresses is that when the generated tensile stresses is lower than the bond resistance between the bonding course of the asphalt pavement layer and the subbase or the basecourse material.

Under the assumption that the asphalt concrete is fully bonded to the underneath sublayer and has infinite length, the bond resistance will work as a constrained to the pavement section, encouraging more stresses to be generated. Hills, (1966) stated that the 
crack will appear in the surface layer when the tensile strength of the restrained asphalt pavement is not able to handle any more thermal generated tensile stresses.

Typical values for thermal and mechanical properties of asphalt pavement are provided in Table 5.1. Data are obtained from the literature (Shalaby, 1997), and utilized to present the tensile stresses and the tensile strength models which were discussed in the aforementioned sections as shown in Figure 5.5. From the figure it is noticed that, as the temperature starts to decrease, the tensile strength of the $\mathrm{AC}$ mix will resist the generated stresses and prevent the occurrence of surface cracks. If the temperature continues to decrease, it will reach the cracking temperature, at this temperature the tensile stresses is equal to the pavement tensile strength, point (A) in Figure 5.5. As the thermal stresses increases beyond this point the pavement material tensile strength will no longer resist these stresses and rupture is expected to occur to the asphalt surface material. At any temperature higher than the cracking temperature, the tensile strength of the asphalt material is often higher than the induced thermal stresses.

Table 5.1 Main input parameters

\begin{tabular}{|l|l|}
\hline Variable & Value \\
\hline Loading time & $10 \mathrm{~s}$ \\
\hline $\begin{array}{l}\text { Maximum tensile strength of the } \\
\text { asphalt pavement layer, } \mathrm{H}_{\max }\end{array}$ & $2.4 \mathrm{MPa}$ \\
\hline Coefficient of thermal contraction, $\alpha$ & $0.000014 /{ }^{\circ} \mathrm{C}$ \\
\hline $\begin{array}{l}\text { Temperature of the penetration test, } \\
\text { TPT }\end{array}$ & $24.0^{\circ} \mathrm{C}$ \\
\hline Softening point, $\mathrm{T}_{\mathrm{R} \& \mathrm{~B}}$ & $50.0^{\circ} \mathrm{C}$ \\
\hline Air voids & $7.50 \%$ \\
\hline Retained penetration after TFOT & $47 \%$ \\
\hline $\begin{array}{l}\text { Young's modulus of asphalt } \\
\text { pavement }\end{array}$ & $2500 \mathrm{MPa}$ \\
\hline
\end{tabular}




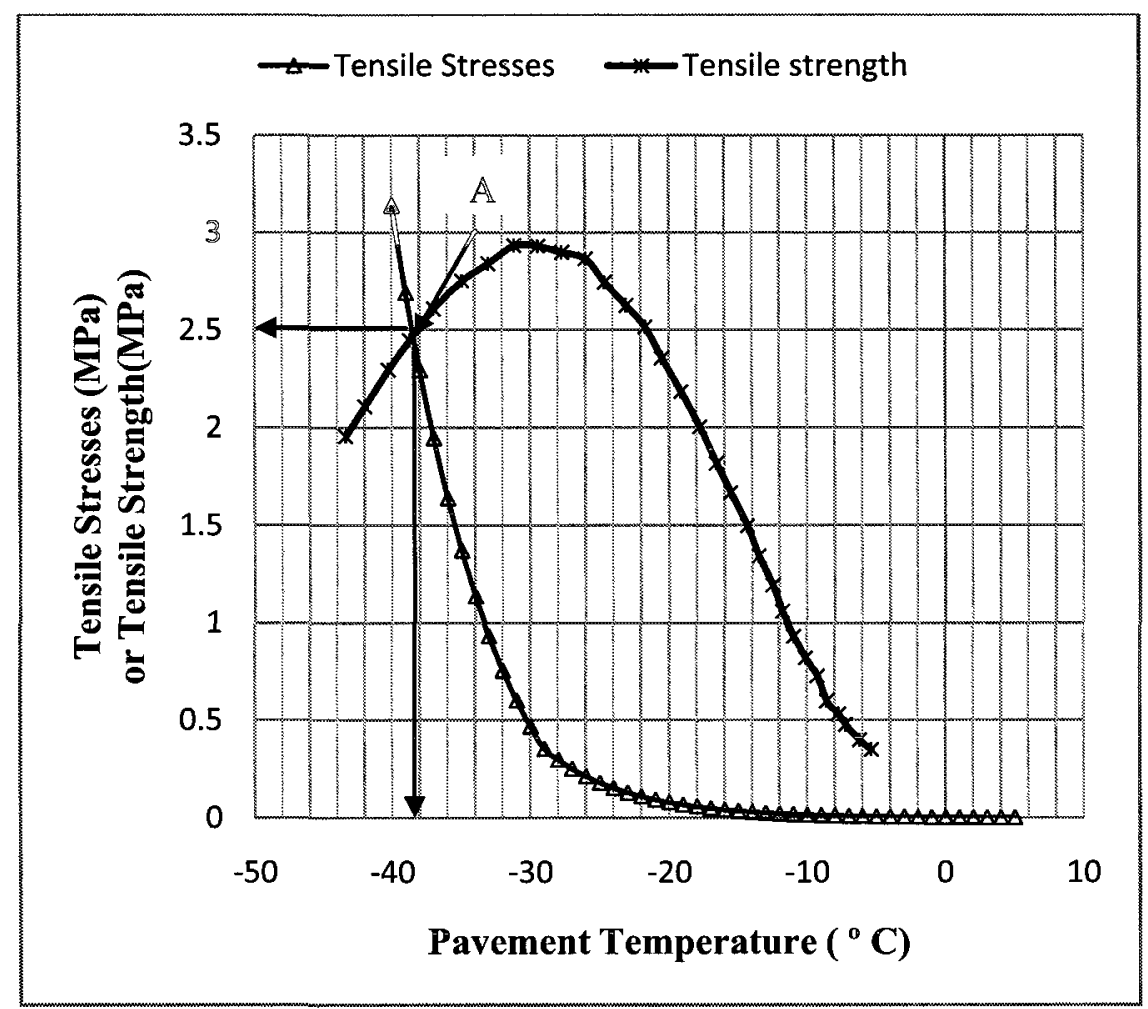

Figure 5.5 Cracking temperature: when tensile stresses is equal to the asphalt pavement tensile strength

The assumption that the asphalt concrete surface is fully bonded to the underneath layer and has infinite length is not realistic. Defects in the asphalt pavement layer, construction joints, and existing cracks are considered to act as free edge boundary condition. The free edge will affect thermal stresses development since it has the potential to change the stresses state along the length of the pavement under different bonding conditions. At the beginning, thermal stresses will cause deformation to the asphalt layer; this deformation will be resisted by the bonding resistance along the length of the asphalt pavement. Since the bond resistance equal zero at the free edge, the asphalt pavement section will deform at this point. The deformation will decrease along the asphalt pavement so that at some location the bonding resistance will be adequate to counteract the thermal deformation. 
At this location thermal stresses will be balanced with the bond resistance, point (A) in Figure 5.6. This location is assumed to be a fixed end condition on the underneath layer, which definitely represent the infinitely extending of the undemeath layer in the horizontal direction. The thermal stresses shown in Figure 5.6 represent part of the stresses which will be balanced by the incremental value of the bond resistance and is expressed by the following equation (Marasteanu, et al., 2004).

$\sigma_{\mathbf{x}}=\mathbf{E \alpha} \Delta \mathbf{T}-\mathbf{f}_{\mathrm{s}} \mathbf{x}$

Where: $\mathrm{x}=$ distance from point $(\mathrm{A})$ in the figure

$\mathrm{E}=$ Young's modulus $(\mathrm{MPa})$

$\alpha=$ coefficient of thermal contraction $\left(/{ }^{\circ} \mathrm{C}\right)$

$\Delta \mathrm{T}=$ temperature change $\left({ }^{\circ} \mathrm{C}\right)$

$\mathrm{f}_{\mathrm{s}}=$ frictional sliding force per length $(\mathrm{N} / \mathrm{mm})$

In Figure 5.6 it is shown that the development in thermal stresses resisted by the bond resistance starts from the free edge and increases linearly to the maximum stress value at the fixed end. The drop in temperature control the amount of the maximum stresses, while fractional properties of the underneath layer control the rate of increasing the thermal stresses.

The bond resistance will start to increase along the length of the asphalt pavement under the effect of thermal stresses, starting from the free edge till it reaches its maximum value at point (A). At that point the bond resistance will be balanced with the thermal stresses. Since the thermal stresses is constant under specific drop in the temperature, then, at any point before point (A) part of the thermal stresses which will not be resisted by the bond resistance will affect on the tensile strength of the asphalt pavement. The 


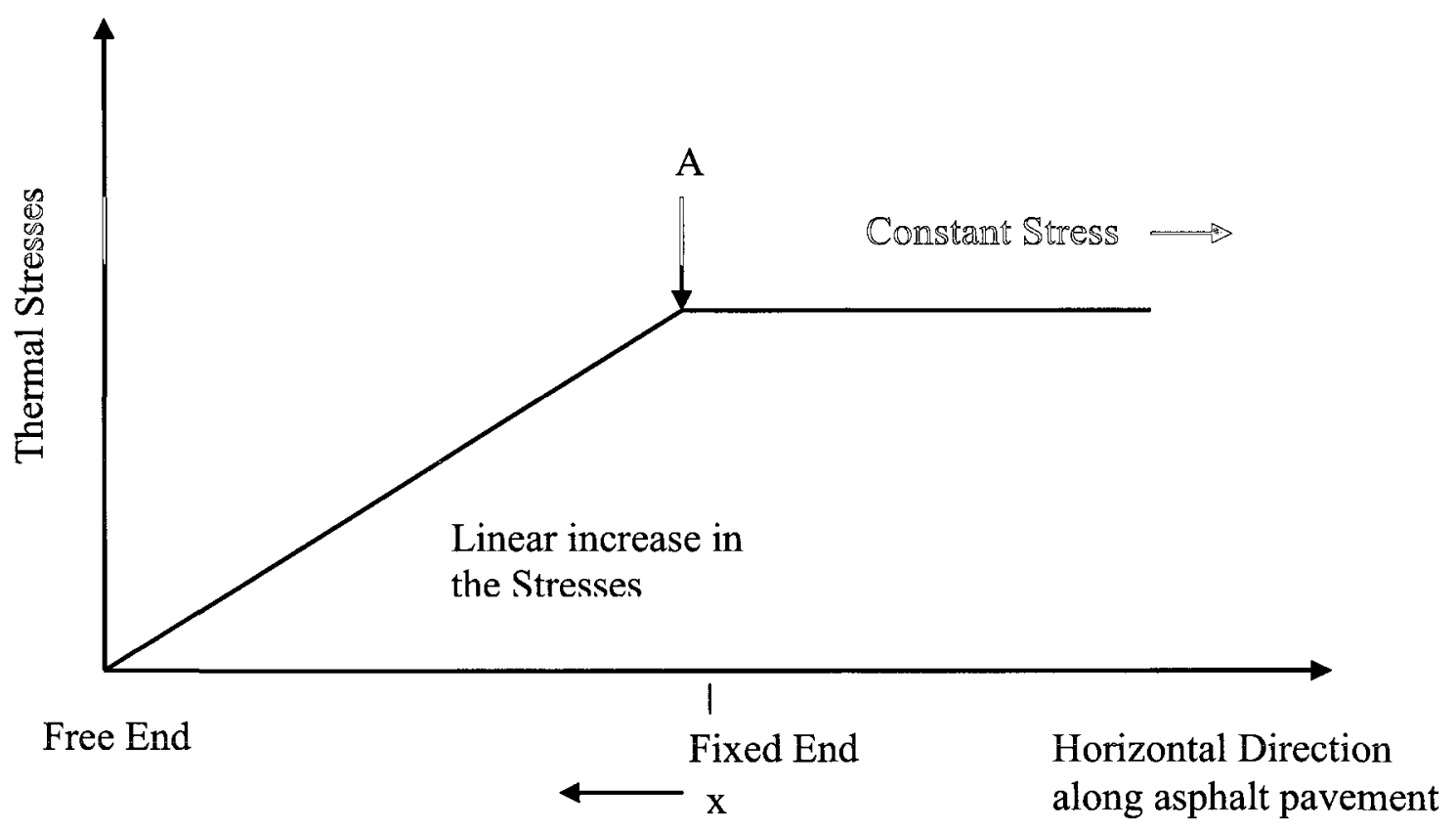

Figure 5.6 Development in the thermal stresses

tensile strength of the asphalt pavement depends in the drop of the temperature too. For the same drop in temperature, if the tensile strength was less than the amount of tensile stresses that is not resisted by the bond resistance, cracks will occur; otherwise the tensile strength will resist the thermal stresses, preventing the occurrence of thermal cracks.

In the above analysis the cracking temperature occurred when both the thermal tensile stresses and the tensile strength of the asphalt pavement reach a value of approximately $2.5 \mathrm{MPa}$. The cracking temperature was about $-38^{\circ} \mathrm{C}$ as shown in Figure 5.5. That means, for the crack to occur the calculated bond resistance between the asphalt pavement and the underneath layer should reach to a value bigger than or equal to the value of $2.5 \mathrm{MPa}$. Less bond resistance will work as if there is not enough constrains to the pavement structure. If the bond resistance is small enough to resist the generated stresses, the pavement will expand and the generated tensile stresses will be balanced 
with the available bond resistance. In the case the generated tensile stresses were lower than the tensile strength then the pavement surface should not experience any cracks.

Considering the drop in temperature in the above amalysis between $+5^{\circ} \mathrm{C}$ and -38 ${ }^{\circ} \mathrm{C}$ which is $-43{ }^{\circ} \mathrm{C}$, then according to equation 5.13 and using the data in table 5.1, the maximum bond resistance which is equal to $\mathrm{E} \alpha \Delta \mathrm{T}$, equation 5.13 , was found to be (1.5 $\mathrm{MPa}$ ). It is shown that the stresses at the cracking temperature are higher than the maximum value of the bond resistance at the same temperature as shown in Figure 5.7.

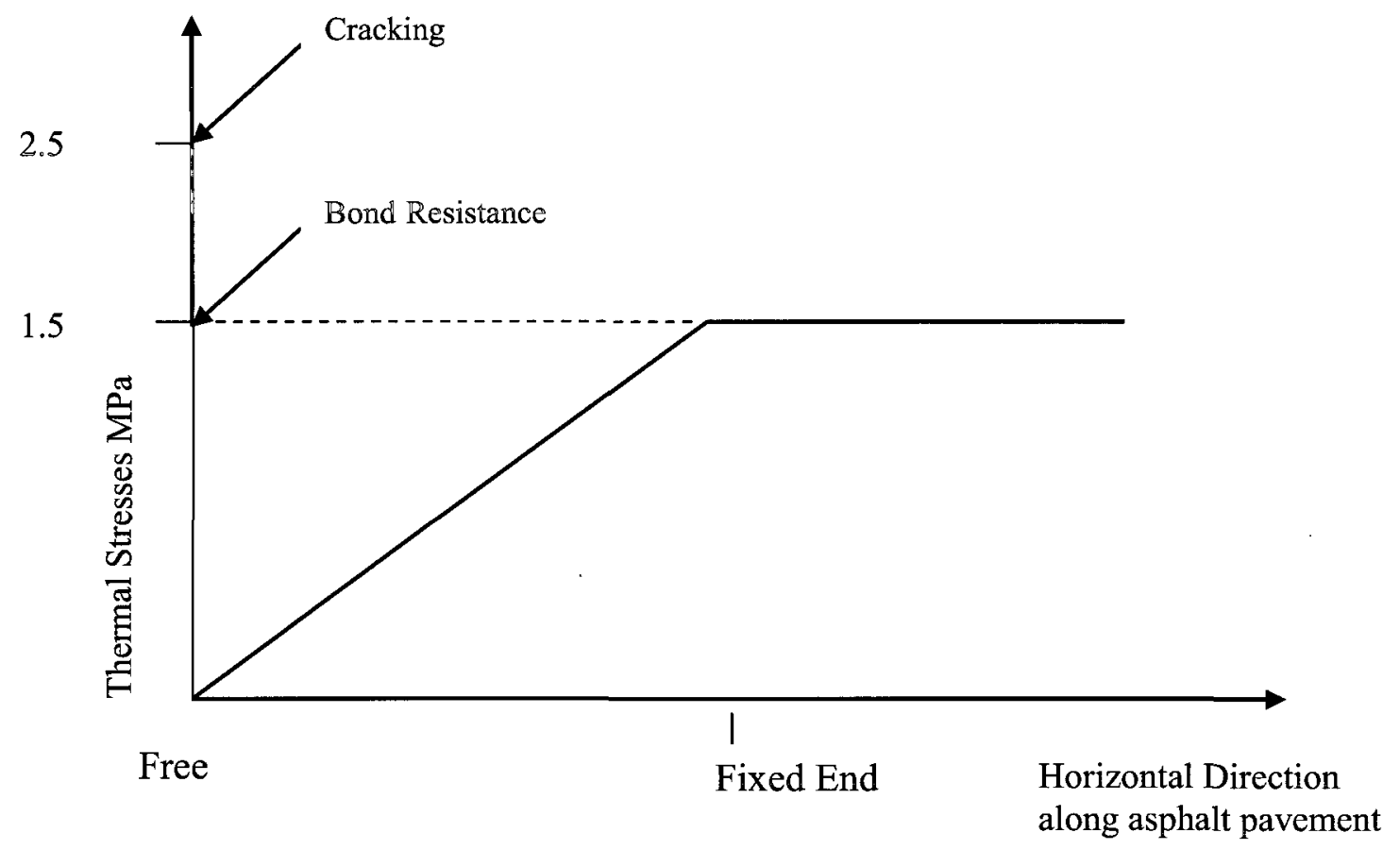

Figure 5.7 Bond resistance and cracking stresses

Moreover, Raab, C. and, Partl, M. N, (2009), conduct a long term performance study of bonding properties of binder, base and subbase asphalt concrete layers, by measuring the 
maximum shear force values after construction and the maximum shear force values after about 10 years later. In case of the values immediately after construction all points were mean values of at least seven specimens. They concluded that shear force between the layers ranges between $10 \mathrm{kN}$ and $35 \mathrm{kN}$ from which the shear strength was calculated to be $0.50 \mathrm{MPa}$ to $2.3 \mathrm{MPa}$, considering the diameter for the core that went under test to be $150 \mathrm{~mm}$.

The bond resistance between the asphalt layers interface was also investigated by Wheat, (2007) who studied the shear strength of asphalt to asphalt interface when shear and normal forces are acting on core specimen at the same time. The normal load was applied to represent the vehicle load when it rolls on the asphalt pavement, also considering the normal load results in more shear resistance to be expected. The core samples were obtained from pavement layers built with conventional methods. The core samples were tested in the lab. Wheat, (2007) applied different rate of tack coat between the asphalt layers. The experimental work done suggested that the shear strength between the interfaces is not affected by the tack coat application rate. It was concluded that the bond resistance between the asphalt layers was ranging between 0.105 and $0.109 \mathrm{MPa}$. The bonding between the asphalt layer and the base layer is expected to be higher than the bond between the asphalt layers as was revealed by Ziari and Khabiri (2007) who reported that the bonding between the asphalt layer and the base layer is more effective in handling the stresses than the bond between the asphalt layers.

It is seen that the bond resistance was lower than the tensile stresses for most of the time which was found to be $2.5 \mathrm{MPa}$ in the typical numerical example as shown in Figure 5.5, when the fracture temperature is reached. This observation means that the 
tensile stresses will be balanced with the bond resistance causing a free expansion to the asphalt layer before it reaches the cracking point and no cracks will appear. That could bring us to conclude that thermal stresses are not considered as a main factor for the initiation of TDC. Moreover, based on field observations reported by Abd El Halim, (1994) on typical cracked sections in Ottawa region, it was revealed that the spacing between each subsequent transverse cracks is less than the width of the pavement section. However no thermal crack was observed in the longitudinal direction as shown in Figure 5.8. It is important to notice that the longitudinal crack appear in the figure still does not present thermal cracks, while the width of the lateral two pavement sections is still larger than the length of the generated short slabs. Furthermore, the longitudinal crack appeared in the figure to be adjacent to the middle line between the two lanes, which means that it is not located in the wheelpath area. This longitudinal crack could be explained as a cause of the construction process. It might be the construction joint between two lanes.

These results of comparing model predictions and the analytical observations of transverse thermal cracking showed that, analytical models failed to explain the main cause of thermal transverse cracking. The appearance of the cracks in the transverse direction cannot be explained as a cause of thermal induced stresses. The study done in Chapter three showed that the cracks have been initiated at an earlier stage as a compaction induced cracks as shown in Figure 5.9. After the crack initiation, the tensile strength of the asphalt layer is supposed to be decreased. At this point the cracking temperature should be much less than the one studied in the previous numerical example. Moreover the bond resistance between the asphalt layer and the underneath supporting layer will be sufficient enough so that thermal stresses will act to propagate the already 


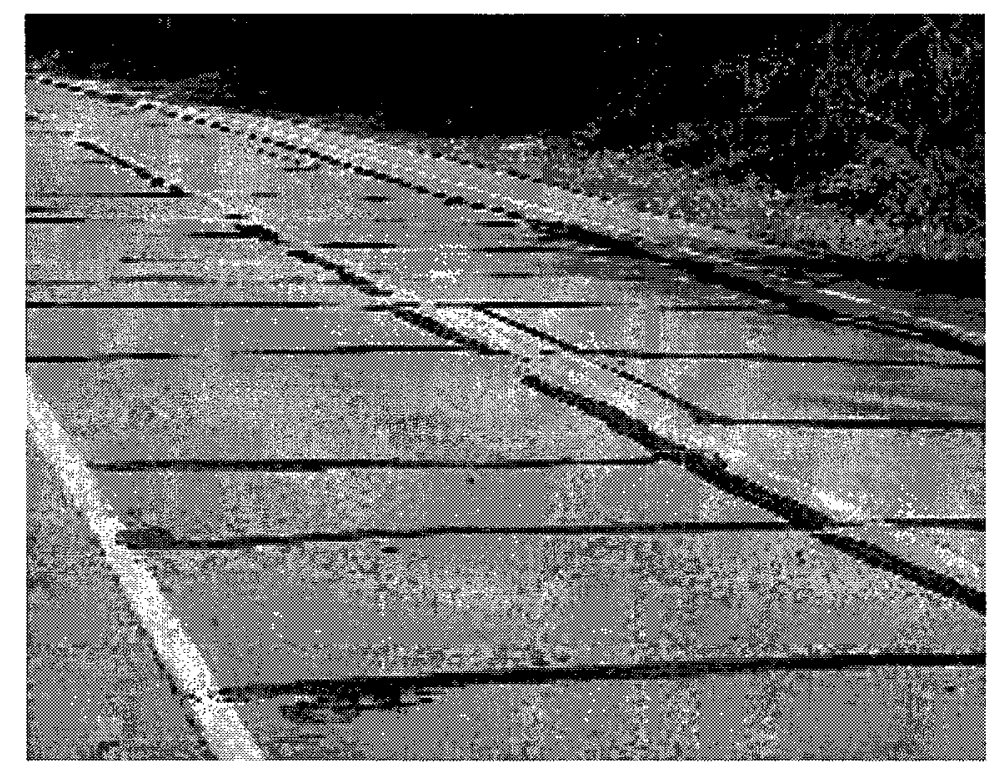

Figure 5.8 Spacing between transverse cracks is less than the width of the pavement section (Kercher Engineering, Inc)
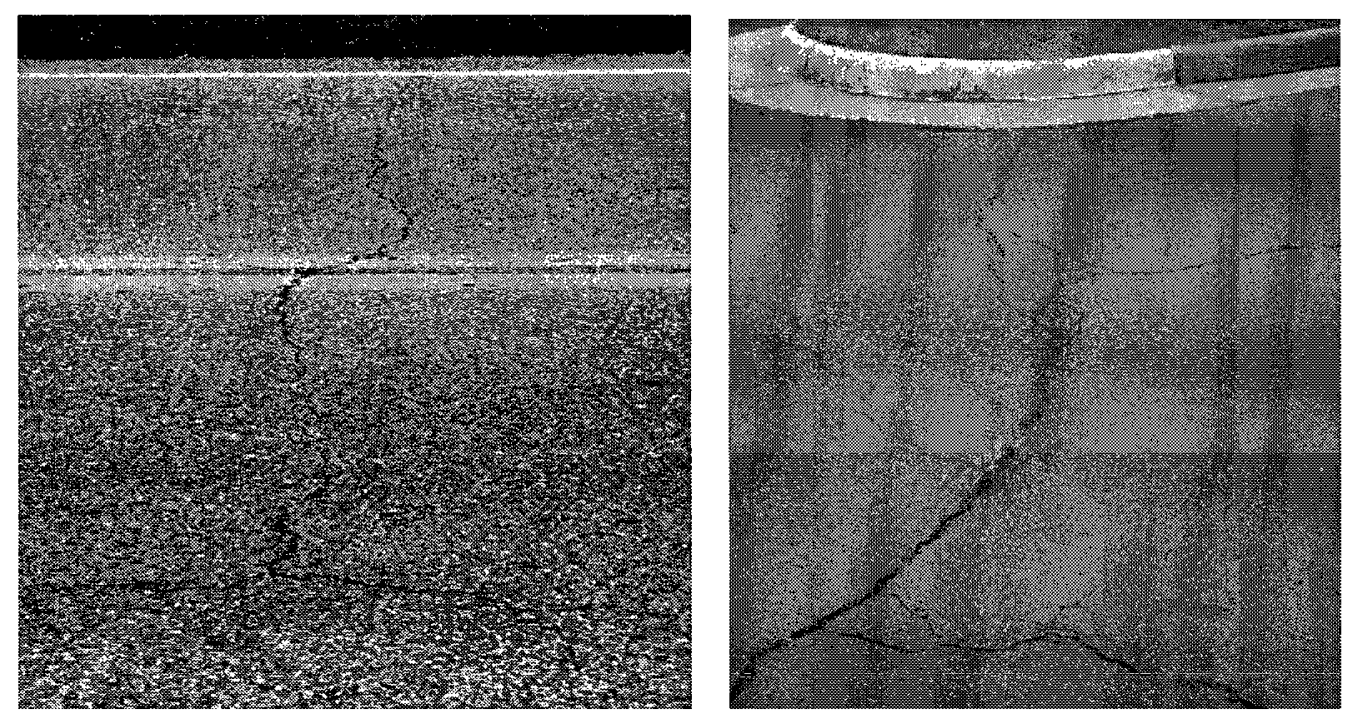

Figure 5.9 Cracks have been initiated at an earlier stage as a compaction induced cracks (EZ Asphalt Technology)

initiated cracks as shown in Figure 5.10. Those cracks were supposed to be the main contributor to transverse cracks phenomena. It could be concluded that, according to Abd 
El Halim (1985 to 1988), the crack initiation in the asphalt pavement layer was based in the concept of the relative rigidity, it was explained earlier how these cracks are initiated in new asphalt pavement layers during compaction at a high temperature.
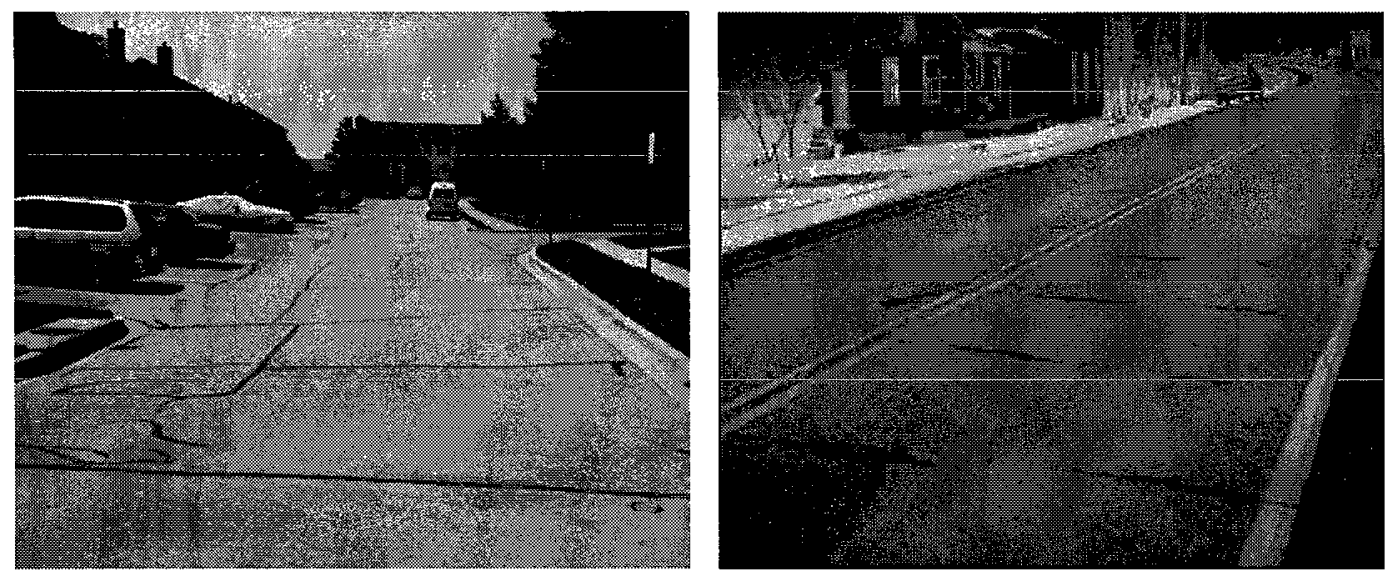

Figure 5.10 Thermal stresses will act to propagate the already initiated cracks (EZ Asphailt Technology)

Guylain and Claude, (1999) stated that the frequency of low temperature cracks is usually greater for pavements constructed on sand subgrades than on cohesive subgrades. They explain that as the sand subgrades will provide lower bond resistance than the cohesive subgrades due to the lower friction factor between the asphalt concrete surface and the sand material. However the sand surface will not provide a restrained boundary condition to the asphalt pavement. In this case the pavement layer will be free to expand and hence to relax the accumulated thermal stresses. Therefore the bond resistant will not be enough to build up thermal stresses and cracks should not appear. These observations again suggest that the cause of these cracks is not thermal stresses and leads us to the other explanation of the main cause of these surface cracks. The fact that the sand is uncompressible material which has high stiffness than tradition subbase material and 
according to the method of relative rigidity produced by Abd El Halim, (1985 to 1988), an explanation for the surface cracks could be due to high stiffness in the subbase material.

Kandhal, et al., (1996) evaluate low temperature cracking in Pennsylvania project in U.S. The research project consisted of $38 \mathrm{~mm}$ resurfacing of the existing asphalt pavement in September. Kandhal reported that transverse cracking was developed in January (after 4 months). According to the recorded data, rapid cooling caused cracking to the tested pavement. The lowest air temperature was recorded to be $-29^{\circ} \mathrm{C}$. According to Figure 5.5, at temperature of $-29^{\circ} \mathrm{C}$ the pavement stiffens is still higher than the thermal induced tensile stresses and cracks should not occur. However, the occurrence of the cracks could be explained due to low value of the asphalt pavement tensile strength. The initiated cracks during the compaction stage could also be explained as the main cause of weakling the asphalt stiffness and keep it borne to cracks under thermal stresses.

\subsection{Load Induced Tensile Stress}

According to some researchers, like Svasdisant et al., (2001), it was hypothesized that the load induced by the traffic which is presented by the wheel load is the main cause of TDC; they studied the deflection in the pavement as a response to the load. Field tests conducted showed that moving away from the centre of the loaded area will cause a decrease in the deflection. The area which is beneath the tire experienced tension in the bottom fiber of the AC and compression in the top fiber. Svasdisant et al., (2001) explained the occurrence of the longitudinal cracks in a parallel position to the wheel path because of the negative curvature just outside the wheelpaths, which is an indication for 
tension stresses at the top of the AC surface as illustrated in Figure 5.11. According to these findings Svasdisant et al., (2001) confirmed that whenever the pavement is subject

\section{Horizontal distance from the center of the wheel $(\mathrm{cm})$}

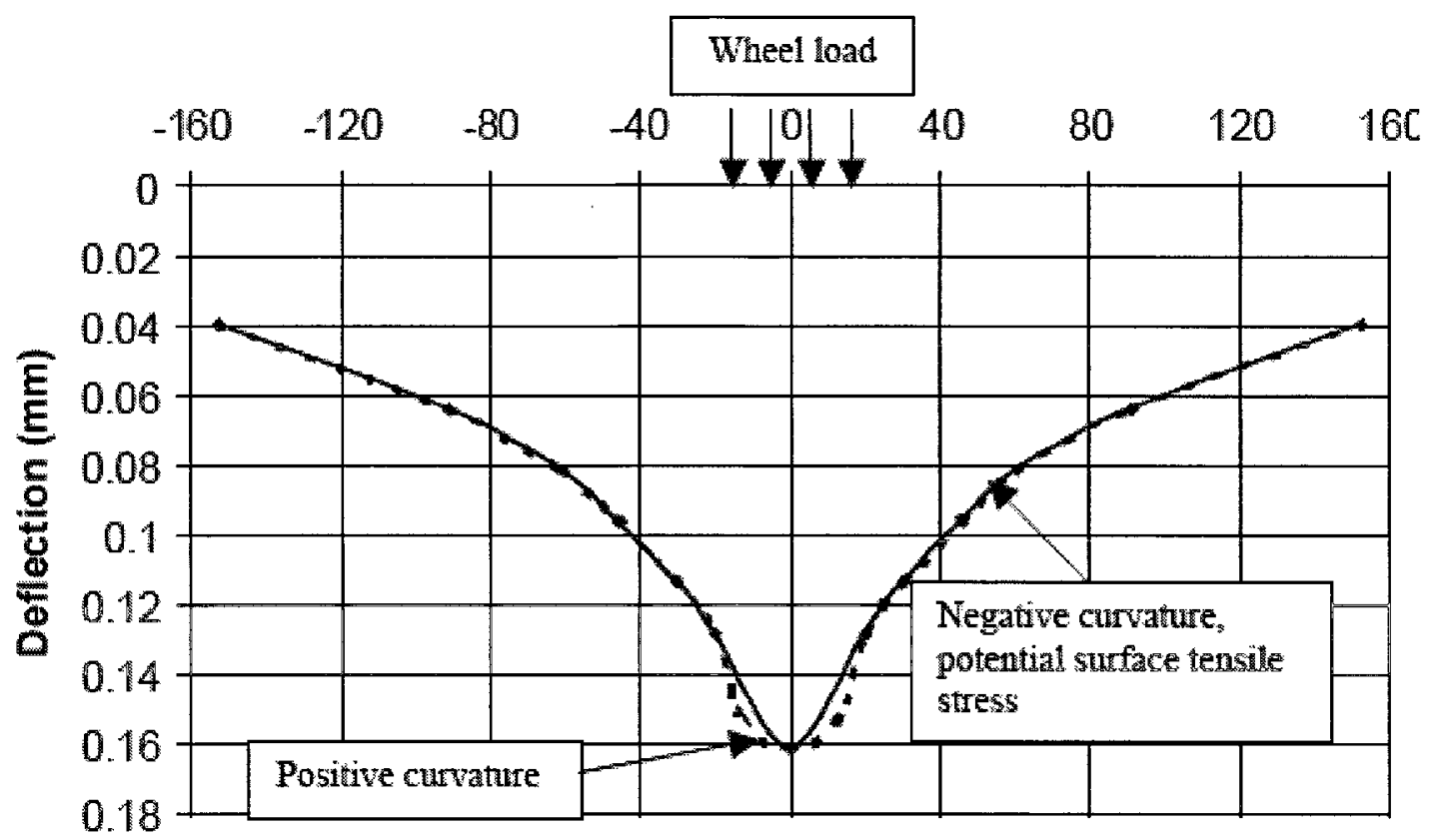

Figure 5.11 An indication for tensile stresses at the top of the AC surface (Svasdisant et al., 2001)

to wheel load it will experience radial tensile stress at the AC surface in the same direction of traffic movement.

Practically the pavement surface will be exposed to wheel load just after the pavement is opened to traffic, that mean immediately after the compaction process. In this stage the asphalt pavement is getting harder and the stiffness is increased and it is ready to accommodate the expected traffic loads. As it is well known, during the construction of the asphalt pavement the last two stages before the road is opened to traffic is the compaction process which is a number of passes by the conventional steel 
drum roller followed by the pneumatic roller. The load induced by both the steel roller and the pneumatic roller is much higher than the load which will be induced by the traffic load when the road is opened to service. Therefore, assuming that the hypotheses reported by Svasdisant et al., (2001) is true, (i.e. the wheel load induces tensile stresses just adjacent to the wheelpath). Then the rollers are supposed to provide much more load and deflection on the asphalt pavement than the traffic load. Hence the negative curvature should appear in the top surface of the pavement layer during the compaction process due to the pressure induced by either of the rollers. This load is supposed to cause large magnitude of the tensile stresses at the top surface. However, it was presented in the literature (Matsuno and Nishizawa 1992; Nunn 1998), that longitudinal TDC which is caused due to the induced tensile stresses does not appear during or right after the compaction process, but after some years from opening the pavement to traffic. From the presented discussion it is obvious that traffic load which is applied on the surface of the asphalt pavement is not a reasonable cause for the occurrence of longitudinal TDC, since the load induced from the roller at the end of the compaction process in much higher than the load induced from the traffic load.

It was also reported by Schorsch, (2003) that the potential for cracking due to tensile stresses is dependent on the relation between the applied stress and the tensile strength of the asphalt pavement which is called the stress ratio. High stress ratio causes a decrease in the fatigue life and hence TDC potential. It appeared from the field tests which were conducted by Schorsch, (2003) on measuring the maximum load induced surface tensile stresses, that, some tested sites have no TDC, and other sites experienced longitudinal TDC. The cracks were located at a distance very close to the centre of the 
wheel paths. This approach contradict the mechanistic analysis conducted by Svasdisant et al., (2001) who stated that the load induced by the traffic which act on the area beneath the tire gemerate tension in the bottom fiber of the $\mathrm{AC}$ and compression in the top fiber. The compression zone in the top fiber prevents the occurrence of tensile stresses as stated by Schorsch, (2003). The reason was justified by Schorsch, (2003) as there are other combination of factors that causes these cracks and it is not load related. He attributed these factors to the tensile stresses due to temperature expansion, or due to aging. But yet the cracks occurs at the pavement surface due to thermal tensile stresses, as was discussed earlier, have been seen on the pavement surface as transverse cracks, and it does not appear in the longitudinal direction. This issue can be explained by the fact that other causes like the compaction problems could be the major reason of these TDC.

From a study done by Rolt et al., (1986) who conducted a number of field tests on selected sections of a main route, it has been reported that although the traffic load on one route was much larger than the traffic on the other route, but the degree of cracking on both sides of the road was partially identical. The results of his analysis show that fatigue resistance of the pavement layer did not depend on the deflection induced from the traffic load, but the behaviour of the asphalt layer which influence the fatigue resistance depends on the mix characteristic, such as the air voids, density, and the binder content and as was discussed earlier, any deficiencies in these properties are related to poor compaction problems Svasdisant et al., (2001).

From the previous discussion it is concluded that the load induced due to the contact between the wheel and the pavement cannot be considered as a major factor that could cause the initiation of TDC. 


\subsection{Compaction Process}

Understanding the mechanism of how the asphalt material binds the granular particles after been reoriented during the compaction process is considered as a key for analyzing these TDCs causes under compaction factor (Rickards et al., 1999).

The HMA is prepared at an asphalt mixing facility; the asphalt binder is heated to allow sufficient fluidity to coat the aggregate. The aggregate should be heated too to minimize the air voids in the mix. HMA depends on the graduation of the aggregate and the grade of the asphalt cement. After the process in the mixing facility the mix conveyed to the site by trucks and then disposed into pavers, the later spreads the material over the roadway, the asphalt paver which is equipped with a vibratory screed initiates the compaction process during the lay down phase, prior to the use of the steel, pneumatic or vibratory rollers. In order to allow proper compaction the material should be fluid enough to flow between the aggregate particles and that could be achieved by controlling the material temperature between $85^{\circ} \mathrm{C}$ and $150^{\circ} \mathrm{C}$ (Rickards et al., 1999).

Considering the case of granular layer like the basecourse or the subbase layers as to compare between different methods of compaction, the aggregate material is mixed with the optimum water content and air, which is required for a high dens mix. High density is also achieved by reorienting the aggregate particles to make them as close to each other as possible, that could be achieved by applying the steel drum roller over the base layer. Because the water is a low-viscosity binder, it will flow easily between the aggregate particles leaving no voids in the mix. While the viscosity of the water is low, therefore the steel compactor will be sufficient enough to provide the required load on the 
mix in a short contact time to achieve the desired density. For high density more than one pass is required in most cases (Lauter, 1998; Rickards et al., 1999).

\section{In the case of bitumimous material that is used as an asplhalt binder, it has specific} viscoelastic proprieties which are dependent on temperature, the amount of the applied load, and the time taken by that load over the compacted part. Which means under low temperature becomes stiffer, and the mix can no longer be compacted to the desired density level. As the temperature becomes lower the mix becomes more stiffer, therefore using the same compactor (the steel roller) which has been mentioned earlier for the same purpose with the existence of the bituminous material without any other consideration will provide short contact time which is not enough to allow the viscoelastic material to flow between the aggregate particles to achieve the desired density, instead the high pressure with the short contact time will increase the stiffness of the asphalt mix rapidly, (Asphalt Institute, 1989; Lauter, 1998; Rickards et al., 1999).

Even though the physical and mechanical characteristics of aggregate layers and asphalt concrete are extremely different, and the principle for each of the aforementioned process is different, however, in the asphalt industry the compaction equipment used to compact aggregate layers has subsequently been used for the compaction of asphalt pavement surfaces. That is why it has been reported in the literature that this compaction method is not suitable for the asphalt concrete mix and it will produce a poorly compacted layer with non-uniform aggregate gradation. Moreover it would damage the asphalt mix during the compaction process (Asphalt Institute, 1989; Lauter, 1998; Rickards et al., 1999). 


\section{Summary}

- This chapter revealed that many understandings lead a lot of researchers to suggest that load-induced tensile stresses and strain are not the sole cause of TDCs. The research study herein also was meant to examine some existing analytical models to predict thermal cracking of asphalt pavement which have been used in the literature over the past decades. These models were based on low temperature cracking and thermal fatigue cracking. The review was set to explain and predict thermal stresses and asphalt pavement tensile strength, to analyze the occurrence of thermal cracking phenomenon. The results of comparing model predictions and the analytical observations of transverse thermal cracking showed that analytical models failed to explain the main cause of thermal transverse cracking. Nevertheless, it seemed that the compaction method continues to be the most probable cause of TDC and thermal stresses act as a propagator to these initiated cracks.

- The literature review and work presented in the previous chapters showed that present approaches and theories determining the causes and mechanisms of top down cracks have serious deficiencies. The natural consequence of these deficiencies is that many of the recommended treatments and solutions failed to prevent the repeated occurrence of the observed phenomenon. For example, one of the main causes for the failure of suggested approaches is that most of the solutions were established on the assumption that the cracks seen on the surface would start at the bottom from the existing cracks in the rigid or older underlayer, and reflect upward. Another fallacy of the present techniques is the assumption that finished pavements are crack free and structurally sound, thus all the analyses were carried out on pavement structures 
opened to traffic. Another major contributor to the present problems facing the asphalt pavement industry has to do with the major weaknesses associated with the laboratory work that has been performed to date to simulate the problem in the labs which contains no cracks or defects at all within the bituminous overlay. As a result of these deficiencies most attempted field trails to prevent the top down cracking as well as the cracking problem in general have met very little success.

While the work presented in this thesis has discussed the actual reasons of the cracking problem facing asphalt engineers and managers, it is important to evaluate the effects of these cracks on both the structural and environmental functions. A well planned laboratory and field investigation was implemented to assess the effects of the top down cracks on the mechanical characteristics and properties of the asphalt layer. Also, a unique laboratory testing program was performed to evaluate the effects of these cracks on protective function of the asphalt layer to the environment. 


\section{CHAPTER SIX}

\section{Influence of Top-Down Cracks on the Integrity of Asphalt Concrete}

\section{Pavement}

\subsection{Introduction}

Construction of new asphalt pavement includes, among other operations, the placement and compaction of new hot asphalt mix. In these two operations, the loose asphalt mix is treated in a process where the aggregate particles are re-oriented to a more closely spaced arrangement reducing the percentage of air voids to reach a desirable density and tight surface texture. Improper placement and/or compaction will cause surface defects in the form of Top-Down Crack (TDC), which will reduce the density and increase the permeability of the asphalt layer (Abd El Halim and Haas, 1994).

During the Canadian winter seasons, highway authorities in many parts of Canada use salt on the pavements which act to melt the ice and hence improve the friction between the wheels and the road surface, thus enhancing the driving conditions and overall safety. The melting action of the salt, which softens the ice and helps forming a mix of salt and water, will promote the chemical interaction with the asphalt mix in the presence of TDC. TDC plays a major role in this interaction mechanism leading thawed ice on the road to drain through the asphalt surface, thus, polluting the underground layers. The contaminants carried by the melted ice may be one of the main factors that adversely affect the integrity of asphalt pavement as well as the environment around the road. 
Although, the addition of oil products into the asphalt concrete mix is required in order to achieve adhesive properties for the asphalt mixture, also most bitumen consist of natural oil (Katamine, 2000), however, the spilled oil from vehicle engine which is hydrocarbonbased material on the road could affect negatively the quality of the bitumen. When oil and its products infiltrate the asphalt pavement surfaces through TDC they attack the bond between the asphalt and the aggregate and may soften the bituminous material leading to stripping and raveling (Villanueva et al., 2008).

Therefore the main objectives of this Chapter are:

(1) Investigate the influence of TDC on the density, and permeability of the finished asphalt paved layers by performing laboratory tests on extracted asphalt pavement specimens from the field,

(2) Examine the chemical changes occurred in the properties of water passing through the tested specimens,

(3) Measure the percent of oil that may be absorbed by the specimen and that could seepage to the underneath layers,

(4) Determine the quantity of induced damage to the asphalt layer by determining the fragmented and the extracted materials from the specimen due to the effect of oil seepage through it, and

(5) Evaluate the effect of the TDC on the indirect tensile strength of the extracted asphalt specimens

A laboratory and field testing investigation was planned and performed in order to achieve these objectives. The laboratory testing program included the determination of the effects of TDCs on the physical and mechanical properties of the asphalt layer as well 
as the environmental conditions of the pavement structure. The field investigation dealt with actual measurements of permeability of the surface of the pavement. The following section provides the details of these teats.

\subsection{Laboratory and Field Investigations}

Thirty three AC specimens were selected for the lab testing. The selected specimens were recovered from two sets of asphalt cores. The first set consists of 18 specimens and were recovered from field sections in the city of Ottawa compacted using the conventional compaction method; steel vibratory roller followed by pneumatic multi-wheel roller. The surface of these specimens exhibited the known surface cracks induced during compaction as discussed in previous chapters of this thesis and were termed "cracked specimens" and labeled the symbol (SC). Figure 6.1 shows surfaces of two of these test specimens.

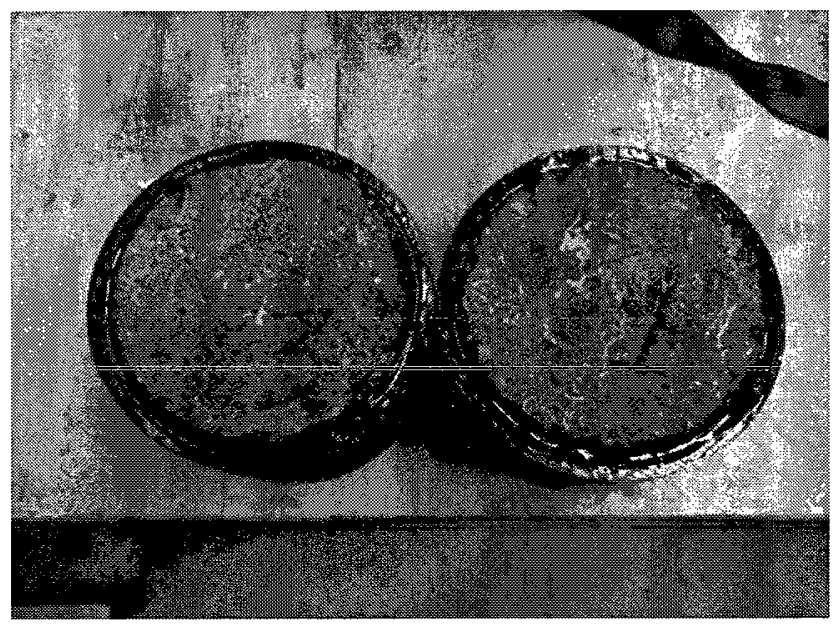

Figure 6.1 Cracked specimens (SC1\&SC3) 
The second set consists of 15 specimens and were recovered from a field site which was compacted using the newly developed AMIR compactor which prevents compaction induced cracks. These samples were used as reference specimens and were termed "Uncracked specimens" and labeled the symbol (ANC). Figure 6.2 shows a surface of one of these test specimens.

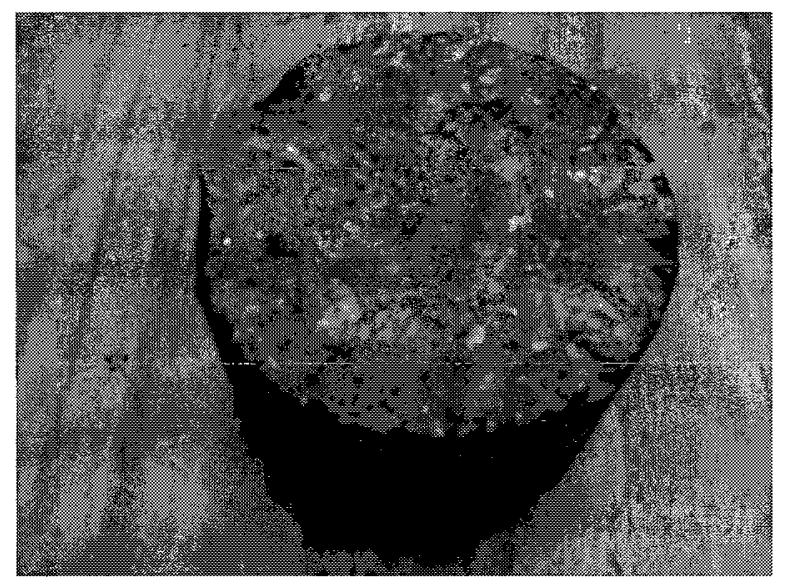

Figure 6.2 Reference un-cracked specimen

In order to assess the influence of TDC on the asphalt pavement structure, the test specimens were subjected to four laboratory tests as follows:

- Density test; this test method covers the determination of bulk specific gravity of specimens of compacted bituminous mixtures (ASTM D 2726).

- Permeability test; it is a procedure performed in the laboratory to determine the permeability of the asphalt pavement specimens. Field permeability test (Operation \& Maintenance Manual, 2004) was also conducted to perform a comparison between both methods.

- Water analysis test; this test was performed to measure any changes in the chemical and/or physical properties of the water used for the permeability test. And the test is 
carried out by measuring and analyzing the differences between the water properties before and after it passing through the tested specimens. The test results were used to investigate the influence of TDCs on the integrity of the constructed pavement.

- Investigating the effects of spilled oil on the asphalt pavement integrity by quantifying the amount of damage induced to the test specimens by measuring the extracted materials from the tested asphalt concrete specimens after the oil has passed through, the amount of oil absorbed by the asphalt specimen, and the effects on the strength of the asphalt concrete specimens by measuring the indirect tensile strength for the specimens.

\subsubsection{Specific Gravity Tests}

This test method covers the determination of the specific gravity and density of the specimens of compacted bituminous mixtures (ASTM D 2726). The test was applied on a number of the selected specimens to compare the effect of the two compaction methods on the density of the specimens as shown in Figure $6.3(a, b)$.

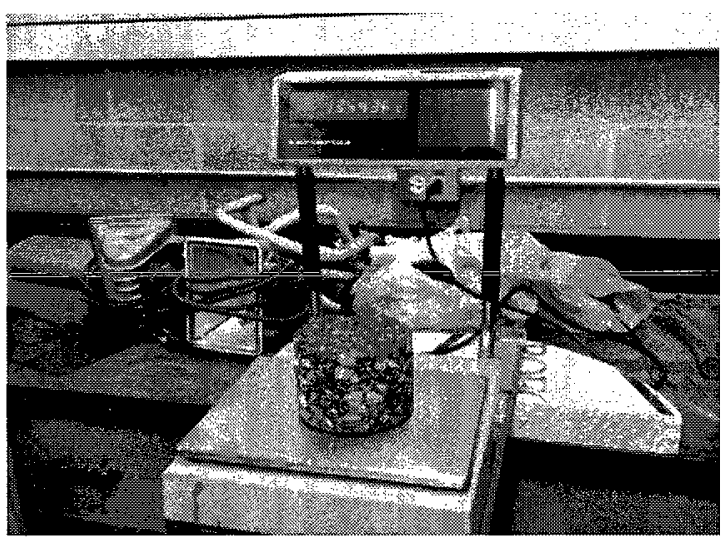

(a) Measuring the weight of the specimen for the dry and the saturated surface

dry case

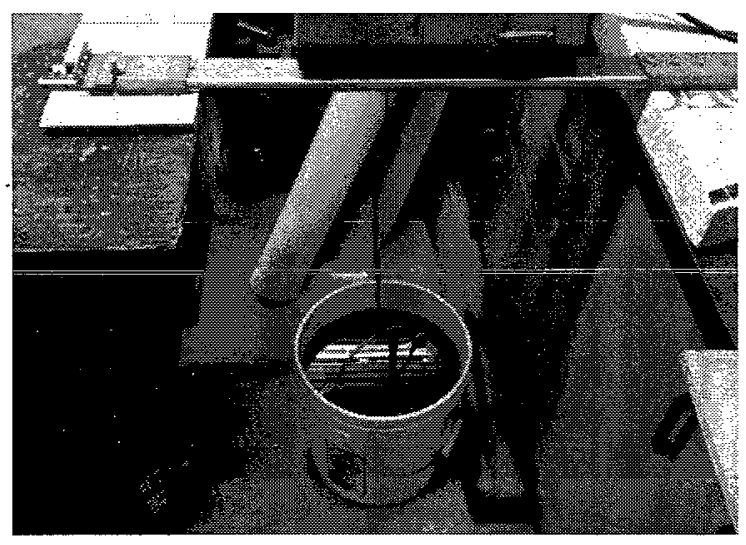

(b) Measuring the weight of the specimen immersed in water. 


\section{Figure 6.3}

- Results and Discussion of the Density Test

The results of the specific gravity tests that were conducted in the lab for six selected specimens are tabulated in Table 6.1.

Table 6.1 Results of the specific gravity tests

\begin{tabular}{|c|c|c|c|c|c|c|}
\hline Test number & 1 & 2 & 3 & 4 & 5 & 6 \\
\hline Sample description & $\mathrm{SC} 1$ & $\mathrm{SC} 2$ & $\mathrm{SC} 3$ & ANC5 & ANC6 & ANC7 \\
\hline $\begin{array}{l}\text { Dry weight in air } \\
\text { (Wd) } \mathrm{g}\end{array}$ & 1092.61 & 1116.41 & 1145.13 & 1354.15 & 1330.40 & 1342.3 \\
\hline $\begin{array}{l}\text { Sat. surf. Dry weight } \\
\text { (Ws) g }\end{array}$ & 1094.29 & 1119.09 & 1147.70 & 1354.24 & 1330.78 & 1342.5 \\
\hline $\begin{array}{l}\text { Weight in Water } \\
\text { (Ww) } g\end{array}$ & 614.99 & 624.38 & 641.06 & 795.95 & 784.47 & 790.21 \\
\hline $\begin{array}{l}\text { Bulk Specific Gravity } \\
=\left(\mathrm{Wd} /\left(\mathrm{W}_{\mathrm{S}}-\mathrm{W}_{\mathrm{w}}\right)\right) \\
\mathrm{g} / \mathrm{cm} 3\end{array}$ & 2.280 & 2.257 & 2.260 & 2.426 & 2.435 & 2.430 \\
\hline Standard deviation & 1.006 & 0.996 & 0.997 & 0.998 & 1.001 & 0.999 \\
\hline
\end{tabular}

The results revealed that the average density for the pavement cores compacted with conventional steel rollers which experienced TDC is $2.27 \mathrm{~g} / \mathrm{cm}^{3}$, while the average density for the reference specimens which have no surface cracks is $2.43 \mathrm{~g} / \mathrm{cm}^{3}$. It should be mentioned that the only difference between the two set of specimens was the compaction methods used in the field as reported by Svec and Abd El Halim, (1991). Therefore, one possible explanation of the measured difference of $7.0 \%$ is the effect of the top-down-cracks induced during the compaction operation. This shows that a higher density of the asphalt concrete specimen is achievable in the absence of TDC. 


\subsubsection{Permeability Test}

Permeability is the ability of water and air to pass through the surface of a finished asphalt mix, where the primary purpose of the asphalt layer is to prevent the water from penetrating its surface and help draining it off the pavement surface. Furthermore, the surface layer must have a tight texture in order to prevent the water from leaching through the asphalt pavement layer and destroying its structure. This will eliminate and/or prevent the interactions between the dissolved materials in the water with the asphalt components, consequently reducing the negative influence on the integrity of the road pavement (Kandil, 2002). Lab permeability test is a procedure performed in the laboratory to compare between the permeability of asphalt pavement specimens and was conducted in this thesis to quantify the effect of TDC on the measured permeability of the finished asphalt layer. The test results were used to determine the highest value of the permeability of the cracked specimen and compare it with that of the reference specimens. Field tests were also conducted to investigate the permeability of cracked and un-cracked pavement sections in the field and verify the laboratory findings.

Early filed and lab investigations were carried out by Mostafa (2005), to identify the significant factors that affect the permeability of asphalt concrete pavements.

Although the investigations were implemented to achieve different objectives than the research presented in this thesis, both investigations aimed to measure the permeability of two different pavement structures. One structure was cracked and the other was uncracked asphalt concrete pavement. The work done by Mostafa (2005), aimed to examine the relationship between permeability and asphalt mix characteristics in addition to developing relationships between the air voids content and permeability of the test 
pavement sections. The lab test was conducted on asphalt concrete slabs prepared in the lab while the field permeability tests were conducted and measured at different locations in Ottawa area that were compacted by steel drum or the AMIR compactor. The field permeameter was used as a falling head device to record the permeability of the asphalt concrete specimens in both cases. The previous work did not lend itself to the effects on the environmental question and the problems that may be caused by the surface cracks which were pioneered in this investigation.

\subsubsection{Laboratory Permeability Test}

A special laboratory permeameter device was assembled in the lab to fit the diameter of the specimens extracted from the two field sections. The laboratory permeameter was assembled to allow a head of water applied on the top of the tested specimen and at the same time to collect the water that leaked through the body of the tested core as shown in Figure 6.4. The time spent by the water to pass through the specimen was measured for both types of specimens (ASTM Geotechnical Testing Journal, 2002).

Asphalt specimens with small diameter sidewalls required special testing considerations when measuring the permeability in the lab assembled permeameter. Sidewall leakage was shown to be caused by different diameters of the specimens and the assembled permeameter pipe. Applying double thin layers of rubber tab around the sides of the asphalt specimen will centralize the specimen with the pipe as shown in Figure 6.5. And applying a thin layer of silicone grease around the top and bottom edges of the asphalt specimen as shown in Figure 6.6 makes an effective seal between the specimen and the permeameter pipe and arrested the sidewall leakage, thereby permitting the whole 
water to go through the specimen to get more accurate measurements (ASTM Geotechnical Testing Journal, 2002).

\section{Instrumentation and test procedures}

- Timing device was used to record the time of travel of water in the pipe.

- Cylindrical laboratory assembled permeameter, was used to direct water through the specimen as shown in Figure 6.4.

- Rubber tab was secured around the middle part of the specimen such that the specimen is centered with the pipe as shown in Figure 6.5 .

- Tested specimen was placed in a small cylindrical piece of pipe of the laboratory assembled permeameter.

- Silicon sealant was secured around the pipe at the top and bottom edges of the test specimen such that the water does not flow around the tested specimen. Water must flow through the test specimen as shown in Figure 6.6.

- The joint was placed such that it assembles the small piece of pipe including the specimen with the long part of the pipe.

- The conical collector was placed at the bottom. The small pipe and the joint were tightly secured such that water does not flow around the joint as shown in Figure 6.7.

- The long pipe was placed with the joint to finish assembling the laboratory permeameter device as shown in Figure 6.8.

- The permeameter was filled with four litres of water, approximately $465 \mathrm{~mm}$ above the top of the specimen, and then the timing device was started. 
- The time and distance for the water travels from the top marking on the water level till all or part of the water goes through the specimen was recorded.

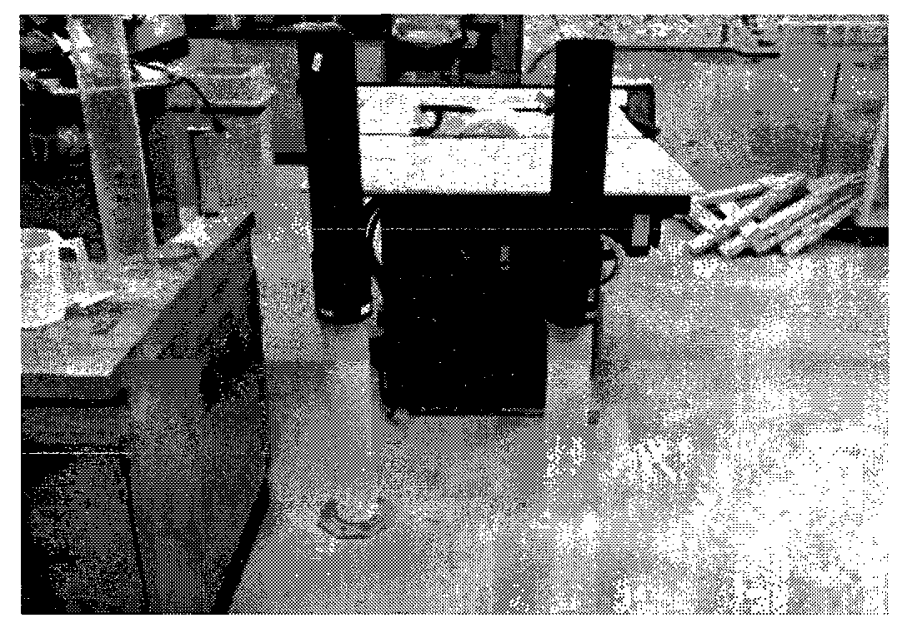

Figure 6.4 Laboratory assembled permeameter

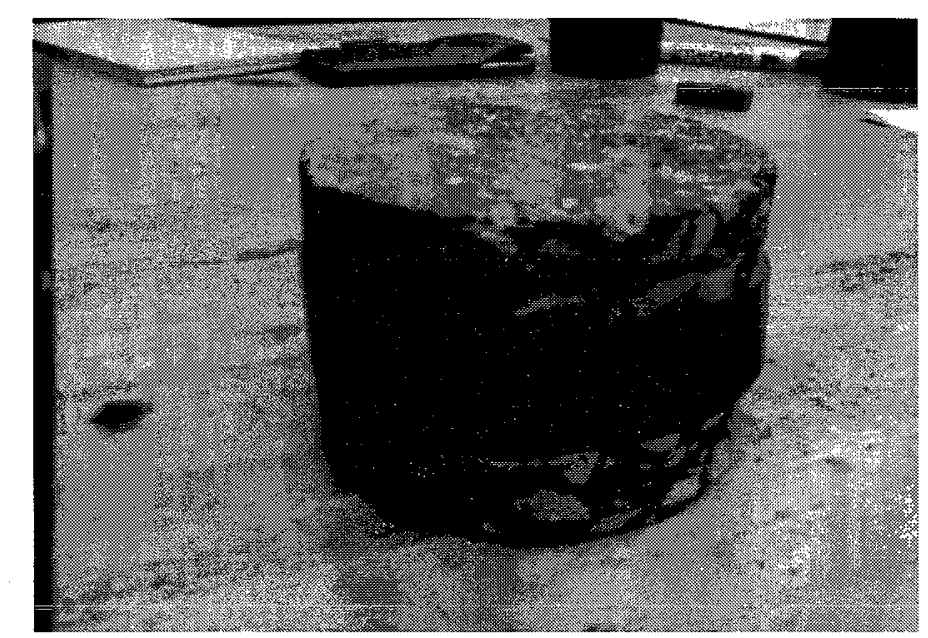

Figure 6.5 Rubber tab was secured around the middle part of the specimen

\section{Results and Discussion of the Laboratory Permeability Test}

Results of the permeability tests for the specimens extracted from conventionally compacted pavement which caused surface cracks are plotted in Figures 6.9, and 6.10. 


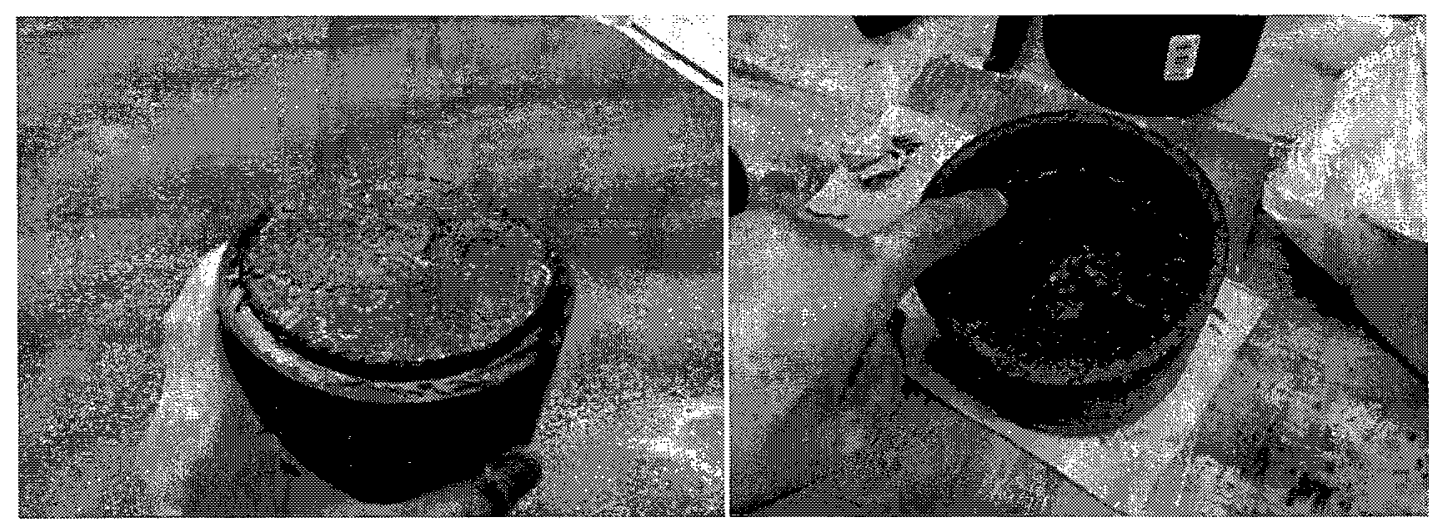

Figure 6.6 Silicon sealant was secured around the pipe at the top and bottom edges of the test specimen
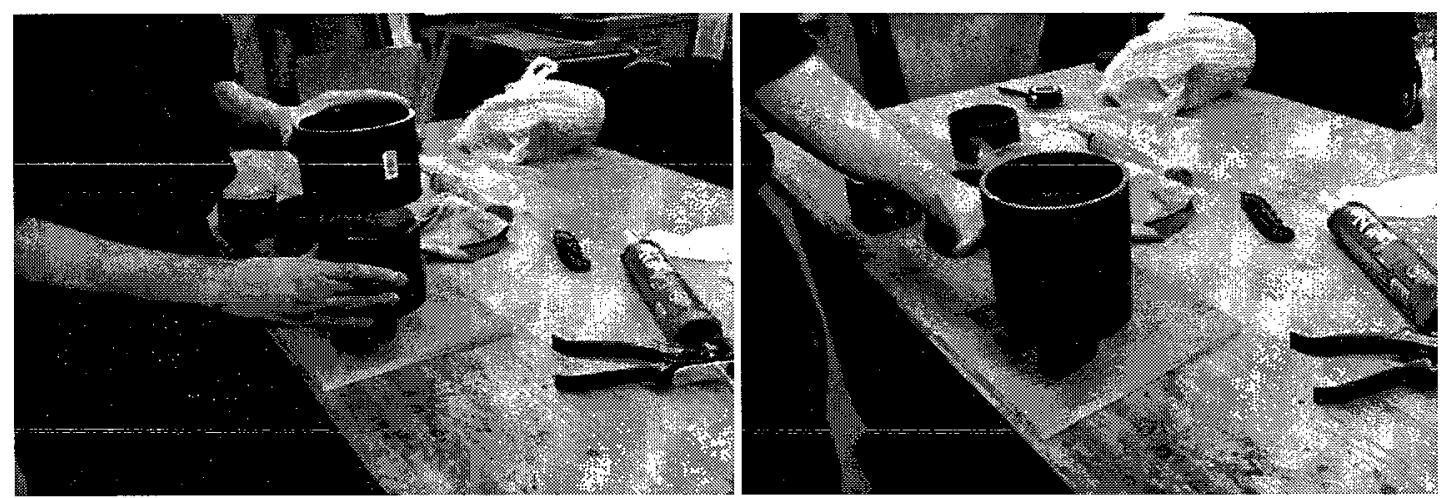

Figure 6.7 The small pipe with the joint and the collector were placed \& the pipes with the joint were tightly secured

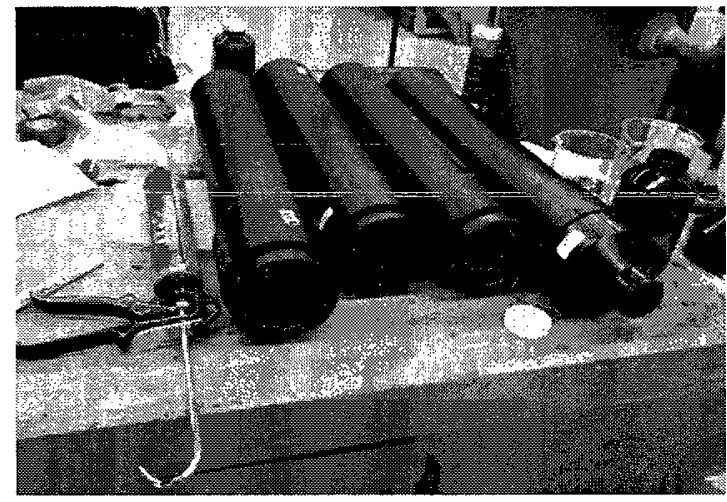

Figure 6.8 The long pipe with the joint and the specimen were placed 


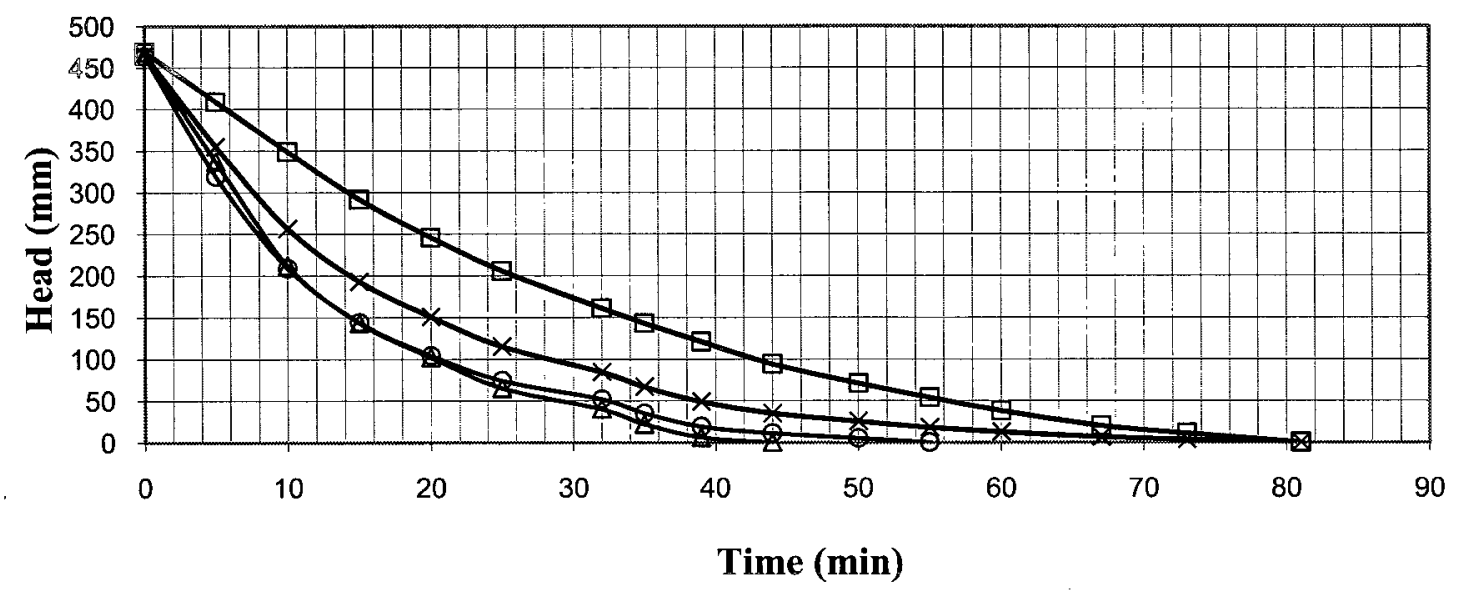

$\multimap \mathrm{SC} 1 \multimap \mathrm{SC} 2 \simeq \mathrm{SC} 3 \longrightarrow \mathrm{SC}$ "Average"

Figure 6.9 Calculated water head (SC)

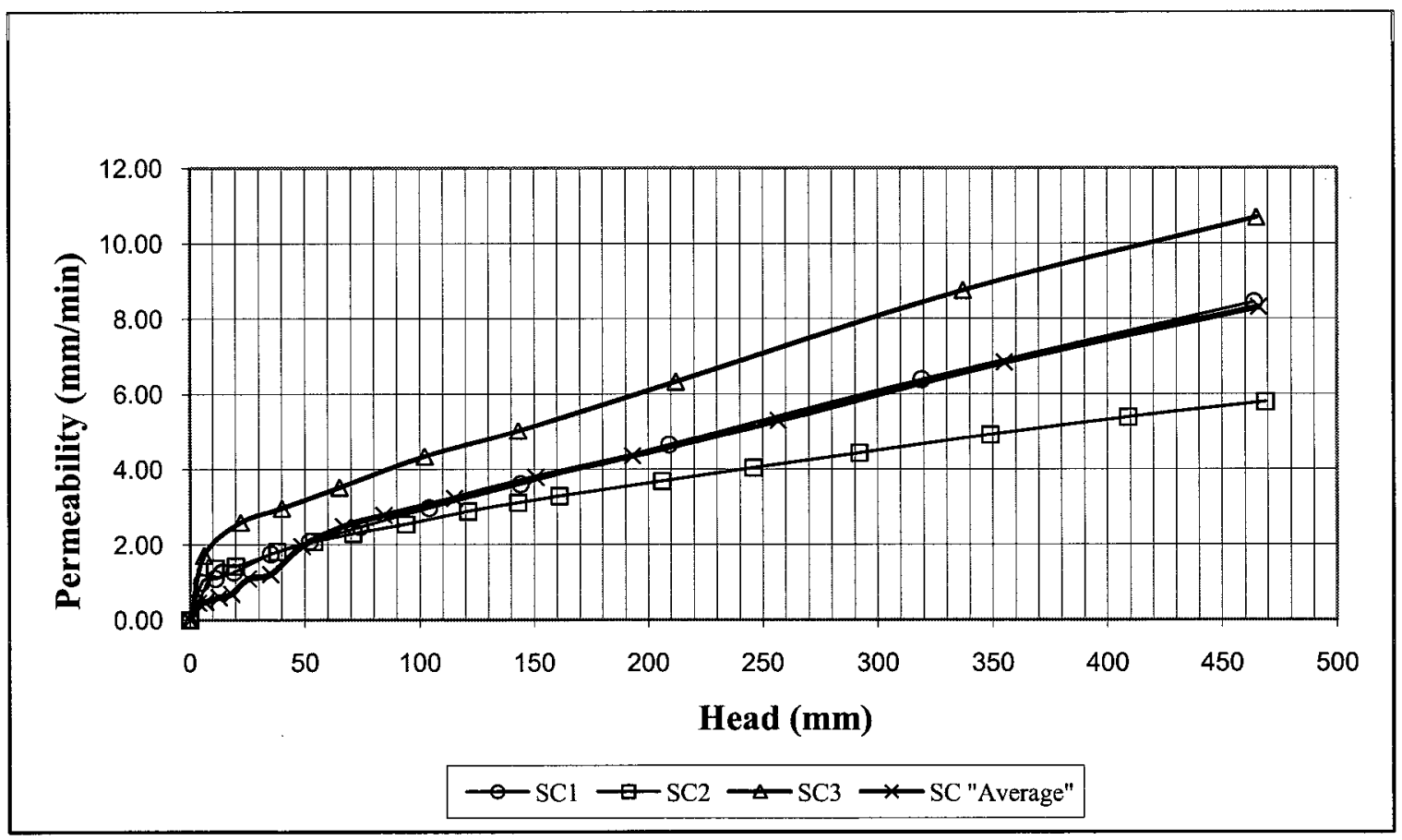

Figure 6.10 Calculated permeability for each head (SC) 
Results of the permeability tests for the control specimens extracted from pavement compacted using the AMIR prototype which have no cracks on the surface are given in Figures 6.11 , and 6.12 .

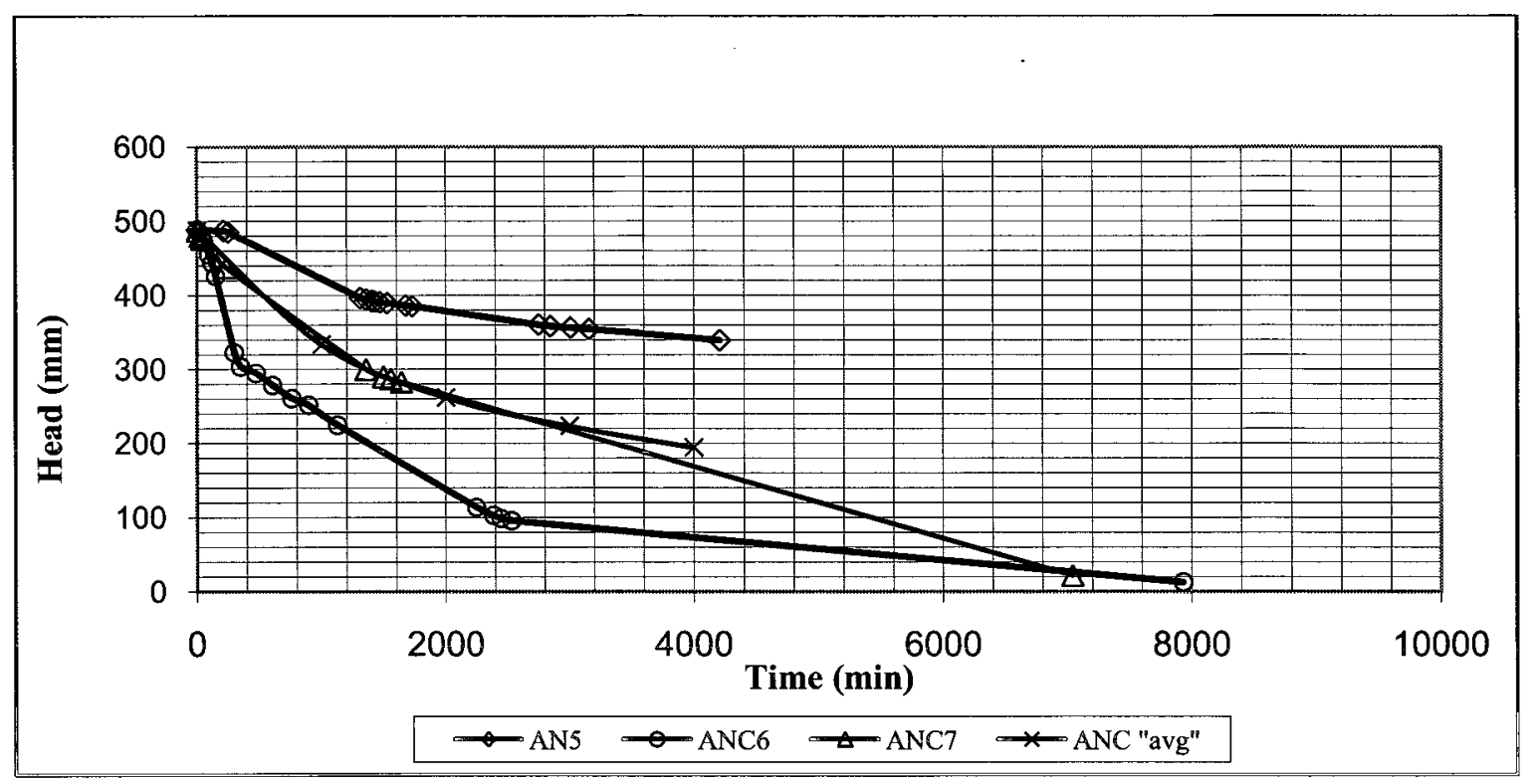

Figures 6.11 Calculated water head (ANC)

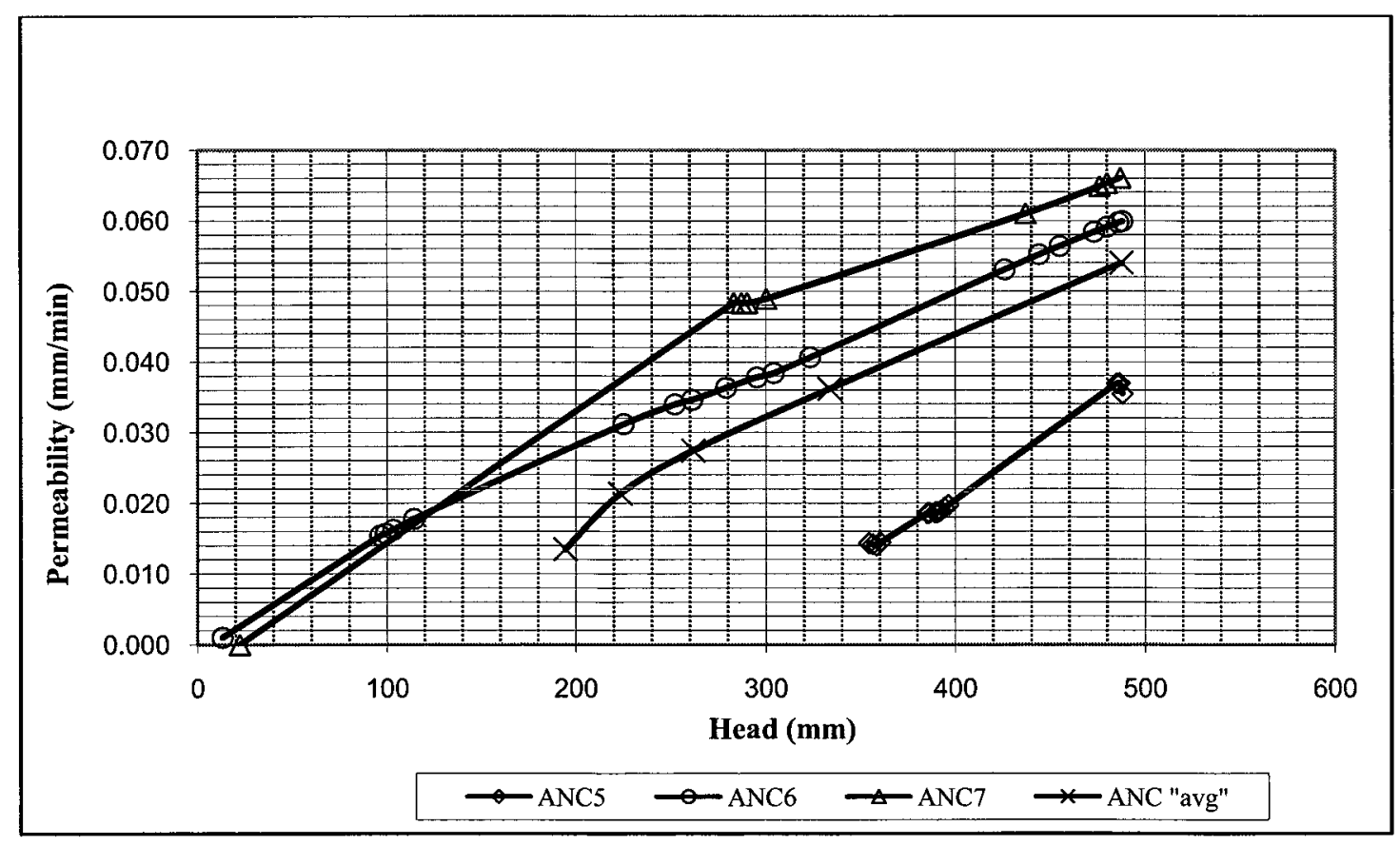

Figures 6.12 Calculated permeability for each head (ANC) 


\section{Discussion}

- Although Figures 6.9 and 6.10 represented test results of three specimens from the same section compacted using the "conventional compaction". As shown in the figure, the time needed for the water to go through each of the three specimens was very short and in all three specimens the head water reached zero suggesting that the surface cracks extended through the entire depth of the specimens. This observation is confirmed by the fact that the water went through the specimens and was fully recovered when collected at the bottom. This is one of the known characteristics of TDC.

- Figure 6.9 shows that the maximum time needed for the water to go through the cracked specimens was measured to be approximately $80 \mathrm{~min}$ for a water head of approximately $465 \mathrm{~mm}$. However, from figure 6.11 , it is noticed that there is an initial period of time where no water was experienced to penetrate through the un-cracked specimen suggesting that uncracked surface pavements will require longer periods of time to build sufficient head to allow the water to penetrating the asphalt layer. The test results showed that the water started to penetrate the surface after $210 \mathrm{~min}$ suggesting that tighter texture and that the voids in the specimen are very low.

- Figure 6.10, shows that specimen SC2 exhibits low permeability compared to the other two specimens, either for each time period or for each head; and that could be explained by the fact that the other two specimens might have higher number of cracks on the core surface due to poor compaction process.

- Figure 6.11 shows that the rate of water penetration of the un-cracked section decreased with time until it reached a steady state value under such a head due to the 
higher density of the core and absence of cracks. This head is the minimum head pressure under which the water will go through the specimen at very slow rates as emphasized in specimens ANCS, ANC6.

- The average total time needed for the $465 \mathrm{~mm}$ head of water to go through the uncracked specimens ANC6 \& ANC7 was approximately 7500 minutes (also this could be assumed for specimen ANC5 where the test was stopped at the time $4200 \mathrm{~min}$ ). Clearly, this time is considered very long for the water to stay over the pavement. Actual field conditions and good drainage system will be effective in removing it off the pavement surface.

\section{Comparison between the permeability of the cracked and the un-cracked specimens}

- From visual observation to the two different kinds of cores, it is obvious that uncracked cores was able to produce a satisfactory crack free and tight surface texture. Whereas a number of surface cracks can be observed on the cores those were taken from the section that have TDCs.

- The average values of the results of the permeability tests for the specimens of the crack free AMIR compacted specimens and those which compacted with traditional compactors and show TDCs are plotted in Figures 6.13, and 6.14.

As illustrated in the figures, the un-cracked cores show a significant improvement in reducing the permeability of asphalt concrete layers. At water head of $200 \mathrm{~mm}$ the average permeability of the specimens which have TDC was about 200 times the average permeability for the specimens which have no TDC. At the same water head, the variance 
in the average permeability for the cracked specimens was 140 while the variance in the average permeability for the un-cracked specimens was $1.5 \mathrm{E}-4$.

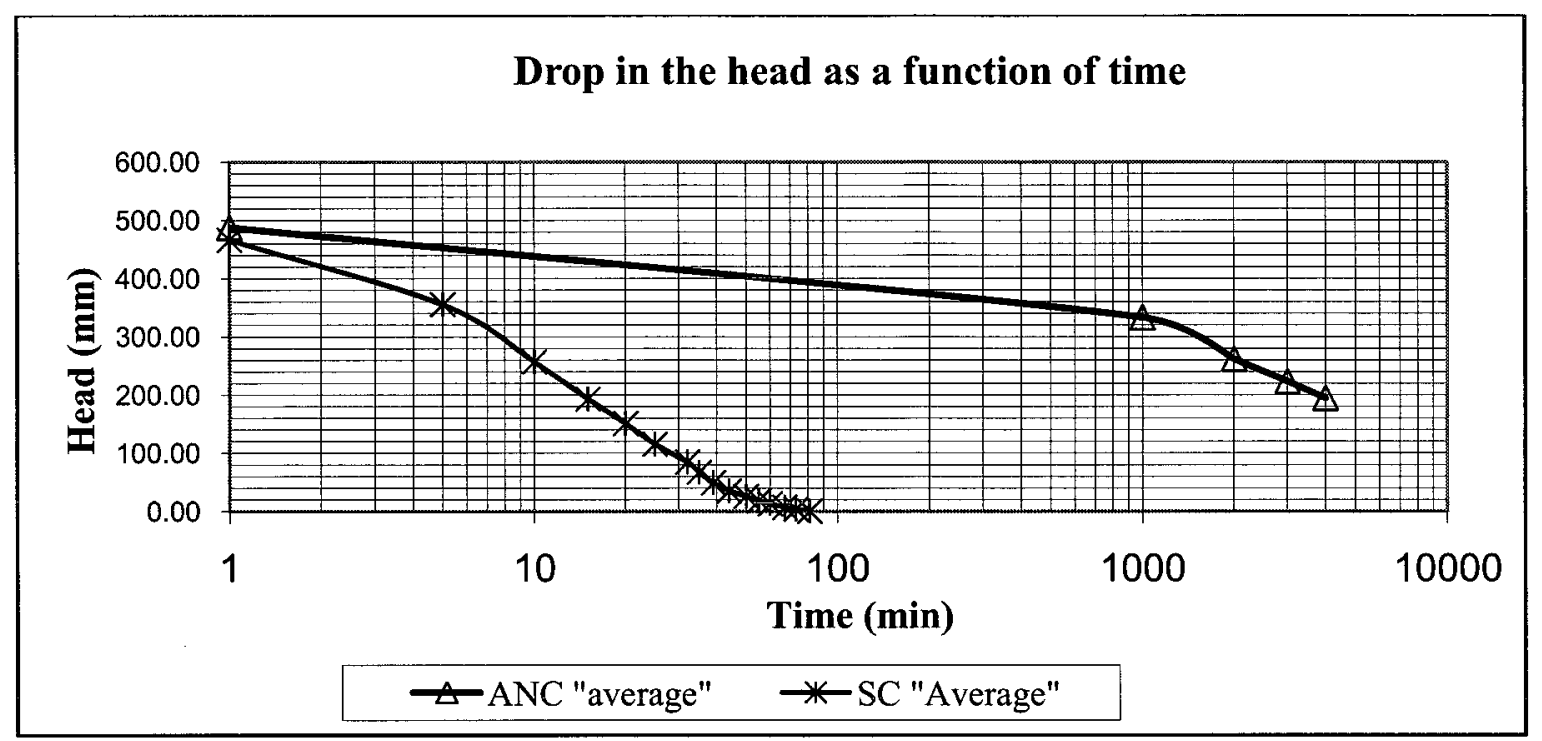

Figure 6.13 Calculated average water head

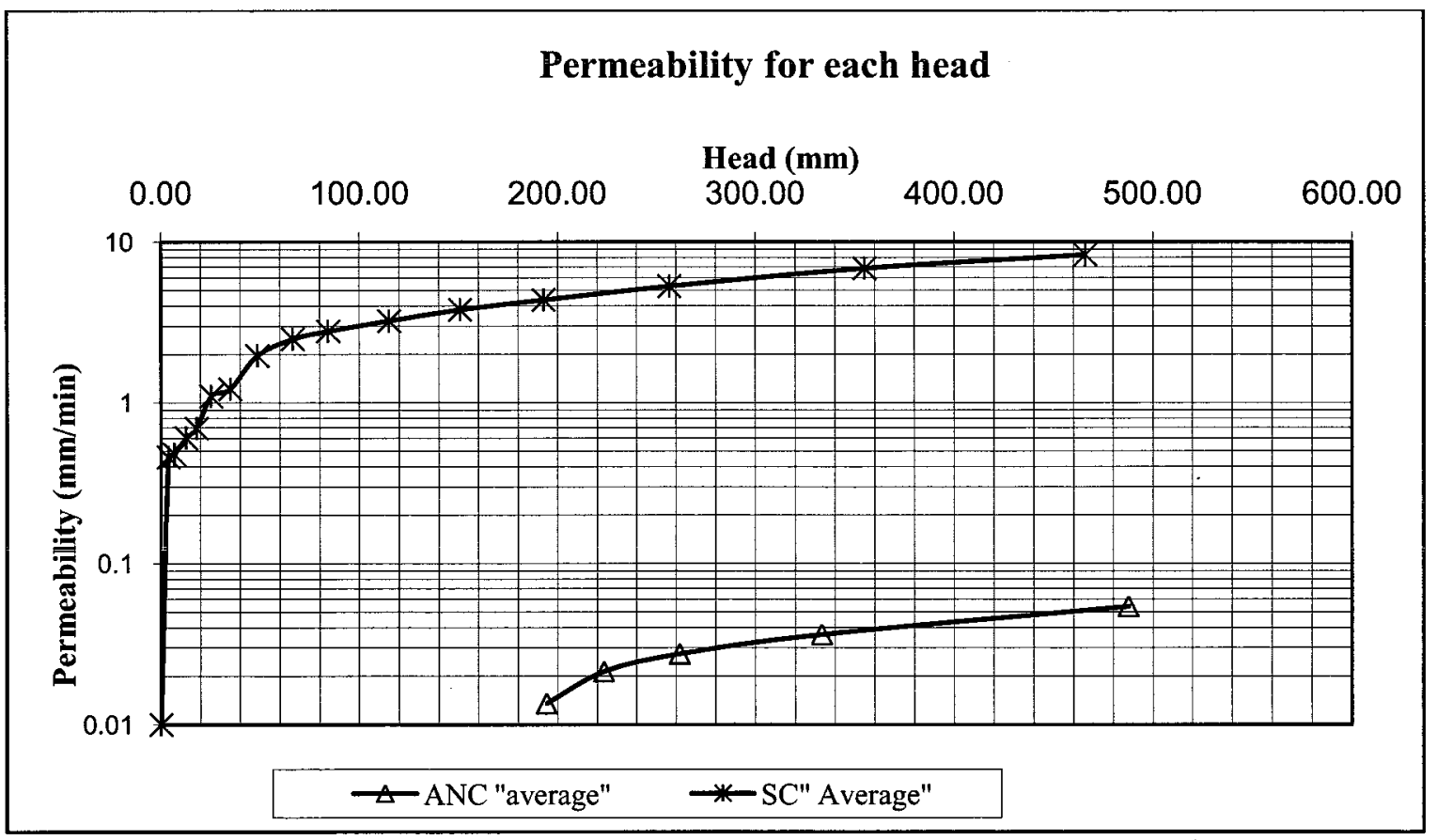

Figure 6.14 Calculated average permeability 


\subsubsection{Field Permeability Test}

Measurements of the permeability of asphalt surface layer in order to calculate the coefficient of permeability $(k)$ were performed on two pavement sections in the city of Ottawa, Canada. The first pavement section showed visible TDC while there were no surface cracks visible on the other section. Ten independent tests were performed along different locations spaced at about $13 \mathrm{~m}$ apart in the cracked section, and three tests were performed the un-cracked section to facilitate a comparison between the permeability of the cracked and un-cracked pavement. The test site was in the westbound of the Mackenzie King Bridge, and the un-cracked sections were located in the car lane, while the cracked sections were located in the bus lane.

To evaluate the field permeability of an asphalt concrete pavement, the NCAT field permeameter developed by NCAT and purchased from Gilson, Inc as shown in Figure 6.15 was used. The apparatus was used to measure the permeability in the field. The test is a falling head permeability test using water as the permeate. The drop in water level in the graduated standpipe over a given time interval is measured. The permeameter is divided into four standpipe portions and the time interval required for water to pass through the two levels within one of four different portions is recorded. According to the permeability of the tested pavement, the first upper level is used when the asphalt layer is a low permeable pavement whereas the second level is used when the asphalt pavement mix is relatively more permeable. 


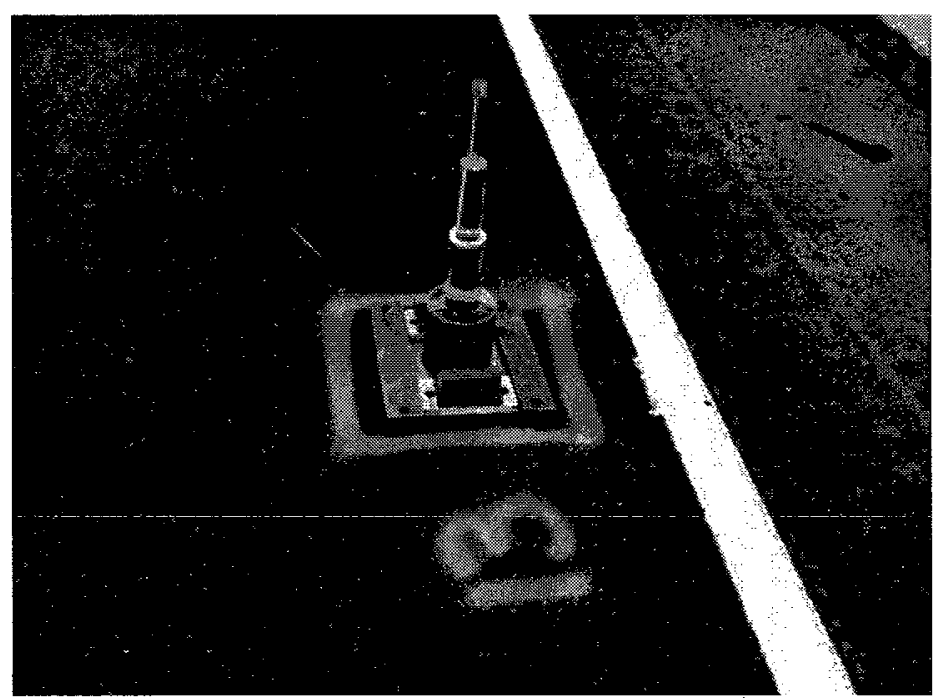

Figure 6.15 Permeability test equipment

The area where the permeability test is conducted was cleaned thoroughly to remove the surface dust. Then the permeameter is fitted with a rubber gasket and a mouldable sealant, which ensures a watertight seal between the base of the permeameter and the pavement surface. About $4 \mathrm{~kg}$ weight is added to each edge of the permeameter to prevent the permeameter from being uplifted due to the water column pressure. Without applying this weight, the water pressure can break the seal between the permeameter and the surface of the pavement. Water is then filled into the permeameter with a filling tube at a steady rate up to the top and then a portion is selected for monitoring the permeability, which is neither too fast nor too slow for accurate measurement of permeability

The water level in the permeameter dropped from its top to the second portion or level of the standpipe when used on the cracked pavement sections due to the rapid flow of the head through the section as shown in Figure 6.16 while in the un-cracked pavement section the flow of water was slow enough so that the first portion of the standpipe was 
selected for efficient recording of data as shown in Figure 6.17 (Operation \& Maintenance Manual, 2004).

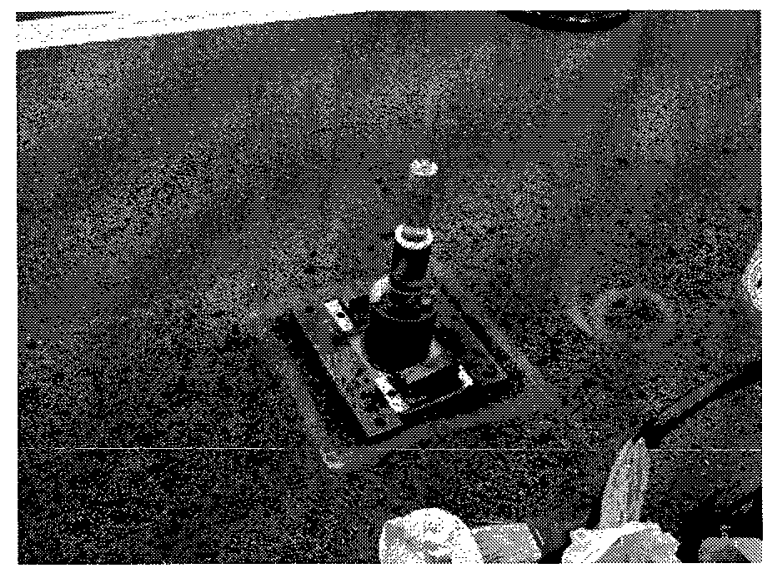

Figure 6.16 More permeable pavement

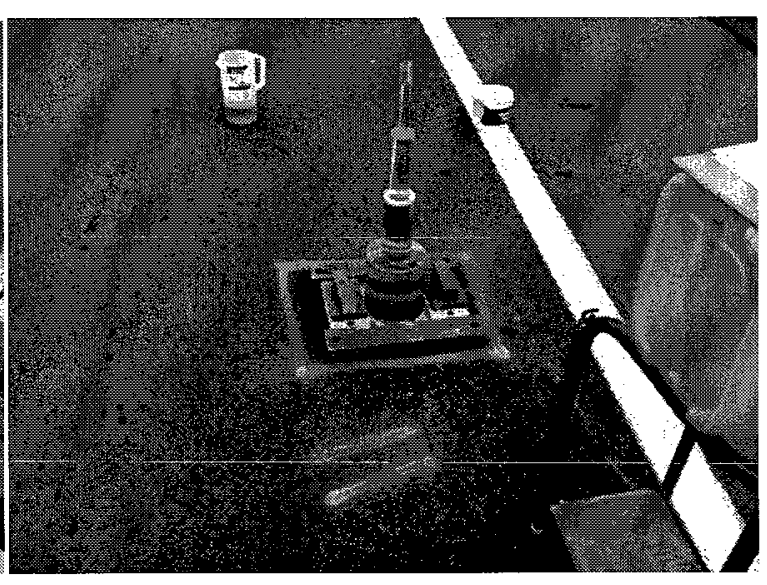

Figure 6.17 Low permeable pavement

The permeability coefficient of each of the ten and the three individual measurements tests was calculated using Equation (6.1) (Operation \& Maintenance Manual, 2004).

$k=(\mathbf{a L} / \mathbf{A t}) * \ln \left(\mathbf{h}_{1} / \mathbf{h}_{2}\right)$

Where: $\mathrm{k}=$ coefficient of permeability, $\mathrm{cm} / \mathrm{sec}$

$\mathrm{a}=$ inside cross-sectional area of standpipe, $\mathrm{cm}^{2}$, varies depending on tier used for testing according to each portion in the permeameter.

Tier $1=2.85 \mathrm{~cm}^{2}$

Tier $2=15.52 \mathrm{~cm}^{2}$

Tier $3=38.32 \mathrm{~cm}^{2}$

Tier $4=167.53 \mathrm{~cm}^{2}$

$\mathrm{L}=$ length of sample (thickness of the asphalt mat), $\mathrm{cm}$ 
$\mathrm{A}=$ cross-sectional area of permeameter through which water can penetrate the pavement, $167.53 \mathrm{~cm}^{2}$

$t=$ elapsed time between $h_{1}$ and $h_{2}$, sec.

$\mathrm{h}_{\mathrm{l}}=$ initial head, $\mathrm{cm}$

$\mathrm{h}_{2}=$ final head, $\mathrm{cm}$

$\ln =$ Natural Logarithm

Table 6.2 illustrates the measured data and the average calculated permeability coefficient for the un-cracked lane in the westbound, while Table 6.3 illustrates the measured data and the average calculated permeability coefficient for the bus/cracked lane.

The results illustrated in Tables 6.2 and 6.3 show that the average permeability of the cracked section was $146.82 \mathrm{E}-06$ which is approximately 90 times the average permeability of the un-cracked section which was $1.6246 \mathrm{E}-06$. This result validate the lab

Table 6.2 Calculated permeability coefficient for the car/un-cracked lane

\begin{tabular}{|l|l|l|l|l|l|l|l|l|l|l|}
\hline $\begin{array}{l}\text { Test } \\
\text { Location } \\
\text { No. }\end{array}$ & $\begin{array}{l}\text { Tier } \\
\text { No. }\end{array}$ & $\begin{array}{l}\text { Water } \\
\text { Temp. }\end{array}$ & $\begin{array}{l}\text { Correction } \\
\text { Factor C }\end{array}$ & $\mathrm{a}$ & $\mathrm{L}$ & $\mathrm{h} 1$ & $\mathrm{~h} 2$ & \multicolumn{2}{|c|}{$\mathrm{t}$} & $\mathrm{K}$ \\
\hline & $\mathrm{C}$ & $\begin{array}{l}20^{\circ} \mathrm{C} \text { is the } \\
\text { standard }\end{array}$ & $\mathrm{cm} 2$ & $\mathrm{~cm}$ & $\mathrm{~cm}$ & $\mathrm{~cm}$ & $\mathrm{sec}$ & $\mathrm{sec}$ & $\mathrm{cm} / \mathrm{s}$ \\
\hline 11 & 1 & 10 & 1.3 & 2.85 & 8 & 63.5 & 63.1 & 22 & 622 & $1.79743 \mathrm{E}-06$ \\
\hline 12 & 1 & 9 & 1.3 & 2.85 & 8 & 65.5 & 65.3 & 30 & 390 & $1.38731 \mathrm{E}-06$ \\
\hline 13 & 1 & 11 & 1.26 & 2.85 & 8 & 65.7 & 65.3 & 20 & 620 & $1.68904 \mathrm{E}-06$ \\
\hline \multicolumn{2}{|l}{ Average (K) } & & & & & & & & &
\end{tabular}


Table 6.3 Calculated permeability coefficient for the bus/cracked lane.

\begin{tabular}{|l|l|l|l|l|l|l|l|l|l|}
\hline $\begin{array}{l}\text { Test } \\
\text { Nocation }\end{array}$ & $\begin{array}{l}\text { Tier } \\
\text { No. }\end{array}$ & $\begin{array}{l}\text { Water } \\
\text { Temp. }\end{array}$ & $\begin{array}{l}\text { Correction } \\
\text { Factor } \mathbb{C}\end{array}$ & $\mathrm{a}$ & $\mathrm{L}$ & $\mathrm{h} 1$ & $\mathrm{~h} 2$ & $\mathrm{t}$ & $\mathrm{K}$ \\
\hline 1 & 1 & 13 & 1.2 & 2.85 & 8 & 65 & 55 & 303 & $9.00405 \mathrm{E}-05$ \\
\hline 2 & 1 & 13 & 1.2 & 2.85 & 8 & 66 & 64 & 360 & $1.39596 \mathrm{E}-05$ \\
\hline 3 & 1 & 13 & 1.2 & 2.85 & 8 & 61.9 & 61.6 & 463 & $1.71367 \mathrm{E}-06$ \\
\hline 4 & 2 & 12 & 1.23 & 15.52 & 8 & 50 & 39.5 & 257 & 0.000836107 \\
\hline 5 & 1 & 11 & 1.26 & 2.85 & 8 & 57.5 & 52 & 257 & $6.70848 \mathrm{E}-05$ \\
\hline 6 & 2 & 11 & 1.26 & 15.52 & 8 & 50.5 & 44.4 & 321 & 0.000374496 \\
\hline 7 & 1 & 13 & 1.2 & 2.85 & 8 & 64 & 63.5 & 360 & $3.55806 \mathrm{E}-06$ \\
\hline 8 & 1 & 12 & 1.23 & 2.85 & 8 & 65.5 & 58.2 & 316 & $6.25963 \mathrm{E}-05$ \\
\hline 9 & 1 & 11 & 1.26 & 2.85 & 8 & 66.5 & 66 & 385 & $3.36154 \mathrm{E}-06$ \\
\hline 10 & 1 & 11 & 1.26 & 2.85 & 8 & 65 & 63 & 350 & $1.53119 \mathrm{E}-05$ \\
\hline $\begin{array}{l}\text { Average } \\
(\mathbf{K})\end{array}$ & & & & & & & & & $\mathbf{1 4 6 . 8 2 \mathrm { E } - 0 6}$ \\
\hline
\end{tabular}

permeability test results, were the average permeability of the specimens which have TDC was 200 times the average permeability of the specimens that do not have any surface cracks or TDC. One of the reasons for the variation between the laboratory and field comparison is the fact that the AMIR compacted specimens were fully crack free and hence the ratio of 200 . On the other hand, the comparison between the two field sections was made between two sections compacted by the same traditional method which may have induced more cracks in one section than the other, hence the ratio of 90 . 
It was also shown from the work conducted by Mostafa (2005), at different site tests that the asphalt layers which were compacted using the AMIR compactor (crack free sections) were, on average ten times less permeable than the same asphalt layers when compacted using the steel drum compactor. While both studies agree on the outcome that AMIR compacted crack free asphalt layers are much less permeable than the ones compacted with current rollers the differences in the comparative values can be explained by several factors. Among these factors are the compaction method, where the tested slabs were compacted in the lab using the rubber-vibratory plate compactor simulating the compaction method using the AMIR roller and that could be the reason for less improvement in the permeability, a ratio of 10 .

Also, results of previous permeability tests performed in Canada and Australia showed that the elimination of the construction cracks resulted in significant reduction in the permeability of the newly compacted asphalt mat by more than $400 \%$ (Abd El Halim et al., 1993; Rickards et al., 1999; Mostafa and Abd El Halim 2006) and thus, confirming the ratios found in this lab investigation.

\subsubsection{Chemical Analyses of Water}

Chemical analyses tests were applied to evaluate the environmental effect of the TDC. The test was performed by analyzing samples from the water used for the permeability test before and after going through the specimens. The water used for the permeability test was fully distilled water in the first stage to insure that all the contamination associated with the collected water was as a result of the water interaction with the 
asphalt specimen components. In the second stage salt was added to the water in the amount of $50 \mathrm{~g} / 1$. The conducted chemical analysis tests are:

\section{- $p H$}

$\mathrm{pH}$ is defined as the intensity factor of acidity and used in alkalinity and carbon dioxide measurements. At a given temperature the intensity of the acidic or basic character of a solution is indicated by $\mathrm{pH}$, (Arnold et al., 1992).

\section{- Conductivity}

Conductivity is a measure of the ability of an aqueous solution to carry an electric current. This ability depends on the presence of ions; on their total concentration, mobility, and valence; and on the temperature of measurement. Solutions of most inorganic compounds are relatively good conductors. Conversely, molecules of organic compounds that do not dissociate in aqueous solution conduct a current very poorly, (Arnold et al., 1992).

\section{- Total Dissolved Solids}

It is calculated with the conductivity, using the same instrument, and it is a ratio of 0.666 of the conductivity measured, (Arnold et al., 1992).

\section{- Turbidity}

Turbidity is a measure for the clarity of water, and an expression of the optical properties of water. It is caused by suspended matter such as clay, silt, finely divided organic and 
inorganic matter, soluble colored organic compounds, and plankton and other microscopic organisms, (Arnold et al., 1992).

\section{- Total Organic Carbon (TOC)}

The organic carbon in water is composed of a variety of organic compounds in various oxidation states. To determine the quantity of organically bond carbon, the organic molecules must be broken down to single carbon units and converted to a single molecular form that can be measured quantitatively. TOC methods convert organic carbon to carbon dioxide (CO2). The $\mathrm{CO} 2$ may be measured by different ways, (Arnold et al., 1992). Table 6.4 illustrates the results of the chemical analysis test.

\section{Discussion of the Chemical Analyses of Water}

\section{1- Case of applying still water to the cracked specimens, as an example.}

(a) Results from cracked specimen, $\mathrm{SC} 2$ is presented.

- $\mathrm{pH}$ slightly changed after the water goes through the asphalt specimen. Before the test $\mathrm{pH}$ was about 7 and after the test it gets a little bit lower but still not far from 7 and this could be due to some acidity released from the specimen as the water goes through it (Arnold et al., 1992).

- Conductivity and the total dissolved solids have increased after the water went through the specimen. This could be explained due to some interaction with the 
Table 6.4 Results of chemical analysis tests

\begin{tabular}{|c|c|c|c|c|c|c|c|c|c|c|c|c|c|c|}
\hline \multirow[b]{2}{*}{ Specimen No } & \multicolumn{2}{|c|}{$\begin{array}{c}\text { Time } \\
\text { duration }\end{array}$} & \multirow[b]{2}{*}{$\mathrm{pH}$} & \multirow[b]{2}{*}{$\begin{array}{c}\% \\
\text { Increase } \\
\text { in } \mathrm{pH}\end{array}$} & \multirow[b]{2}{*}{$\begin{array}{l}\text { Conductivity } \\
(\mathrm{uS} / \mathrm{cm})\end{array}$} & \multirow[b]{2}{*}{$\begin{array}{l}\% \text { Increase in } \\
\text { Conductivity }\end{array}$} & \multirow[b]{2}{*}{$\begin{array}{c}\text { Total } \\
\text { dissolved } \\
\text { solid } \\
(\mathrm{mg} / \mathrm{L})\end{array}$} & \multirow{2}{*}{$\begin{array}{c}\% \\
\text { Increase } \\
\text { in Total } \\
\text { dissolved } \\
\text { solid }\end{array}$} & \multirow[b]{2}{*}{ Turbidity } & \multirow[b]{2}{*}{$\begin{array}{c}\% \\
\text { Increase } \\
\text { in } \\
\text { Turbidity }\end{array}$} & \multicolumn{4}{|c|}{ Total Carbon (duplicate) } \\
\hline & $\mathrm{h}$ & $\min$ & & & & & & & & & $\begin{array}{c}\text { Total } \\
\text { Carbon } \\
\mathrm{mg} / \mathrm{L}\end{array}$ & $\begin{array}{c}\% \\
\text { increase in } \\
\text { Total } \\
\text { Carbon }\end{array}$ & $\begin{array}{c}\text { Total } \\
\text { Organic } \\
\text { Carbon } \\
\mathrm{mg} / \mathrm{L}\end{array}$ & $\begin{array}{c}\text { Inorganic } \\
\text { Carbon } \\
\mathrm{mg} / \mathrm{L}\end{array}$ \\
\hline \multicolumn{4}{|c|}{ DW no salt (before) $\quad 7.22$} & 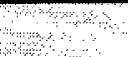 & 3.22 & 24 & 2,08 & की & 0 & $x^{2}=1$ & 1.085 & 5 & 0.42 & 0.67 \\
\hline $\mathrm{SC} 21$ st, $2^{\text {nd }} \mathrm{L}$ & 0 & 20 & 6.43 & -11 & 9.7 & 201 & 6.63 & 219 & 0.19 & & 4.21 & 288 & 2.06 & 2.15 \\
\hline $\mathrm{SC} 24^{\text {th }}$ liter & 1 & 19 & 6.73 & -7 & 13.14 & 308 & 8.88 & 327 & 0.02 & -89 & 5.18 & 377 & 2.65 & 2.53 \\
\hline ANC5 $1^{\text {st }} \mathrm{L}$ & 45 & 49 & 7.15 & -1 & 62.8 & 1850 & 41.6 & 1900 & 0.3 & 58 & 10.38 & 857 & 6.94 & 3.44 \\
\hline \multirow[t]{2}{*}{ ANC5 $2^{\text {nd }} L$} & 70 & 3 & 7.45 & 3 & 465 & 14341 & 309 & 14756 & 0.3 & 58 & 14.75 & 1259 & 9.86 & 4.89 \\
\hline & & & & & $\mathrm{mS} / \mathrm{cm}$ & & $\mathrm{g} / \mathrm{L}$ & & & & & & & \\
\hline \multicolumn{3}{|c|}{$\mathrm{DW}+$ salt $50 \mathrm{~g} / \mathrm{L}$ (before) } & 9.68 & +2 & 330 & 3 & 221 & 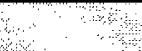 & 2 & 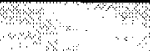 & 9.25 & 8 & 685 & 2.40 \\
\hline $\mathrm{SC} 31,2^{\text {nd }} \mathrm{L}$ & 0 & 11 & 9.4 & -3 & 309 & -6 & 213 & -4 & 0.4 & -80 & 14.16 & 53 & 10.73 & 3.43 \\
\hline $\mathrm{SC} 33^{\text {rd }}$ liter & 0 & 20 & 9.53 & -2 & 324 & -2 & 215 & -3 & 0.34 & -83 & 11.33 & 22 & 9.15 & 2.18 \\
\hline $\mathrm{SC} 34^{\text {th }}$ liter & 0 & 50 & 9.52 & -2 & 307 & -7 & 204 & -8 & 0.48 & -76 & 11.92 & 29 & 8.99 & 2.93 \\
\hline ANC6 $1^{\text {st }} \mathrm{L}$ & 5 & 47 & 9.14 & -6 & 320 & -3 & 215 & -3 & 1.41 & -30 & 16.83 & 82 & 12.4 & 4.43 \\
\hline ANC6 $2^{\text {nd }} \mathrm{L}$ & 7 & 52 & 9 & -7 & 324 & -2 & 216 & -2 & 1.44 & -28 & 18.79 & 103 & 13.01 & 5.78 \\
\hline ANC6 $3^{\text {rd }} \mathrm{L}$ & 28 & 20 & 8.58 & -11 & 338 & 2 & 228 & 3 & 1.02 & -49 & 20.45 & 121 & 12.37 & 8.08 \\
\hline ANC6 $4^{\text {th }} \mathrm{L}$ & 132 & 11 & 7.58 & -22 & 336 & 2 & 224 & 1 & 0.66 & -67 & 27.35 & 196 & 14.59 & 12.76 \\
\hline \multicolumn{3}{|c|}{$\mathrm{DW}+25 \mathrm{~g} / \mathrm{L}$ salt (before) } & 9.06 & wa & $114: 9$ & & 77.4 & ?. & 0.18 & 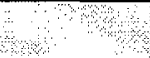 & 4.838 & 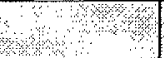 & 3.74 & 1.10 \\
\hline ANC7 $1^{\text {st }} \mathrm{L}$ & 22 & 35 & 8.82 & -3 & 117.9 & 3 & 78.5 & 1 & 0.41 & 128 & 17.6 & 264 & 17.04 & 0.56 \\
\hline $\begin{array}{c}\text { ANC7 }(2,3,4) \\
\text { L }\end{array}$ & 117 & 20 & 7.04 & -22 & 117.1 & 2 & 79.4 & 3 & 1.22 & 578 & 22.85 & 372 & 9.96 & 12.89 \\
\hline
\end{tabular}


asphalt specimen which causes some releasing of the ions; and that causes other reactions which lead to the increase in the total carbon.

- The imcrease in Turbidity in the outcome water means that the water has extracted some substances from the asphalt specimen as it goes through. These substances are higher in the first collected quantities, as the water washes the specimen and then continues to move through.

(b) Results from un-cracked specimen, ANC5 is presented.

- $\mathrm{pH}$ slightly changed after the test, it gets a little bit lower and higher but still not far from 7 and this could be due to slight acidity or alkalinity released from the specimen as the water goes through it.

- The increase in the conductivity and the total dissolved solids looks much higher than that of the cracked specimens which appears much clear in the second letter.

- The time duration for the water to interact with the specimen was much higher in the un-cracked specimen and that was the cause of the increase in the turbidity and the total carbon in the collected water.

- The time factor here is considered as a significant factor where the total pollution is much higher in the water collected from the cracked specimens.

\section{2- Case of applying still water with $50 \mathrm{~g} / \mathrm{L}$ salt,}

\section{(a) Results from cracked specimen, $\mathrm{SC} 3$ is presented:}

- It is noticed that the amount of total carbon increased, that could be due to some reactions between the salted water and the specimen, and we can see that in the 
reduction of alkalinity, conductivity and the total dissolved solids, where the dissolved salt was a factor causing the decrease of these parameters.

\section{(b) Results from un-cracked specimen, ANC6 is presented:}

- The time duration for the water to interact with the specimen was much higher and this enables the release of more carbon, also the alkalinity has reduced significantly.

- The time duration for specimen $\mathrm{SC} 3$ was $11 \mathrm{~min}$ for the total carbon to increase by $4.91 \mathrm{mg} / 1$ while it took $7931 \mathrm{~min}$ to increase the total carbon by $18.1 \mathrm{mg} / 1$ for specimen ANC6. This means that the rate of pollution produced by the cracked specimens $(0.446 \mathrm{mg} / 1 / \mathrm{min})$ is almost 225 times that for the un-cracked specimen $(0.002 \mathrm{mg} / 1 / \mathrm{min})$. This is considered very high rate which could cause serious damage to the environment and can affect the long term performance of the asphalt pavement.

\subsubsection{Effect of Spilled Oil on the Asphalt Pavement Integrity}

\section{Instrumentation and test procedures}

Oil can be found or spilled on the surface of the asphalt roads due to leak of engines of different vehicles or during transportation of oils as commodities. A test was conducted to measure the damage that could be inflicted due to the presence of oil products on a cracked surface of asphalt road. The test was performed on 9 un-cracked specimens and 12 cracked specimens. Oil was applied over each specimen after fitting the specimen in the same assembled permeameter that was used for the water permeability test. The oil was up to a level of $100 \mathrm{~mm}$ and left over the specimen until it all went through the specimen or for a period of time of about 24 hours as shown in Figure 6.18 . 


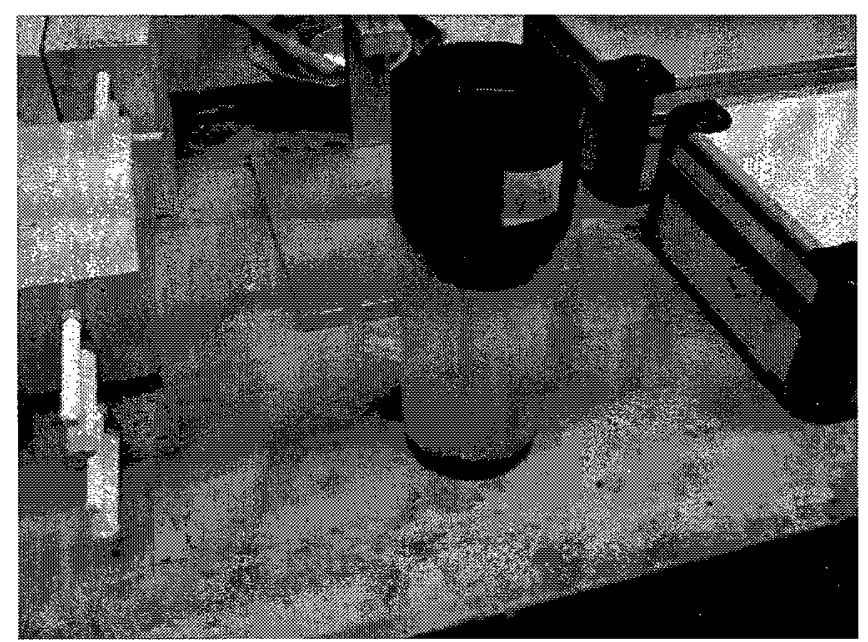

Figure 6.18 Oil is applied over and collected under the asphalt specimen

\section{Results and Discussion of the Oil Test}

The amount of oil that could pass through the specimens, and that could be absorbed by it was determined and presented in Tables 6.5 and Figures $6.19 \& 6.20$.

The test results showed that the total amount of oil which was applied over the asphalt specimen has fully passed through the surface of most of the test specimens with cracked surface. On the other hand, it was noted that hardly any of the oil on top of the un-cracked specimens has gone through them as illustrated in Figure 6.19. This is a very important observation since oils are known to attack the asphalt mixtures and damage the bond between its aggregates and the asphalt binder, thus causing serious damage to the mix and its ability to provide its expected function as shown in Figure 6.21. Figures 6.19 and 6.20 shows that not only the amount passing through the body of the asphalt core was much higher for the cracked specimens but also the amount absorbed by the same specimens. Clearly, the passing and absorbed amounts would increase the damage caused 
to the road which could be stripping, softening and disintegration of the mixture itself in addition to the environmental effects of the oil seepage into the soil and water sources.

Table 6.5 Influence of TDC on the absorption percent by the specimens.

\begin{tabular}{|c|c|c|c|c|c|c|c|c|c|}
\hline \multirow{2}{*}{ 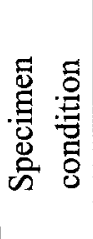 } & $\begin{array}{l}\text { Specimen } \\
\text { No. }\end{array}$ & $\begin{array}{l}\text { Specimen } \\
\text { Dry } \\
\text { Weight } \\
\text { in Air }\end{array}$ & $\begin{array}{l}\text { Applied } \\
\text { Oil over } \\
\text { the } \\
\text { Specimen }\end{array}$ & $\begin{array}{l}\text { Oil } \\
\text { Collected } \\
\text { under the } \\
\text { Specimen }\end{array}$ & $\begin{array}{l}\text { Time } \\
\text { Duration }\end{array}$ & $\begin{array}{l}\text { Remaining } \\
\text { Oil Over } \\
\text { Specimen }\end{array}$ & $\begin{array}{l}\text { Oil } \\
\text { Absorbed } \\
\text { by the } \\
\text { Specimen }\end{array}$ & Absorption & Absorption \\
\hline & & $\mathrm{g}$ & $\mathrm{g}$ & $\%$ & $\mathrm{hr}$ & $\mathrm{g}$ & $\mathrm{g}$ & $\%$ & Avg. $\%$ \\
\hline \multirow{9}{*}{ 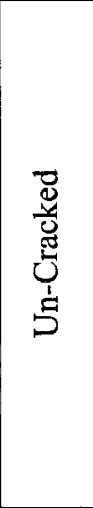 } & Anc5 & 1354.15 & 412.29 & 35.75 & 23 & 242.12 & 22.79 & 1.7 & \multirow{9}{*}{1.55} \\
\hline & Anc6 & 1330.4 & 412.29 & 35.59 & 18 & 251.03 & 14.54 & 1.1 & \\
\hline & Anc7 & 1343.3 & 549.72 & 25.85 & 20 & 387.13 & 20.46 & 1.5 & \\
\hline & Anc11 & 827.61 & 412.29 & 0.00 & 22 & 407.88 & 4.41 & 0.5 & \\
\hline & Anc23 & 849.77 & 355.88 & 0.00 & 29 & 328.94 & 26.94 & 3.2 & \\
\hline & Anc24 & 1308.05 & 353.33 & 0.00 & 29 & 342 & 11.33 & 0.9 & \\
\hline & Anc25 & 1411.19 & 381.16 & 0.00 & 13 & 374 & 7.16 & 0.5 & \\
\hline & Anc26 & 1000.76 & 371.03 & 2.70 & 29 & 340.9 & 20.13 & 2.0 & \\
\hline & Anc27 & 777.4 & 375.4 & 0.00 & 29 & 355.8 & 19.6 & 2.5 & \\
\hline \multirow{12}{*}{ 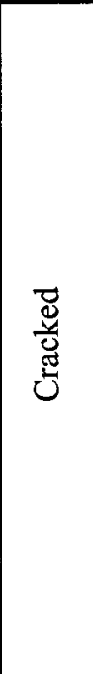 } & $\mathrm{Sc} 2$ & 1116.41 & 549.72 & 92.70 & 3.5 & 0 & 40.14 & 3.6 & \multirow{12}{*}{4.57} \\
\hline & Sc3 & 1145.13 & 549.72 & 94.01 & 2 & 0 & 32.95 & 2.9 & \\
\hline & Sc10 & 780.96 & 417.42 & 92.75 & 3 & 0 & 30.27 & 3.9 & \\
\hline & $\mathrm{Sc} 12$ & 828.77 & 504 & 89.83 & 1.5 & 0 & 51.27 & 6.2 & \\
\hline & Sc13 & 1026.98 & 401.37 & 91.14 & 4 & 0 & 35.56 & 3.5 & \\
\hline & Sc14 & 1033.4 & 398.66 & 87.71 & 4 & 0 & 49.01 & 4.7 & \\
\hline & Sc17 & 642.25 & 295.46 & 88.43 & 4 & 0 & 34.19 & 5.3 & \\
\hline & Sc18 & 923.8 & 378.56 & 90.06 & 4 & 0 & 37.63 & 4.1 & \\
\hline & Sc19 & 923.18 & 363.26 & 86.84 & 1 & 0 & 47.8 & 5.2 & \\
\hline & Sc20 & 805.53 & 406.15 & 88.51 & 4 & 0 & 46.66 & 5.8 & \\
\hline & Sc21 & 834.28 & 386.41 & 17.71 & 30 & 269.96 & 48.01 & 5.8 & \\
\hline & Sc22 & 855.32 & 361.49 & 49.53 & 29 & 148.01 & 34.44 & 4.0 & \\
\hline
\end{tabular}




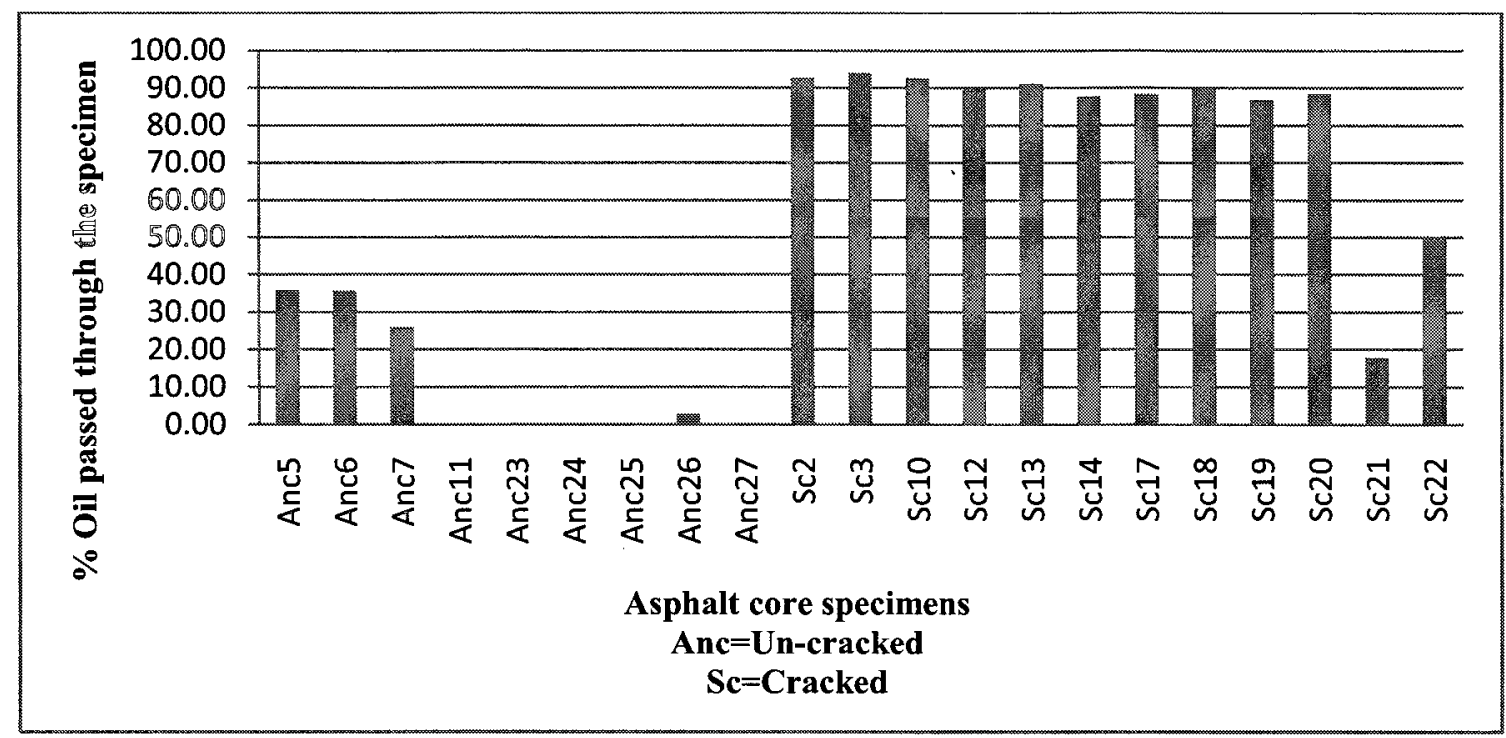

Figure 6.19 Percent of penetrated oil through the specimens

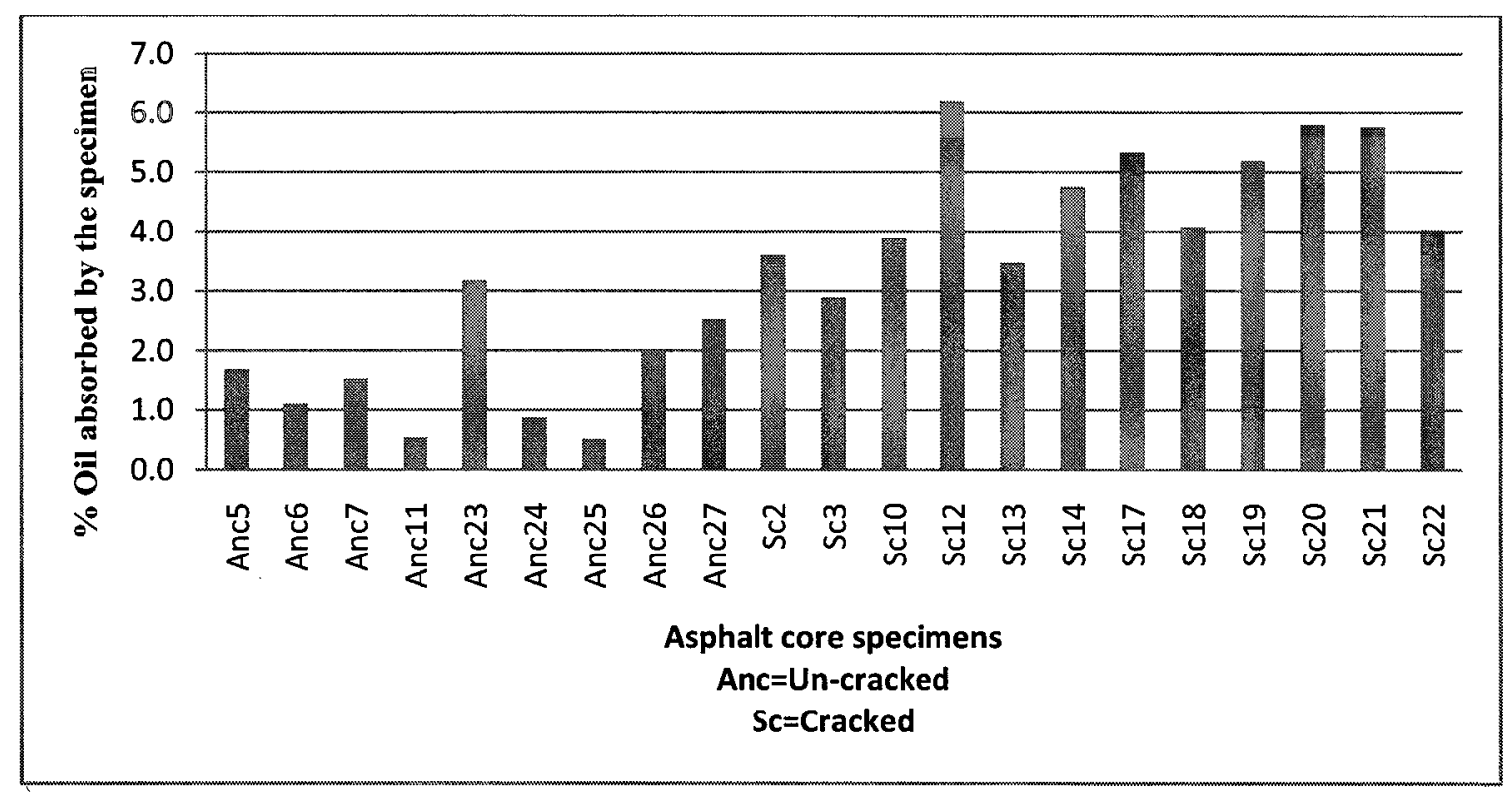

Figure 6.20 Percent of absorbed oil by the specimens

TDC promote the exposed oil to the pavement surface to go through and negatively affect the underneath soil. From the oil tests it was indicated that oil which passes through the specimen will draw some components from the asphalt mixture. Figure 6.22 shows a 


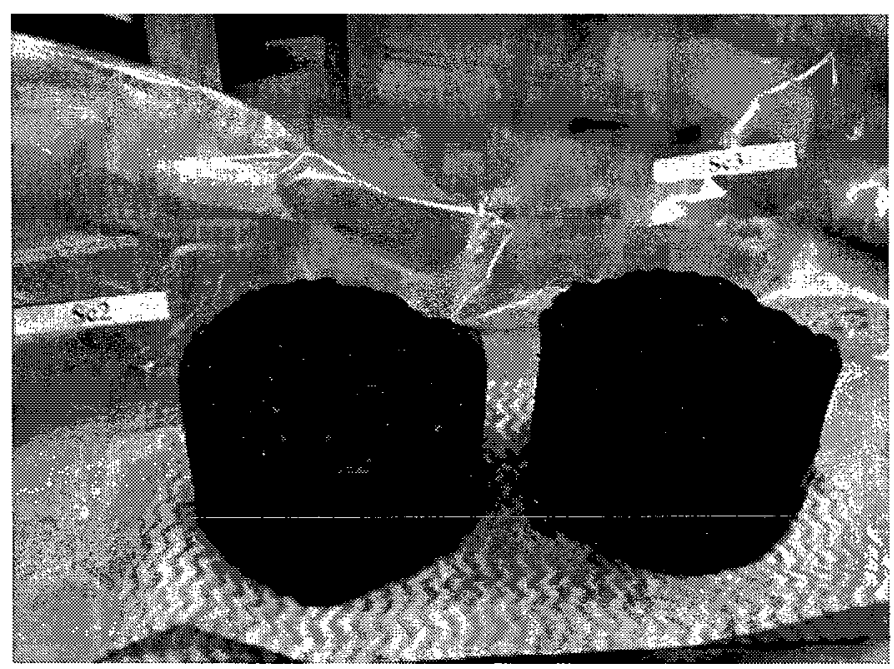

Figure 6.21 Stripping occurred to cracked specimens (SC2, SC3) after been applied to the effect of oil

difference in the color of the collected oil under the cracked specimens compared to the color of the original applied oil. A slightly difference in color was also seen in some of the specimens as shown in Figure 6.22 and that was hardly occurred to some of the uncracked specimens, while most of the un-cracked specimens does not allow the oil to go through as illustrated in Figure 6.23.

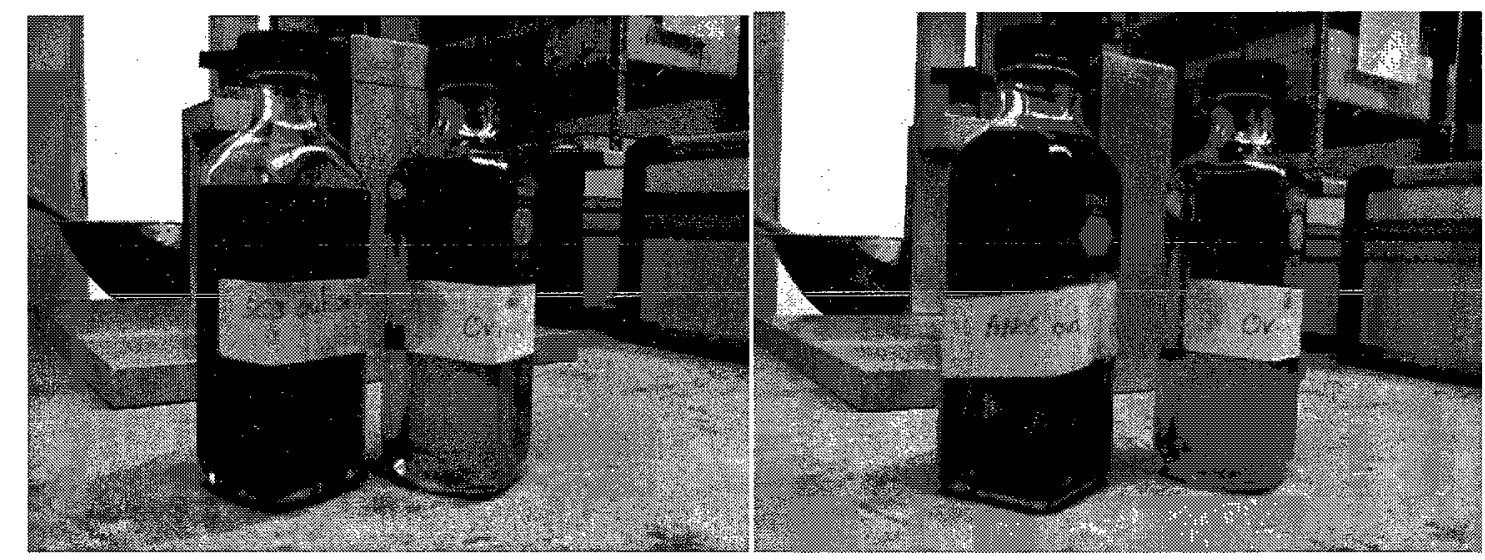

(a)

(b)

Figure 6.22 Collected oil under (a) cracked specimen (b) un-cracked specimen 


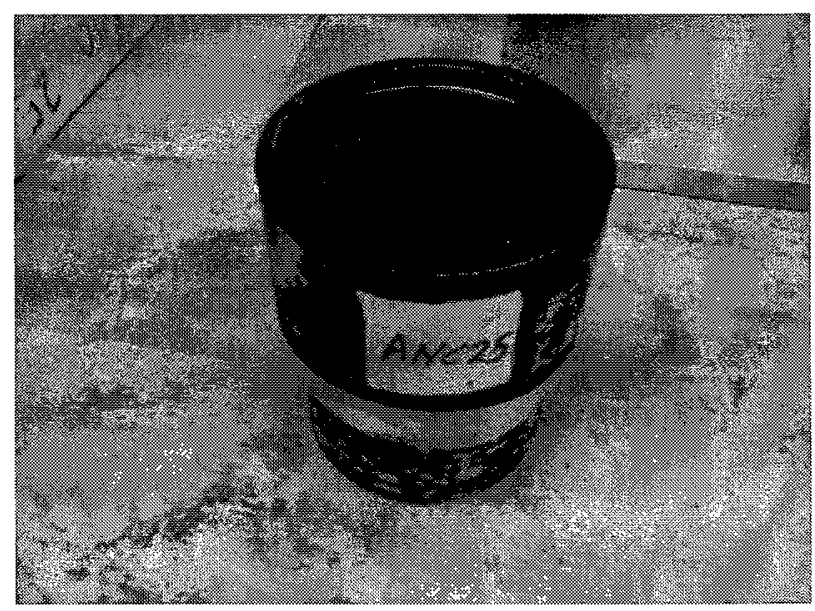

Figure 6.23 No oil passed through the specimen (ANC25)

The weight of the specimen was measured at the end of the test and the weight of the fragmented parts which were separated from the test specimens under the effect of oil was calculated and presented in Table 6.6 and Figure 6.24.

Based on the findings of the present laboratory oil test, it was demonstrated that with the existence of TDC on the pavement surface, oil exposed to cracked asphalt pavement could negatively affect the quality of the pavement such as reducing the adhesiveness to the aggregates, leading to stripping. Figure 6.24 illustrates that one of the major factors influencing the effect of oil in the asphalt pavement integrity was the existence of TDC. It was revealed that the average percent of the released and fragmented material from the un-cracked tested asphalt specimens showed low value, which was less than $1.5 \%$ the weight of the specimen, while it showed high value of more than $4 \%$ in the case of cracked asphalt specimen. This is a significant ratio of $267 \%$.

As can be seen from Figures 6.19, 6.20, 6.24, although the cracked specimens were extracted from different field sections which may have different asphalt concrete mixtures, however it was noted that there was no significant variation in the results in 
terms of the percent of oil absorbed by the specimens, quantity of oil passed through the specimens, and the total fragmented material due to the effect of oil which passed through the specimens. This indicates that the effect of TDC on the integrity of the asphalt pavement and on the underground soil is not mix related but rather due to external factors.

Table 6.6 Influence of TDC on the fragmented material percent from the specimens.

\begin{tabular}{|c|c|c|c|c|c|c|c|}
\hline $\begin{array}{l}\text { Specimen } \\
\text { situation }\end{array}$ & $\begin{array}{l}\text { Specimen } \\
\text { No. }\end{array}$ & $\begin{array}{l}\text { Specimen } \\
\text { Dry } \\
\text { Weight in } \\
\text { Air }\end{array}$ & $\begin{array}{l}\text { Weight of } \\
\text { Specimen } \\
\text { Saturated } \\
\text { with Oil }\end{array}$ & $\begin{array}{l}\text { Oil Absorbed } \\
\text { by the } \\
\text { Specimen }\end{array}$ & $\begin{array}{l}\text { Material } \\
\text { Fragmented } \\
\text { from } \\
\text { Specimen }\end{array}$ & $\begin{array}{l}\text { Material } \\
\text { Fragmented } \\
\text { from } \\
\text { Specimen }\end{array}$ & $\begin{array}{l}\text { Material } \\
\text { Fragmented } \\
\text { from } \\
\text { Specimen }\end{array}$ \\
\hline & & $\mathrm{g}$ & $\mathrm{g}$ & $\mathrm{g}$ & $\mathrm{g}$ & $\%$ & Avg. \% \\
\hline \multirow{9}{*}{ 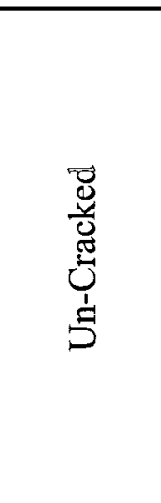 } & Anc5 & 1354.15 & 1352.7 & 22.79 & 24.2 & 1.79 & \multirow{9}{*}{1.28} \\
\hline & Anc6 & 1330.4 & 1327.4 & 14.54 & 17.5 & 1.32 & \\
\hline & Anc7 & 1342.3 & 1340.4 & 20.46 & 22.4 & 1.67 & \\
\hline & Anc11 & 827.61 & 831.01 & 4.41 & 1.0 & 0.12 & \\
\hline & Anc23 & 849.77 & 858.97 & 26.94 & 17.7 & 2.09 & \\
\hline & Anc24 & 1308.05 & 1310.23 & 11.33 & 9.1 & 0.70 & \\
\hline & Anc25 & 1411.19 & 1412.89 & 7.16 & 5.5 & 0.39 & \\
\hline & Anc26 & 1000.76 & 1011.34 & 40.13 & 15.4 & 1.54 & \\
\hline & Anc27 & 777.4 & 785.97 & 23.6 & 15.03 & 1.93 & \\
\hline \multirow{12}{*}{ 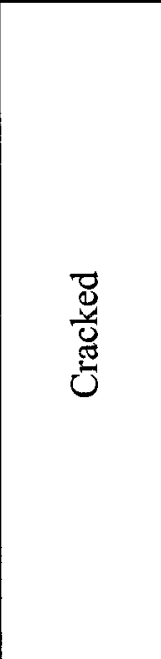 } & Sc2 & 1116.41 & 1066.79 & 40.14 & 89.8 & 8.04 & \multirow{12}{*}{4.49} \\
\hline & $\mathrm{Sc} 3$ & 1145.13 & 1114.37 & 32.95 & \begin{tabular}{|l|l|}
63.7 &
\end{tabular} & 5.56 & \\
\hline & Sc10 & 780.96 & 753.44 & 30.27 & 57.8 & 7.40 & \\
\hline & $\mathrm{Sc} 12$ & 828.77 & 798.64 & 51.27 & 81.4 & 9.82 & \\
\hline & $\mathrm{Sc} 13$ & 1026.98 & 1051.9 & 35.56 & 10.6 & 1.04 & \\
\hline & Sc14 & \begin{tabular}{|l|}
1033.4 \\
\end{tabular} & 1056.59 & 49.01 & 25.8 & 2.50 & \\
\hline & $\mathrm{Sc} 17$ & 642.25 & 655.55 & 34.19 & 20.9 & 3.25 & \\
\hline & $\mathrm{Sc} 18$ & \begin{tabular}{|l|l|}
923.8 \\
\end{tabular} & 945.06 & 37.63 & 16.4 & 1.77 & \\
\hline & $\mathrm{Sc} 19$ & 923.18 & 927.89 & 47.8 & 43.1 & 4.67 & \\
\hline & Sc20 & 805.53 & 831.09 & 46.66 & 21.1 & 2.62 & \\
\hline & Sc21 & 834.28 & 849.35 & 48.01 & 32.94 & 3.95 & \\
\hline & Sc22 & 855.32 & 861.64 & 34.44 & 28.1 & 3.29 & \\
\hline
\end{tabular}




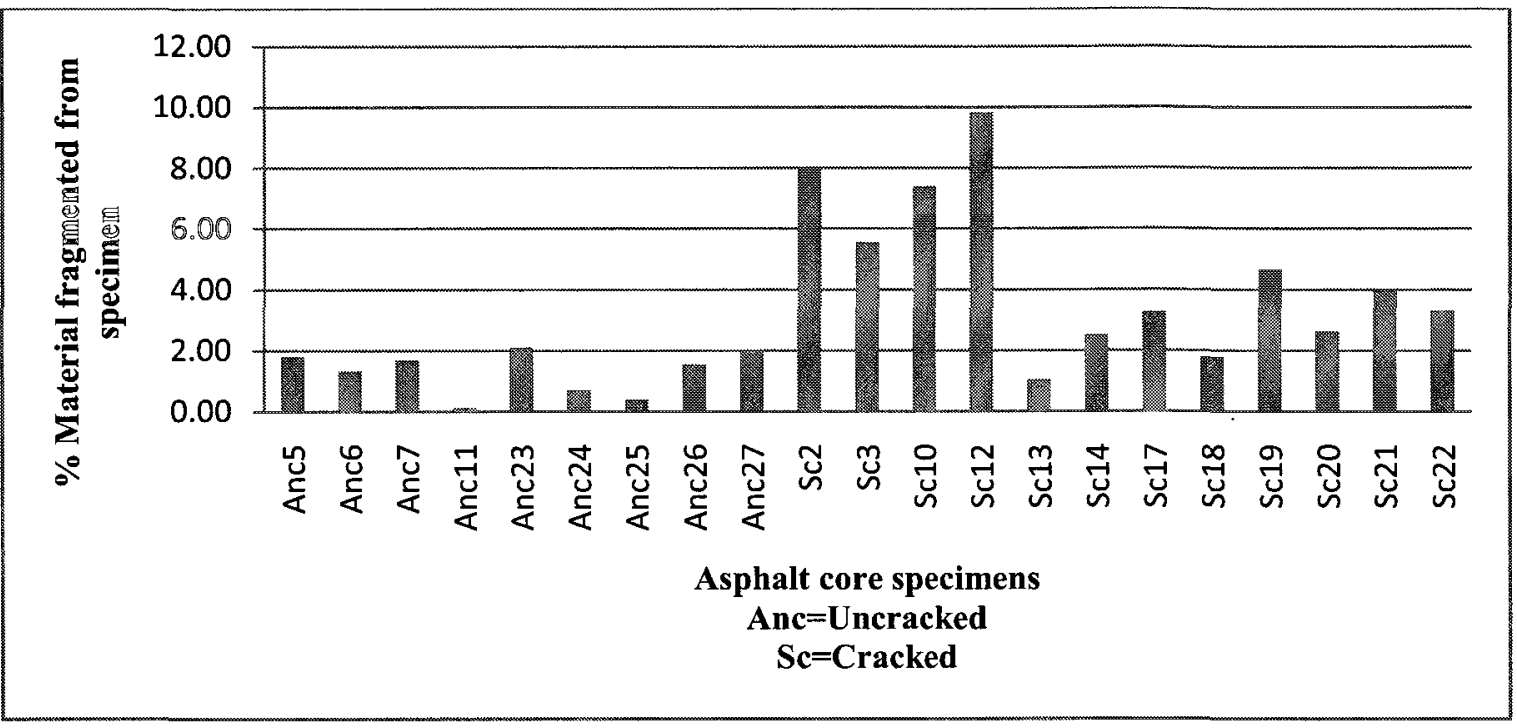

Figure 6.24 Percent of fragmented material from the specimens

\subsubsection{Indirect Tensile Strength Test}

All specimens went under the oil test were subsequently subjected to indirect tensile strength test to find out the changes occurred to the strength of the specimens after being subjected to vehicle engine oil for both cracked and the un-cracked specimens. Moreover, the indirect tensile test was conducted on another 12 specimens, six from each site section, these 12 specimens were not subjected to the effect of oil; hence they were treated as reference specimens. The indirect tensile strength test is used to determine the tensile properties of the asphalt concrete, which can be further related to the cracking properties of the pavement (Texas Department of Transportation, 2004).

This test is performed by applying compressive loads along a diametrical plane across the circular section through two opposite loading strips as shown in Figure 6.25(a). The loading causes a tensile deformation perpendicular to the loading direction, which yields a tensile failure. The test loads were continued until the breaking point, where the 
specimen failed by splitting along the vertical diameter as shown in Figure 6.25(b) and the maximum load carried by the specimen was recorded, the specimens' dimensions were measured.

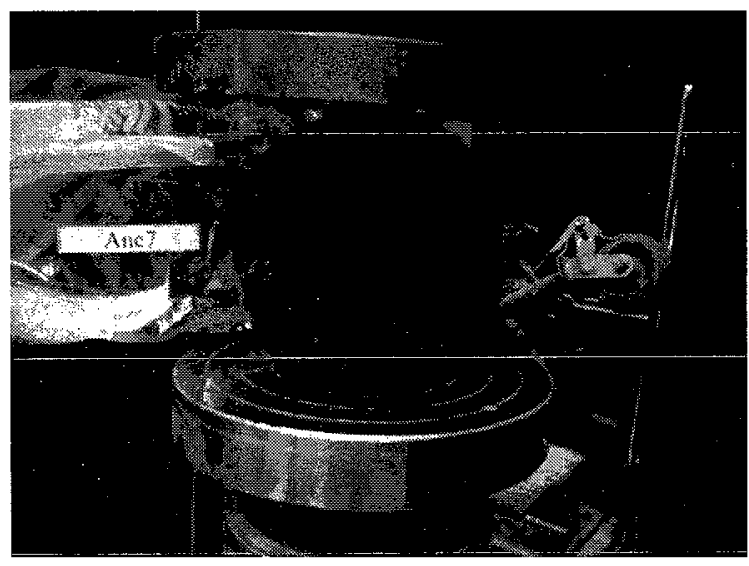

(a)

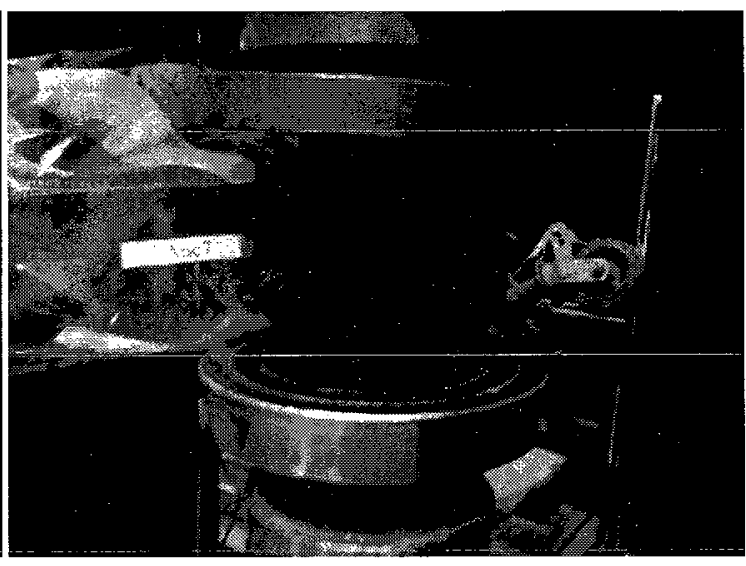

(b)

Figure 25 Indirect tensile strength test a) loading mode, b) failure mode

Result and discussion of the indirect tensile strength test.

\section{Results}

The indirect tensile strength of the specimens was determined at failure using Equation 6.2 (Texas Department of Transportation, 2004) and the results of the indirect tensile test were presented in Table 6.7. Indirect tensile strength for each group of specimens was averaged and reported as the indirect tensile strength of that group.

$S_{T}=2 F /(3.14 h d)$

Where:

$\mathrm{S}_{\mathrm{T}}=$ Indirect tensile strength, $\mathrm{MPa}(\mathrm{psi})$

$\mathrm{F}=$ Total applied vertical load at failure, $\mathrm{N}(\mathrm{lb}$.) 
$\mathrm{h}=$ Height of specimen, in $\mathrm{mm}$ (in.)

$\mathrm{d}=$ Diameter of specimen, $\mathrm{mm}$ (in.).

\section{Discussion}

\section{References specimens}

The average value of the indirect tensile strength tests for the six reference un-cracked specimens was $1165.56 \mathrm{kPa}$. The cracked specimens showed decreased tensile strengths with an average of $690.04 \mathrm{kPa}$. The difference in the indirect tensile strength values of the specimens are illustrated in Figure 6.26. The results showed that clearly, un-cracked specimens had the highest tensile strengths. TDC was the major distress mechanisms which causes a decrease in the tensile strength of the asphalt specimens of about $40 \%$.

\section{Specimens went under oil test}

Figure 6.27 illustrates the results of the indirect tensile strength test for all the specimens which were exposed to the oil test. The average indirect tensile strength of the cracked and the un-cracked specimens is $216 \mathrm{kPa}$, and $1032 \mathrm{kPa}$ respectively. Although the decrease in the tensile strength values of the reference specimens was $40 \%$ due to the existence of TDC in the specimens, however, when both the cracked and the un-cracked specimens were exposed to the effect of oil, the decrease in the strength was relatively very high, it reached up to $80 \%$. 
Table 6.7 Indirect tensile strength test results

\begin{tabular}{|c|c|c|c|c|c|c|}
\hline $\begin{array}{l}\text { Specimen } \\
\text { condition }\end{array}$ & $\begin{array}{l}\text { Specimen } \\
\text { No. }\end{array}$ & Height & Diameter & Load & Strength & $\begin{array}{l}\text { Average } \\
\text { Strength }\end{array}$ \\
\hline & & h & $\mathrm{d}$ & $\mathrm{F}$ & $\overline{\mathrm{St}}$ & $\mathrm{St}_{\mathrm{avg}}$ \\
\hline Group & & $\mathrm{mm}$ & $\mathrm{mm}$ & $\mathrm{N}$ & $\mathrm{kPa}$ & $\mathrm{kPa}$ \\
\hline \multirow{9}{*}{ 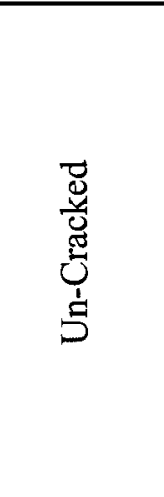 } & Anc5 & 70 & 100 & 13833.0 & 1258.69 & \multirow{9}{*}{1031.74} \\
\hline & Anc6 & 70 & 100 & 12741.0 & 1159.33 & \\
\hline & Anc7 & 60 & 100 & 10040.0 & 1065.82 & \\
\hline & Anc11 & 50 & 95 & 7256.0 & 972.98 & \\
\hline & Anc23 & 50 & 100 & 7021 & 894.39 & \\
\hline & Anc24 & 70 & 100 & 14243 & 1296.00 & \\
\hline & Anc25 & 75 & 100 & 14064 & 1194.39 & \\
\hline & Anc26 & 60 & 97 & 7124 & 779.65 & \\
\hline & Anc27 & 50 & 95 & 4955 & 664.43 & \\
\hline \multirow{6}{*}{ 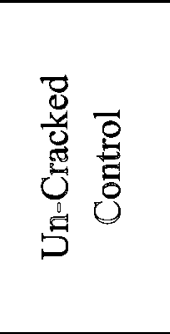 } & $\mathrm{A} 1$ & 60 & 95 & 11624 & 1298.92 & \multirow{6}{*}{1165.56} \\
\hline & $\mathrm{A} 2$ & 55 & 97 & 10313 & 1231.26 & \\
\hline & A3 & 55 & 97 & 9151 & 1092.53 & \\
\hline & $\mathrm{A} 4$ & 55 & 97 & 8688 & 1037.26 & \\
\hline & A5 & 75 & 97 & 13618 & 1192.29 & \\
\hline & A6 & 85 & 97 & 14771 & 1141.09 & \\
\hline \multirow{12}{*}{ 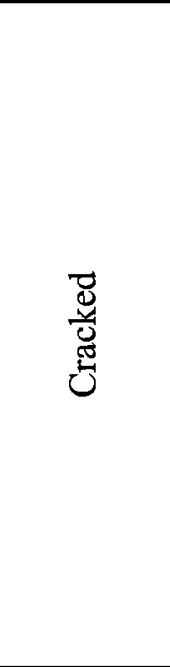 } & $\mathrm{Sc} 2$ & 68 & 94 & 4805.0 & 478.80 & \multirow{12}{*}{215.78} \\
\hline & $\mathrm{Sc} 3$ & 70 & 97 & 5920.0 & 555.33 & \\
\hline & Sc 10 & 50 & 97 & 1237.0 & 162.45 & \\
\hline & Sc12 & 50 & 97 & 1257.0 & 165.08 & \\
\hline & $\mathrm{Sc} 13$ & 65 & 97 & 1837.0 & 185.58 & \\
\hline & Sc14 & 65 & 97 & 1730.0 & 174.77 & \\
\hline & $\mathrm{Sc} 17$ & 45 & 97 & 861.0 & 125.64 & \\
\hline & Sc18 & 58 & 97 & 2086.0 & 236.16 & \\
\hline & Sc19 & 65 & 97 & 689.0 & 69.60 & \\
\hline & $\mathrm{Sc} 20$ & 50 & 97 & 735.0 & 96.53 & \\
\hline & $\mathrm{Sc} 21$ & 50 & 97 & 1383 & 181.63 & \\
\hline & $\mathrm{Sc} 22$ & 45 & 100 & 1115 & 157.82 & \\
\hline \multirow{6}{*}{ 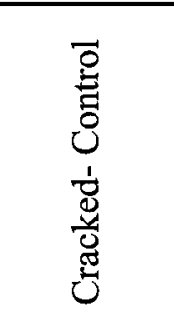 } & $\mathrm{C} 1$ & 60 & 97 & 5707 & 624.58 & \multirow{6}{*}{690.04} \\
\hline & $\mathrm{C} 2$ & 70 & 97 & 8222 & 771.27 & \\
\hline & $\mathrm{C} 3$ & 60 & 97 & 6404 & 700.86 & \\
\hline & $\mathrm{C} 4$ & 55 & 95 & 6005 & 732.03 & \\
\hline & $\mathrm{C} 5$ & 65 & 97 & 5482 & 553.80 & \\
\hline & C6 & 70 & 95 & 7911 & 757.72 & \\
\hline
\end{tabular}




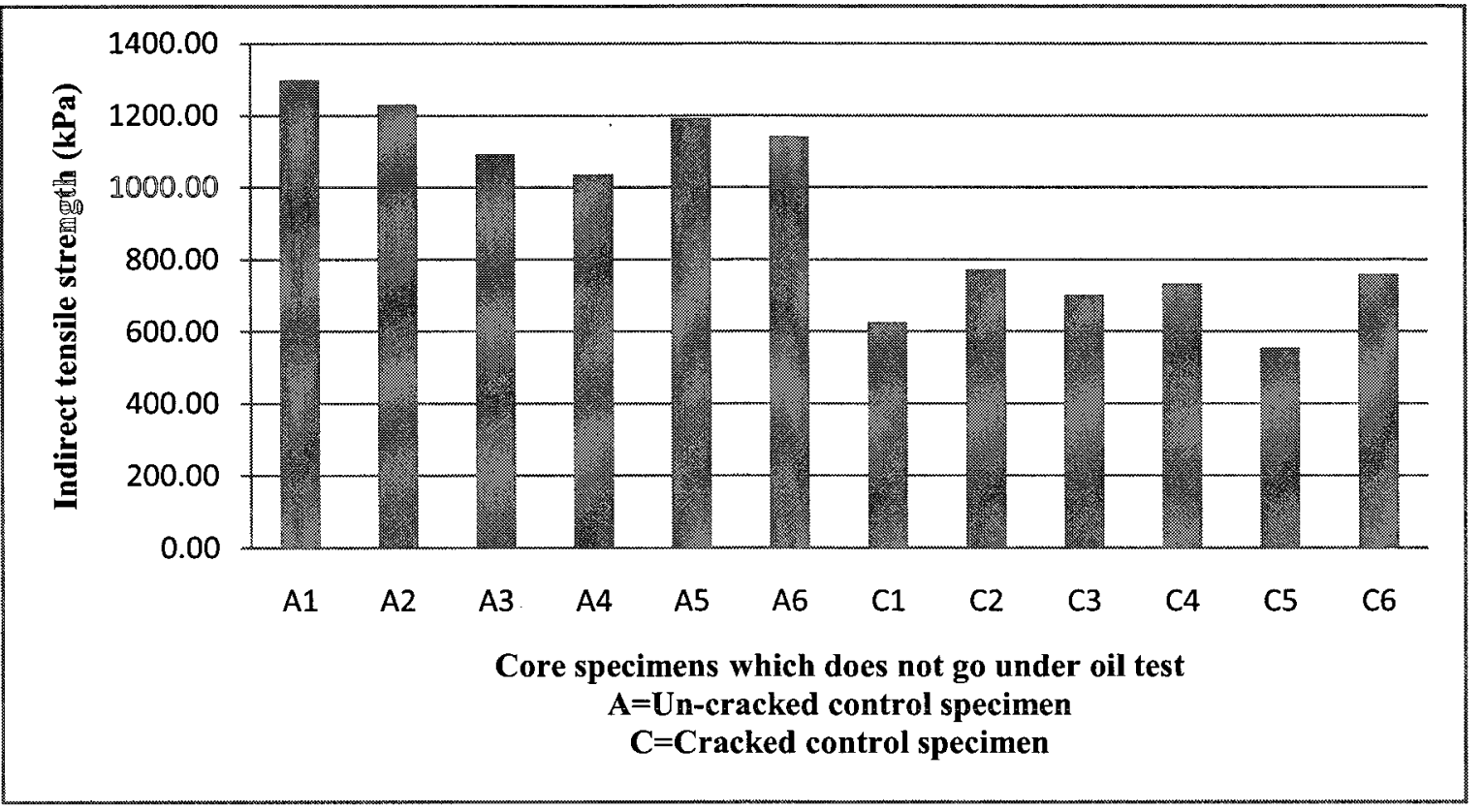

Figure 6.26 Measured indirect tensile strength test for control specimens.

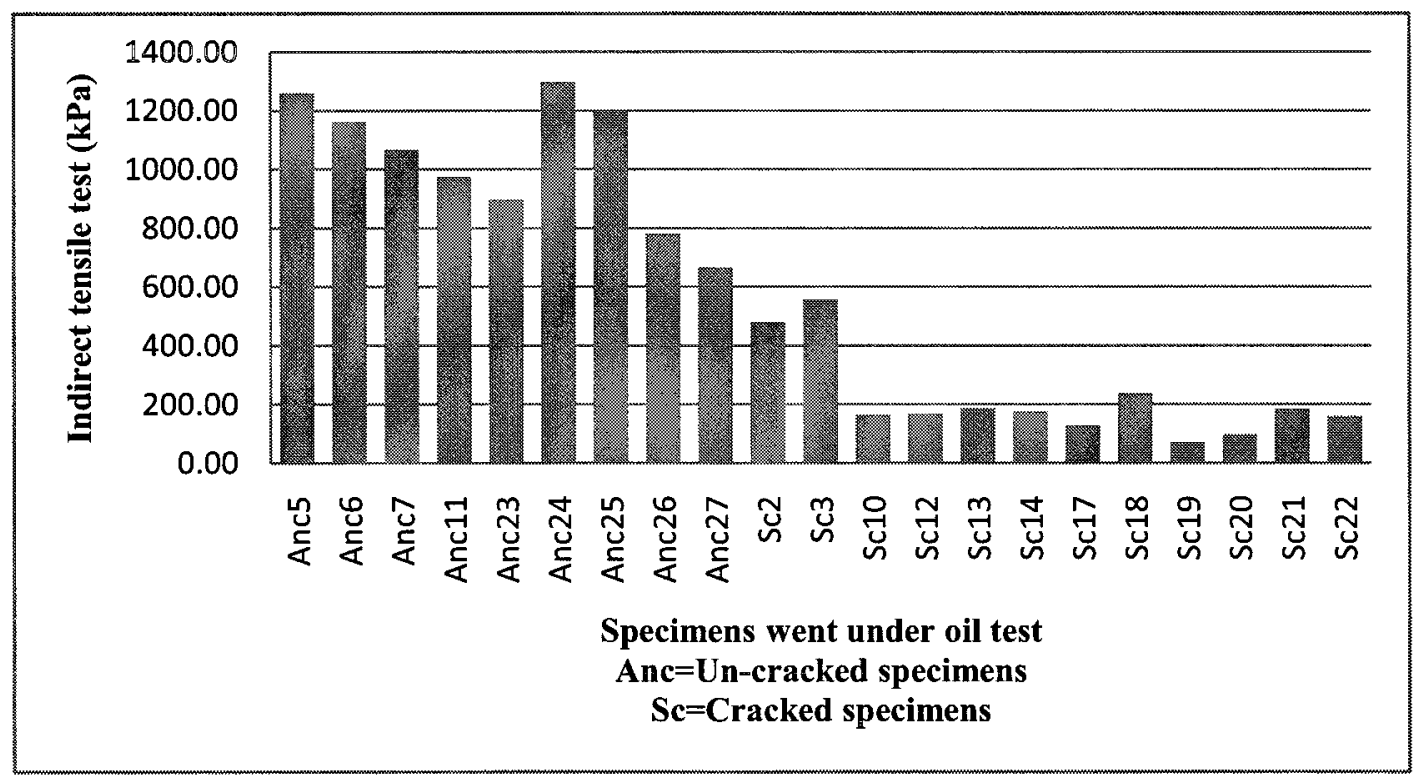

Figure 6.27 Effect of oil spill on the measured indirect tensile strength

Indirect tensile strength values for the cracked and the un-cracked asphalt specimens, those went under the oil test are lower compared with the reference specimens that do not go under the oil test and which is under the same distress condition. In the case of un- 
cracked asphalt cores the decrease in the tensile strength for the asphalt specimens after it goes under the oil test was insignificant as it was demonstrated in Figure 6.28. The decrease was about $11 \%$ of the initial tensile strength, which is relatively very small compared to the decrease in the tensile strength of the cracked specimens after they were exposed to oil test, which reaches $69 \%$. Figure 6.29 illustrates the significant drop in the tensile strength in the case of cracked specimens after exposing the specimens to the oil test. This indicates that the cracked mixtures exposed to oil have significant lower values of tensile strength at failure static loading. This revealed that the inclusion of TDC increased the quantity of oil that passes through the specimen and hence extracted more compounds from the specimen and weaken the asphalt binder causing a reduce in the tensile strength of the specimens. The results proved that the presence of TDC in asphalt concrete pavement reduces the tensile strength of the asphalt concrete pavement.

On the other hand, it is important to note that the measured tensile strength of uncracked surface specimens were not significantly affected by the presence of oil since it did not penetrate into the body of the tested specimens. Clearly, the higher tensile strength in the un-cracked specimens is the result of a stronger resistance to the effect of oil and its prevention from seeping into the asphalt specimen. 


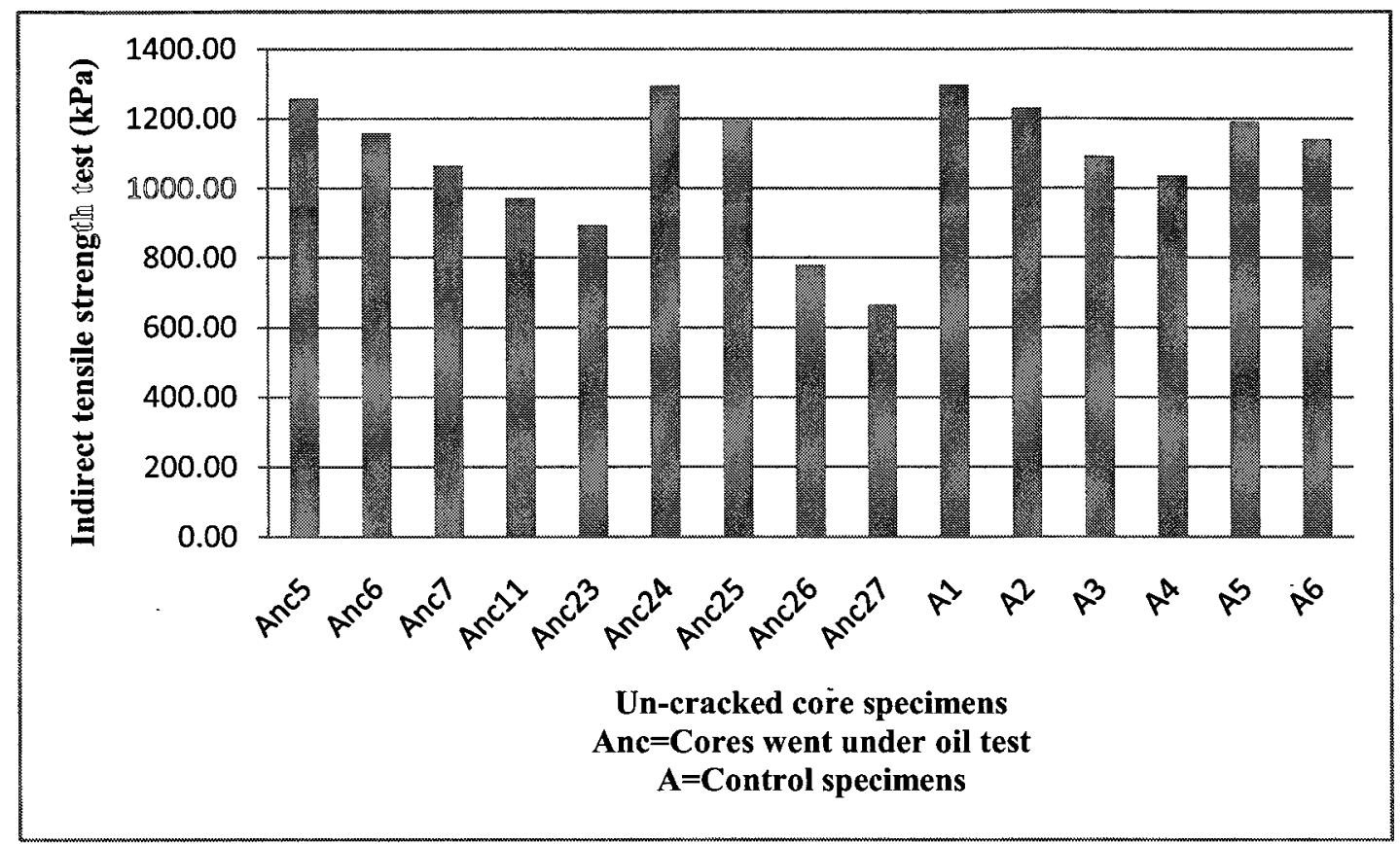

Figure 6.28 Indirect tensile strength test results for un-cracked specimens, those went under the oil test and the control specimen as well

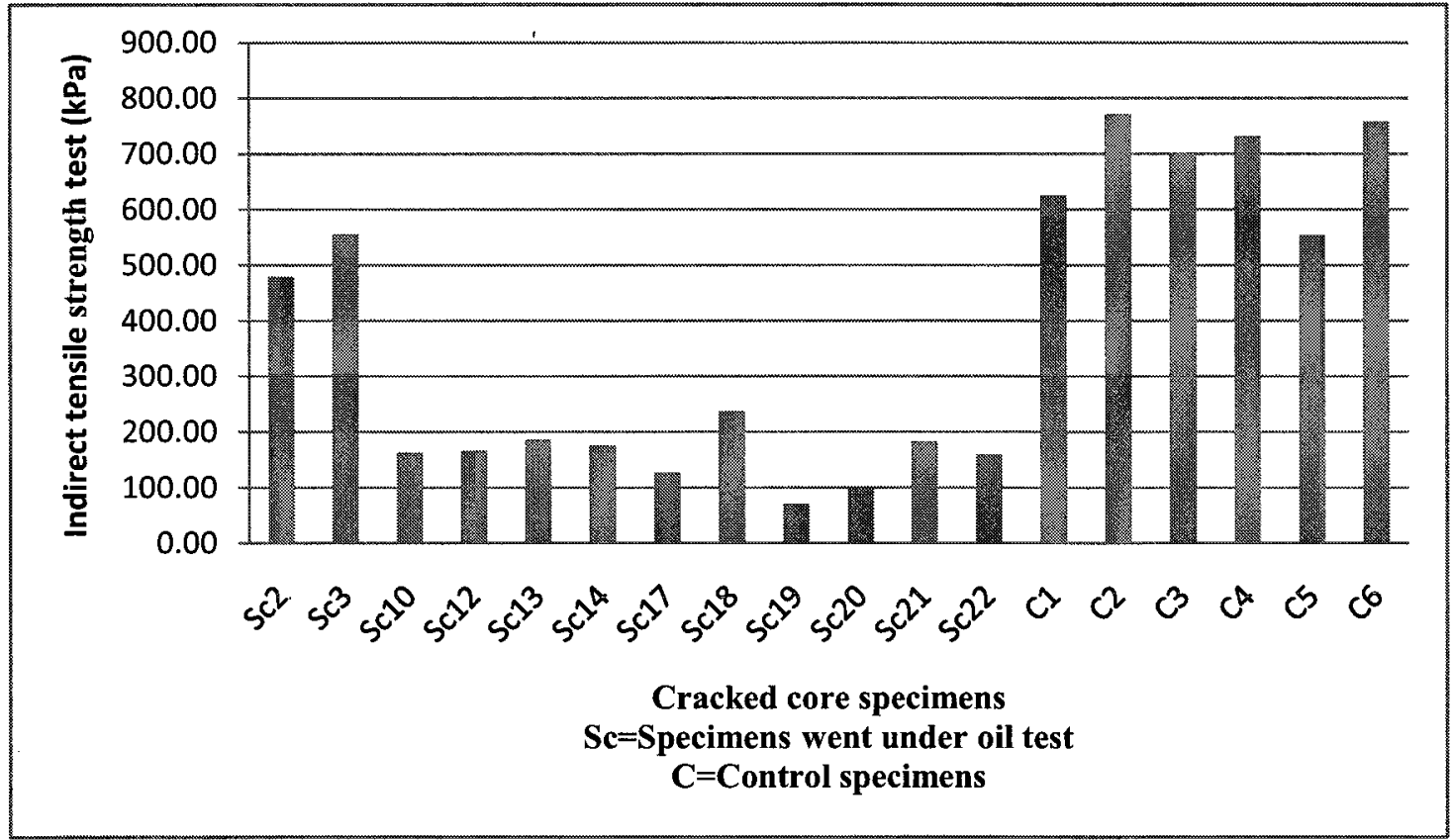

Figure 6.29 Indirect tensile strength test results for cracked specimens, those went under the oil test and the control specimen as well 


\section{Summary}

- In this chapter, the objectives, equipment and procedures for investigating the effect of TDC in the integrity of the asphalt concrete pavement was demonstrated. The tests "density, permeability, water analysis, indirect tensile strength, and the effect of oil" were introduced and defined. The last test was established in this chapter to describe the changes in the condition of the asphalt specimen when it is experiencing TDC and is exposed to oil, which significantly affects the integrity of the asphalt pavement. The Chapter also addressed the field and laboratory investigations of the asphalt pavement permeability, which was conducted in this study. The field investigation consisted of examining the permeability of two pavement sections, one experienced TDC and the other does not have any cracks in the surface. The laboratory investigation included permeability measurements, specific gravity tests, and indirect tensile strength test for specimens from different pavement sections. The later test was used to assess the impact of oil on cracked and un-cracked pavement by comparing the changes occurred to the tensile strength of the asphalt specimens.

- The results of the laboratory and field tests presented in this Chapter showed that surface cracks induced in the wearing asphalt course could lead to several deficiencies ranging from lower densities to fully damaged layer and seriously threatening the environment. It is time that pavement engineers and researchers pay more attention to develop effective methods to prevent the occurrence of surface cracks not only to protect the initial investment in the construction of the pavements but also to protect the environment and our water resources. 


\section{CHAPTER SEVEN}

\section{Conclusions}

This thesis presented a detailed review of the state-of the-art on the problem of TopDown-Cracks and its history. A literature review was conducted for the current and previous efforts invested to illustrate the initiation and propagation mechanisms, causes, and the recommended remedies to TDC in asphalt layers made of hot mix asphalt mixtures. Also, the study included an analytical investigation to examine the long held belief that thermal stresses initiates surface cracks in the top asphalt layer. Finally, a well planned laboratory and field investigation was performed to assess the effects of the topdown-cracks on the physical, mechanical and environmental properties of the asphait structure. Various conclusions were drawn and are presented below:

- A review in the literature revealed a major deficiency or a gap in current pavement construction equipment, mainly, the absence of a proper compaction equipment that can effectively compact the asphalt concrete material in the last stage of the construction posses without inducing surface defects or cracks. In the absence of an adequate understanding of the main causes of the problem of TDC, the pavement industry has been applying the same compaction equipment since the first asphalt lane was compacted more than 100 years ago.

- Top-down-cracks initiate at the surface of the top wearing course and propagates down to the binder course. Therefore conventional theories of bottom-up fatigue cracks and reflective cracks can no longer appropriate to follow when the service life 
of the pavement is in question. This conclusion may have prompted many researchers to identify the true causes and nature of TDC initiation and try to understand the factors affecting its causes.

- The literature review concluded that TDC initiation is attributed by numerous researchers to two major factors, namely:

- High surface tensile stresses that are induced by load and thermal stresses.

- Low tensile strength of the AC mix that is due to poor compaction and/or segregation.

The only commonality in the previous research works while studying the various factors that can induce cracks is the conventional compaction process. The hypothesis this research presents is that the compaction process is the root cause of the initiation of TDC.

- Once the cracks are initiated at the surface, it will be a matter of time when these cracks will propagate vertically downward into the entire depth of the asphalt layer of the pavement and laterally along and across the surface at different rates. The tensile stresses that is induced at the crack tip promote the propagation of the initiated crack downward toward the base course, while the degree of segregation propagate the crack longitudinally and transversely on the pavement surface.

- As TDC adversely affected the pavement performance in both short and long term, full understanding of the initiation and propagation mechanisms of Top-Down-Cracks would give us a guide to identify the different stages TDC takes to form a severe distress to the asphalt pavement. Also it is essential in order to implement appropriate preventive maintenance actions 
- Top-down-cracks which appear at the pavement surface very early after the compaction process and known as compaction induced cracks are attributed to the cylindrical shape and to the stiffiness of the material of the conventional steel drums of the roller. The initiation of these cracks at the very early stage of the pavement life contributes to the severe loss of tensile strength of the asphalt layer as well as the overall mechanical properties of the structure.

- Stresses induced due to the contact between the truck axle/wheel loads and the pavement is not a major factor that could cause the occurrence of TDC, however it could be a factor for the propagation of the initiated cracks.

- Current thermal stress approaches failed to explain many of the observations associated with the phenomenon of transverse cracking. However, Thermal induced tensile stresses, resulting from either a combined action of low temperatures and thermal fatigue caused by daily temperature variation or from one of them, greatly contributes to the propagation of cracks initiated at earlier stage.

- To eliminate or minimize TDC, more efforts should be directed toward the control of crack initiation during compaction and construction of the pavement. A gradual exercise of long duration loading on the asphalt surface at high temperatures is considered one of the major remedies in the asphalt concrete construction industry. That was achieved by the invention of the Asphalt Multi Integrated Roller (AMIR). Using AMIR roller demonstrated that the match between the geometry and the relative rigidity between the AMIR roller and the asphalt mat could provide a smooth surface with no surface cracks. Moreover the large flat contact between the rubber 
belt and the flat asphalt minimize the horizontal forces those produced on the asphalt pavement under the roller.

- More over applying a sufficient load for a longer time will result in viscous fllow and compaction of the asphalt mixture. The amount of flow will increase as the temperature remains high, and thus the optimum compaction will be achieved. Thus, an asphalt mat can be more effectively compacted when subjected to a load of sufficient duration at higher temperatures.

The mechanical and environmental influences of the Top-Down-Cracks on the overall performance of the asphalt pavement have been investigated through a well planned and implemented laboratory and field investigation. Based on the outcomes of the field and laboratory investigation the following conclusions are presented below:

- Specimens compacted with the AMIR roller were able to produce a satisfactory crack free with tight surface texture. Whereas a number of surface cracks can be observed on the specimens compacted using current compaction equipment.

- Measured densities of asphalt specimens extracted from the field were the first indication of deficiencies of the asphalt concrete mix compacted with traditional rollers. The asphalt specimens confirmed that crack free pavements will have higher densities when compared to those having TDCs.

- Laboratory and field investigations revealed that the permeability of the cracked specimens was significantly much higher than the un-cracked specimens and that could only be explained due to the existence of Top-Down Cracks. 
- As the layers become permeable, water can infiltrate into the mix and subsequently cause moisture damage in the pavement, therefore, influencing badly the environmental performance of the pavement, the soils and water resources connected to the paved road.

- Top-down-crack promoted the chemical interaction between the salt in the melted ice and the asphalt mix, hence, increases the reaction occurring with asphalt and subsequently raising the possibilities of pollution. The total pollution produced by the cracked specimens was almost 200 times that caused by un-cracked specimens.

- The time factor here is considered a significant factor where the total pollution is much higher in the water collected from the cracked specimens. This means that the rate of pollution produced by the cracked specimens $(0.446 \mathrm{mg} / 1 / \mathrm{min})$ is almost 225 times that for the un-cracked specimen $(0.002 \mathrm{mg} / \mathrm{l} / \mathrm{min})$. This is considered very high rate which could cause serious damage to the environment and can affect the natural and water resources near the cracked pavement. As well as the long term performance of the asphalt pavement.

- Oil spilled on cracked asphalt pavement could negatively affect the integrity of the asphalt pavement such as reducing the adhesiveness and bond to the aggregates, leading to stripping, disintegration of the asphalt matrix and reduction in the tensile strength of the asphalt pavement.

- The passing and absorbed amounts of spilled oil would increase the damage caused to the road in addition to the environmental effects of the oil seepage on the soil and water sources. 
- The effect of TDC on the integrity of the asphalt pavement and on the underground soil is not mix related, but rather due to external factors, since different cracked core specimens show no significant variation in the results in terms of the percent of oill absorbed by the specimens, quantity of oil passed through the specimens, and the total fragmented material due to the effect of oil.

- It was demonstrated that the presence of TDC in asphalt concrete pavement reduces the tensile strength of the asphalt concrete pavement.

- Measured tensile strength of un-cracked surface specimens was not significantly affected by the presence of oil since the oil did not penetrate into the body of the tested specimens. Clearly, the higher tensile strength in the un-cracked specimens is the result of its tighter texture and higher resistance seeping of oil into the asphalt specimen.

- The results of the laboratory and field tests presented in this thesis showed that surface cracks induced in the wearing asphalt course could lead to several deficiencies ranging from lower densities to fully damaged layer and seriously threatening the environment. It is time that pavement engineers and researchers pay more attention to developing effective methods to prevent the occurrence of surface cracks not only to protect the initial investment in the construction of the pavements but also to protect the environment and our water resources.

- The study presented in this thesis showed that careful understanding of basic assumptions commonly used in the pavement industry and serious challenging of their validity can lead to more reliable solutions of some of the problems that have been unsolved for a long time. 
- Finally, it is recommended to simulate the problem of thermal cracking in the laboratory, the simulation should be performed on asphalt specimens reflecting the actual geometry and construction conditions in the field. 


\section{References}

Abd El Halim, A.O., and Razaqpur, A.G., "Minimization of reflection cracking through the use of geogrid and better compaction". Proceedings 20 of the Second International RILEM Conference., 1993.

Abd El Halim, A.O. and Haas, R., "Effect of Field Compaction Method on Fatigue Life of Asphalt Pavements". Transportation Research Record 1469, TRB, National Research Council, Washington, D.C., pp. 43-49, 1994.

Abd El Halim, A.O., Aljassar, A., Hassan Y., and Haas R.C., "Transverse Cracking". Canadian Technical Asphalt Association Proceedings, pp 174-192, 1994.

Abd El Halim, A.O., "Experimental and Field Investigation of the Influence of Relative Rigidity on the Problem of Reflection Cracking". Transportation Research Record 1060, NRC, Washington DC, pp.88-98, 1986.

Abd El Halim, A.O., "Geogrid reinforcement of asphalt pavements". PhD Thesis, University of Waterloo, 1983

Abd El Halim, A.O., Phang, W.A., Haas, R., "Realizing Structural Design Objectives Through Minimization of Construction Induced Cracking". Sixth international conference, structural design of asphalt pavements, volume I, proceeding, University of Michigan, July 13-17, 1987.

Abd El Halim, A.O., "The Myth of Reflection Cracking.". Proceeding, Canadian Technical Asphalt Association Saskatoon, 1984.

Abd El Halim, A.O., Haas, R., and Svec, O.J. "Improved asphalt pavement performance through a new method of compaction". Proceedings of the Association of Asphalt Paving Technologists. Vol. 17, pp.175-191, 1994.

Abd El Halim, A.O., Phang, W., and Haas, R.C., "Unwanted legacy of asphalt pavement compaction". Journal of Transportation Engineering, 119 (6), pp 914 932, 1993.

Abd El Halim, A.O., "Influence of Relative Rigidity on the Problem of Reflection Cracking". Transportation Research Record 1007, NRC, Washington DC, pp.53-58, 1985.

Anderson, D., Lapalul, L., and Marasteanu, M., "Low-temperature thermal cracking of asphalt binders as ranked by strength and fracture properties". In Transportation Research Record 631, Washington, D.C.1, pp. 1-6, 200. 
Andrew D., Yavuzturk, C.C., and Ksaibati, K., "Linearized Approach for Predicting Thermal Stresses in Asphalt Pavements due to Environmental Conditions". Journal of Materials in Civil Engineering, ASCE, Vol. 118, February 2008.

Amold, E.G., Lenore, S.C., Andrew, D.E., "Standard methods for the examination of water and wastewater". 18th edition, 1992.

\section{ASTM D 2726 REV A Document Information}

ASTM Geotechnical Testing Journal for publication, "Sidewall Leakage in Hydraulic Conductivity Testing of Asphalt Concrete Specimens", June 2002.

Brock, J.D., May, J.G., and Renegar, G., "Segregation causes and cures", Technical Paper T-117, Astec Industries, 1996.

Brown, E.R., Ronald, C., and Brownfield, J.R., "Investigation of segregation of asphalt mixtures in the state of Georgia", Transportation Research Record 1217, TRB, National Research Council, Washington, D.C., pp1-8, 1989.

Brown, E.R., "Density of asphalt concrete - How much is needed?", Transportation Research Record, TRB, Washington, D.C., 69th annual meeting, 1990.

Chang, C.M, "Detecting Segregation in Bituminous Pavements and Relating its Effects to Performance," A Ph.D. Thesis, Department of Civil and Environmental Engineering, Michigan State University, 2000.

Chang, C.M., Baladi, G.Y., and Wolff, T.F., "Detecting Segregation in Bituminous Pavements," Transportation Research Record, TRB, National Research Council, Washington, D.C., 2002, pp 77-86.

Dauzats, M., and Rampal, A., "Mechanism of Surface Cracking in Wearing Courses". Proceedings, 6 th International Conference. University of Michigan, Ann Arbor, Michigan, pp. 232-247, July 1987.

Deme, I.J., Young, F., "Ste. Anne Test Road Revisited Twenty Years Later", Canadian Technical Asphalt Association Proceedings, pp 254-283, 1987.

Dempsey, B. J., "Development and Performance of Interlayer Stress- Absorbing Composite in Asphalt Concrete Overlays". In Transportation Research Record 1809, TRB, National Research Council, pp. 175-183, 2002. 
Easa, S.M., Shalaby, A., and Abd El Halim, A.O., "Reliability- based model for predicting pavement thermal cracking". Journal of Transportation Engineering, Vol. 374, 1996.

El Hussein, H.M., Kim, K.W., and Ponniah, J." Asphalt concrete damage associated with extreme low temperatures". ASCE Journal of Materials in Civil Engineering, 10 (4): 269274, 1998.

Epp J.A., and Monismith C.L., "Influence of mixture variables on flexural fatigue properties of asphalt concrete ". Proceedings, Association of asphalt paving technologists Vol. 38, p.423, 1969.

EZ Asphalt Technology, LLC, PRI Asphalt Technologies "Asphalt Binder Cracking Device" U.S department of transportation, Federal highway administration, 2003. www.fhwa.dot.gov/hfl/partnerships/asphalt_ppt.cfm

Fabb, T.R.J., "The Influence of Mix Composition, Binder Properties and Cooling Rate on Asphalt Cracking at Low Temperatures". Proceedings of the Association of Asphalt Paving Technologists. Vol. 43, p.285-33, February 1974.

Freeman T. E. "Evaluation of Concrete Slab Fracturing Techniques in Mitigating Reflective Cracking Through Asphalt Overlays". Report VTRC 03-R3, Virginia Transportation Research Council, Charlottesville, Virginia. 2002.

Freitas, E. \& Pereira, P.L., Santos, P., "Assessment of Top Down Cracks causes in asphalt pavement", 2003.

Fromm, H.J. and Phang, W.A., "A Study of Transverse Cracking of Bituminous Pavement". Proceedings of asphalt Paving Technology, Volume 41, 383-423, 1972.

Gerritsen, A.H., van Gurp, C.A.P.M., van der Heide, J.P.J., Molenaar, A.A.A. and Pronk, A.C. "Prediction and Prevention of Surface Cracking in Asphaltic Pavements". Proceedings, 6th International Conference Structural Design of Asphalt Pavements, The University of Michigan. Ann Arbor, Michigan, pp. 378-391, July 1987.

Guylain B., and Claude L., "Thermal Cracking of Asphalt Pavement". Canadian Technical Asphalt Association Proceedings CTAA, pages 157-173, 1999.

Haas, R.C.G., and Hajek, J.J., "Predicting low-temperature cracking frequency of asphalt concrete pavements". Highway Research Board, HR record 407, pp. 39-54, 1972. 
Haas, R.C.G., Joseph, A., "Low Temperature Cracking Through Asphalt Overlayers". Sixth International Conference on the Structural Design of Asphalt Pavement, Michigan, 1987.

Hachiya, Y., and Sato, K., "Effect of Tack Coat on Bonding Characteristics at Interface Between Asphalt Concrete Layers," Eight International Conference on the Structural Design of Asphalt Pavements. Proceedings., Washington State University, 1997.

Harmelink, D., and Ascheenbrener, T., "Extent of top-down cracking in Colorado". Colorado Department of Transportation, CDOT, 2003.

Harmelink, D., Shuler, S., and Aschenbrener, T., "Top-Down Cracking in Asphalt Pavements: Causes, Effects, and Cures", 2008.

Henault, J.W., "Development of Guidelines for Reduction of Temperature". Australian Asphalt Pavement Association, Advisory Note 18, 1999.

Heukelom, W., "Observations on theology and fracture of bituminous and asphalt mixes". Proceeding of Asphalt Paving Technologists, 35, 358-399, 1966.

Highway Research Board, "Standard nomenclature and definitions for pavement components and deficiencies"., Highway Research Board, National Academy of Sciences, Washington, D.C, 1970

Hills, J.F., and Brien, D.,"The fracture of bituminous and asphalt mixes by temperature induced stresses". Proceedings, Association of Asphalt Paving Technologists, Vol. 35, pp 292-309, 1966.

Isaac L.H., and Robert S.J., "Bottom up Fatigue Cracking Analysis of low Volume Flexible Pavement Based on Instrumented Testing", 2008

Kandil, K.A., "Analytical and experimental study of field compaction of asphalt mixes", 2002.

Katamine, N.M., "Physical and mechanical properties of bituminous mixtures containing oil shales"., Journal of Transportation Engineering, 126, pp. 178-184, 2000.

Khedaywi, T.S., and White, T.D., "Effect of Segregation on Fatigue Performance of Asphalt Paving Mixtures". Transportation Research Record 1543, TRB, National Research Council, Washington, D.C., pp 63-70, 1996. 
Kim, K.W., and E1 Hussein, M., "Effect of differential thermal contraction on fracture toughness of asphalt materials at low temperatures". Journal of the Association of Asphalt Paving Technologists, 64: 479-499, 1995.

Kim K.W., Kweon S.J., Doh Y.S., and Park T.S., "Fracture toughness of polymer-modified asphalt concrete at low temperatures", 2003.

Lauter, K. A., "Field and Laboratory Investigation of the Effect of Cold In-Place Recycled Asphalt on Transverse Cracking". Master Thesis, Carleton University, 1998.

Kandhal, P. S., Dongre, R., Malone, M. M., "Prediction of low temperature cracking using superpave binder specifications". National Center for Asphalt Technology. U.S. Report No. 96-2, 1996.

Kercher Engineering, Inc "The need for a superior pavement material" www.kercherei.com/.../sp_partl.html

Lim S.C., "Asphalt pavement on semi-rigid road base for high-class highways", 1998.

Linden R.N., Mahoney, J.P., and Jackson, N.C, "Effect of compaction on asphalt concrete performance". Transportation Research Record 1217, TRB, National Research Council, Washington, D.C., PP. 20-28, 1989.

Lippert, D. L., "Discussion in the same paper Ref no. 50 Propagation mechanisms for surface- initiated longitudinal wheel path cracks", 2001.

Loria, L. G., "Reflective Cracking of Flexible Pavements Literature, Analysis Models, and Testing Methods". Master thesis University of Nevada, Reno, 2008.

Lunardini, V.J., "Analytical methods for ground thermal regime calculations" part of Thermal design considerations in frozen ground engineering, American Society of Civil Engineering state of the practice report, pp 204-257, 1985.

Matsuno, S., and Nishizawa, T., "Mechanism of Longitudinal Surface Cracking in Asphalt Pavement". Proceedings, Volume 2, 7th International Conference on Asphalt Pavements, The University of Nottingham, pp. 277-291, 1992.

McGennis, "Evaluating Polymer Modified Asphalt Binders". Journal of Materials in Civil Engineering, 1995. 
Marasteanu, M.O., Li, X., Clyne, T.R., Voller, V.R., Timm, D.H., and Newcomb, D.E., "Low Temperature Cracking of Asphalt Concrete Pavements". Report No. MN/RC - 200423, 2004.

Molenaar, A.A., "Fatigue and Reflective Cracking due to Traffic (With Discussion)". Proceedings of the Association of Asphalt Paving Technologists, Volume 53, pp 440-474, 1984.

Mostafa, A.E., and Abd El Halim, A. O." Asphalt multi-integrated rollers and steel drum compactors evaluating effect of compaction on permeability of asphalt pavements" Transportation Research Record, n 1967, p 173-180, 2006

Mostafa, A.E., "The stripping susceptibility of airfield asphalt mixes: the development of guidelines for a laboratory test method". PhD Thesis, Carleton University, 2005

Mun S., "Nonlinear finite element analysis of pavements and its application to performance evaluation". North Carolina State University PhD Thesis, 2003.

Myers, L., and Roque, R., "Top-Down Crack Propagation in Bituminous Pavements and Implications for Pavement management". Proceedings of the Association of Asphalt Paving Technologists, Volume 71, pp 651-670, 2002.

Myers, L.A., "Development and propagation of surface-initiated longitudinal wheel path cracks in flexible highway pavements". A PhD Thesis, University of Florida, 2000.

Myers, L.A., Roque, R., and Ruth B.E., "Mechanisms of Surface-Initiated Longitudinal Wheel Path Cracks in High-Type Bituminous Pavements". Proceedings, Volume 67, Association of Asphalt Paving Technologists, pp 401-432, 1998.

Myers, L.A., Roque, R., and Birgisson, B., "Propagation Mechanisms for Surface- Initiated Longitudinal Wheel Path Cracks". In Transportation Research Record 1778, Transportation Research Board, National Research Council, Washington, D.C., pp. 113-121, 2001.

Myers, L.A., Roque, R., Ruth, B.E., and Drakos, C., "Measurement of Contact Stresses for Different Truck Tire Types to Evaluate Their Influence on Near-Surface Cracking and Rutting," In Transportation Research Record 1655, TRB, National Research Council, Washington, D.C., , pp. 175-184, 1999.

Noonan, J.E, "Reduction of reflection cracking in bituminous overlays on overlays on pavement on rigid pavements". Research report 80, 1980. 
Nunn, M., "Design of Long-Life Roads for Heavy Traffic". Australian Asphalt Pavement Association Industry Conference. Surfers Paradise, Queensland, Australia, 1998.

Operation \& Maintenance Manual, Asphalt Field Permeameter Model AP-1B. Gilson Company, Inc., Lewis Center, Ohio, August 2004.

Pagani J., Hassan Y., Abd El Halim O.A, "Compaction Technology- then and now". Canadian Technical Asphalt Association Proceedings CTAA, pp 27 - 47, 1999.

Pfeiffer, V.Ph., and Van Doormaal, P.M., "The rheological properties of asphalt bitumen". Proceedings Association of Asphalt Paving Technologists, Vol. 22, 1936.

Raab, C., Partl, M.N., "Interlayer bonding of binder, base and subbase layers of asphalt pavements: Long-term performance". Construction and Building Materials 23, 2926-2931, 2009.

Rajbongshi, P., and Das, A., "Estimation of Temperature Stress and Low Temperature Crack Spacing in Asphalt Pavements". Journal of transportation engineering, ASCE, 745, October 2009

Read, S.A., "Construction Related Temperature Differential Damage in Asphalt Concrete Pavements". University of Washington, 1996.

Rickards, I., Goodman. S., Pagani, J., Abd El Halim, A.O, and Haas, R., "Practical Realization of a New concept for Asphalt Compaction". In Transportation Research Record 1730, TRB, National Research Council, Washington, D.C., pp. 27-35, 1999.

ROLT, J, SMITH, H.R. and JONES, C.R., "The design and performance of bituminous overlays in tropical environments." Proceedings. Second Int. Conf. on the Bearing Capacity of Roads and Airfield. Plymouth, UK, 1986.

ROLT, J., "Top-Down Cracking: Myth or Reality?". The World Bank Regional Seminar on Innovative Road Rehabilitation and Recycling Technologies, Amman, Jordan, 2000.

Scherocman, J, A., and Martenson, E. D., "Placement and Compaction of asphalt Mixture, ASTMSTP". 829, Philadelphia, Pa., 1982.

Scherocman, J.A, "Guidelines for compacting asphalt concrete pavement", Better Road, Vol. 54, No. 3, pp. 12-17, 1984. 
Schorsch, M., Chang, C.M., and Baladi, G.Y., "Effects of segregation on the initiation and propagation of top-down cracks". $5^{\text {th }}$ International RILEM Conference, Limoges, France, 2004.

Schorsch, M. R., "Determining the causes of top-down cracks in bituminous pavements" . M.A.Sc. Thesis Department of Civil and Environmental Engineering Michigan State University, 2003.

Seddik, and Kamel, H. M., "Establishing Fracture Temperatures of Asphaltic Concrete Mixes for Low-Temperature Cracking". Master of Applied Science, Thesis. University of Waterloo, Canada, 1995.

Shahin, M. Y., and McCullough B. F., "Prediction of Low-Temperature and ThermalFatigue Cracking in Flexible Pavements". Report 123-14. Texas Transportation Institute, 1972.

Shalaby, A., "Analytical and Experimental investigation of thermal cracking in asphalt pavement", PhD. Thesis, 1997.

Shields, B.P., Anderson, K.O., and Dacyszyn. J.M., "Cracking of Asphalt Pavement Due to Thermal Effects". Proceedings of the Association of Asphalt Paving Technologists, pp. 247$262,1964$.

Svasdisant T., "Analysis of Top-Down Cracking in Rubblized and Flexible Pavements," A Ph.D. Thesis, Department of Civil and Environmental Engineering, Michigan State University, 2003.

Svasdisant, T., Achorsch, M., Baladi, G.Y., and Pinyosunun, "Mechanistic Analysis of Topdown Cracks in Asphalt Pavement". Accepted for presentation and publication by the Transportation Research Board, Washington DC, 2001.

Svec, O. J., and Abd El Halim, A.O., "Field Verification of a New Asphalt Compactor, AMIR. Canadian Journal of Civil Engineering". Vol. 18, No. 3, pp. 465-471, 1991.

Taylor, D.A., Abd El Halim, A.O., and Mohamed, El H. H., "Systems to Prevent Reflective Cracking in Pavements". 4th International RILEM Conference on Reflective Cracking in Pavement, 2000.

Texas Department of Transportation "Indirect Tensile Strength Test". TxDOT Designation: Tex-226-F, 2004. 
Thomas W.K., James M., and Ronald J.C., "Validation in the SHRP Asphalt Research Program", October, 1991.

Togunde, 0 ., "Low temperature investigation on asphalt binder". Master Thesis in Queen's Uni. Kingston, 2008.

U.S Department of Transportation, "Distresses for pavements with concrete surfaces", 2003 http://www.tfhrc.gov/pavement/ltpp/reports/03031/01.htm\#transverse

Uhlmeyer, J.S., Willoughby, K., Pierce, L.M., and Mahoney, J.P., "Top-Down Cracking in Washington State Asphalt Concrete Wearing Courses". Transportation Research Record 1730. Transportation Research Board, National Research Council, Washington, D.C., pp. 110-116, 2000.

Villanueva, A., Susanna, H., and Zanzotto L., "Asphalt modification with used lubricating oil”. Can. J. Civ. Eng, 35, pp. 148-157, 2008.

Vinson T.S, "Modifications to Pavement Design Based on Field Performance". Asphalt Contractor, 1989.

Wang, L B., Myers, L.A., Mohammad, L.N., and Fu, Y.R., "Micromechanics Study on TopDown Cracking". Transportation research Record, 2003.

Wheat, M., "Evaluation of bond strength at asphalt interfaces". $\mathrm{PhD}$ Thesis, Kansas state university, 2007.

Yoder, E.J., and Witczak, M.W., "Principles of Pavement Design". 2nd Edition, John Wiley \& Son, 1975.

Zhang, X, Huber, G., "Effect of asphalt binder on pavement performance: an investigation using the superpave mix design system". Asphalt Paving Technology: Association of Asphalt Paving Technologists-Proceedings of the Technical Sessions, v 65, p 449-490, 1996.

Ziari, H., Khabiri M., "Interface condition influence on prediction of flexible pavement life". Journal of civil engineering and management. Volume XIII, No 1, 71-76, 2007.

Zubeck, H.K., and Vison, T.S., "Prediction of Low - Temperature Cracking of Asphalt Concrete Mixture with Thermal Stress Restrained Specimen Test Results". In Transportation Research Record 1545, TRB, National Research Council, Washington, D.C., pp. 50-58, 1996. 